\title{
Characterization of host cell factors used by emerging coronaviruses for entry into target cells
}

\author{
Dissertation \\ for the award of the degree \\ "Doctor rerum naturalium"
}

of the Georg-August-Universität Göttingen

within the doctoral program Emerging Infectious Diseases (EIDIS)

of the Georg-August University School of Science (GAUSS)

submitted by

Hannah Laura Kleine-Weber

Ostercappeln, Germany

Göttingen 2020 


\section{Thesis Committee}

Prof. Dr. Stefan Pöhlmann

Infection Biology Unit, German Primate Center

Prof. Dr. Uwe Groß

Department of Medical Microbiology, Institute for Medical Microbiology, University Medical Center Göttingen

Dr. Marcel Müller

Institute for Virology, Charité- University Medicine Berlin, Berlin

\section{Members of the Examination Board}

Referee: Prof. Dr. Stefan Pöhlmann

Infection Biology Unit, German Primate Center

$2^{\text {nd }}$ Referee: Prof. Dr. Uwe Groß

Department of Medical Microbiology, Institute for Medical Microbiology, University Medical Center Göttingen

\section{Further members of the Examination Board}

Dr. Marcel Müller

Institute for Virology, Charité - University Medicine Berlin, Berlin

Prof. Dr. Lutz Walter

Department of Primate Genetics, German Primate Center

Dr. Alexander Hahn

Junior Research Group Herpesviruses, German Primate Center

Prof. Dr. Rüdiger Behr

Platform Degenerative Diseases, German Primate Center

Date of oral examination: 14.07.2020 


\section{Index}

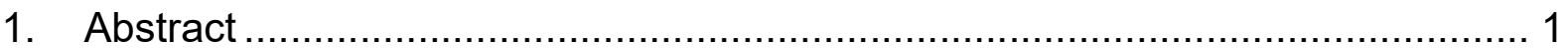

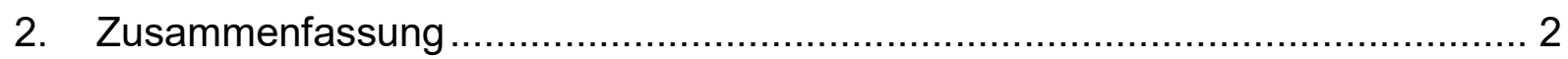

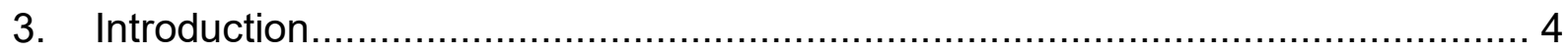

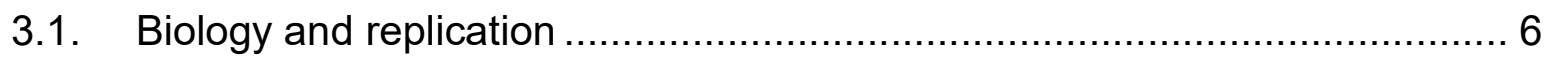

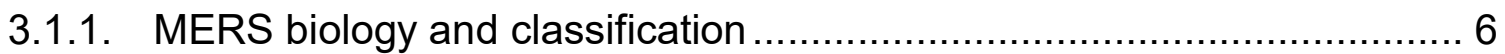

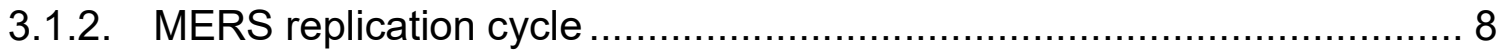

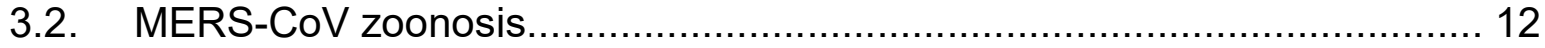

3.2.1. Incubation period and symptoms ............................................ 13

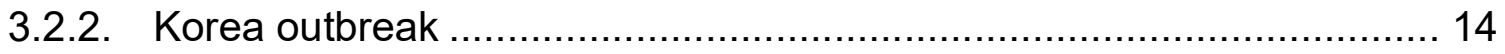

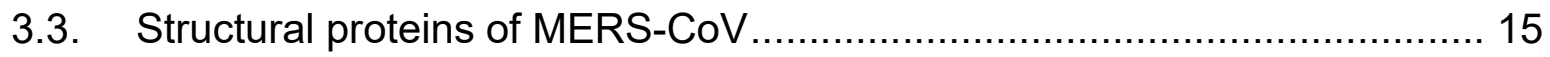

3.3.1. The MERS-CoV spike protein: Domain organization and entry reaction17

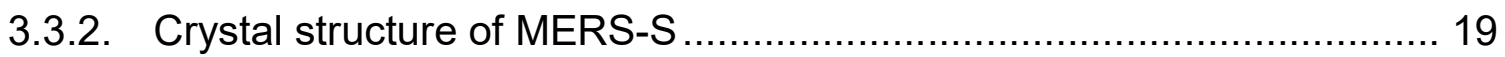

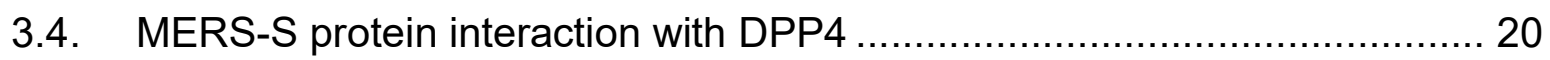

3.4.1. Biological function of host cell factors required for MERS-CoV entry.... 21

3.4.1.1. Dipeptidyl-peptidase 4 (DPP4) ............................................. 21

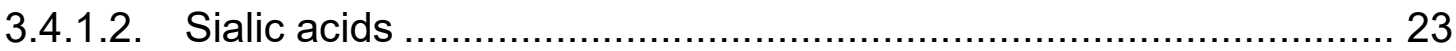

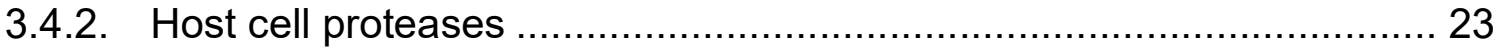

3.4.2.1. Proprotein Convertases (PPC) ............................................ 24

3.4.2.2. Type II transmembrane serine proteases ............................... 25

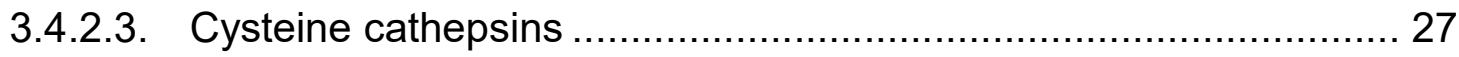

3.5. The novel emerging Coronavirus - SARS-CoV-2 …........................... 28

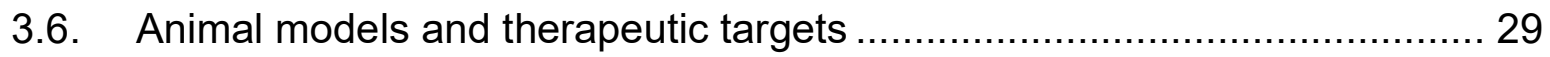

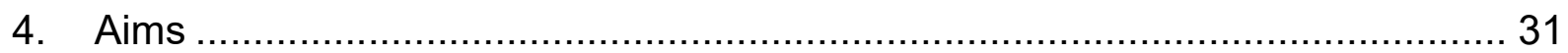

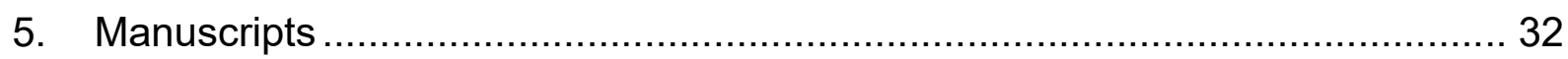

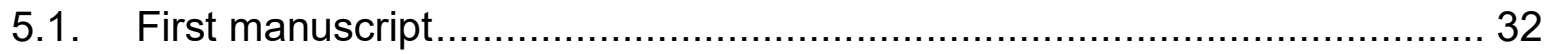

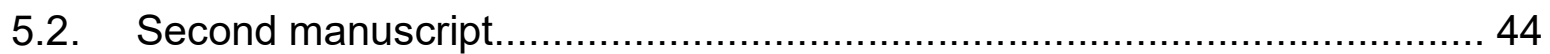

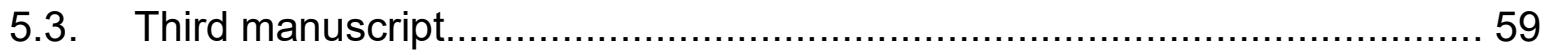




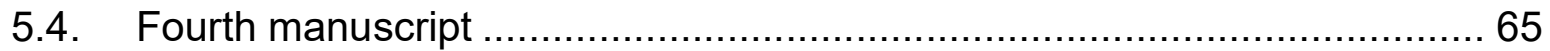

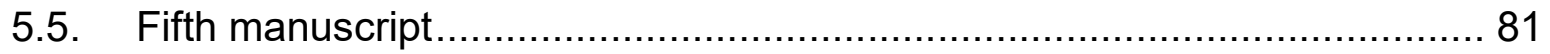

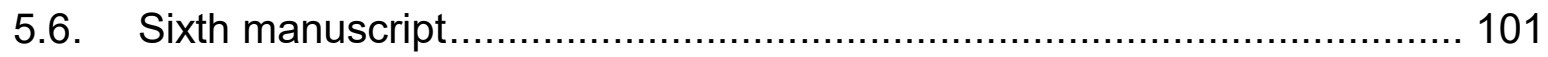

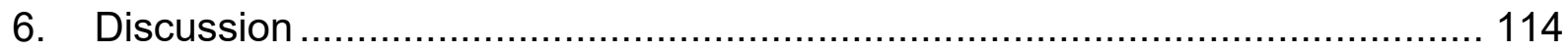

6.1. Functional characterization of host cell factors required for cellular entry driven by the S protein of MERS-CoV .......................................................... 115

6.1.1. Analysis of molecular requirements for $S$ protein priming revels cell type specific priming strategies for MERS-S

6.1.2. Natural sequence variations in the $S$ protein of MERS-CoV isolates or the cellular receptor DPP4 affect viral entry and viral resistance against antibody-mediated neutralization

6.1.3. S proteins of MERS-CoV isolates that were recently found in dromedary camels in Africa enable efficient viral entry into human cells

6.2. Identification of ACE2, furin and TMPRSS2 as host cell factors required for cellular entry of SARS-CoV-2

6.3. Inhibition of S protein priming by the cellular protease TMPRSS2 provides a strategy for antiviral therapy

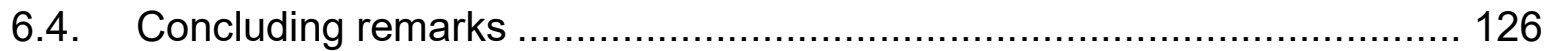

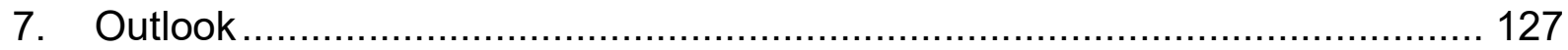

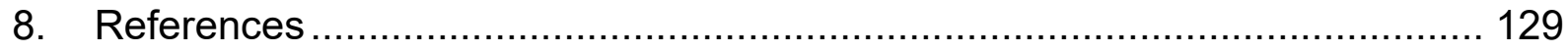

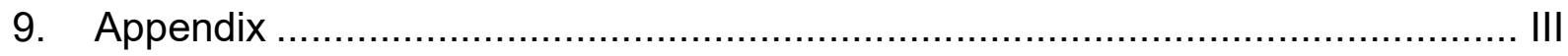

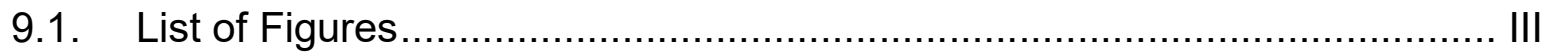

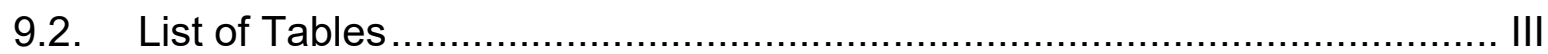

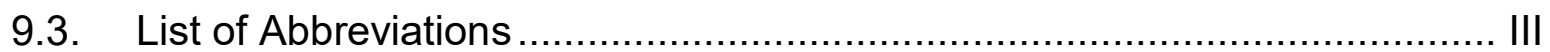

9.4. Acknowledgement ....................................................................... VII

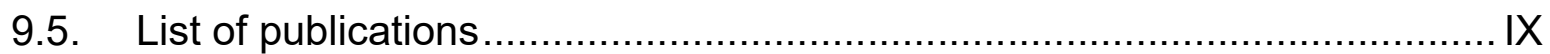

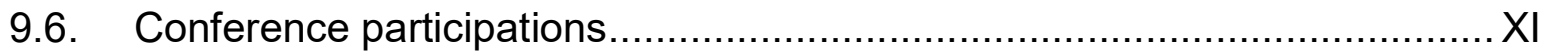




\section{Abstract}

Human coronaviruses (HCoV) mainly cause common cold-like symptoms. However, in the last two decades the emerging coronaviruses the severe acute respiratory syndrome coronavirus (SARS-CoV) (in 2002), Middle East respiratory syndrome coronavirus (MERS-CoV) (in 2014) and SARS-CoV-2 (in 2019) were introduced into the human population from animal reservoirs and were found to cause severe disease. Novel antiviral strategies are required to combat these viruses particularly the pandemic SARS-CoV-2, the causative agent of coronavirus disease 2019 (COVID-19). Coronaviruses harbor a spike glycoprotein (S) in their envelope, which is responsible for host cell entry. Entry depends on S protein interactions with cellular receptors and on S protein activation by host cell proteases. The goal of this thesis was to identify these interaction partners and to characterize these interactions on the molecular level, with the ultimate goal to identify targets for antiviral intervention. The thesis work revealed that MERS-CoV and SARS-CoV-2 S proteins depend on furin-mediated cleavage at the so called $\mathrm{S} 1 / \mathrm{S} 2$ site for subsequent $\mathrm{S}$ protein cleavage at the S2' site, which results in S protein activation for entry into human lung cells. Moreover, the results of this thesis show that polymorphisms in the $S$ protein of MERS-CoV can protect the virus against antibody mediated neutralization and that polymorphisms in the viral receptor dipeptidyl peptidase 4 (DPP4), modulate entry efficiency. Finally, it was uncovered that SARS-CoV-2, like SARS-CoV, employs angiotensin-converting enzyme 2 (ACE2) and the transmembrane serine protease subtype 2 (TMPRSS2) for entry into lung cells and evidence was provided that the clinically proven TMPRSS2 inhibitor camostat mesylate could be used for COVID-19 treatment. In sum, the study provided key insights into host cell entry of MERS-CoV and SARS-CoV-2 and defined TMPRSS2 as target for intervention. 


\section{Zusammenfassung}

Humane Coronaviren ( $\mathrm{HCoV})$ führen in den meisten Fällen zu Erkältungen. Allerdings sind in den letzten zwei Jahrzenten neuartige Coronaviren, severe acute respiratory syndrome coronavirus (SARS-CoV) (2002), Middle East respiratory syndrome coronavirus (MERS-CoV) (2014) and SARS-CoV-2 (2019) von Tieren auf den Menschen übergesprungen und verursachen schwere Erkrankungen. Um diese Viren, besonders das pandemische SARS-CoV-2 und die daraus resultierende Krankheit coronavirus disease 2019 (COVID-19) zu bekämpfen werden neue antivirale Strategien benötigt. Coronaviren tragen auf ihrer Hülle ein Spike (S) Glykoprotein, welches für den zellulären Eintritt verantwortlich ist. Der Eintritt beruht auf der Interaktion des S Proteins mit dem zellulären Rezeptor und der Aktivierung des S Proteins durch Wirtszellproteasen. Das Ziel dieser Arbeit war es diese Interaktionspartner zu identifizieren und die Interaktion auf einem molekularen Level zu charakterisieren, um neue Targets für antivirale Strategien zu finden. Diese Arbeit hat ergeben, dass MERS-CoV und SARS-CoV-2 S Proteine für die Spaltung an der S2 Schnittstelle, zunächst auf die Furin-vermittelte Spaltung an der S1/S2 Schnittstelle angewiesen sind. Dies führt zu der Aktivierung der S Proteine für den Eintritt in humane Lungenzellen. Des Weiteren konnte in dieser Arbeit gezeigt werden, dass Polymorphismen in dem S Protein von MERS-CoV das Virus vor Antikörper-vermittelter Neutralisation schützen und dass Polymorphismen in dem viralen Rezeptor Dipeptidyl-pepdiase 4 (DPP4) die Eintrittseffizienz verändern. Zum Schluss wurde entdeckt, dass SARS-CoV-2, wie SARS-CoV, Angiotensinkonvertierendes Enzyme 2 (angiotensin-converrting enzyme 2 (ACE2)) und die Transmembrane Serine Protease Subtype 2 (TMPRSS2) für den Eintritt in humane Lungenzellen benötigt. Darüber hinaus wurde der Nachweis erbracht, dass der klinisch geprüfte TMPRSS2 Inhibitor Camostat mesylate für die Behandlung von 
COVID-19 Patienten verwendet werden kann. Zusammengefasst liefert diese Arbeit wichtige Ergebnisse bezüglich des zellulären Eintritts von MERS-CoV und SARSCoV-2 und definiert TMPRSS2 als Ziel für antivirale Interventionen. 


\section{Introduction}

Coronaviruses (family Coronaviridae) are enveloped viruses of animals and humans that, depending on the virus and host species, can cause mild to severe diseases. In total seven human coronaviruses (HCoV) have been identified so far, HCoV-NL63 (Fouchier et al., 2004; Van Der Hoek et al., 2004) and HCoV-229E (Hamre and Procknow, 1962), which belong to the Alphacoronavirus genus and HCoV-OC43 (McIntosh et al., 1967), HCoV-HKU1 (Woo et al., 2005), severe acute respiratory syndrome coronavirus (SARS-CoV) (Drosten et al., 2003; Peiris et al., 2003), SARSCoV-2 (Gorbalenya et al., 2020; Wang et al., 2020; Zhu et al., 2020) and Middle East respiratory syndrome coronavirus (MERS-CoV) (Zaki et al., 2012), which belong to Betacoronavirus genus. HCoV-229E, OC43, HKU-1 and NL63 circulate worldwide and cause the common cold. Before 2002, HCoV were believed to only cause mild, common cold-like disease in otherwise healthy adults but this perception changed. In 2002 an outbreak and subsequent epidemic spread of a novel lung disease, severe acute respiratory syndrome (SARS), occurred in China. SARS was caused by SARSCoV, which was transmitted from civet cats to humans (Drosten et al., 2003; Peiris et al., 2003; De Wit et al., 2016).SARS-CoV infections were reported until May 2004 (WHO, 2004). Roughly ten years later, the emergence of a new lung disease, Middle East respiratory syndrome (MERS) caused by another novel coronavirus was observed in the Middle East in 2012. The causative agent MERS-CoV was first detected in the Kingdom of Saudi Arabia (KSA) and is transmitted from dromedary camels to humans (Zaki et al., 2012; Mohd, Al-Tawfiq and Memish, 2016). Coronaviruses can also be found in livestock and companion as well as wild animals. In livestock and companion animals different coronaviruses have been identified, which affected animal health and thus can lead to economic losses due to reduced productivity of livestock: Transmissible gastroenteritis virus (TGEV) and porcine 
epidemic diarrhea virus (PEDV) in pigs, bovine coronavirus (BCoV) in cattle; infectious bronchitis virus (IBV) in poultry and feline enteric coronavirus (FCoV) which can mutate and become the highly virulent variant feline infectious peritonitis virus (FIPV) (Fehr and Perlman, 2015). In case of MERS-CoV, dromedary camels and bats are the most relevant animal species harboring coronaviruses. Dromedaries were, as mentioned before identified as the natural reservoir of MERS-CoV and represent the main source of human infections (Azhar et al., 2014; Reusken et al., 2016; Alshukairi et al., 2018; Conzade et al., 2018). In bats, several coronaviruses were identified e.g. BatCoV-HKU4 and BatCoV-HKU5, which belong to the lineage C of the genus Betacoronavirus and are closely related to MERS-CoV. (Woo et al., 2012; Lau et al., 2013). As of May, $13^{\text {th }}$, the pandemic SARS-CoV-2 has infected over four million people worldwide and more than 280,000 deaths can be attributed to the associated severe respiratory illness coronavirus disease 2019 (COVID-19) (WHO, 2020). One factor important for the pandemic potential of SARS-CoV-2 is the high transmissibility between humans (Shereen et al., 2020). In comparison to SARSCoV-2 human-to-human transmission of SARS-CoV and MERS-CoV is less efficient. Nevertheless, MERS-CoV has been introduced into 27 countries via air travel, led to large hospital outbreaks (e.g. in 2015 in the Republic of Korea) and new cases are constantly emerging in the Middle East (Anderson et al., 2004; Memish et al., 2013; Drosten et al., 2014; Ki, 2015; Mackay and Arden, 2015). Dromedary camels were identified as the natural reservoir of MERS-CoV. The prevalence in dromedary camels in the Middle East and in Africa is around 90 \% (Reusken et al., 2013, 2014; Alagaili et al., 2014; Alexandersen et al., 2014; Chu et al., 2014; Memish, Cotten, Meyer, et al., 2014). MERS-CoV belongs to the lineage $C$ of the genus Betacoronavirus, and MERS-CoV isolates can be further classified into two major clades, A and B (Lau et al., 2017). Clade A contains a total of five virus strains, 
including the first isolate of MERS-CoV (human betacoronavirus 2c EMC/2012) (Lau et al., 2017). Clade B includes most MERS-CoV strains including those isolated during the outbreak in the Republic of Korea in 2015 (Lau et al., 2017). Furthermore, MERS-CoV isolates found in Africa form into a separate group, clade C (D. Chu et al., 2018). In order to group MERS-CoV strains into the different clades the amino acid (aa) residues at position 1020 in the viral spike glycoprotein is of importance. While for clade A MERS-CoV this position contains a glutamine (Q1020), clade B MERS-CoV harbor an arginine residue (R1020) (Lau et al., 2017).

\subsection{Biology and replication}

\subsubsection{MERS biology and classification}

Coronaviruses are positive single stranded (+ss) RNA viruses and belong to the family Coronaviridae. Together with Arteriviridae, and Roniviridae they form the order Nidovirales. Furthermore, the family Coronaviridae can be divided in the two subfamilies Coronavirinae and Torovirinae, and among the subfamily Coronavirinae four genera, Alpha-, Beta-, Gamma- and Deltacoronavirus were defined (Gorbalenya et al., 2006; de Groot et al., 2012). Alpha- and betacoronaviruses primarily infect mammals, while gamma- and deltacoronaviruses mainly infect birds (Nakagawa, Lokugamage and Makino, 2016). Coronaviruses in general cause mild lower respiratory tract infections and gastrointestinal symptoms (Gorbalenya et al., 2006; Van Der Hoek, 2007). The zoonotic human coronaviruses, SARS-CoV, MERS-CoV and SARS-CoV-2, belong to the group Betacoronavirus, which is divided into the different lineages $A, B$ and $C$. MERS-CoV belongs to lineage $C$ and can be further classified into different clades (Lau et al., 2013, 2017), while SARS-CoV and SARSCoV-2 belong to lineage B (Cascella et al., 2020). 
The coronavirus virion has a spherical shape and a diameter of $120-160 \mathrm{~nm}$. In electron microscopy, all virions show $20 \mathrm{~nm}$ long club-shaped projection from the outer envelope, which are representing spike (S) protein trimers. Those projections resemble a "crown" (lat. Corona), which is the origin for the virus name. All members of the family Coronaviridae harbor the membrane glycoprotein (M), the envelope (E) glycoprotein and the S protein, which share similarities in size and structure, thereby giving evidence of a common ancestor. Especially the $S$ protein has a domain organization: signal peptide (SP), receptor binding domain (RBD), fusion peptide (FP), heptad repeats 1 and 2 (HR1 und HR2) and the transmembrane domain (TD). Moreover, the betacoronaviruses of the lineage A harbor a membrane anchored hemagglutinin-esterase (HE) (Gorbalenya et al., 2006; Bakkers et al., 2017). The positive +ss RNA genome of coronaviruses is associated with the viral nucleoprotein (N) and contained inside the virion as a helical nucleocapsid with $9-11 \mathrm{~nm}$ in diameter. The genome is non-segmented, capped at the 5'-end and harbors a polyadenylated 3'-end. Coronaviruses have the largest genome of all RNA viruses with a size of 27-32 $\mathrm{kb}$ and ten open reading frames (ORF). MERS-CoV and SARSCoV-2 have 30119 and 29891 nucleotide large genomes, respectively. The ORF1a and ORF1b encode for two thirds of the viral genome and include 16 non-structural proteins (nsp), which are required for synthesis of viral proteins and viral genome replication. The remaining nine ORFs encode for the structural proteins $(S, M, E, N)$ and for further nsps, 3, 4a, 4b, 5 8b with largely unknown function (Almazán et al., 2013; Boheemen, Graaf and Lauber, 2013; Scobey et al., 2013; Cascella et al., 2020). 


\subsubsection{MERS replication cycle}

The MERS-CoV replication cycle starts with the binding of the virus to the surface of the host cell. Binding is mediated by the $S$ protein, which interacts with the cellular receptor dipeptidyl peptidase 4 (DPP4) via its receptor binding domain (RBD). After receptor binding the $S$ protein fuses the viral membrane with a target cell membrane allowing delivery of the viral genome into the host cell. Membrane fusion requires cleavage of the $S$ protein by host cell proteases, which activates the $S$ protein, as discussed in detail later (Taguchi et al., 1995; Fehr and Perlman, 2015). The translation of the replicase proteins, based on the viral RNA, is the next step of the replication cycle. The replicase proteins are encoded by the two large ORFs, ORF1a and ORF1b, which encode for two polyproteins, pp1a and pp1b, respectively. These polyproteins are cleaved into individual nsps by a virus encoded protease (Brierley, Digard and Inglis, 1989; Ziebuhr, Snijder and Gorbalenya, 2000; Sawicki, Sawicki and Siddell, 2007). MERS-CoV, like other coronaviruses, expresses two cysteine proteases (papain-like proteases (PLpros) and the main protease (Mpro)), which are necessary for expression of mature viral proteins and viral pathogenesis (Malik and Alsenaidy, 2017). The PLpros cleaves nsp1/2, nsp2/3 and nsp3/4, while the other boundaries are cleaved by Mpro. The suitable environment for RNA synthesis, including the RNA replication and transcription of sub-genomic RNAs, is provided by the assembly of nsps into the replicase-transcriptase complex. Besides its function to form the replicase-transcriptase complex the nsps contain other enzymatic functions important for RNA replication (Fehr and Perlman, 2015). The synthesis produces genomic and sub-genomic RNAs, where the sub-genomic RNAs serve as messenger RNAs (mRNA) for the structural and accessory genes (Sethna, Hofmann and Brian, 1991). This is followed by the translation of the structural proteins (S, E and M) and there insertion into the endoplasmatic reticulum (ER). The structural proteins move 
along the secretory pathway into the ER-Golgi-intermediate compartment (ERGIC). At the ERGIC the viral genomes are encapsidated by $\mathrm{N}$ and virions bud into the ERGIC membrane where mature virions are produced. The virions are transported to the cell membrane and released by exocytosis (de Haan and Rottier, 2005; Durai et al., 2015a; Fehr and Perlman, 2015; Zumla et al., 2015). 
Table 1: Function of coronavirus non-structural proteins (nsp).

The table shows the indicated coronavirus nsps with their known function. The table has been adapted from (Fehr and Perlman, 2015)

\begin{tabular}{|c|c|}
\hline Non-structural Protein (nsp) & Function \\
\hline nsp1 & blocks host innate immune response \\
\hline nsp2 & unknown \\
\hline nsp3 & $\begin{array}{l}\text { interacts with N Protein, promotes } \\
\text { cytokine expression, cleaves viral } \\
\text { polyproteins and blocks host innate } \\
\text { immune response }\end{array}$ \\
\hline nsp4 & $\begin{array}{c}\text { potential transmembrane scaffold } \\
\text { protein }\end{array}$ \\
\hline nsp5 & encodes for the main protease (Mpro) \\
\hline nsp6 & $\begin{array}{c}\text { potential transmembrane scaffold } \\
\text { protein }\end{array}$ \\
\hline nsp7 & forms hexadecameric complex with nsp8 \\
\hline nsp8 & forms hexadecameric complex with nsp7 \\
\hline nsp9 & RNA binding protein \\
\hline nsp10 & $\begin{array}{l}\text { cofactor for nsp16 and nsp14, forms } \\
\text { heterodimer with both and stimulates } \\
\text { exoribonuclease (ExoN) and 2-O-MT } \\
\text { activity }\end{array}$ \\
\hline nsp11 & unknown \\
\hline nsp12 & $\begin{array}{c}\text { encodes the RNA-dependent RNA } \\
\text { polymerase (RdRp) domain }\end{array}$ \\
\hline nsp13 & $\begin{array}{l}\text { encodes the RNA helicase domain and } \\
\text { RNA 5'-triphosphatase activity }\end{array}$ \\
\hline nsp14 & $\begin{array}{l}\text { encodes the ExoN involved in replication } \\
\text { fidelity and N7-methyltransferase activity }\end{array}$ \\
\hline nsp15 & $\begin{array}{c}\text { encodes endoribonuclease (NendoU) } \\
\text { activity }\end{array}$ \\
\hline nsp16 & $\begin{array}{c}\text { encodes } 2 \text { '-O- methyltransferase activity } \\
\text { blocking immune response }\end{array}$ \\
\hline
\end{tabular}




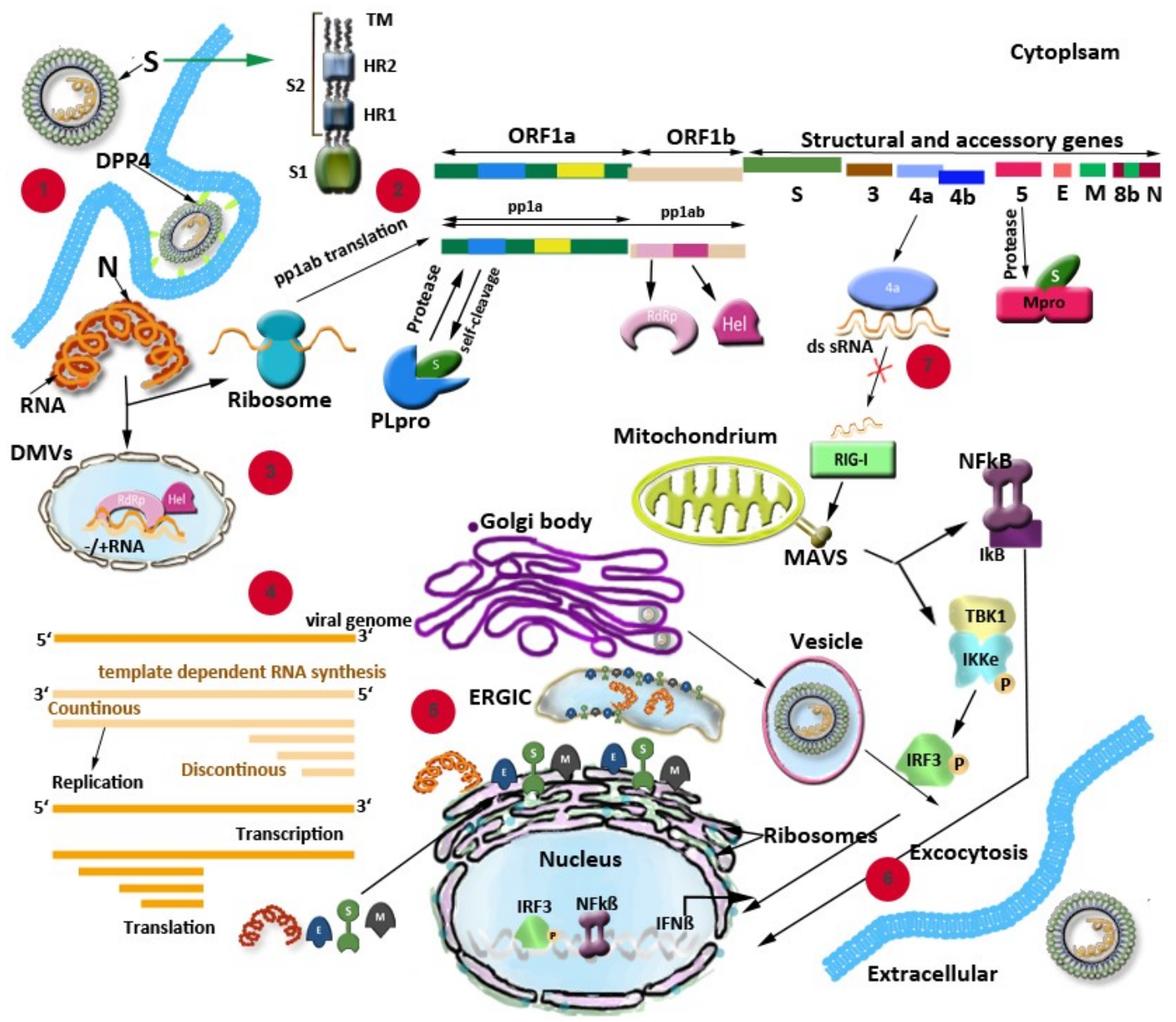

Figure 1: MERS-CoV replication cycle.

1) The viral spike (S) protein binds to the host cell receptor dipeptidyl peptidase 4 (DPP4) which, leads to the release of the viral RNA into the cellular cytoplasm. 2) The two large open reading frames (ORF), ORF1a, ORF1b are translated into the polyproteins pp1a and pp1ab, respectively, which are cleaved by the virus encoded proteases (papain-like protease (PLpro)) into non-structural proteins (nsps). 3) The proteins necessary for replication accumulate in double membrane vesicles (DMV) derived from the endoplasmic reticulum (ER). 4) During RNA synthesis discontinued subgenomic RNA and full-length RNA for replication are synthesized. 5) The newly synthesized RNA is encapsidated in the nucleoprotein $(\mathrm{N})$ in the cytosol, transported to the ER-Golgi intermediate compartment (ERGIC) for assembly. The $S$, membrane $(M)$ and envelope $(E)$ proteins are inserted into the membrane of the ER and transported to the ERGIC where progeny virions are assembled. 6) Vesicles containing virions are transported to the plasma membrane and released by exocytosis. 7) During viral replication double-stranded (ds) RNAs are generated. The 4a competes with the retinoic acid-inducible gene I (RIG-I) to bind the dsRNA and evades the host immune response. The figure is adapted from (Durai et al., 2015b). 


\subsection{MERS-CoV zoonosis}

MERS-CoV is zoonotically transmitted to humans (Zaki et al., 2012). Dromedary camels have been identified as natural reservoir of MERS-CoV. The seroprevalence between dromedary camels is around $90 \%$, including camels in the Middle East and Africa (Sikkema et al., 2019). However human cases are only reported from the Middle East. It is unclear why the virus was able to cross the species barrier in the Middle East but not in Africa (Reusken et al., 2013, 2014; Alexandersen et al., 2014; Chu et al., 2014; Memish, Cotten, Meyer, et al., 2014; Meyer et al., 2014; Müller et al., 2014; Mohd, Al-Tawfiq and Memish, 2016).

Primary transmission of MERS-CoV between dromedaries and humans occurs via close contact or consumption of row camel meat (Müller et al., 2015). Most cases of human-to-human transmission are detected in hospitals between the index person and its relatives or the medical staff. Several major hospital outbreaks of MERS have been reported, including a hospital outbreak in the Republic of Korea in 2015, which involved 186 causes and 36 deaths and was caused by a single infected person who traveled from the Middle East to the Republic of Korea (Khan et al., 2015; Ki, 2015). MERS-CoV infections have been detected in 27 different countries. MERS-CoV infections are detected in many countries in the Arabian Peninsula but were also detected in Europe or the USA. The introduction in other countries outside the Arabian Peninsula is mainly possible due to air travel. 


\subsubsection{Incubation period and symptoms}

Normally HCoV cause mild, common cold like respiratory symptoms. Typical symptoms of MERS-CoV infection are coughing, shortness of breath often associated with non-specific signs like fatigue, myalgia fever, and headache Furthermore, MERS-CoV infections can also be associated with gastrointestinal symptoms like vomiting and diarrhea. In severe cases, MERS-CoV infection leads to atypical pneumonia, renal failure or multiorgan failure. The median incubation period of MERS is roughly five days (Bermingham et al., 2012; Guery et al., 2013; Omrani et al., 2013; Memish, Cotten, Watson, et al., 2014; Rabeeah et al., 2014; Tsiodras et al., 2014; Zhou et al., 2017). Moreover different studies have shown that females and males are equally affected and MERS patients can be found at all ages. Severe cases of MERS-CoV infections might be detected in patients with comorbidities: hypertension, diabetes mellitus, renal or cardiovascular disease, obesity, smoking, lung disease like cystic fibrosis and asthma or patients with immunosuppression (Guery et al., 2013; Al-Tawfiq and Memish, 2014; Memish, Cotten, Watson, et al., 2014; Rabeeah et al., 2014; Oboha et al., 2017). 


\subsubsection{Korea outbreak}

The pandemic potential of MERS-CoV is highlighted by several major hospital outbreaks. The outbreak in the Republic of Korea in 2015 was the largest hospital outbreak. The outbreak was caused by one single infected person (68-year old man), who traveled from the Middle East to the Republic of Korea (Khan et al., 2015). The outbreak involved three cycles of human-to-human transmission and was due to insufficient safety measurement, travel of patients between hospitals and crowed patients rooms (Choi, 2015; Khan et al., 2015; Ki, 2015; Lee and Wong, 2015; Mizumoto et al., 2015). Further spread of the virus was prevented by isolation of patients with unknown respiratory disease, visitation routines and improvement of hygiene routines in public hospital, e.g. disinfection and hand-washing (Khan et al., 2015; Jeon and Kim, 2016). Notably, the MERS outbreak in Korea encompassed transmission of viral variants with mutations in the $S$ protein that reduced neutralization of virus by antibodies, providing evidence that the virus can evolve to evade immune control in humans. 


\subsection{Structural proteins of MERS-CoV}

MERS-CoV particles contain four structural proteins, which have different functions: E, M, N and S (de Haan and Rottier, 2005) (Figure 2A). E is encoded by all coronaviruses but only few copies of the protein are incorporated into the viral envelope (Kuo and Masters, 2003). A deletion of the E protein can lead to a blockade of virus maturation, decreasing virus release and spread (Fischer et al., 1998; Wilson et al., 2004). The E protein belongs to the group of viroporins. Viroporins form ion channels in the virion envelope and thereby modify membrane permeability. Furthermore, the $E$ protein can affect the release of progeny virions from infected cells by modifying the plasma membrane (Gonzalez and Carrasco, 2003). The E protein of MERS-CoV is involved in ion channel activity as virulence factor and thereby could be a potential drug target (Yang et al., 2013). The M protein is also incorporated into the viral envelope protein and controls most protein-protein interactions required for assembly of coronaviruses. In case of MERS-CoV, M was hypothesized to be an interferon (IFN) antagonist (Yang et al., 2013). The N-terminus of the $\mathrm{M}$ protein is located outside of the particle whereas the $\mathrm{C}$-termini is directed to the virus interior (Escors, Camafeita, et al., 2001; Escors, Ortego, et al., 2001). The $\mathrm{N}$ protein is associated with the viral genome to form the nucleocapsid and can modulate sub-genomic RNA synthesis and genome replication (Almazan, Galan and Enjuanes, 2004; Schelle et al., 2005). The MERS-CoV N protein was shown to suppress the type I and type II IFN (Chang et al., 2020). As in all coronavirus, the trimers of the viral $S$ protein are inserted into the viral membrane and facilitate entry into target cells, as described in detail (Lu et al., 2013; Wang et al., 2013; Li, 2015). 


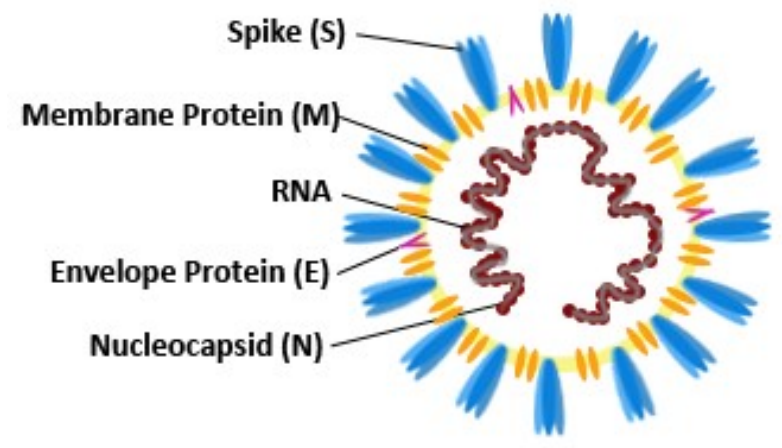

Figure 2: Schematic MERS-CoV particle.

MERS-CoV particles include the four structural

proteins: trimeric Spike (S) protein (blue), membrane (M) protein (orange), envelope (E) protein (purple), the nucleocapsid (N) (red) and the RNA (gray) are labeled (Xu et al., 2019). 


\subsubsection{The MERS-CoV spike protein: Domain organization and entry reaction}

The MERS-CoV-S protein (MERS-S) mediates viral entry into target cells. For this, the S protein binds to its host cell receptor, DPP4, and fuses the viral membrane with the cellular membrane. Receptor binding and membrane fusion are mediated by different subunits of MERS-S. The subunit 1 (S1) contains the RBD, which binds to DPP4, while the transmembrane subunit 2 (S2) harbors the functional elements required for membrane fusion (Drosten et al., 2003; Gao et al., 2013; Raj et al., 2013; Wang et al., 2013; Lu et al., 2014). The RBD harbors the receptor binding motif (RBM) that directly contacts DPP4, and a core subdomain. The RBD spans from aa 367 to 606 , the RBM itself from aa 484 to 567 . The core subdomain of the RBD is composed of a five stranded antiparallel betasheet and several connecting alpha helices, stabilized by sulfate bonds. The RBM is divided into a four-stranded antiparallel betasheet connected via intervening loops (Chen et al., 2013; Lu et al., 2013; Wang et al., 2013). The S2 subunit contains HR1 and HR2, the FP and the TD (Figure 4A), functional elements that are also found in glycoproteins of other viruses that all mediate membrane fusion in a similar fashion and are termed class I membrane fusions. Membrane fusion commences with insertion of the MERS-S fusion peptide into the target cell membrane. Next, the HR1 and HR2 fold back onto each other and from a six-helix-bundle $(6 \mathrm{HB})$, thereby bringing the viral and host cell membrane in close proximity for the following membrane fusion (Figure 4B) (Gao et al., 2013; Lu et al., 2014). Finally, MERS-S-driven host cell entry critically depends on $S$ protein cleavage between the $S 1$ and $S 2$ subunits, termed $S 1 / S 2$ and a cleavage site located directly upstream of the fusion peptide (S2') (Figure 4A) and both sites need to be cleavage for entry, as discussed below (Gierer et al., 2013; Qian, Dominguez and Holmes, 2013; Shirato, Kawase and Matsuyama, 2013; Millet and Whittaker, 2014). 
(A)

MERS-S

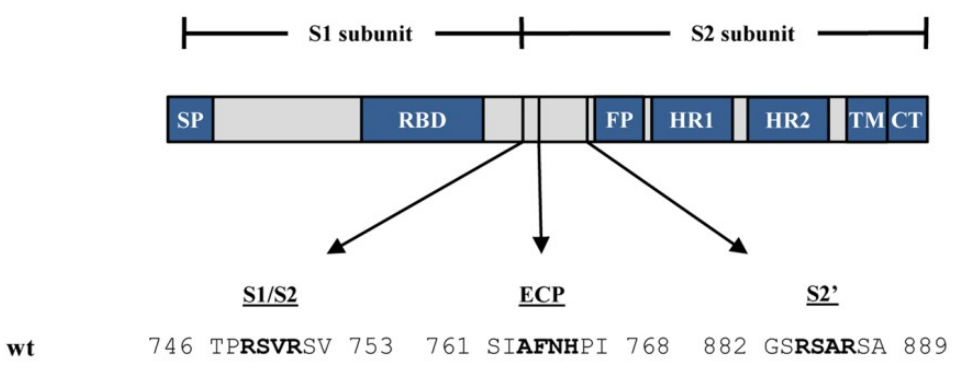

(B)
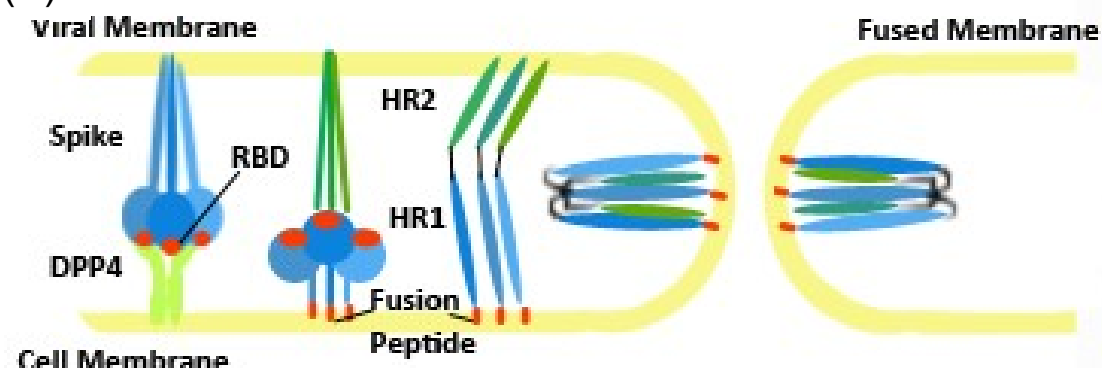

1

2

3

4

RBD binds

the host cell
conformational six helix change bundel (6HB) is formed

Membrane

Fuison

\section{Figure 3: Spike protein structure.}

(A) The MERS-CoV-S (MERS-S) contains a surface subunit (S1) and a transmembrane subunit (S2).The S1 subunit harbor the signal peptide (SP) and the receptor binding domain (RBD), which directly interacts with the host cell receptor DPP4. The S2 subunit harbors the fusion peptide (FP), the heptad repeat 1 (HR1) and 2 (HR2), the transmembrane domain (TM) and the cytoplasmic tail (CT). MERS-S harbors three cleavage sites for host cell proteases: The S1/S2 cleavage site is located at the border of the S1 and the S2 subunit, the S2' cleavage site is located directly upstream of the FP and a cathepsin $\mathrm{B} / \mathrm{L}$ cleavage site (ECP, endosomal cathepsin proteases) is proposed to be located between the S1/S2 and S2' site. (B) Membrane fusion driven by MERS-S. The binding of the S protein to the host cell receptor DPP4 triggers a conformational change, resulting in the formation of a prehairpin intermediate structure, in which the fusion peptide (red) is introduced into the target cell membrane. The pre-hairpin intermediate folds into stabilized trimer of hairpins, called the six helix bundle structure $(6 \mathrm{HB})$. This leads to the close proximity of the target cell membrane and the viral envelope and thereby to membrane fusion. The figure is adapted from (Kleine-Weber et al., 2018; Xu et al., 2019) 


\subsubsection{Crystal structure of MERS-S}

Single particle cryo-electron microscopy was used to resolve the crystal structure of MERS-S trimers. Two different conformations were detected regarding the RBD, which can either be "standing" or "laying" (Yuan et al., 2017). Trimers of MERS-S with one or two out of three RBDs in a standing position were observed. It was hypothesized that the conformational state with all three RBDs in a standing position was not detected due to easy dissociation of the $\mathrm{S} 1$ trimer form the $\mathrm{S} 2$ component (Yuan et al., 2017). Apart from the flexible RBDs the rest of the trimeric structure remained stable. The S1 subunit includes the N-terminal domain (NTD) and two additional domains which form the base of a hairpin structure with the RBD/NTD ring complex on top (Yuan et al., 2017). The NTD harbors the binding site for cellular glycans e.g. sialic acids (Li et al., 2017). The dynamic characters of the RBDs enables the interaction with the host cell receptor as it is only exposed during the "standing" state while in the "laying" state the residues are buried inside the trimer. It was hypothesized that the dimeric DPP4 may cross-link two trimeric S proteins by binding two standing RBDs from different trimers S proteins (Yuan et al., 2017).
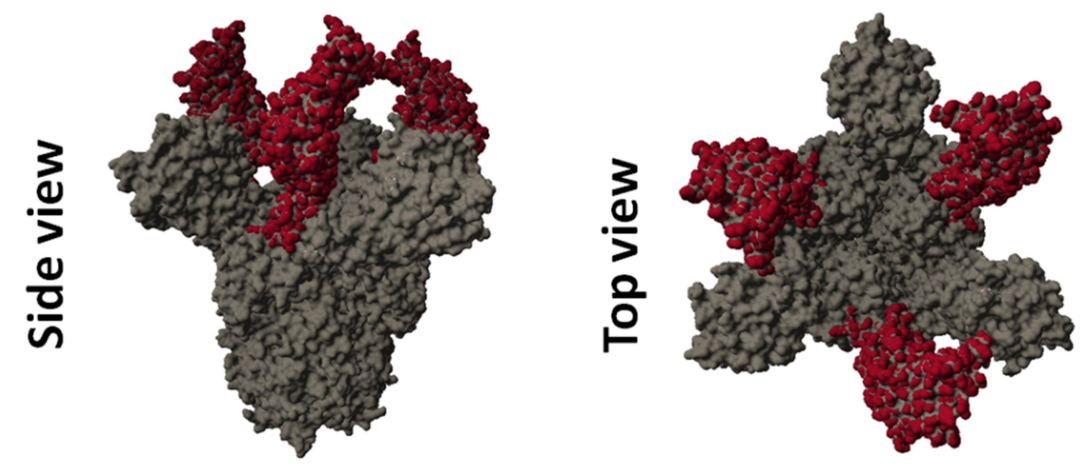

Figure 4: Spike protein crystal structure.

The crystal structure of the trimeric spike protein in a side view and a top view is shown. The residues of the receptor binding domain (RBD) are colored in red. The protein model was constructed on the published crystal structure (5X59) deposited in RSCB PDB. 


\subsection{MERS-S protein interaction with DPP4}

The viral S-driven host cell entry relies as mentioned before on the binding of the $S$ protein with the host cell receptor DPP4. The interface of these proteins is known. 15 amino acid residues in DPP4 bind to 14 amino acid residues in MERS-S (Raj et al., 2013; Wang et al., 2013).

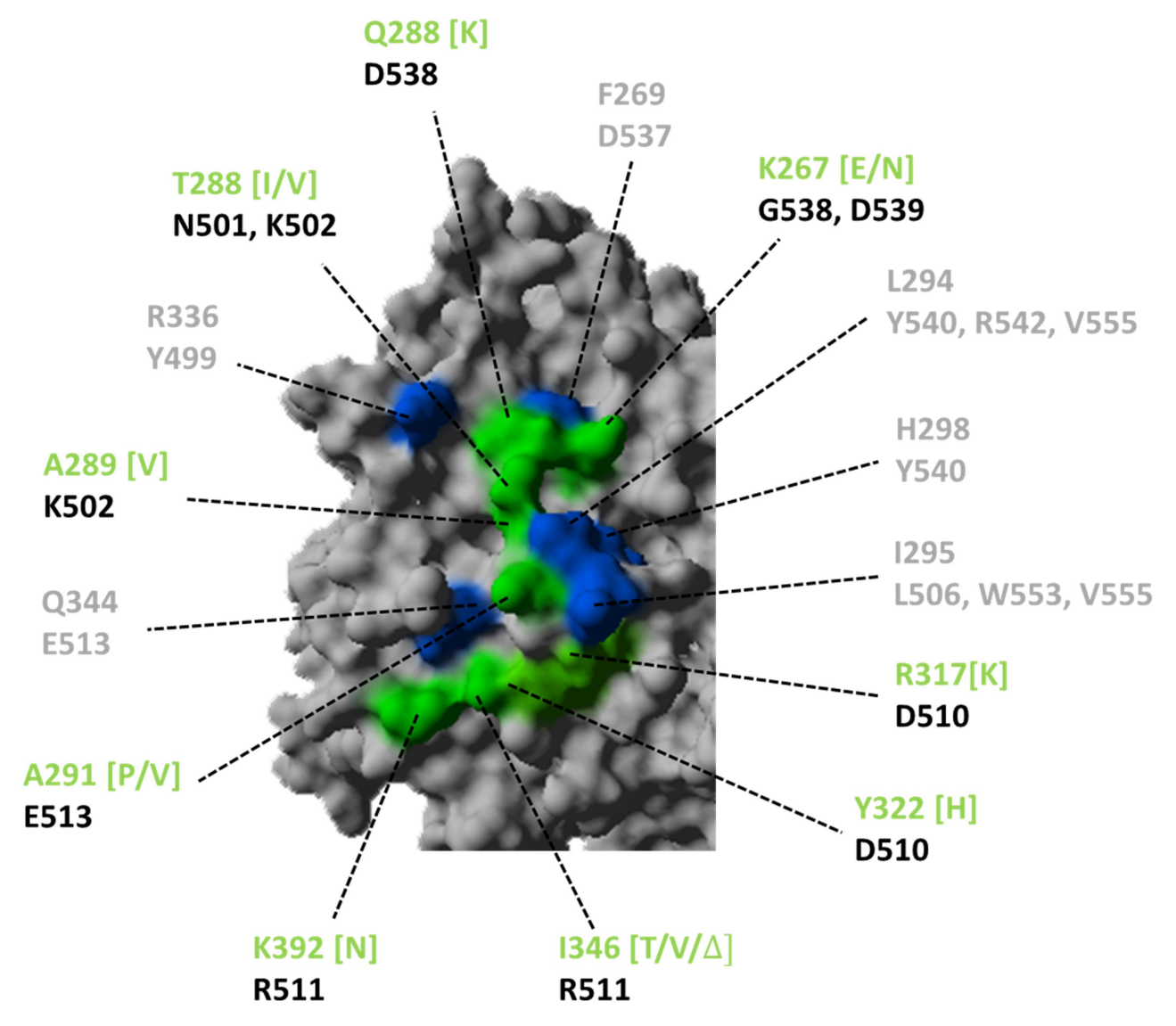

Figure 5: Polymorphic amino acid residues in DPP4 at the binding interface with MERS-S.

In the DPP4 close-up all interacting residues are labeled with possible polymorphisms and the interacting MERS-S residue. The non-polymorphic sides are marked in blue. The polymorphic residues are labeled and marked in green. The protein model was constructed on the published crystal structure (4PV7) deposited in RSCB PDB. 


\subsubsection{Biological function of host cell factors required for MERS-CoV entry}

\subsubsection{Dipeptidyl-peptidase 4 (DPP4)}

The host cell receptor needed for the $S$ protein driven host cell entry is DPP4 (DPPIV, CD26, also known as adenosine deaminase binding protein). It was originally described in 1966 by Hopsu-Havu and Glenner (Hopsu-Havu and Glenner, 1966; Hopsu-Havu, Jansén and Järvinen, 1970; Raj et al., 2013). DPP4 is a serine protease with the unique ability to cleave a peptide bond. It preferentially cleaves dipeptides of the free $\mathrm{N}$-terminus when proline or alanine is present. DPP4 is a type II membrane protein with various tissue expression, while it is most abundant in kidney and the small intestine (Darmoul et al., no date; Walter and Post-proline, 1978; Kettmann, Humbel and Holzhausen, 1992; Tanaka et al., 1992; Zhou et al., 2017). It was further found at ciliated and non-ciliated cells in the airways but was more often observed with higher levels in small airways. However, DPP4 was rarely observed in the epithelial of nasal mucosa, which could influence the infection of the lower airways by MERS-CoV (Vliegen et al., 2017). Even if DPP4 is classified as a membrane protein it is also active in its soluble form found in bone marrow, adipocytes skeletal muscle and vascular smooth muscle cells (Lamers et al., 2011; Raschke et al., 2013; Röhrborn, Eckel and Sell, 2014; Wang et al., 2014).

The primary structure of DPP4 is composed of a six aa long cytoplasmic tail, 22 aa transmembrane domain and 738 aa extracellular domain. The extracellular portion includes a flexible stalk, a glycosylation-rich region, a cysteine-rich region and a catalytic domain which comprises the catalytic residues $\operatorname{Ser}_{630}, \operatorname{Asp}_{708}$ and His $\mathrm{H}_{740}$. DPP4 is a homodimer and is anchored in the membrane by its signal peptide (Weihofen et al., 2004; Chung et al., 2010). Each monomer can be divided into two domains: the eight blade propeller and the alpha/beta-hydrolase. The propeller domain can be further divided into subdomains which consist of blade II to $\mathrm{V}$ for the 
glycosylation-rich region or VI to VIII for the cysteine-rich region (De Meester et al., 1999; Lambeir et al., 2003; Gorrell, 2005). The two main regions important for binding with the $\mathrm{S}$ protein are located within blade $\mathrm{V}$ and $\mathrm{VI}$. The soluble form of DPP4 only misses the CT and the TD, so that it is not membrane anchored anymore but still has all catalytic domains and thereby is still active (Klemann et al., 2016; Peck et al., 2017).

In general DPP4 is involved in many different physiological processes: the immune response by T-cell activation with binding to caveolin-1 or adenosine deaminase (ADA) which both bind to the glycosylation-rich region, the cell adhesion by binding extracellular matrix molecules like fibronectin which interacts with the cysteine-rich region, the degradation into and assimilation of proline containing peptides and the glucose metabolism, by degradation of insulinotropic peptides (Kameoka et al., 1993; De Meester et al., 1994, 1999; Lambeir et al., 2003; Demuth, Mclntosh and Pederson, 2005; Gorrell, 2005). DPP4 is important for the body homeostasis for example Diabetes mellitus can occur depending on the disruption of the glucose metabolisms. DPP4 cleaves the incretins glucagon-like peptide 1 (GLP1) and the gastric inhibitory polypeptide (GIP) respectively glucose-dependent insulinotropic peptide. These enzymes are responsible for the insulin secretion when intact glucose is present. Both have a half-time of a few minutes and are degraded strictly depended on DPP4 activity (Pederson et al., 1998; Yasuda et al., 2002; Conarello et al., 2003; Demuth, Mclntosh and Pederson, 2005). Furthermore diabetes is comorbidity for MERS-CoV infections as well as obesity, smoking or lung disease like asthma and cystic fibrosis. It was shown that soluble DPP4 is upregulated in the lung epithelia of smokers and patients with lung disease which could increase MERS-CoV infection (Assiri, Al-Tawfiq, et al., 2013; Assiri, McGeer, et al., 2013; Al-Tawfiq et al., 
2014; Memish, Al-Tawfiq, et al., 2014; Al-abdallat et al., 2016; Meyerholz, Lambertz and McCray, 2016; Seys et al., 2018).

\subsubsection{Sialic acids}

Sialic acids are monosaccharide's which are expressed at the surface of all eukaryotic cells and can cap oligosaccharides on $\mathrm{N}$ and $\mathrm{O}$ linked glycoprotein's or glycolipids (Varki, 2009). Furthermore glycans terminating in sialic acids serve as class of receptors for many different viruses. Sialic acids can be cleaved from the glycan sequences on the host cells by neuraminidase which can inhibit viral spread. A-5-N-acetyl-neuraminic-acid (Neu5Ac) is the most common structure of sialic acids. It can bind to the hemagglutinin (HA) of influenza virus A and B (Sauter et al., 1992; Wang et al., 2007; Gamblin and Skehel, 2010; Viswanathan et al., 2010) and the HE of the BCoV (Zeng et al., 2008). The MERS-S protein provides a dual binding site for the host cell receptor DPP4 and sialic acids via distinct domains. DPP4 interacts with the RBM in the $\mathrm{S} 1$ subunit and sialoglycans can bind in the first part of the $\mathrm{S} 1$ subunit between aa 18-355. In case of MERS-CoV, the expression of sialoglycans is not sufficient for host cell entry but they can serve as an attachment receptor and can increase viral entry in presence of DPP4. Finally, MERS-S is highly selective for the Neu5Ac variant of sialic acids (Li et al., 2017).

\subsubsection{Host cell proteases}

MERS-S needs to be proteolytic primed by host cell proteases for efficient host cell entry. Proprotein convertases (PPC), serine proteases or cysteine cathepsins can activate MERS-S and may cleave it at two distinct sites, S1/S2 or S2'. 


\subsubsection{Proprotein Convertases (PPC)}

PPC are endoproteolytic processing enzymes of the secretory pathway in humans (Steiner, 1998). In general newly synthesized proteins are inactive precursor proteins which need to be proteolytically activated. This precursor cleavage can be mediated by PPC and mainly occurs at a multibasic cleavage site (also known as multibasic motif): $R / K-X n-R / K \downarrow$. The Xn marks an undefined number of any aa. and PPC's cleave after the second $\mathrm{R} / \mathrm{K}$ residue indicated by the arrow (Seidah and Chretien, 1999). In 1989 furin was the first discovered PPC (Fuller, Brake and Thorner, 1989). It is one of the main proteases necessary for the proteolytic activation of MERS-S. The cleavage motif of furin is more stringent. The motif: R-X-R/K-R $\downarrow$, starts and ends with an arginine. In between are only two aa located, one undefined and the second needs to be an arginine or lysine. However the furin cleavage is further influenced by other aa in close proximity to the cleavage motif. In general, not all cleavage sites contain the furin specific cleavage motif and not all sites that include the specific motif are cleaved by furin due to the further characteristics. Furin has a preference for basic arginine $(\mathrm{R})$ or lysine $(\mathrm{K})$ residues at P3, P5 and P6. P1' and P2' are characterized by the absence of lysine residues, while P1' preferentially include aa's with polar or negatively charged side chains. All these positions influence the cleavage (Nakayama, 1997; Henrich et al., 2003). In MERS-S the S1/S2 as well as the S2' cleavage site can be processed by furin. In contrast to SARS-CoV, SARSCoV-2 harbors a multibasic motif and might proteolytically activated by furin cleavage (Millet and Whittaker, 2014; Hoffmann, Kleine-Weber, et al., 2020). PPC's are involved in a large variety of protein activation like peptide hormones, growth and differentiation factors, adhesion factors, receptors, extracellular matrix proteins and exogenous proteins e.g. coat glycoprotein's of virus particles. It was shown 
previously that furin is able to cleave the glycoprotein of human immunodeficiency virus 1 (HIV-1) and influence A virus (IAV) (Duckert, Brunak and Blom, 2004).

\subsubsection{Type II transmembrane serine proteases}

Type II transmembrane serine proteases (TTSPs) are expressed in all vertebrates. Transmembrane serine protease subtype 2 (TMPRSS2) can be found in epithelial of gastrointestinal, urogenital and respiratory tracts (Vaarala et al., 2001). TMPRSS2 plays an essential role for activation of $\mathrm{HCoV}$ because the host cell entry of $\mathrm{HCoV}$ including HCoV-OC43, HCoV-HKU1, HCoV-229E, SARS-CoV, MERS-CoV and SARS-CoV-2 is mediated via the cell surface pathway (Szabo and Bugge, 2008; Kawase et al., 2012; Shirato, Kawase and Matsuyama, 2018a; Hoffmann, KleineWeber, et al., 2020). TTSPs are composed of different N-terminal transmembrane domains, a C-terminal extracellular serine protease domain which contains the catalytic histidine, aspartic acid and serine domains and a stem region. TTSPs can be divided into four different classes: HAT/DESC, hepsin/TMPRSS, matripase and corin. TMPRSS2 belongs to the second family, the hepsin/TPMRSS class. The specificity of this class is a group A scavenger domain in its stem region, proceed by a low-density-lipoprotein receptor class A domain in TMPRSS2/3/4. TTSPs are synthesized as inactive precursor proteins, which need to be activated by cleavage. Even after activation these proteins remain membrane anchored due to a disulfide bond that links the prodomain and the catalytic domain (Hooper et al., 2001; Szabo and Bugge, 2008). The main function of TTSPs is to stabilize the basic homeostasis rather than re-establish it after external challenging like infections. Furthermore they are involved in growth factor activation or initiation of proteolytic cascades (Bugge, Antalis and $\mathrm{Wu}, 2009)$. TMPRSS2 itself was found in the basal epithelium of the prostate epithelium and later in the epithelial cells of kidney, upper airways, alveoli 
and ovaries. TMPRSS2 is proposed to regulate epithelial sodium currents in the lung via proteolytic cleavage of sodium channels and to regulate inflammatory response in the prostate (Lin et al., 1999; Afar et al., 2001; Donaldson et al., 2002; Wilson et al., 2005). In the context of IAV infection it was shown that TMPRSS2 knock-out (KO) mice exhibited a decreased viral spread and increased survival rates. However TMPRSS2 KO mice did not show any phenotype by which the physiological role remains unclear (Bugge, Antalis and Wu, 2009; Hatesuer et al., 2013). TMPRSS2 is expressed in many cells in the respiratory tract which may drive virus infection of IAV and SARS-CoV shown to be activated by TMPRSS2 (Glowacka et al., 2011; Bertram et al., 2012). Furthermore, TMPRSS2 is able to activate MERS-S at the S2' site. The cleavage by TMPRSS2 relies on the presence of a monobasic arginine motif. In case of TMPRSS2 a monobasic motif preferentially at P1 is sufficient for cleavage in contrast to furin, which requires a multibasic motif (Kleine-Weber et al., 2018).

Camostat mesylate is a serine protease inhibitor, which blocks the activity of TMPRSS2. Treatment of cells with TMPRSS2 was shown to block MERS-CoV, SARS-CoV and IAV replication (Kawase et al., 2012; Shirato, Kawase and Matsuyama, 2013; Yamaya et al., 2015; Hoffmann, Kleine-Weber, et al., 2020). 


\subsubsection{Cysteine cathepsins}

Cathepsins are proteases that are active in a slightly acidic environment. Besides the cysteine cathepsins to which e.g. cathepsins B, L, V, K belong, two other major cathepsin groups are described which are the serine and aspartic protease cathepsins (Turk et al., 2012). Most cysteine cathepsins including cathepsin L (CTSL) are ubiquitously expressed in human tissue. However, it was shown that in human lung cells (e.g. Calu-3) CTSL isles expressed compared to TMPRSS2 (Park et al., 2016). Cysteine cathepsins are active in slightly acidic environment and are unstable at neutral $\mathrm{pH}$, thus they are intracellular proteases involved in degradation of intra- and extracellular proteins (Turk et al., 2012). Furthermore, CTSL was shown to be involved in the endosomal proteolytic activation of the S protein of MERS-CoV (Gierer et al., 2013; Park et al., 2016).

Cathepsin activity can be blocked by different compounds. MDL28170 a cathepsin B (CTSB) and CTSL inhibitor can reduce the EBOV-GP driven host cell entry and was also shown to act in blocking the S-driven host cell entry of SARS-CoV and MERSCoV (Afar et al., 2001; Kawase et al., 2012; Gierer et al., 2013; Hoffmann et al., 2019). Ammonium chloride $\left(\mathrm{NH}_{4} \mathrm{Cl}\right)$ elevates the endosomal $\mathrm{pH}$ and mediates inhibition of cathepsins by disrupting the acidic environment needed for activation of cathepsins. Thus, ammonium chloride treatment could inhibited the SARS-S-driven host cell entry (Simmons et al., 2005). 


\subsection{The novel emerging Coronavirus - SARS-CoV-2}

In December 2019, a novel betacoronavirus SARS-CoV-2, emerged in the city of Wuhan, Hubei region in China. SARS-CoV-2 is phylogenetically-related to SARSCoV, which has caused the SARS pandemic 2002/2003. While SARS-CoV was transmitted from civet cats to humans, the animal spillover host for SARS-CoV-2 remains to be identified (Guan et al., 2003; De Wit et al., 2016; Zhu et al., 2020). Similar to SARS-CoV, SARS-CoV-2 employs the angiotensin-converting enzyme 2 (ACE2) as host cell receptor and the viral $S$ protein can be proteolytic primed by TMPRSS2 (Li et al., 2004; Hoffmann, Kleine-Weber, et al., 2020). The carboxypeptidase ACE2 is a type I integral membrane protease expressed in various tissues like kidney, endothelium, lung and heart. ACE2 is further involved in the renin-angiotensin system (RAS), which itself is necessary for the regulation of homeostasis of the vascular functions (Donoghue et al., 2000; Tipnis et al., 2000; Crowley et al., 2005; Tikellis and Thomas, 2012). Infection of humans with SARSCoV-2 can lead to the disease COVID-19, that can manifest itself as self-limiting, common cold like disease with, fever and coughing. However, also development of severe, life-threatening pneumonia is possible and it is believed that severe disease might correlate with increased age and pre-existing comorbidities, like diabetes, respiratory diseases and/ or obesity (Guo et al., 2020). The median incubation period of SARS-CoV-2 infection is five to six days and thus equally to incubation periods observed for MERS-CoV (Guan et al., 2020; Guo et al., 2020). Different to SARSCoV and MERS-CoV, SARS-CoV-2 can be transmitted with high efficiency between humans. Through trading and air travel, SARS-CoV-2 has been introduced into countries worldwide, resulting in a pandemic (Anderson et al., 2004; Mackay and Arden, 2015; Shereen et al., 2020). The pandemic spread of COVID-19 highlights the urgent need for specific antiviral treatment options and vaccines against 
coronaviruses. Until today, no antiviral therapeutic or vaccine is licensed for treatment of coronavirus infections in humans.

\subsection{Animal models and therapeutic targets}

The most efficient prevention of virus infections including coronaviruses is vaccination. Vaccines are available for a few animal coronaviruses including IBV and TGEV. But those vaccines cannot be used permanently because of lack of efficiency or recombination events. In case of MERS-CoV no vaccine is licensed for humans or for camels. However, two vaccines candidates entered clinical trials for use in humans (GLS-5300 and MERS0001). In addition another candidate has been tested in dromedary camels for human or veterinary use (modified vaccinia virus Ankara (MVA) vector to express MERS-S) (Xu et al., 2019).Therapeutic targets for the tretament could be for example the S protein, accessory proteins, DPP4 or host cell proteases. The $S$ protein can be targeted at the RBD or NTD via neutralizing antibodies. Here, monoclonal antibodies targeting residues close to the interacting sites were proven most efficient (Wang et al., 2015, 2018). JC57-14 (non-human primate (NHP)) and F11 (mice) are two of those monoclonal RBD-specific antibodies. JC57-14 interacts with S protein residue W535 and F11 interacting with S protein residue D509, both were able to show neutralizing potential. However, for both antibodies escape mutations were observed (Wang et al., 2018). The accessory protein 4a was shown to target the host IFN response; the blocking of this function by anti-viral therapeutics could inhibit viral spread (Niemeyer et al., 2013). The host cell receptor DPP4 is important for viral entry. Besides the S protein, DPP4 can bind to other cellular factors at the cell surface like ADA. ADA is a cofactor for DPP4 which can antagonize the $S$ protein binding by blocking DPP4 (Raj et al., 2014). Furthermore the host cell proteases are necessary for entry: Furin, TMPRSS2 and 
CTSL are necessary for the viral activation. Those proteases can also be used as therapeutic targets. TMPRSS2 can be blocked efficiently by camostat mesylate and CTSL by the inhibitor MDL28170, both compounds were shown to inhibit MERS-S driven host cell entry in cell culture (Gierer et al., 2013; Shirato, Kawase and Matsuyama, 2013). However, MDL28170 was shown to introduce rapid mutations which lead to resistance of VSV-EBOV to MDL28170 (Hoffmann et al., 2019). All compounds shown to be affective in vitro still need to be tested in vivo.

Animal models are necessary to prove the effect of vaccines and therapeutics. For MERS-CoV different animal models were established. Rhesus macaques were the first established animal model. The animals were permissive for viral infection and showed acute transient, moderate respiratory disease with coughing and fever (De Wit et al., 2013; Falzarano et al., 2013; Munster, de Wit and Feldmann, 2013; Falzarano, Wit, et al., 2014; Yao et al., 2014). Another animal model is common marmosets, which develop a severe respiratory disease that rapidly becomes lethal. The respiratory and immune system of common marmosets and rhesus macaques is similar to humans, which is an advantage for confirming vaccines and antiviral therapeutics (Falzarano, de Wit, et al., 2014). Nevertheless, mouse models were also developed for MERS-CoV, but to be efficient they need to be DPP4 transduced or transgenic DPP4 mice. The advantage of mice models is that they are easy to handle and useful for screening. However, mice develop other symptoms than humans and transgenic mice present a global overexpression of DPP4 (Baseler, de Wit and Feldmann, 2016). The ongoing SARS-CoV-2 pandemic shows the urgency for treatment options of coronaviruses. Therefore already approved antiviral therapeutics are tested for the treatment for COVID-19 patients. Nevertheless, the need for effective antiviral therapeutics and vaccines is urgent. 


\section{Aims}

MERS-CoV can cause a life-threatening pneumonia in humans and has pandemic potential. The general potential of emerging coronaviruses to cause pandemics is presently demonstrated by the ongoing COVID-19 pandemic. While MERS-CoV can be transmitted from dromedary camels to humans, also for SARS-CoV-2 it is very likely that initial human infections occurred via close contact with an (at present unknown) infected animal. The coronaviral S protein mediates viral entry into target cells and is a viral key determinant that defines the range of susceptible host species and cell types. The $S$ protein engages specific cellular receptors and, upon proteolytic activation (priming) by cellular proteases, induces fusion of the viral and cellular membranes thereby delivering the viral genome into the cell. The underlying virus-host-cell-interactions are crucial for viral entry and thus might serve as targets for antiviral therapy. Therefore two central questions were addressed in this thesis:

1) Which host cell factors are required for the cellular entry driven by MERS-S? In detail, are there cell type-specific protease requirements with respect to the S1/S2 and S2' cleavage sites. Further, do naturally occurring polymorphisms in the MERS-CoV cell receptor DPP4 or MERS-S itself impact the viral entry efficiency?

2) Which host cell factors are crucial for the host cell entry of SARS-CoV-2? In particular, is the $S$ protein of SARS-CoV-2 also primed by TMPRSS2 and can TMPRSS2 thus be a therapeutic target? 


\section{Manuscripts}

\subsection{First manuscript}

\section{Functional analysis of potential cleavage sites in the}

\section{MERS-coronavirus spike protein}

Kleine-Weber H, Elzayat MT, Hoffmann M, Pöhlmann S.

License:

This work is licensed under the Creative Commons Attribution 4.0 International License: http://creativecommons.org/licenses/by/4.0/.

Individual contribution:

In the manuscript, the experiments and analysis for Figure 2: "Incorporation of MERS-S proteins into rhabdoviral particles.", Figure 3: "Expression of DPP4 and host cell proteases in target cell lines and lung tissue.", Figure 4: "Requirement of the S1/S2 site for MERS-S-driven entry is cell type dependent, while the S2' site is universally required.", Figure 5: "A single arginine at the S2' site is sufficient for MERS-S activation.", Figure 6: "An intact S1/S2 site promotes but is not essential for MERS-S activation by TMPRSS2" and Figure 7: "Cathepsin L activity is required for Vero E6 cell entry driven by a mutant $\mathrm{S}$ protein that lacks the S1/S2 and the S2' sites." were conducted by myself. 


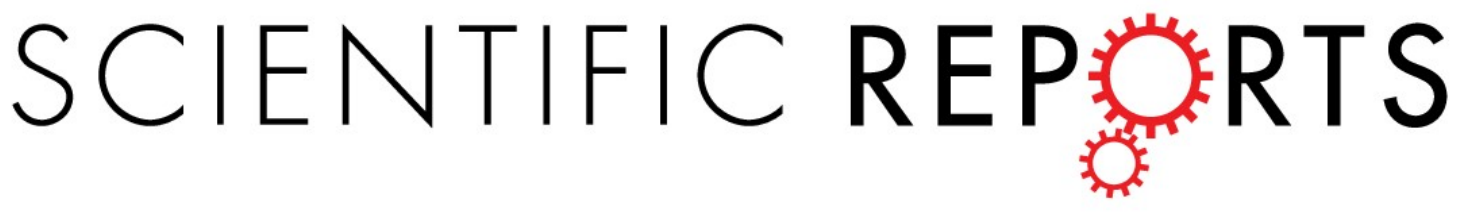

\section{OPEN Functional analysis of potential cleavage sites in the MERS- coronavirus spike protein}

Received: 22 June 2018 Accepted: 18 October 2018 Published online: 09 Nowember 2018
Hannah Kleine-Weber ${ }^{1,2}$, Mahmoud Tarek Elzayat ${ }^{1}$, Markus Hoffmann $\mathbb{D}^{1}$ \& Stefan Pöhlmann ${ }^{1,2}$

The Middle East respiratory syndrome-related coronavirus (MERS-CoV) can cause severe disease and has pandemic potential. Therefore, development of antiviral strategies is an important task. The activation of the viral spike protein $(S)$ by host cell proteases is essential for viral infectivity and the responsible enzymes are potential therapeutic targets. The cellular proteases furin, cathepsin $L$ and TMPRSS 2 can activate MERS-S and may cleave the $S$ protein at two distinct sites, termed S1/S2 and S2'. Moreover, a potential cathepsin L cleavage site in MERS-S has been reported. However, the relative importance of these sites for MERS-S activation is incompletely understood. Here, we used mutagenic analysis and MERS-S-bearing vectors to study the contribution of specific cleavage sites to $S$ proteindriven entry. We found that an intact $\mathrm{S} 1 / \mathrm{S} 2$ site was only required for efficient entry into cells expressing endogenous TMPRSS2. In keeping with a previous study, pre-cleavage at the S1/S2 motif (RSVR) was important although not essential for subsequent MERS-S activation by TMPRSS2, and indirect evidence was obtained that this motif is processed by a protease depending on an intact RXXR motif, most likely furin. In contrast, the S2' site (RSAR) was required for robust viral entry into all cell lines tested and the integrity of one of the two arginines was sufficient for efficient entry. These findings suggest that cleavage at $\mathrm{S2}^{\prime}$ is carried out by proteases recognizing a single arginine, most likely TMPRSS2 and cathepsin L. Finally, mutation of the proposed cathepsin L site did not impact viral entry and double mutation of S1/S2 and S2' site was compatible with cathepsin L- but notTMPRSS2-dependent host cell entry, indicating that cathepsin $L$ can process the $S$ protein at auxiliary sites. Collectively, our results indicate a rigid sequence requirement for $S$ protein activation by TMPRSS 2 but not cathepsin $L$.

The family Coronaviridae comprises enveloped, positive sense RNA viruses that infect mammals (members of the subfamilies Coronavirinae and Torovirinae), birds (Coronavirinae) and fish (Torovirinae) ${ }^{1}$. Coronaviruses can have zoonotic potential and transmission of animal coronaviruses of the genus Betacoronavirus to humans has resulted in novel, severe respiratory diseases: The outbreak of severe acute respiratory syndrome (SARS; caused by SARS-related coronavirus, SARS-CoV) in Southern China in 2002 and its subsequent global spread were associated with almost 800 deaths, with the vast majority of cases occurring in Asia and Canada ${ }^{2}$. Although no new SARS cases were observed after 2004, another severe respiratory disease caused by a new betacoronavirus emerged in 2012: Middle East respiratory syndrome (MERS), caused by MERS-related coronavirus (MERS-CoV) $)^{3,4}$, was so far diagnosed in 2,229 patients and was responsible for 791 deaths ${ }^{5}$. The majority of cases were documented in the Middle East but the virus, like SARS-CoV, has been introduced into other countries via air travel and a MERS outbreak in South Korea was associated with more than 100 cases $^{6}$. Importantly, MERS-CoV is still endemic in the Middle East and the virus may have pandemic potential. Therefore, it is important to devise novel antiviral strategies to combat MERS

The MERS-CoV spike protein (MERS-S) is inserted into the viral envelope and mediates viral entry into target cells. For this, MERS-S binds to the cellular receptor dipeptidyl peptidase 4 (DPP4/CD26) ${ }^{7}$ via its surface unit, S1, and then employs its transmembrane unit, S2, to fuse the viral membrane with a host cell membrane which allows the delivery of the viral genome into the host cell cytoplasm. However, receptor binding alone is not

${ }^{1}$ Infection Biology Unit, German Primate Center - Leibniz Institute for Primate Research, Kellnerweg 4, 37077 Göttingen, Germany. 'Faculty of Biology and Psychology, Wilhelm-Weber-Str. 2, University Göttingen, 37073, Göttingen, Germany. Correspondence and requests for materials should be addressed to M.H. (email: mhoffmann@ dpz.eu) orS.P. (email: spoehlmann@dpz.eu) 
MERS-S

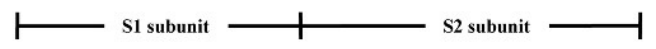

\begin{tabular}{|l|l|l|l|l}
\hline SP & \\
\hline
\end{tabular}

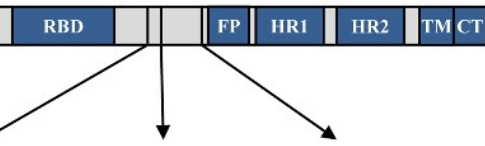

$\underline{\mathbf{S 1} / \mathbf{S 2}}$

$\underline{\text { ECP }}$

$\underline{\mathbf{S 2}}$

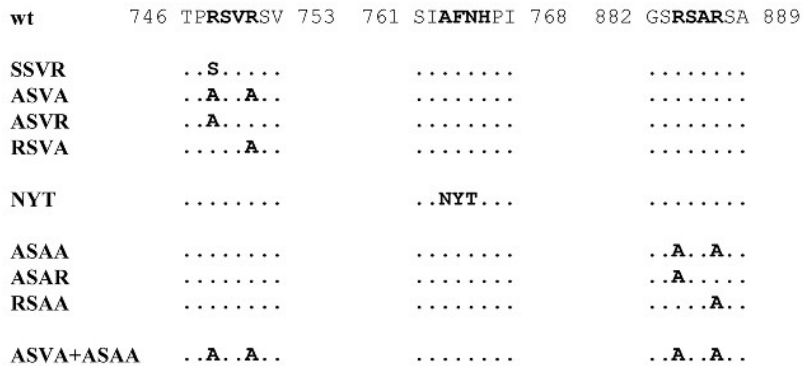

Figure 1. Domain organization and protease cleavage sites of MERS-S. MERS-S possesses two subunits, a surface subunit (S1) and a membrane-anchored subunit (S2). The S1 subunit harbors an N-terminal signal peptide (SP) and the receptor binding domain (RBD) while the S2 subunit contains domains required for membrane fusion, the fusion peptide (FP), two heptad repeats (HR1, HR2), and a transmembrane domain (TM). Moreover, the S2 subunit contains a cytoplasmic tail (CT). The S1/S2 cleavage site is located at the border between the S1 and S2 subunits while the S2' site is located at the N-terminus of the FP. A proposed cleavage site for cathepsin L is located between the $\mathrm{S} 1 / \mathrm{S} 2$ and $\mathrm{S} 2$ ' sites (ECP, endosomal cysteine protease). The amino acid residues of the $\mathrm{S} 1 / \mathrm{S} 2$, cathepsin $\mathrm{L}$ and $\mathrm{S}^{\prime}{ }^{\prime}$ sites are printed in bold and the mutations introduced into the cleavage sites are indicated.

sufficient for S protein-driven entry. The $\mathrm{S}$ protein is synthesized as an inactive precursor and is converted into its active form upon cleavage by host cell proteases ${ }^{8,9}$. In fact, proteolytic processing of MERS-S might be sufficient to trigger the membrane fusion reaction and is subsequently referred to as activation. The host cell proteases responsible for MERS-S activation constitute potential targets for antiviral intervention and the identification of their cleavage sites might instruct the generation of inhibitors. Therefore, the proteolytic activation of MERS-S is in the focus of ongoing research endeavours.

The following host cell proteases can activate MERS-S in cell culture: Cathepsin $\mathrm{L}^{10-12}$, an endosomal,
the focus ongoing research endeavours. $\mathrm{pH}$-dependent cysteine protease, furin ${ }^{13,14}$, a proprotein convertase expressed in the Golgi apparatus and to a lesser extent at the cell surface, and TMPRSS2 ${ }^{10,15}$, a type II transmembrane serine protease that is believe to process the $\mathrm{S}$ protein and other substrates at or close to the cell surface. TMPRSS2 expression in target cells renders MERS-S-driven entry independent of the activity of cathepsin $\mathrm{L}^{10,15}$, indicating that during viral entry MERS-CoV makes contact with a TMPRSS2-positive compartment, most likely the plasma membrane, before MERS-CoV makes contact with a TMPRSS2-positive compartment, most likely the plasma membrane, before
it is trafficked into cathepsin L-positive endosomes. Cleavage of the S protein in the Golgi apparatus of infected cells has been proposed to be essential for subsequent MERS-S activation by TMPRSS2 or furin during entry into target cells because it may endow the $S$ protein with sufficient structural flexibility to engage these proteases for processing ${ }^{16}$. Notably, activity of TMPRSS 2 but not cathepsin L might be important for viral spread in the host. Thus, TMPRSS2 but not cathepsin L was found to be expressed at high levels in the respiratory epithelium ${ }^{16,17}$ and an inhibitor active against TMPRSS2 reduced SARS-CoV spread and pathogenesis in a rodent model while a cathepsin $\mathrm{L}$ inhibitor had little effect ${ }^{18}$. Moreover, activation by cathepsin $\mathrm{L}$ has been suggested to be a cell culture adaptation, at least in the context of the human coronaviruses $229 \mathrm{E}, \mathrm{HKU} 1$ and OC43 ${ }^{19,20}$. Finally, the contribution of furin to MERS-S activation in the host remains to be determined. In this context, it is noteworthy that one study questioned whether cleavage by furin contributes to MERS-CoV infectivity in cell culture ${ }^{21}$ while another showed that furin is not involved in S protein activation during host cell entry ${ }^{22}$.

The activation of MERS-S by host cell proteases requires $\mathrm{S}$ protein processing at defined sites. MERS-S harbors two cleavage sites found in all CoV S proteins: An S1/S2 site, composed of the amino acids RSVR, is located at the border between the S1 and S2 subunits, while an S2' site, composed of the amino acids RSAR, is located upstream of the putative fusion peptide present within the S2 subunit (Fig. 1). The S1/S2 site is believed to be processed by furin in infected cells ${ }^{14,21}$ while the $\mathrm{S} 2^{\prime}$ site should be processed during viral entry by all $\mathrm{S}$ protein activating proteases identified today since generation of a free $\mathrm{N}$-terminus of the fusion peptide is required for membrane fusion. Finally, an AFNH motif located between the S1/S2 site and the S2' site was reported to be 


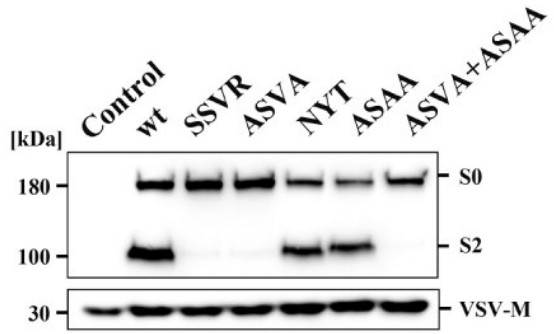

Figure 2. Incorporation of MERS-S proteins into rhabdoviral particles. Equal volumes of culture supernatants containing pseudoparticles harboring MERS-S wt or the indicated S protein mutants equipped with a C-terminal V5-tag were centrifuged and the pellets subjected to Western blot analysis, using an anti-V5 antibody. Arrow heads indicate bands corresponding to uncleaved precursor MERS-S (S0) and S2 subunit generated by cleavage at the S1/S2 border. The detection of VSV-M served as loading control. Shown is a representative Western blot from a total of twelve independent experiments

required for S protein-driven host cell entry and is believed to be processed by cathepsin $\mathrm{L}^{23}$. However, direct evidence that MERS-S activation depends on S protein processing at the $\mathrm{S} 1 / \mathrm{S} 2$, cathepsin $\mathrm{L}$ and/or S2' sites is frequently lacking. For instance, the sites required for $\mathrm{S}$ protein activation by TMPRSS2 are unknown. Moreover, it is largely unclear whether certain S protein activating proteases can use auxiliary sites in case S1/S2 and/or S2 are not available.

Here, we perfor med mutagenic analysis to define the contribution of specific cleavage sites to MERS-S-driven entry into cell lines which expressed defined S protein activating proteases. Moreover, we used inhibitors to investigate protease choice. We found that the requirement for an intact S1/S2 site for MERS-S-mediated entry was cell type dependent while the integrity of the $\mathrm{S}^{\prime}$ site was universally required. In contrast, mutation of the proposed cathepsin L site did not impact S protein-driven entry and we obtained evidence that this protease can use an auxiliary site for $\mathrm{S}$ protein activation if $\mathrm{S}^{\prime}$ is not available. Finally, our results are compatible with the concept that the $\mathrm{S} 1 / \mathrm{S} 2$ site is processed by proprotein convertases while the $\mathrm{S}^{\prime}$ site is cleaved by TMPRSS 2 .

\section{Results}

The S2' site but not the S1/S2 site is universally required for MERS S-driven host cell entry. We first investigated whether the $\mathrm{S} 1 / \mathrm{S} 2$, the cathepsin $\mathrm{L}$ and the $\mathrm{S} 22^{\prime}$ cleavage sites (Fig. 1) were universally required for MERS-S-driven entry or were only required for entry into certain target cells. For this, we used a set of previously established S protein mutants $\mathrm{s}^{21,23}$ and a VSV-based pseudotyping system. Mutants SSVR and ASVA harbored an altered S1/S2 site, the alteration in mutant NYT was previously shown to abrogate $\mathrm{S}$ protein activation by cathepsin $\mathrm{L}^{23}$ while mutant ASAA contained a mutated S2' site (Fig. 1). Moreover, in mutant ASVA + ASA A both the S1/S2 and the S2' site were altered (Fig. 1). We next employed a previously described VSV-based pseudotyping system ${ }^{24}$ to investigate how the mutations introduced into MERS-S modulated viral entry. For this, we first analyzed S protein incorporation into VSV particles produced in 293T cells. Immunoblot analysis revealed that all S protein mutants studied were efficiently incorporated into VSV particles, although some variation of incorporation efficiency was observed between experiments, and that mutation of the S1/S2 site largely abrogated proteolytic processing of the $S$ protein in particle producing cells (Fig. 2), as expected ${ }^{14,16,21}$.

Next, we selected target cells for the analysis of MERS-S-driven entry. The human colon-derived cell line Caco-2, the human adrenal gland-derived cell line 293T (either untransfected or transfected to express high levels of DPP4) as well as the African green monkey kidney-derived cell line Vero E6 were chosen for analysis, since these cells were previously reported to be susceptible to MERS-S-driven entry and both Caco- 2 and Vero E6 cells are known to allow amplification of authentic MERS-CoV ${ }^{14,15,21,23}$. Quantitative RT-PCR analysis of Caco-2, 293T and Vero E6 cells as well as human lung tissue, the natural target of MERS-CoV infection, revealed that Vero E6, 293T and lung tissue expressed roughly comparable amounts of DPP4 mRNA, while expression in Caco-2 cells was elevated (Fig. 3). In contrast, appreciable levels of TMPRSS2 mRNA were only detected in Caco-2 cells and lung tissue (Fig. 3), in keeping with published data ${ }^{10,17}$. Finally, mRNAs for cathepsin $\mathrm{L}$ as well as furin were readily detected in all cell lines tested and in lung tissue (Fig. 3). Thus, the cell lines under study were all positive for the MERS-CoV receptor, DPP4, but expressed different proteases known to be used by MERS-S for activation while expression of all proteases was robust in lung tissue.

All cell lines under study were readily susceptible to transduction by control particles bearing VSV-G and were largely refractory to transduction by particles bearing no viral glycoprotein (Fig. 4a,b), as expected. Transduction mediated by wildtype MERS-S was comparable for Vero E6 and Caco- 2 cells $\left(\sim 3 \times 10^{4}\right.$ c.p.s. $)$ and generally higher as compared to untransfected $293 \mathrm{~T}$ cells $\left(\sim 10^{3}\right.$ c.p.s. $)$ (Fig. 4a). However, when $293 \mathrm{~T}$ cells were previousl transfected with expression plasmid for DPP4, transduction levels were as high as for Vero E6 and Caco-2 cells (Fig. 4a). Transduction of target cells with particles bearing MERS-S revealed that alteration of the S1/S2 site markedly reduced entry into Caco-2 (approx. 12-15-fold reduction) but not 293T, 293T+DPP4 or Vero E6 cells (Fig. 4b). In contrast, an intact S2' site was universally required for S protein driven entry, although the effects observed upon transduction of Vero E6,293T and 293T+DPP4 were less pronounced than those seen for Caco-2 


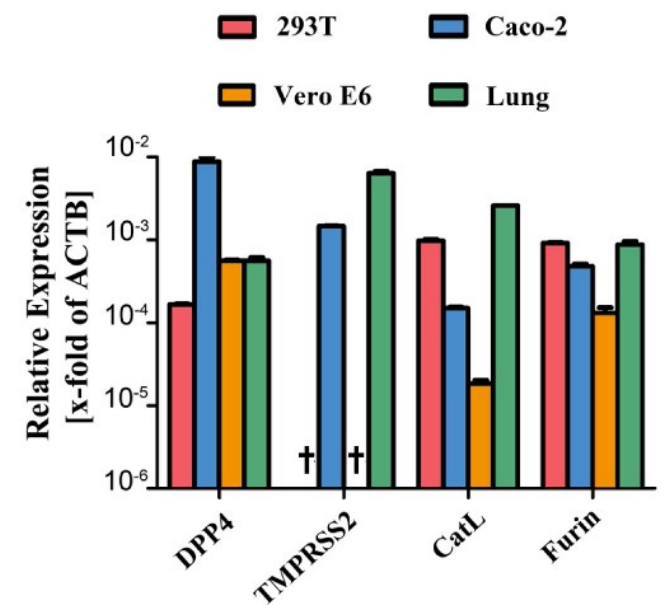

Figure 3. Expression of DPP4 and host cell proteases in target cell lines and lung tissue. Total cellular RNA was extracted from 293T, Caco-2 and Vero E6 cells, reverse-transcribed into cDNA and quantified for DPP4 and protease transcript numbers by quantitative RT-PCR. cDNA from human lung tissue was also included in the analysis. The numbers of DPP4/protease mRNA copies are shown relative to the housekeeping gene $B$-actin (ACTB). Er ror bars indicate standard deviation (SD). Crosses indicate samples for which no transcripts were (ACTB).

cells (Fig. 4 b, roughly 300 -fold reduction in Caco- 2 as compared to $4-5$-fold reduction in the other cell lines tested). Finally, mutation of the cathepsin L site had, contrary to published data ${ }^{23}$, no impact on S protein-driven entry into any of the cell lines studied.

The S1/S2 and S2' site in MERS-S are processed by different proteases. We next determined whether the $\mathrm{S} 1 / \mathrm{S} 2$ and the $\mathrm{S} 2{ }^{\prime}$ sites are cleaved by proteases exhibiting the same cleavage specificity or by enzymes that recognize different cleavage sites. Thus, both sites contain an RXXR motif, a prerequisite for cleavage by proprotein convertases, and could thus be processed by furin or related enzymes. Alternatively, these sites migh be cleaved by proteases for which motifs encompassing a single arginine residue can be sufficient for cleavage, potentially cathepsin L and TMPRSS2. In order to discern between these two possibilities, we investigated entry driven by $\mathrm{S}$ protein mutants in which either one or both arginines were mutated. For this, we employed Vero E6 and Caco-2 cells as targets. Immunoblot revealed that all MERS-S mutants were efficiently incorporated into VSV particles (Fig. 5a) and none of the mutations introduced into the S1/S2 site markedly reduced entry into Vero E6 cells (Fig. 5b), in keeping with our findings stated above, although the 1.5-2.6-fold reduction observed in this set of experiments was statistically significant (note that the average of three experiments is shown in Fig. 4 while the average of nine experiments is shown in Fig. 5b). In contrast, mutation of a single arginine within this site was sufficient to reduce entry into $\mathrm{Cac0}-2$ cells by 4.5 to 29.4 -fold (Fig. $5 \mathrm{~b}$ ), suggesting that the $\mathrm{S} 1 / \mathrm{S} 2$ site is processed by a protease that depends on the presence of two arginines, like furin. Furthermore the second but not the first arginine within the $\mathrm{S} 2^{\prime}$ site was sufficient for efficient $\mathrm{S}$ protein-driven entry into Caco- 2 cells while mutation of any single arginine at the $\mathrm{S} 2^{\prime}$ site had only a minor, although statistically significant, effect on S protein-mediated transduction of Vero E6 cells (Fig. 5b). These results suggest that in Caco-2 and Vero E6 cells the S2' site is mainly processed by a protease that requires a single arginine at its cleavage site, likely TMPRSS2 (Caco-2, see below) and cathepsin L (Vero E6).

An intact S2' but not S1/S2 site is essential for MERS-S activation by TMPRSS2. Our analyses had so far suggested that cleavage at $\mathrm{S} 1 / \mathrm{S} 2$ is required for robust MERS-S-driven entry into Caco- 2 cells, which express TMPRSS2. Therefore, we next asked whether cleavage at this site is also required for S protein-driven entry into cells in which only the TMPRSS2-activation pathway is operative. For this, we blocked MERS-S-driven entry into 293T+DPP4 cells by the cathepsin L inhibitor MDL28170 and asked whether this blockade can be overcome by expression of TMPRSS2. Entry driven by MERS-S wt and all S protein variants with mutations in overcome by expression of TMPRSS2. Entry driven by MERS-S wt and all S protein variants with mutations in
the S1/S2 site was inhibited at least 13.7 -fold by MDL28170 treatment and entry driven by MERS-S wt was fully rescued by directed expression of TMPRSS2 in target cells (Fig. 6a). Entry mediated by the S protein mutants with inactivated S1/S2 site was also rescued by TMPRSS2, although with reduced efficiency as compared to MERS-S wt (Fig. 6a), indicating that precleavage at $\mathrm{S} 1 / \mathrm{S} 2$ is not an absolute prerequisite for subsequent $\mathrm{S}$ protein activation by TMPRSS2. In contrast, mutation of the S2 $^{\prime}$ site abrogated MERS-S activation by TMPRSS2. Moreover, analysis of MERS-S cleavage in a cis setting (i.e. protease and S protein expressed in the same cell) showed that mutation 
a)
口Vero E6 口 Caco-2
口 293T
口 293T+DPP4

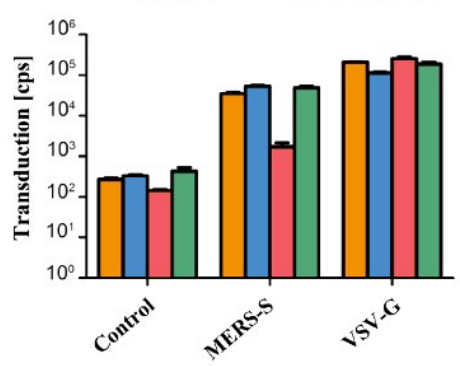

b)

Caco-2

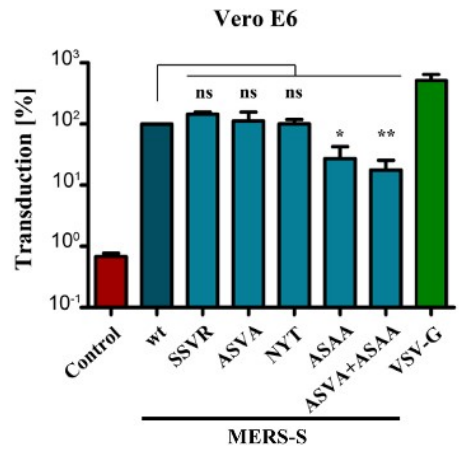

293T

$293 T+D P P 4$
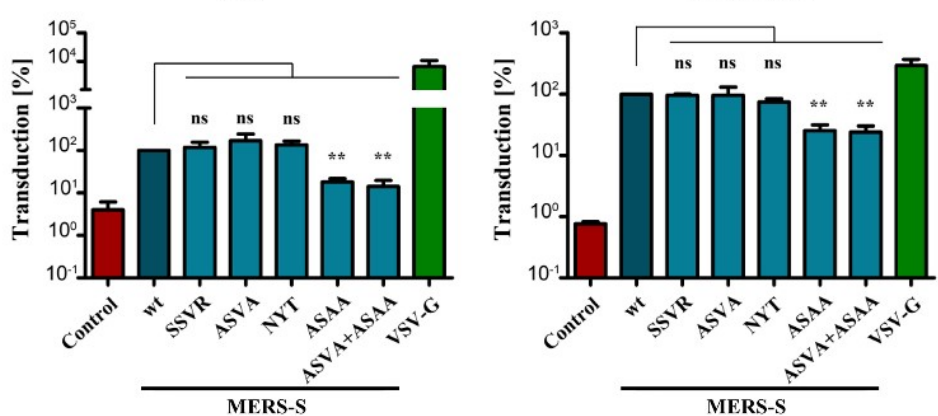

Figure 4. Requirement of the $\mathrm{S} 1 / \mathrm{S} 2$ site for MERS-S-driven entry is cell type dependent, while the $\mathrm{S} 2$ ' site is universally required. (a) Equal volumes of rhabdoviral vectors harboring MERS-S wt, the indicated S protein mutants, VSV-G or no glycoprotein at all (negative control) were used for transduction of Caco-2, Vero E6 cells or 293T cells that were either untreated or transfected with expression plasmid for DPP4. Transduction efficiency was quantified at $18 \mathrm{~h}$ post inoculation by measuring the activity of virus-encoded luciferase in

efficiency was quantified at $18 \mathrm{~h}$ post inoculation by measuring the activity of virus-encoded luciferase in
cell lysates. Shown are the data from one representative experiment performed with quadruplicate samples, error bars indicate standard deviation (SD). Similar results were obtained in two separate experiments. (b) The combined results of three independent experiments carried out as described for panel a are shown. For normalization, transduction mediated by VSV particles harboring MERS-S wt was set as $100 \%$. Error bars indicate standard error of the mean (SEM). Statistical significance of differences between transduction mediated by wt and mutant $\mathrm{S}$ proteins was analyzed using a paired, two-tailed students $\mathrm{t}$-test $\left({ }^{*} \mathrm{p} \leq 0.05 ; * * \mathrm{p} \leq 0.01\right.$; $* * * \mathrm{p} \leq 0.001 ; \mathrm{ns}$, not significant) 
a)

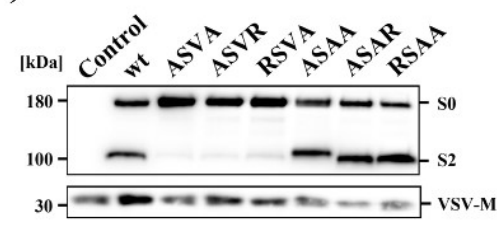

b)

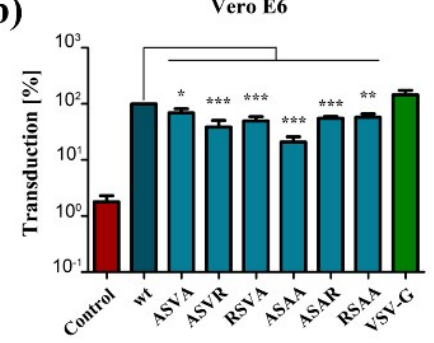

MERS-S

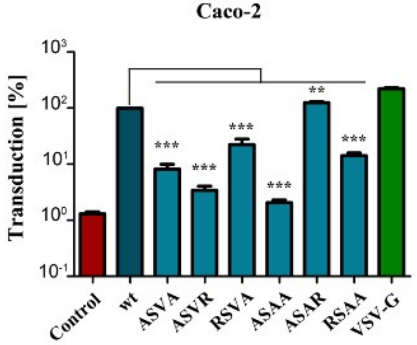

MERS-S

Figure 5. A single arginine at the $\mathrm{S} 2^{\prime}$ site is sufficient for MERS-S activation. (a) Equal volumes of culture supernatants containing pseudoparticles harboring MERS-S wt or the indicated $S$ protein mutants equipped with a C-terminal V5-tag were centrifuged and the pellets subjected to Western blot analysis, using an anti-V5 antibody. The results were confirmed in four separate experiments. (b) Vero E6 and Caco-2 cells were transduced with pseudoparticles harboring MERS-S wt, the indicated S protein mutants, VSV-G or no glycoprotein at all (negative control), and transduction efficiency was analyzed as described in the legend to Fig. 4. The average of nine separate experiments is shown, in which transduction mediated by MERS-S wt was set as $100 \%$. Error bars indicate SEM. Statistical significance of differences between transduction mediated by wt and mutant $\mathrm{S}$ proteins was analyzed using a paired, two-tailed students $\mathrm{t}$-test $\left({ }^{*} \mathrm{p} \leq 0.05 ;{ }^{* *} \mathrm{p} \leq 0.01\right.$; $* * * \mathrm{p} \leq 0.001 ; \mathrm{ns}$, not significant).

of the S2' site resulted in aberrant cleavage products as compared to MERS-S wt and S protein mutants with alterations in the S1/S2 site (Fig. 6b). Finally, we asked whether the residual entry into the TMPRSS2 ${ }^{+} \mathrm{Caco}_{-2}$ cells observed upon mutation of the S1/S2 site was dependent on cathepsin L activity, as suggested by a previous study $^{16}$, or was promoted by TMPRSS2. Preincubation of Caco-2 cells with protease inhibitors showed that entry driven by S proteins lacking an intact S1/S2 site was dependent on TMPRSS2 but not cathepsin L activity (Fig. 6c), indicating a dominant role of TMPRSS2 in S protein-driven host cell entry into Caco-2 cells. In sum, our data suggests that an intact $\mathrm{S} 1 / \mathrm{S} 2$ site promotes but is not essential for MERS-S-activation by TMPRSS2.

Residual Vero E6 cell entry observed upon mutation of the $S 1 / S 2$ and $S 2^{\prime}$ site is promoted by cathepsin L activity. We found that simultaneous inactivation of the $\mathrm{S} 1 / \mathrm{S} 2$ and $\mathrm{S} 2{ }^{\prime}$ site markedly reduced entry into Caco- 2 cells, which depends on TMPRSS2, but only modestly reduced S protein-driven into Vero E6 cells, which depends on cathepsin L activity (Fig. 4). The latter finding raised the question whether the residual entry into Vero E6 cells was still dependent on cathepsin L activity. We addressed this question by analyzing transduction of Vero E6 cells which were preincubated with the cathepsin L inhibitor MDL28170 or the TMPRSS2 inhibitor camostat. Camostat did not reduce $S$ protein-driven entry, as expected. In contrast, cell entry driven by all S proteins analyzed was comparably reduced upon MDL28170 treatment (Fig. 7). Remarkably, the cathepsin $\mathrm{L}$ dependence was also observed for mutants in which the $\mathrm{S} 2^{\prime}$ was inactivated, indicating that cathepsin $\mathrm{L}$, unlike TMPRSS2, can employ auxiliary cleavage sites for $\mathrm{S}$ protein activation.

\section{Discussion}

MERS-CoV infection is associated with a case-fatality rate of $36 \%$ and the virus has pandemic potential ${ }^{5}$. Therefore, the identification of therapeutic targets is important and the cellular proteases responsible for $S$ protein activation are candidates. However, cell line specific differences in protease choice and the sites in MERS-S that are processed by these proteases have not been fully elucidated. Our data support the concep that pre-cleavage of MERS-S at the S1/S2 site by furin promotes subsequent S protein activation by TMPRSS2 ${ }^{16}$ However, pre-cleavage was not essential for S protein activation by TMPRSS2 and Caco- 2 cell entry driven by a MERS-S variant lacking pre-cleavage was still TMPRSS2 dependent. Moreover, our results suggest that the S2 site, specifically the second arginine, is important for efficient $\mathrm{S}$ protein activation by TMPRSS 2 and indicate that 
a)

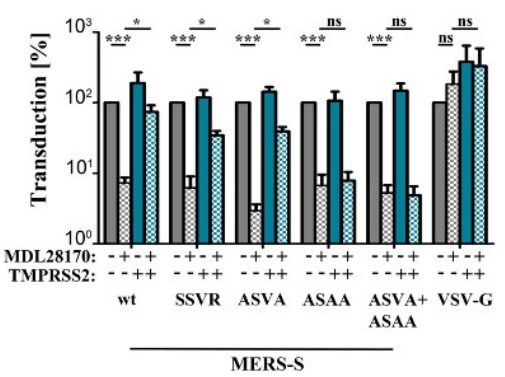

c)

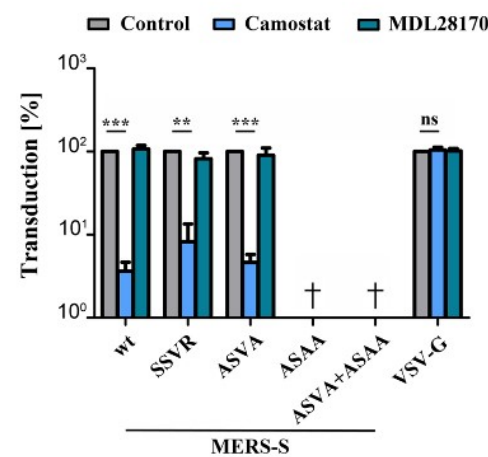

b)

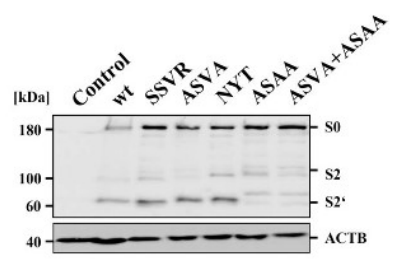

Figure 6. An intact S1/S2 site promotes but is not essential for MERS-S activation by TMPRSS2 (a) 293T cells were transfected with DPP4 plasmid or cotransfected with DPP4 and TMPRSS2 plasmid. At $24 \mathrm{~h}$ post transfection, cells were incubated with DMSO or cathepsin L inhibitor MDL28170 before being inoculated with pseudoparticles harboring MERS-S wt, the indicated S protein mutants or VSV-G. Transduction efficiency was quantified by measuring the activity of virus-encoded luciferase in cell lysates at $18 \mathrm{~h}$ post transduction. The average of three individual experiments is shown. Transduction of untreated, DPP 4 transfected cells was The average of three individual experiments is shown. Transduction of untreated, DPP4 transfected cells was
set as $100 \%$. Error bars indicate SEM. (b) 293 T cells were cotransfected with TMPRSS2 plasmid and plasmids encoding MERS-S wt or the indicated S protein mutants equipped with a C-terminal V5-tag. Transfection of empty plasmid served as negative control. At $48 \mathrm{~h}$ post transfection, $S$ protein expression in cell lysates was analyzed by Western blot. Bands representing uncleaved MERS-S (S0), the S2 subunit generated by cleavage at the S1/S2 site and an S2 fragment generated upon cleavage at the S2' site are highlighted. Detection of B-actin served as loading control. Similar results were obtained in two separate experiments. (c) Caco- 2 cells were pre-incubated with the serine protease inhibitor camostat (bright blue) or the cathepsin L inhibitor MDL28170 (dark blue), or were control-treated with DMSO (gray). Subsequently, the cells were inoculated with equal volumes of preparations of pseudoparticles harboring MERS-S wt, the indicated S protein mutants or VSV-G. At $18 \mathrm{~h}$ post inoculation, transduction efficiency was quantified by measuring the activity of virus-encoded luciferase in cell lysates. The average of three independent experiments is shown. Transduction of controltreated cells was set as $100 \%$. Crosses indicate samples for which no transduction above background levels was detected. Error bars indicate SEM. Statistical significance of differences between transduction of control-treated and inhibitor-treated cells was analyzed using a paired, two-tailed students t-test $\left(* * \mathrm{p} \leq 0.01 ;{ }^{* * *} \mathrm{p} \leq 0.001 ; \mathrm{ns}\right.$, not significant).

cathepsin L but not TMPRSS2 can employ alternative sites for S protein activation. Collective, our results advance our understanding of the proteases facilitating $S$ protein activation and of their cleavage sites within the $S$ protein.

We employed a rhabdoviral pseudotyping system to study MERS-S-driven entry into target cells. This sys tem and related ones have previously been shown to adequately mirror important aspects of CoV entry into target cells and allow studying this process without the need to work with infectious virus ${ }^{25}$. The wt $\mathrm{S}$ protein and all S protein mutants analyzed were readily incorporated into VSV particles, although some variations between particle preparations were observed. Uncleaved as well as cleaved forms of the S protein were detected 


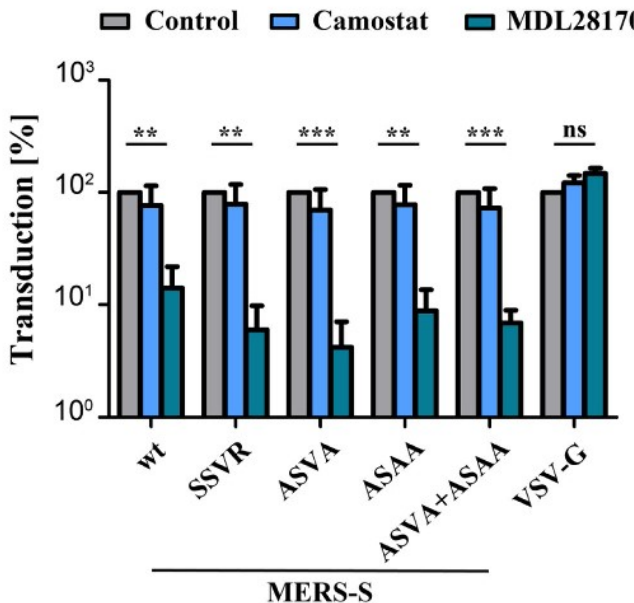

Figure 7. Cathepsin L activity is required for Vero E6 cell entry driven by a mutant S protein that lacks the S1/ S2 and the S2' sites. Vero E6 cells pre-incubated with serine protease inhibitor (camostat, bright blue), cathepsin L inhibitor (MDL28170, dark blue) or DMSO (control, gray) were inoculated with pseudoparticles as described for the Caco-2 cells in panel $\mathrm{c}$ of Fig. 6 . At $18 \mathrm{~h}$ post inoculation, transduction efficiency was quantified by measuring the activity of virus-encoded luciferase in cell lysates. The average of three independent experiments is shown. Transduction of control-treated cells was set as $100 \%$. Er ror bars indicate SEM. Statistical significance of differences between transduction of control-treated and inhibitor-treated cells was analyzed using a paired, two-tailed students $\mathrm{t}$-test (** $\mathrm{p} \leq 0.01 ; * * * \mathrm{p} \leq 0.001 ; \mathrm{ns}$, not significant).

in particles, with the exception of mutants with altered S1/S2 site, which exclusively incorporated uncleaved S protein. Thus, alteration of the S1/S2, cathepsin L and S2' sites is compatible with particle incorporation of the S protein and only mutation of $\mathrm{S} 1 / \mathrm{S} 2$ site abrogates $\mathrm{S}$ protein processing in particle producing cells. For the analysi of MERS-S-driven entry, well characterized cell lines were employed and two of them, Vero E6 and Caco-2, cells are permissive to MERS-CoV infection ${ }^{21,26}$. All cell lines analyzed as well as lung tissue expressed cathepsin L and furin mRNA, in keeping with the previously documented broad expression of these enzymes ${ }^{27,28}$, although cathepsin L levels in Vero E6 cells were relatively low. In contrast, robust levels of TMPRSS2 mRNA were only found in Caco- 2 cells and lung tissue, again in agreement with published data ${ }^{29}$. Finally, all cell lines and lung tissue were positive for DPP4 mRNA, with Caco-2 cells expressing the highest levels, and transfection of DPP expression plasmid revealed that the low amounts of endogenous DPP4 in 293T cells limit the efficiency of S protein driven entry. In sum, well characterized particles as well as cell lines were employed to study the contribution of potential cleavage sites in MERS-S to proteolytic activation of the $S$ protein.

The analysis of S protein mutants demonstrated that alteration of the S1/S2 motif markedly inhibited entry into Caco- 2 cells but not the other cell lines studied. The requirement of S1/S2 for robust Caco- 2 cell entry was perhaps not unexpected since only these cells expressed TMPRSS 2 and a previous study reported that furin-mediated cleavage at $\mathrm{S} 1 / \mathrm{S} 2$ in virus producing cells is required for subsequent $\mathrm{S}$ protein activation by TMPRSS2 during entry into target cells ${ }^{16}$. Our findings generally support this concept but suggest that certain aspects need to be reconsidered. Thus, in our hands pre-cleavage at S1/S2 promoted but was not essential for subsequent S protein activation by TMPRSS2, although it should be stated that TMPRSS2 levels in the transiently transfected 293T cells examined here might exceed those in lung tissue. Moreover, residual entry of the S1/S2 mutant into Caco-2 cells was not facilitated by cathepsin L, as one would have expected from previous work with Calu-3 and Huh7/TMPRSS2 cells ${ }^{16}$, but remained TMPRSS2 dependent. Whether these discrepancies reflect cell line specific differences remains to be determined. In this context, it is noteworthy that Caco- 2 cell entry driven by the S protein of SARS-CoV also relied on TMPRSS2 while entry driven by the glycoprotein of Ebola virus, which is known to depend on cathepsin B and cathepsin $\mathrm{L}$ activity ${ }^{30}$, was blocked by the cathepsin $\mathrm{B} / \mathrm{L}$ inhibitor MDL28170 (data not shown). Thus, active cathepsin L seems to be expressed in Caco-2 cells. Finally, our results suggest that the second arginine at the S2' site might be essential for MERS-S activation by TMPRSS2, since mutation of this residue markedly reduced S protein-driven entry into Caco- 2 cells, while mutation of the first arginine did not diminish entry efficiency

Efficient MERS-S-driven entry into Vero E6, 293T and 293T+DPP4 cells was facilitated by cathepsin L and was largely independent of the $\mathrm{S} 1 / \mathrm{S} 2$ site but required an intact S2' site, in keeping with cleavage of this site being required for liberation of the $\mathrm{N}$-terminus of the fusion peptide in the S2 subunit. However, several points are noteworthy regarding this finding. First, mutation of a previously proposed cathepsin L cleavage site $^{23}$ in MERS- $S$ did not diminish viral entry. This site was altered to contain a consensus signal for attachment of an N-linked glycan which was previously shown to abrogate usage of this site ${ }^{23}$. We cannot exclude that the newly introduced 
glycosylation signal was not used in the $293 \mathrm{~T}$ cell line employed for particle production. However, production of the mutant in BHK-21 cells resulted in the same entry phenotype (data not shown), suggesting that differentia $\mathrm{N}$-glycosylation might not account for the discrepant results of the present study and published work. Second, it seemed that the effects of S2' site mutation were slightly more profound when entry into 293T as compared to $293 \mathrm{~T}+\mathrm{DPP} 4$ cells was analyzed. This may suggest that high levels of receptor expression might reduce the requirement for proteolytic activation. However, this conclusion is entirely speculative. Third, it is noteworthy that Vero E6, 293T and 293T+DPP4 cell entry driven by the S protein mutant with altered S1/S2 and S2' sites was only moderately reduced and Vero E6 cell entry remained cathepsin L dependent. This suggests that cathepsin L can use auxiliary S2 ${ }^{\prime}$ and potentially also $\mathrm{S} 1 / \mathrm{S} 2$ sites for $\mathrm{S}$ protein activation, a finding recently also documented for SARS- $\mathrm{S}^{31}$, and the nature of these sites remains to be determined.

Materials and Methods

Plasmids. We employed pCAGGS-based expression plasmids encoding vesicular stomatitis virus (VSV) glycoprotein (VSV-G), wild-type (wt) MERS-S or cleavage site mutants 748 SSVR 751, 748 ASVA 751, 763 NYT 765 884 ASAA 887 and 748 ASVA $751+884$ ASAA 887 that have been described previously ${ }^{10,16,21,23}$. Additionally, MERS-S-proteins containing single amino acid exchanges at the cleavage sites of the S1/S2 border, ASVR (R748A) and RSVA (R751A), or the S2' site, ASAR (R884A) and RSAA (R887A), were generated by overlap extension PCR (S protein mutants are summarized in Fig. 1). For all S proteins, we constructed versions with or without a C-terminal V5 tag. Further, we generated expression plasmids for human TMPRSS2 and human DPP4 N-terminally linked to DsRed (DsRed DPP4) by PCR-based methods and inserted the respective open reading frames and into the PQCXIP vector. In case of the expression vector for TMPRSS2, the vector encoded selection marker for puromycin resistance was exchanged by that for blasticidin resistance taken from the (pcDNA6/TR) vector. The integrity of the PCR-amplified sequences was verified by automated sequence analysis (Microsynth Seqlab).

Cell culture. 293T (human) and Vero E6 (African green monkey) cells were cultivated in Dulbecco's modified Eagle's medium (DMEM; PAN Biotech) while the human colorectal adenocarcinoma cell line Caco-2 was grown in Minimum Essential Media (MEM, Life Technologies). All media were supplemented with $10 \%$ fetal bovine serum (FBS, PAN Biotech) as well as 1x penicillin and streptomycin from a 100x stock solution (PAN Biotech) and cells were incubated in a humidified atmosphere at $37^{\circ} \mathrm{C}$ and $5 \% \mathrm{CO}_{2}$. Transfection of $293 \mathrm{~T}$ cells was performed by calcium-phosphate precipitation.

Protease inhibitors. To test which proteases facilitate MERS-S activation, target cells were preincubated with cathepsin L inhibitor (MDL28170; Sigma-Aldrich) or serine protease inhibitor (Camostat, Sigma-Aldrich) for $2 \mathrm{~h}$, before the cells were inoculated with transduction vectors.

Antibodies. The following antibodies were used as primary antibodies: Anti V5 (Invitrogen), anti $\beta$-actin (Sigma-Aldrich), anti VSV-M (Kerafast). As secondary antibody, an anti-mouse HRP (horse radish peroxidase) conjugated antibody was employed (Dianova). All antibodies were diluted in phosphate buffered saline contain ing $0.5 \%$ Tween 20 (PBS T) and 5\% skim milk.

Production of VSV pseudoparticles (VSVpp) and transduction of target cells. We employed a previously described protocol for VSVpp production ${ }^{25,32}$. In brief, 293T cells were transfected with expression previously described protocol for VSVpp production ${ }^{25,32}$. In brief, $293 \mathrm{~T}$ cells were transfected with expression
plasmids for wild type (wt) or mutant MERS-S, VSV-G (positive control) or empty expression vector (negative control). At $24 \mathrm{~h}$ post transfection, cells were inoculated with VSV* $\Delta \mathrm{G}$ fLuc ${ }^{24}$ (Indiana strain, kindly provided by G. Zimmer) for $1 \mathrm{~h}$ at $37^{\circ} \mathrm{C}$ and $5 \% \mathrm{CO}_{2}$. Next, the inoculum was removed, cells were washed with PBS and standard culture media containing an anti VSV-G antibody (produced in I1 hybridoma cells, ATCC CRL-2700) was added to all cells except for those transfected with VSV-G expression vector. The cells were further incubated for $24 \mathrm{~h}$ before the VSVpp-containing supernatant was harvested, cleared from cellular debris by centrifugation $(3,000 \times \mathrm{g}, 10 \mathrm{~min})$, and either stored at $-80^{\circ} \mathrm{C}$ or directly used for transduction experiments. For the latter, target cells were grown in 96-well plates. If necessary, the cells were previously transfected with expression plasmids for DsRed DPP4 and/or TMPRSS2 ( $24 \mathrm{~h}$ in advance), and/or pre-treated with protease inhibitors ( $2 \mathrm{~h}$ in advance). For transduction, the culture medium was aspirated and VSVpp were added to the cells. Transduction efficiency was quantified by measuring the virus encoded firefly luciferase (fLuc) activity in cell lysates using a commercial kit (PJK) and a plate luminometer (Hidex).

Analysis of MERS-S expression and incorporation into VSVpp. 293T cells were transfected with expression plasmids of wt or mutant MERS-S harboring a C terminal V 5 tag. For analyses focusing on the $S$ protein activation by TMPRSS2, cells were cotransfected with plasmids for the respective MERS-S construct and TMPRSS2. To investigate S protein expression in target cells, whole cells lysates (WCL) were prepared by lysing the cells in $2 x$ SDS-sample buffer $(0.03 \mathrm{M}$ Tris- $\mathrm{HCl}, 10 \%$ glycerol, $2 \%$ SDS, $5 \%$ beta-mercaptoethanol, $0.2 \%$ bromophenolblue, $1 \mathrm{mM}$ EDTA). In the case that incorporation of S proteins into VSVpp was investigated, VSVpp present in cell culture supernatants were pelleted by high speed centrifugation $\left(25,000 \times \mathrm{g}, 2 \mathrm{~h}, 4^{\circ} \mathrm{C}\right)$ through a sucrose cushion and lysed in 2x SDS-sample buffer. Following SDS-PAGE under reducing conditions, protein were transferred onto nitrocellulose membranes (Hartenstein), blocked ( $30 \mathrm{~min}, 5 \%$ skim milk in PBS-T) and incubated with antibodies targeting the V5 tag (S proteins), $B$ actin (WCL loading control) or VSV-M (VSVpp loading control), in combination with HRP-conjugated secondary antibodies (Dianova). Western blots were developed using a self-made chemiluminescence reagent in combination with the ChemoCam imaging system and the ChemoStar Professional software (Intas Science Imaging Instruments). 
Quantitative detection of transcripts via quantitative PCR (qPCR). The relative transcript levels of DPP4, furin, cathepsin L and TMPRSS2 were determined by quantitative PCR (qPCR). For this, total RNA was extracted 293T, Caco-2 and Vero E6 cells by using the RNeasy Mini Kit (QIAGEN GmbH) according to manufacturer's instructions. Afterwards, $1 \mu \mathrm{g}$ RNA was DNase-treated (New England Biolabs) and subsequently reverse transcribed into cDNA by using SuperScript ${ }^{\mathrm{TM}}$ III First-Strand Synthesis System (Thermo Fisher Scientific) both following the manufacturer's specifications. In addition, commercially available cDNA (TAKARA) isolated from human lung tissue was analyzed. The $\mathrm{qPCR}$ was performed with $1 \mu \mathrm{l} \mathrm{cDNA} /$ reaction employing the QuantiTect SYBR $^{\circledast}$ Green PCR kit (QIAGEN GmbH) on a Rotor Gene ${ }^{\circledast} \mathrm{Q}$ (QIAGEN GmbH) platform. All samples were measured in triplicates. Further, serial 10-fold dilutions of expression vectors for $B$-actin (ACTB, housekeeping gene control), DPP4, furin, cathepsin L and TMPRSS2 that contained 1 to $10^{6}$ copies/reaction were measured and used to generate standard curves for ACTB and each target, and to calculate their respective copy number. For normalization, target copy numbers were divided by ACTB copy numbers and are displayed as target gene copies per copy ACTB.

\section{References}

1. Lai, M. M. C., Perlman, S. \& Anderson, L. J. In Fields virology Vol. 1 (eds D. M. Knipe \& P. M. Howley) 1305-1336 (Lippincott, Wiliams \& Wilkins, 2007).

Hilgenfeld, R. \& Peiris, M. From SARS to MERS: 10 years of research on highly pathogenic human coronaviruses. Antiviral Res. 100,

3. Zaki, A. M., van, B. S., Bestebroer, T. M., Osterhaus, A. D. \& Fouchier, R. A. Isolation of a novel coronavirus from a man with pneumonia in Saudi Arabia. N.Engl.J.Med. 367, 1814-1820 (2012).

4. Zumla, A., Hui, D. S. \& Perlman, S. Middle East respiratory syndrome. Lancet 386, 995-1007 (2015).

5. World Health, O. MERS situation update, March $2018 \mathrm{http}: / / \mathrm{www}$. .emro.who.int $/$ pandemic-epidemic-diseases $/ \mathrm{mers}-\mathrm{cov} / \mathrm{mers}-$ situation-update-march-2018.html (2018).

6. Oh, M. D. et al. Middle East respiratory syndrome: what we learned from the 2015 outbreak in the Republic of Korea. Korean JIntern Med 33, 233-246, https://doi.org/10.3904/kjim.2018.031 (2018).

7. Raj, V. S. et al. Dipeptidyl peptidase 4 is a functional receptor for the emerging human coronavirus-EMC. Nature 495, 251-254, https://doi.org/10.1038/nature 12005 (2013).

8. Millet, J. K. \& Whittaker, G. R. Host cell proteases: Critical determinants of coronavirus tropism and pathogenesis. Virus Res. 202, $120-134(2015)$.

9. Simmons, G., Zmora, P., Gierer, S., Heurich, A. \& Pohlmann, S. Proteolytic activation of the SARS-coronavirus spike protein: cutting enzymes at the cutting edge of antiviral research. Antiviral Res 100, 605-614, https://doi.org/10.1016/j.antiviral.2013.09.028 (2013). 10. Gierer, S. et al. The spike protein of the emerging betacoronavirus EMC uses a novel coronavirus receptor for entry, can be activated by TMPRSS2, and is targeted by neutralizing antibodies. J Virol 87, 5502-5511, https://doi.org/10.1128/JVI.00128-13 (2013).

11. Kawase, M., Shirato, K., van der Hoek, L., Taguchi, F. \& Matsuyama, S. Simultaneous treatment of human bronchial epithelial cells with serine and cysteine protease inhibitors prevents severe acute respiratory syndrome coronavirus entry. J.Virol. 86, 6537-6545 (2012).

12. Qian, Z., Dominguez, S. R. \& Holmes, K. V. Role of the spike glycoprotein of human Middle East respiratory syndrome coronavirus (MERS-CoV) in virus entry and syncytia formation. PLoS One 8, e76469, https://doi.org/10.1371/journal.pone.0076469 (2013).

13. Burkard, C. et al. Coronavirus cell entry occurs through the endo-/lysosomal pathway in a proteolysis-dependent manner. PLoS Pathog 10, el 004502, https://doi.org/10.1371/journal.ppat.1004502 (2014)

14. Millet, J. K. \& Whittaker, G. R. Host cell entry of Middle East respiratory syndrome coronavirus after two-step, furin-mediated activation of the spike protein. Proc Natl Acad Sci USA 111, 15214-15219, https://doi.org/10.1073/pnas. 1407087111 (2014).

15. Shirato, K., Kawase, M. \& Matsuyama, S. Middle East respiratory syndrome coronavirus infection mediated by the transmembrane serine protease TMPRSS2. J Virol 87, 12552-12561, https:// doi.org/10.1128/JVI.01890-13 (2013).

16. Park, J. E. et al. Proteolytic processing of Middle East respiratory syndrome coronavirus spikes expands virus tropism. Proc Nat Acad Sci USA 113, 12262-12267, https://doi.org/10.1073/pnas.1608147113 (2016).

17. Bertram, S. et al. Influenza and SARS-coronavirus activating proteases TMPRSS2 and HAT are expressed at multiple sites in human respiratory and gastrointestinal tracts. PLoS.One. 7, e35876 (2012).

18. Zhou, Y. et al. Protease inhibitors targeting coronavirus and filovirus entry. Antiviral Res. 116, 76-84 (2015).

9. Shirato, K., Kanou, K., Kawase, M. \& Matsuyama, S. Clinical Isolates of Human Coronavirus $229 \mathrm{E}$ Bypass the Endo some for Cell Entry. J Virol 91 https://doi.org/10.1128/JVI.01387-16 (2017).

20. Shirato, K., Kawase, M. \& Matsuyama, S. Wild-type human coronaviruses prefer cell-surface TMPRSS2 to endosomal cathepsins for cell entry. Virology 517, 9-15, https:// doi.org/10.1016/j.virol.2017.11.012 (2018)

21. Gierer, S. et al. Inhibition of proprotein convertases abrogates processing of the middle eastern respiratory syndrome coronavirus spike protein in infected cells but does not reduce viral infectivity. J Infect Dis 211, 889-897, https://doi.org/10.1093/infdis/jiu407 (2015).

22. Matsuyama, S. et al. Middle East respiratory syndrome coronavirus spike protein is not activated directly by cellular furin during viral entry into target cells. J Virol, https://doi.org/10.1128/JVI.00683-18 (2018).

23. Yang, Y. et al. Two Mutations Were Critical for Bat-to-Human Transmission of Middle East Respiratory Syndrome Coronavirus. J Virol 89, 9119-9123, https://doi.org/10.1128/JVI.01279-15 (2015).

24. Berger Rentsch, M. \& Zimmer, G. A vesicular stomatitis virus replicon-based bioassay for the rapid and sensitive determination of multi-species type I interferon. PLoS One 6, e25858, https://doi.org/10.1371/journal.pone.0025858 (2011)

25. Glende, J. et al. Importance of cholesterol-rich membrane microdomains in the interaction of the S protein of SARS-coronavirus with the cellular receptor angiotensin-converting enzyme 2. Virology 381, 215-221, https://doi.org/10.1016/.jvirol.2008.08.026 (2008).

26. Chan, J. F. et al. Differential cell line susceptibility to the emerging novel human betacoronavirus 2c EMC/2012: implications for disease pathogenesis and clinical manifestation. $J$ Jinfect

7. Kramer, L., Turk, D. \& Turk, B. The Future of Cysteine Cathepsins in Disease Management. Trends Pharmacol Sci 38, 873-898, https://doi.org/10.1016/j.tips.2017.06.003(2017)

28. Seidah, N. G., Sadr, M. S., Chretien, M. \& Mbikay, M. The multifaceted proprotein convertases: their unique, redundant complementary, and opposite functions. J Biol Chem 288, 21473-21481, https://doi.org/10.1074/jbc.R113.481549 (2013).

29. Bertrom $S$. al TMPRS2 activates the human coronavirus $229 \mathrm{E}$ for cathepsin-independent host cell entry and is expressed in viral

target cells in the respiratory epithelium. J Virol 87, 6150-6160, https://doi.org/10.1128/JVI.03372-12 (2013).
30. Chandran, K., Sullivan, N. J., Felbor, U., Whelan, S. P. \& Cunningham, J. M. Endosomal proteolysis of the Ebola virus glycoprotein is necessary for infection. Science 308, 1643-1645 (2005).

31. Reinke, L. M. et al. Different residues in the SARS-CoV spike protein determine cleavage and activation by the host cell protease

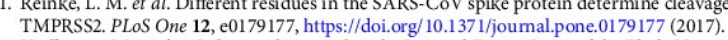

32. Hoffmann, M. et al. A Polymorphism within the Internal Fusion Loop of the Ebola Virus Glycoprotein Modulates Host Cell Entry. J Virol 91, https://doi.org/10.1128/JVI.00177-17 (2017). 
Manuscripts

\section{Acknowledgements}

This work was supported by BMBF (RAPID Consortium, 01KI1723D).

\section{Author Contributions}

H.K.-W. performed experiments, analyzed data and helped writing the manuscript, M.T.E. performed experiments, M.H. performed and designed experiments, analyzed data and helped writing the manuscript, S.P. designed experiments, analyzed data and wrote the manuscript.

\section{Additional Information}

Competing Interests: The authors declare no competing interests.

Publisher's note: Springer Nature remains neutral with regard to jurisdictional claims in published maps and institutional affiliations.

(c) (1) Open Access This article is licensed under a Creative Commons Attribution 4.0 International cc) License, which permits use, sharing, adaptation, distribution and reproduction in any medium or format, as long as you give appropriate credit to the original author(s) and the source, provide a link to the Creative Commons license, and indicate if changes were made. The images or other third party material in this article are included in the article's Creative Commons license, unless indicated otherwise in a credit line to the material. If material is not included in the article's Creative Commons license and your intended use is not permitted by statutory regulation or exceeds the permitted use, you will need to obtain permission directly from the copyright holder. To view a copy of this license, visit http://creativecommons.org/licenses/by/4.0/.

(c) The Author(s) 2018 
5.2. Second manuscript

\title{
Mutations in the Spike Protein of the Middle East
}

\section{Respiratory Syndrome Coronavirus Transmitted inn}

\section{Korea Increased Resistance to Antibody-Mediated}

\author{
Neutralization \\ Kleine-Weber H, Elzayat MT, Wang L, Graham BS, Müller MA, Drosten C, \\ Pöhlmann S, Hoffmann M.
}

Individual contribution:

In the manuscript, the experiments and analysis for Figure 2: "All MERS-S variants analyzed were robustly expressed and incorporated into rhabdoviral particles.", Figure 3: "Polymorphisms found in the $S$ proteins of Korean MERS patients allow robust entry into cells expressing large amounts of DPP4.", Figure 4: "RBD polymorphisms do not modulate sialic acid dependence of MERS-S-driven host cell entry.", Figure 5: "RBD polymorphisms do not impact MERS-S proteolytic activation.", Figure 6: "RBD polymorphisms do not change MERS-S sensitivity toward interferoninduced transmembrane proteins.", Figure 7: "RBD polymorphisms increase resistance of MERS-S against antibody-mediated neutralization." were conducted by myself. 


\title{
Mutations in the Spike Protein of Middle East Respiratory Syndrome Coronavirus Transmitted in Korea Increase Resistance to Antibody-Mediated Neutralization
}

\author{
Hannah Kleine-Weber, ${ }^{\text {a,b }}$ Mahmoud Tarek Elzayat, ${ }^{a}$ Lingshu Wang, ${ }^{c} \odot$ Barney S. Graham, ${ }^{c}$ Marcel A. Müller, ${ }^{d}$ \\ Christian Drosten, d,e Stefan Pöhlmann, ${ }^{\text {a,b }}$ Markus Hoffmann ${ }^{a}$ \\ Infection Biology Unit, German Primate Center, Göttingen, Gemany \\ bFaculty of Biology and Psychology, University of Göttingen, Göttingen, Germany \\ Vaccine Research Center, National Institute of Allergy and Infectious Diseases, National Institutes of Health, Bethesda, Maryland, USA \\ Institute of Virology, Charité-Universitätsmedizin Berlin, Berlin, Germany \\ eGerman Centre for Infection Research, associated partner Charité, Berlin, Germany
}

ABSTRACT Middle East respiratory syndrome coronavirus (MERS-CoV) poses a threat to public health. The virus is endemic in the Middle East but can be transmitted to other countries by travel activity. The introduction of MERS-CoV into the Republic of Korea by an infected traveler resulted in a hospital outbreak of MERS that entailed 186 cases and 38 deaths. The MERS-CoV spike (S) protein binds to the cellular protein DPP4 via its receptor binding domain (RBD) and mediates viral entry into target cells. During the MERS outbreak in Korea, emergence and spread of viral variants that harbored mutations in the RBD, D510G and I529T, was observed. Counterintuitively, these mutations were found to reduce DPP4 binding and viral entry into target cells. In this study, we investigated whether they also exerted proviral effects. We confirm that changes D510G and I529T reduce S protein binding to DPP4 but show that this reduction only translates into diminished viral entry when expression of DPP4 on target cells is low. Neither mutation modulated $S$ protein binding to sialic acids, $\mathrm{S}$ protein activation by host cell proteases, or inhibition of $\mathrm{S}$ proteindriven entry by interferon-induced transmembrane proteins. In contrast, changes D510G and I529T increased resistance of S protein-driven entry to neutralization by monoclonal antibodies and sera from MERS patients. These findings indicate that MERS-CoV variants with reduced neutralization sensitivity were transmitted during the Korean outbreak and that the responsible mutations were compatible with robust infection of cells expressing high levels of DPP4.

IMPORTANCE MERS-COV has pandemic potential, and it is important to identify mutations in viral proteins that might augment viral spread. In the course of a large hospital outbreak of MERS in the Republic of Korea in 2015, the spread of a viral variant that contained mutations in the viral spike protein was observed. These mutations were found to reduce receptor binding and viral infectivity. However, it remained unclear whether they also exerted proviral effects. We demonstrate that these mutations reduce sensitivity to antibody-mediated neutralization and are compatible with robust infection of target cells expressing large amounts of the viral receptor DPP4.

KEYWORDS MERS, antibody, neutralization, spike, virus entry

he family Coronaviridae harbors enveloped, positive-sense RNA viruses that infect mammals and birds (1). Several coronaviruses (CoV) within the genera Alphacoronavirus and Betacoronavirus constantly circulate in the human population and cause

Citation Kleine-Weber H, Elzayat MT, Wang L, Graham BS, Müller MA, Drosten C, Pöhlmann S, Hoffmann M. 2019. Mutations in the spike protein of Middle East respiratory syndrome coronavirus transmitted in Korea increase resistance to antibody-mediated neutralization. J Virol 93:e01381-18. https://doi.org/10.1128/ JVI.01381-18.

Editor Tom Gallagher, Loyola University Medical Center

Copyright $\odot 2019$ American Society for Microbiology. All Rights Reserved. Address correspondence to Stefan Pöhlmann spoehlmann@dpzeu, or Markus Hoffmann, mhoffmann@dpze

Received 10 August 2018

Accepted 25 October 2018

Accepted manuscript posted online

November 2018

Published 4 January 2019 


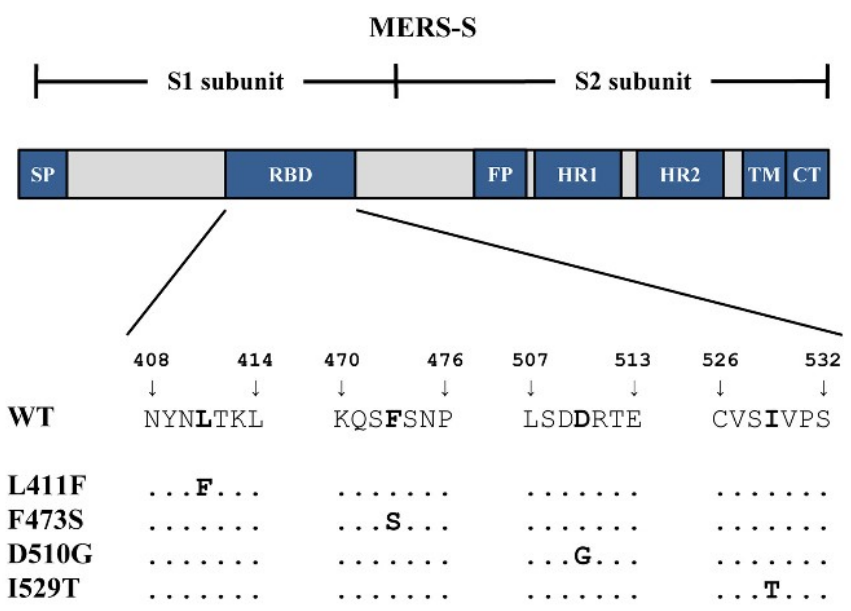

FIG 1 Schematic illustration of the MERS-CoV spike glycoprotein and location of the receptor binding domain (RBD) polymorphisms. The MERS-CoV spike glycoprotein (MERS-S) consists of two subunits (S1 and S2). The S1 subunit contains an N-terminal signal peptide (SP) and an RBD, which binds to the receptor DPP4. The $\mathrm{S} 2$ subunit harbors the functional elements required for membrane fusion, a fusion receptor DPP4. The $S 2$ subunit harbors the functional elements required for membrane fusion, a fusion
peptide (FP), and two heptad repeats (HR1 and HR2), as well as the transmembrane domain (TD) and a peptide (FP), and two heptad repeats (HR1 and HR2), as well as the transmembrane domain (TD) and a
cytoplasmic tail (CT). Below the scheme, the locations of the four amino acid polymorphisms investigated in this study (L411F, F473S, D510G, and I529T) are highlighted (bold letters).

mild respiratory disease. In addition, the betacoronaviruses severe acute respiratory syndrome (SARS)- and Middle East respiratory syndrome (MERS)-CoV can be zoonotically transmitted from animals to humans (1). Camels serve as a natural reservoir for MERS-CoV, and infected animals may exhibit mild respiratory symptoms $(2,3)$. In contrast, transmission of MERS-CoV to humans induces fatal disease in about $36 \%$ of the afflicted patients (4). Most MERS cases have been documented in the Middle East, but the virus has been introduced into several other countries due to international travel. At present, human-to-human transmission of MERS-CoV is inefficient. However, massive MERS outbreaks have been observed in hospital settings (5). For instance, the introduction of MERS-CoV into the Republic of Korea by a single infected traveler in 2015 resulted in 186 infections, including secondary, tertiary, and quaternary cases, and 38 deaths $(6,7)$. Whether the virus responsible for the Korean outbreak harbored mutations that promoted human to human spread is incompletely understood.

The infectious entry of MERS-COV into target cells is mediated by the viral spike glycoprotein (MERS-S), which is incorporated into the viral envelope. MERS-S contains a surface unit, S1, and a transmembrane unit, S2. The S1 subunit binds to the main receptor, DPP4/CD26 (8), and the secondary receptor, sialic acids (9), while the S2 subunit facilitates fusion of the viral envelope with a cellular membrane. Membrane fusion depends on prior proteolytic cleavage (activation) of the inactive $\mathrm{S}$ protein precursor, S0, by host cell proteases. Specifically, the endosomal cysteine protease cathepsin L (CatL) and the type II transmembrane serine protease, TMPRSS2, located at the plasma membrane can activate MERS-S (10-12). Sequence analysis revealed that MERS-CoV variants observed during the Korean outbreak contained polymorphisms D510G and I529T and that the respective viral variants were transmitted to other patients $(13,14)$. The D510G and I529T polymorphisms are located in the receptor binding domain (RBD) (Fig. 1), a portion of S1 that is required for binding to DPP4, and one can speculate that they might increase viral fitness and/or transmissibility. However, counterintuitively, both D510G and I529T were shown to decrease binding to DPP4 and 1529T was shown to decrease MERS-S-driven entry into cells (14), and it is at present unknown whether the virus benefits from these changes. 
Here we show that several parameters controlling efficiency of MERS-S-driven entry, including sialic acid engagement and blockade by interferon (IFN)-induced transmembrane proteins (IFITMs), are not modulated by D510G and I529T. Moreover, we confirm that D510G and 1529T reduce DPP4 binding but show that this translates into reduced entry only when small amounts of DPP4 are expressed. Finally, we demonstrate that D510G and I529T reduce sensitivity to antibody-mediated neutralization, suggesting that these mutations might not alter viral transmissibility but might increase viral spread in infected patients in the presence of an antibody response.

\section{RESULTS}

Polymorphisms D510G and I529T in MERS-S of Korean patients reduce DPP4 binding but allow efficient entry into cells expressing large amounts of DPP4. We first investigated whether polymorphisms identified during the Korean MERS outbreak, D510G and I529T $(13,14)$ (Fig. 1), are compatible with robust S protein expression and $S$ protein-driven host cell entry. For comparison, we analyzed polymorphisms found in MERS-S from viruses from the Arabian Peninsula, L411F and F473S (15-19) (Fig. 1); these changes had previously not been investigated for their impact on MERS-S-driven entry. For our analyses of MERS-S-mediated entry, we employed a previously described vesicular stomatitis virus (VSV)-based pseudotyping system (20), which faithfully mimics central aspects of MERS-CoV entry into target cells (21).

Analysis of 293T cells transfected to express the S proteins under study followed by immunoblot and signal quantification revealed that wild-type (WT) MERS-S and all S protein variants were comparably expressed (Fig. 2A). Similarly, all S proteins were proteolytically processed (Fig. 2A, top), in agreement with the finding that furin processes the $\mathrm{S}$ protein in MERS-S-transfected and MERS-CoV-infected cells. Finally, all $S$ protein mutants were efficiently incorporated into VSV particles, although incorporation of mutant F473S was slightly reduced compared to that of MERS-S WT (Fig. 2B). Thus, the polymorphisms studied did not impact $S$ protein expression, proteolytic processing, or, with the exception of mutant F473S, incorporation into VSV particles.

Next we analyzed whether the polymorphisms impacted entry into the colonderived cell line Caco-2, the African green monkey kidney cell line Vero E6, and the human adrenal gland-derived cell line 293T (either control transfected or transfected with DPP4 expression plasmid [293T + DPP4]). These cell lines were chosen for analysis because they are permissive to MERS-CoV infection and were previously used to study host cell interactions of MERS-CoV (22-25). The selected cell lines were highly permissive to transduction by rhabdoviral particles harboring VSV glycoprotein (VSV-G; positive control), while transduction by particles bearing no glycoprotein (negative control) was within background levels, as expected (Fig. 3A). Changes L411F and F473S observed in MERS-CoV from humans and camels in the Middle East had no effect on transduction efficiency. In contrast, changes I529T and, to a lesser degree, D510G observed in Korean MERS patients reduced entry into Vero E6 and 293T cells (Fig. 3A) and diminished binding to DPP4 (Fig. 3B), in agreement with published data (14). However, these mutations had only a modest effect on transduction of Caco-2 and 293T cells expressing saturating amounts of DPP4 (293T + DPP4), respectively (Fig. 3A and data not shown). The finding that directed expression of DPP4 could largely rescue the inhibitory effect of D510G and I529T on transduction of 293T cells prompted us to investigate whether the impact of these changes on $\mathrm{S}$ protein-driven entry was dependent on the level of DPP4 expression. Indeed, quantitative reverse transcriptionPCR (Fig. 3C) and flow cytometry (Fig. 3D) revealed that Caco-2 and 293T + DPP4 cells, which can be readily transduced by MERS-S D510G and 1529T variants, expressed substantially higher levels of DPP4 than 293T and Vero E6 cells, which are not readily susceptible to transduction mediated by S protein mutants D510G and I529T (Fig. 3C and D). Collectively, our results confirm that D510G and I529T reduce S protein binding to DPP4 but also suggest that this reduction translates into diminished $\mathrm{S}$ protein-driven cell entry only when DPP4 expression is low. 
A)
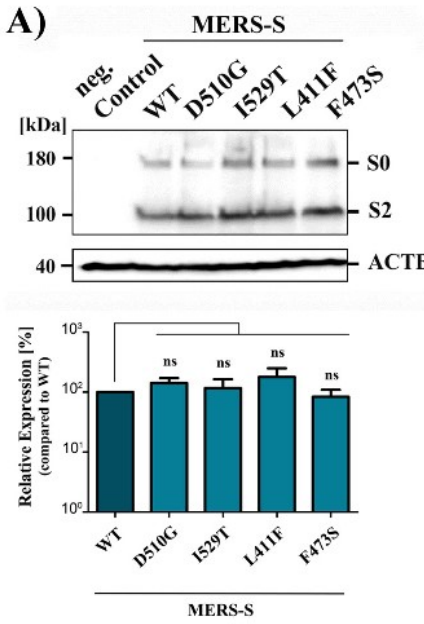

B)
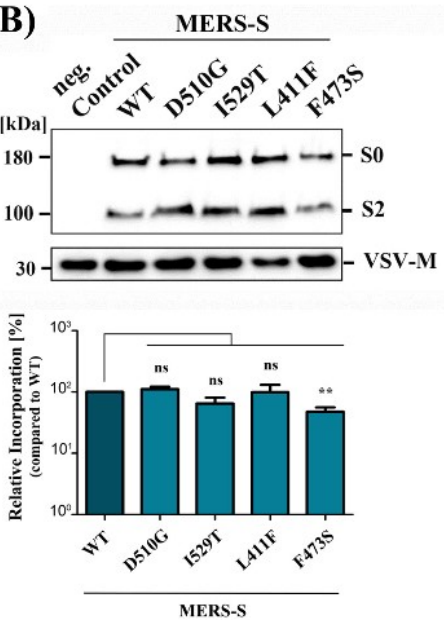

FIG 2 All MERS-S variants analyzed were robustly expressed and incorporated into rhabdoviral particles. (A, top) Expression plasmids for the indicated S proteins or empty plasmid (control) were transfected into 293T cells. Whole-cell lysates (WCL) were prepared from transfected cells, and S protein expression was analyzed by SDS-PAGE and immunoblotting using anti-V5 antibody reactive against the V5 epitope at the $\mathrm{C}$ terminus of the $S$ proteins. Detection of $\beta$-actin (ACTB) served as a negative control. Similar results were obtained in three separate experiments. (B, top) Expression plasmids for the indicated $\mathrm{S}$ proteins or empty plasmid (control) were transfected into $293 \mathrm{~T}$ cells and the cells were then used to produce rhabdoviral particles. The particles were subsequently pelleted by centrifugation through a sucrose cushion and analyzed for $S$ protein expression by SDS-PAGE and immunoblotting. Detection of vesicular stomatitis virus matrix protein (VSV-M) served as a loading control. (A and B, bottom) Immunoblots conducted for panels A $(n=3)$ and $\mathrm{B}(n=6)$ were subjected to quantitative analysis using ImageJ software. S protein signals were normalized against the corresponding signals for ACTB or VSV-M, and expression and particle incorporation, respectively, of MERS-S WT were set as 100\%. For S proteins that yielded two bands ( $\mathrm{S} 0$ and S2), the two signals were combined before normalization. Mean values are shown; error bars indicate SEMs. Statistical significance of differences in particle expression or incorporation efficiency between MERS-SWT and variants was icance of differences in particle expression or incorporation

D510G and I529T do not alter sialic acid dependency of viral entry. A recent study showed that MERS-S can bind to sialic acids, glycans presented on plasma membrane proteins and lipids, and that sialic acid engagement promotes $\mathrm{S}$ proteindriven entry (9). We enzymatically removed sialic acids by neuraminidase (NA) treatment to investigate whether the Korean polymorphisms or the polymorphisms found in the Middle East impact sialic acid dependence. Neuraminidase treatment markedly reduced influenza $A$ virus hemagglutinin (HA)-driven entry but had no effect on entry driven by VSV-G (Fig. 4), as expected. Moreover, entry driven by MERS-S WT and S protein variants was comparably inhibited by neuraminidase treatment (Fig. 4), indicating that none of the amino acid changes in MERS-S altered sialic acid dependence of viral entry.

D510G and 1529T do not alter the choice of MERS-S activating host cell protease. CatL and TMPRSS2 activate MERS-S in cell culture $(10,24)$, and the activity of TMPRSS2 or related enzymes is required for SARS-CoV spread in the host (26). Therefore, we investigated whether the polymorphisms under study modulated the capacity of MERS-S to employ CatL and TMPRSS2 for activation. For this, we first employed 293T cells, which express endogenous CatL but not TMPRSS2 and allow MERS-S-driven entry in a CatL-dependent fashion $(10,24)$. The cells were transfected with DPP4 plasmid and either TMPRSS2 encoding or empty plasmid (control), incubated with the CatL inhibitor MDL28170, and then analyzed for S protein-driven transduction. Incubation of control cells with MDL28170 reduced entry driven by MERS-S WT and S protein variants, and this effect was fully rescued by directed expression of TMPRSS2 (Fig. 5A). Next, we 
А)
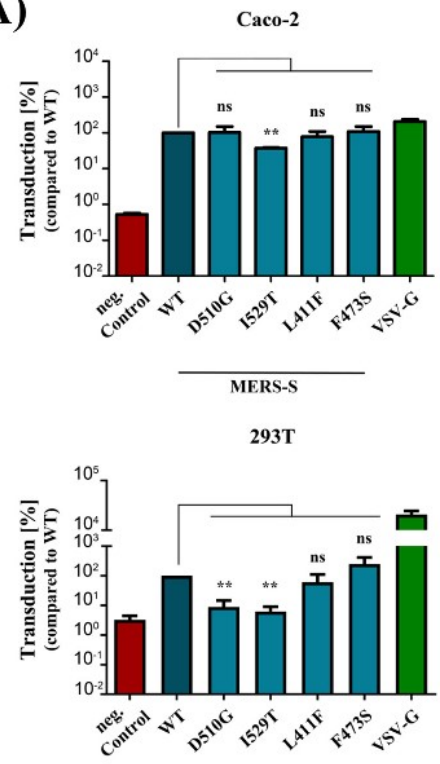

MERS-S

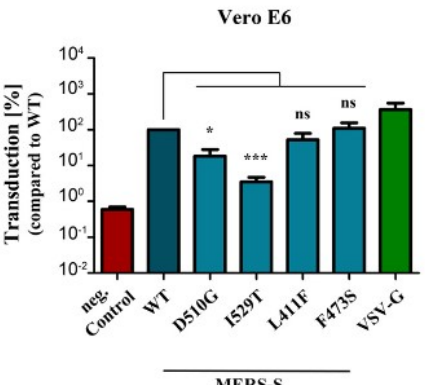

293T+DPP4

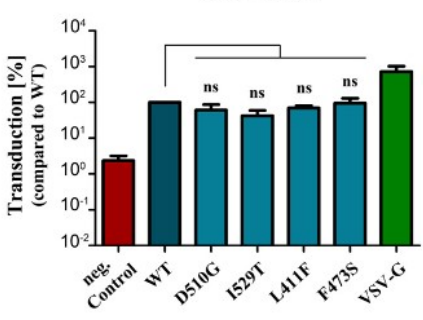

MERS-S

B)

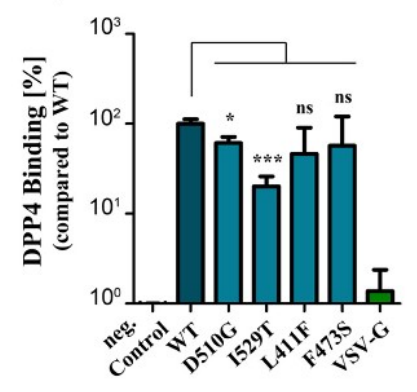

C)

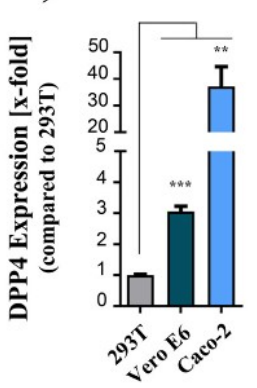

D)

Protein

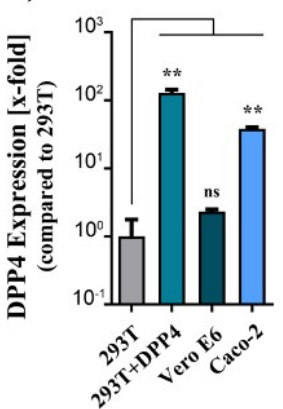

FIG 3 Polymorphisms found in the S proteins of Korean MERS patients allow robust entry into cells expressing large amounts of DPP4. (A) Equal volumes of rhabdoviral particles harboring MERS-SWT, the indicated S protein mutants, VSV-G (positive control), or no glycoprotein (negative control) were inoculated onto Caco-2, Vero E6, 293T, and 293T cells overexpressing DPP4. Transduction efficiency was quantified at $18 \mathrm{~h}$ posttransduction by measuring the activity of virus-encoded luciferase in cell lysates. Transduction mediated by MERS-S WT was set as $100 \%$. The . The (B)

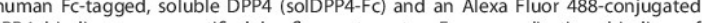
anti-human antibody before DPP4 binding was quantifed by now cylomety. For nomalization, binding of solDPP4-FC to MERS-S WT was set as 100\%. The results of a single representative experiment carried out with triplicate samples are shown and were confirmed in a separate experiment. Error bars indicate SDs. (C) Total cellular RNA was extracted from the indicated cell lines, reverse transcribed to CDNA and DPP4 transcript levels were analyzed by quantitative $P C R$ in combination with the $2^{-\triangle \triangle C}$ method using ACTB as the housekeeping gene control and 293T cells as a reference (DPP4 level was set as 1). The results of a single representative experiment performed with triplicate samples are shown. Error bars indicate SDs. (D) Caco-2, Vero E6, and 293T cells (either untransfected or transfected with expression plasmid for DPP4) were analyzed for DPP4 cell surface expression by

(Continued on next page) 


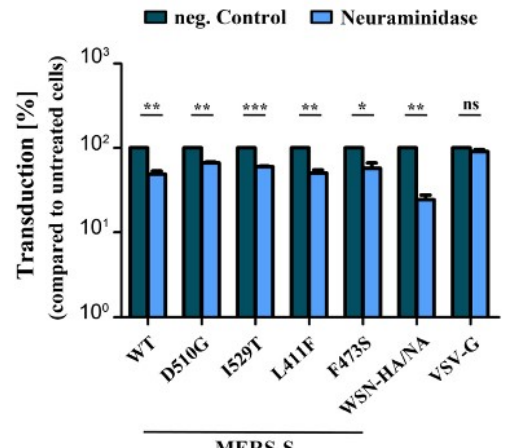

MERS-S

FIG 4 RBD polymorphisms do not modulate sialic acid dependence of MERS-S-driven host cell entry. Caco-2 cells were preincubated with recombinant neuraminidase or were left untreated (control) before being inoculated with rhabdoviral particles harboring MERS-S WT, the indicated S protein mutants, influenza A virus (WSN, subtype H1N1) hemagglutinin and neuraminidase (WSN-HA/NA), or VSV-G. At $18 \mathrm{~h}$ posttransduction, transduction efficiency was quantified by measuring the activity of virus作 $100 \%$. The combined data from three independent expeniments pefomed with quadruplicate samples are presented. Error bars indicate SEMs, and statistical significance was analyzed by paired two-tailed Student $t$ tests.

investigated S protein activation in Caco-2 cells, which express endogenous TMPRSS2 (27) and afforded the opportunity to visualize a potentially more subtle impact of the $\mathrm{S}$ protein polymorphisms on activation by TMPRSS2. However, incubation of Caco-2 cells with rising concentrations of camostat mesylate, a TMPRSS2 inhibitor, comparably reduced entry driven by MERS-S WT and S protein variants and had no effect on VSV-G-mediated entry (Fig. 5B), as expected. These findings suggest that the polymorphisms under study did not compromise S protein activation by CatL and TMPRSS2 and did not endow the $S$ protein with the ability to use low levels of TMPRSS2 activity with increased efficiency for $\mathrm{S}$ protein activation.

D510G and I529T do not modulate IFITM sensitivity. Expression of IFITM proteins is IFN inducible and inhibits MERS-S-driven entry into target cells (28), most likely at the stage of membrane fusion. We investigated whether the $S$ protein polymorphisms under study modulated susceptibility of MERS-S-driven entry to blockade by IFITM proteins. For this, we employed 293T cells stably expressing IFITM1, IFITM2, and IFITM3. Expression of IFITM proteins had little effect on entry driven by the Machupo virus glycoprotein (MACV-GPC), while both IFITM2 and IFITM3 markedly reduced entry by the influenza A virus hemagglutinin (Fig. 6), in accordance with published data (28). Moreover, expression of IFITM2 but not IFITM1 and IFITM3 diminished MERS-S WTmediated host cell entry, as expected, and similar effects were observed for the $\mathrm{S}$ protein variants analyzed (Fig. 6). Finally, comparable results were obtained with 293T cells transiently transfected with escalating amounts of IFTIM2 plasmid, although variant F473S showed a slightly reduced IFITM2 sensitivity under these conditions (data not shown). In sum, the RBD polymorphisms observed in Korean patients and MERSCoV from the Middle East did not markedly alter IFITM sensitivity of viral entry.

D510G and I529T increase resistance to antibody-mediated neutralization. The antibody response significantly contributes to control of MERS-CoV infection in the host. Therefore, we asked whether the polymorphisms under study impact antibody-

FIG 3 Legend (Continued)

flow cytometry using anti-DPP4 and Alexa Fluor 488-conjugated anti-mouse antibodies. For normalization, DPP4 surface expression in untransfected 293T cells was set as 1 . The results of a single, representative experiment performed with duplicate samples are shown error bars indicate SDs. Similar results were obtained in two separate experiments. Statistical significance was analyzed by paired (A) or unpaired (B to D) two-tailed Student $t$ tests. 
A)

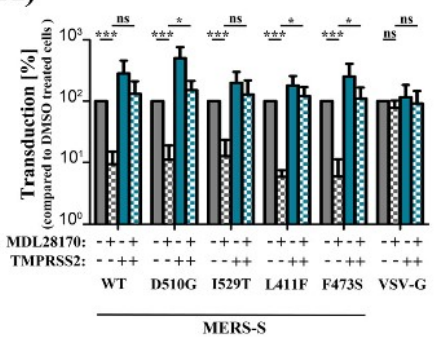

B) $\quad-\mathrm{WT} \rightarrow \mathrm{DS10G} \rightarrow-1529 \mathrm{~T}$

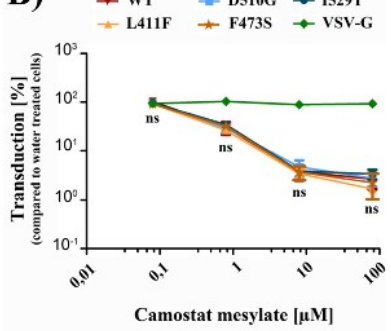

FIG 5 RBD polymorphisms do not impact MERS-S proteolytic activation. (A) 293T cells were transfected with expression plasmid for DPP4 alone (gray bars) or in combination with expression plasmid for TMPRSS (blue bars). At 24 h postransfection, the cells were preincubated with dimethyl sulfoxide TMPSO; (blu bass). At 24 h postransfection, the cells were preincub with with (DMSO; control (filed bars) or cathe being inoculated with rhabdoviral particles harboring MERS-S WT, the indicated S protein mutants, or VSV-G. Transduction efficiency was quantified by measuring the activity of virus-encoded luciferase in cell lysates at $18 \mathrm{~h}$ posttransduction. For normalization, luciferase activity measured for 293T cells overexpressing DPP4 and incubated with DMSO (filled gray bars) was set as 100\%. (B) Caco-2 cells, for which MERS-S-driven entry relies on TMPRSS2 instead of cysteine proteases, were preincubated with medium containing water (control) or increasing concentrations of a TMPRSS2 inhibitor, camostat mesylate, before being inoculated with rhabdoviral pseudotypes harboring MERS-S WT, the indicated S protein mutants, or VSV-G. Transduction efficiency was quantified as described above. For normalization, transduction levels in the absence of inhibitor were set as $100 \%$. The averages of four (A) or three (B) individual experiments performed with quadruplicate samples are shown. Error bars indicate SEMs. Statistical significance of differences of the indicated data pairs (A) or between WT and mutant S proteins (B) was analyzed by paired two-tailed Student $t$ tests.

mediated neutralization. We focused our analysis on D510G and 1529T since these changes modulated the efficiency of host cell entry. First, we tested whether D510G and $1529 \mathrm{~T}$ alter inhibition of S protein-driven entry by the murine antibody F11, which binds to an epitope encompassing amino acid 509, and macaque antibody JC57-14, which recognizes an epitope including amino acid 535 (29). Indeed, exchange D510G rendered MERS-S-driven entry insensitive to inhibition by F11, while I529T reduced

$\square$ CAT $\otimes$ IFITM1 $\square$ IFITM2 $\otimes$ IFITM3

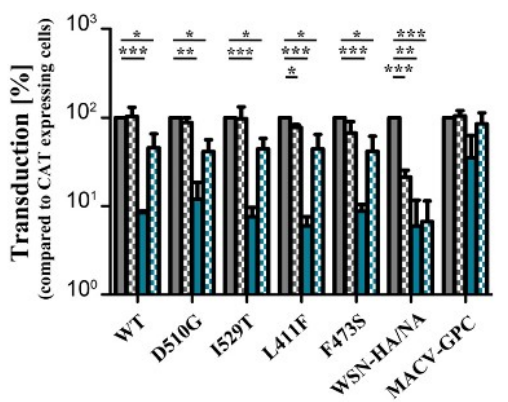

\section{MERS-S}

FIG 6 RBD polymorphisms do not change MERS-S sensitivity toward interferon-induced transmembrane proteins. 293T cells stably expressing interferon-induced transmembrane proteins (IFITM1 to -3 ) or chloramphenicol acetyltransferase (CAT; control) were transduced with rhabdoviral particles harboring MERS-S WT, the indicated S protein mutants, WSN-HA/NA, Machupo virus glycoprotein (MACV-GPC), or no viral glycoprotein (negative control; data not shown). At $18 \mathrm{~h}$ posttransduction, transduction efficiency was quantified by measuring the virus-encoded luciferase activity in cell lysates. For normalization, transduction of control 293T-CAT cells was set as $100 \%$. The averages from three individual experiments performed with quadruplicate samples are shown. Error bars indicate SEMs, and statistical significance was analyzed by paired two-tailed Student $t$ tests. 
A)

JC57-14 (target: spike 535) $\rightarrow \mathrm{WT} \rightarrow \mathrm{D} 510 \mathrm{G} \rightarrow \mathrm{I529T} \rightarrow \mathrm{VSV}-\mathrm{C}$

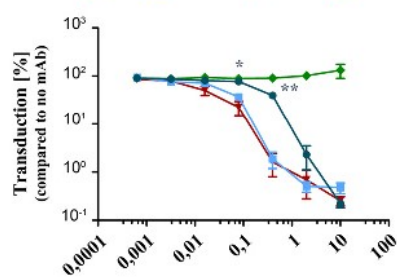

Antibody concentration $[\mu \mathrm{M}]$

B) CSS53

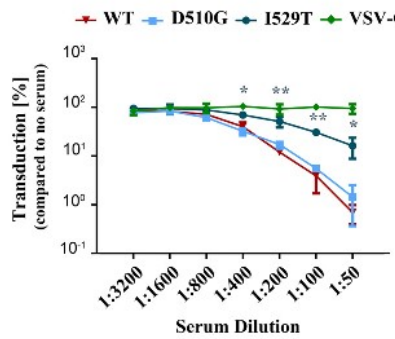

F11 (target: spike 509)

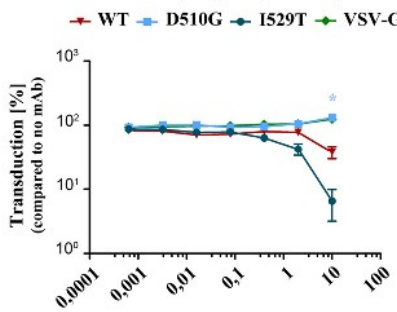

Antibody concentration $[\mu \mathrm{M}]$

C)

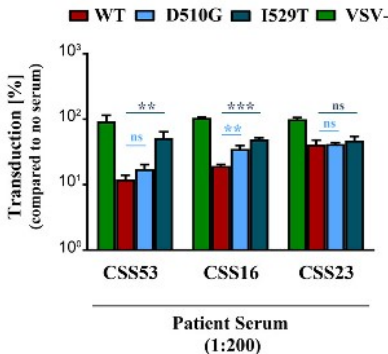

FIG 7 RBD polymorphisms increase resistance of MERS-S against antibody-mediated neutralization. Rhabdoviral particles harboring MERS-S WT, the indicated MERS-S mutants, or VSV-G were preincubated with increasing concentrations of MERS-S-specific monoclonal antibodies (mAb) that target different epitopes in the RBD (F11 or JC57-14) (A) or different dilutions of serum from a MERS patient (CSS53) (B) or a single dilution (1:200) of sera from three different MERS patients (CSS53 [data taken from panel B for direct comparison], CSS16, and CSS23) (C) before being inoculated onto Caco-2 cells. Cells transduced in the absence of $\mathrm{mAb} / \mathrm{serum}$ served as controls. Transduction efficiency was quantified by measuring the activity of virus-encoded luciferase in cell lysates at $18 \mathrm{~h}$ posttransduction. For normalization, transduction in the absence of $\mathrm{mAb} / \mathrm{serum}$ was set as $100 \%$. The averages from three independent experiments performed with quadruplicate samples are presented in panel A error bars indicate SEMs. experiments peristical signifor Statistical significance of differences between transduction mediated by MERS-SWT and the S protein mutants was and results of a single representative experiment performed with triplicate samples are shown in panels B and C and were confirmed in a

blockade of S protein-driven entry by JC57-14 (Fig. 7A). These findings encouraged us to investigate whether D510G and I529T alter susceptibility of MERS-S-driven host cell entry to inhibition by human sera obtained from MERS patients. For this, we studied sera of three patients who had acquired MERS-CoV infection in the Middle East and were admitted to German hospitals in Essen (serum CSS16), Osnabrück (CSS53), and Munich (CSS23) (Table 1). One serum sample was of sufficient quantity for detailed analysis (CSS53), while the others could be tested only at a single dilution (CSS16 and

TABLE 1 Information on the sera used in this study

\begin{tabular}{lllllll}
\hline & \multicolumn{5}{l}{ Patient information $^{a}$} & \\
\cline { 2 - 6 } Serum sample & Age (yrs) & Origin $^{b}$ & Hospital $^{c}$ & Year & Disease outcome & Reference \\
\hline CSS16 & 45 & Qatar $^{\text {TAB }}$ & Essen & 2012 & Recovered & 50 \\
CSS23 & 73 & UAE $^{d}$ & Munich & 2013 & Deceased & 51 \\
CSS53 & 65 & UAE $^{d}$ & Osnabrück & 2015 & Deceased & 52 \\
\hline
\end{tabular}

${ }^{a}$ All patients were male.

${ }^{b}$ Country where the infection was acquired.

German city where the patient was treated.

aUAE, United Arab Emirates. 
CSS23). Remarkably, MERS-S harboring polymorphism D510G showed a significantly increased resistance against neutralization by one serum sample (CSS16), and polymorphism 1529T diminished neutralization by two sera (CSS16 and CSS53 [Fig. 7B and C]). Finally, neither mutation had any impact on neutralization by serum sample CSS23. However, the overall neutralizing activity of this particular serum sample was reduced compared to those of the other sera tested and might have been too low to allow for differential neutralization of MERS-S WT and mutants D510G and I529T. In summary, our results suggest that increased resistance against humoral immune responses might have driven the emergence of the D510G and I529T variants.

\section{DISCUSSION}

The large MERS outbreak within hospitals in the Republic of Korea in 2015 raised the question of whether viral variants with increased transmissibility might have been responsible. Indeed, the majority of patients in Korea harbored viruses with at least one unique mutation in the RBD, D510G and/or I529T $(13,14)$. Unexpectedly, these mutations reduced DPP4 binding and viral entry (14), raising the question of whether they were beneficial to the virus. We found that D510G and I529T were compatible with robust S protein-driven entry into cells expressing large amounts of DPP4 and conferred resistance against antibody-mediated neutralization. These findings support the previously proposed concept that escape from antibody responses might shape MERSCoV evolution and might come at the cost of reduced DPP4 binding (30). However, they also suggest that diminished DPP4 binding may not compromise the ability of MERSCoV to spread in target cells expressing robust levels of DPP4.

The MERS outbreak in the Republic of Korea was initiated by a single infected traveler, comprised 186 cases and 38 deaths, and encompassed primary, secondary, tertiary, and quaternary infections $(6,7)$. The case-fatality rate was roughly $20 \%$ and was thus lower than that reported for MERS patients in the Middle East. This may have various reasons, including differences in patient care and virulence of the MERS-CoV strains responsible for the outbreaks (14). The 1529T mutation has been detected in $72 \%$ of patients in Korea examined by one study and might have already been present in the index patient (14). Similarly, the S protein sequences from 26 out of 38 patients deposited in the virus variation database (https://www.ncbi.nlm.nih.gov/genome/ viruses/variation/) contain the $1529 \mathrm{~T}$ change. Moreover, viruses harboring this mutation established secondary, tertiary, and quaternary infections $(13,14)$. In contrast, the D510G mutation was present in only $8 \%$ of patients analyzed in a previous study, and 6 out of $38 \mathrm{~S}$ protein sequences (16\%) deposited in the virus variation database contained this exchange. Kim and colleagues reported that D510G and particularly 1529T diminish binding of MERS-S to DPP4 and reduce entry into $293 \mathrm{~T}$ cells transfected to express DPP4 (14). Moreover, structural evidence that these mutations disturb the interface between DPP4 and MERS-S was presented (14). However, it remained unclear whether these mutations may also aid virus spread under certain conditions.

Binding of MERS-S to DPP4 is essential for infectious host cell entry (8), and DPP4/S protein interactions are an important determinant of MERS-CoV species tropism (31). Moreover, patients with chronic lung disease were shown to express increased levels of DPP4 $(32,33)$ and are known to be at augmented risk of developing fatal MERS (34), suggesting that DPP4 levels expressed under physiologic conditions might limit viral spread in patients. Therefore, we investigated whether the previously reported negative effect of D510G and I529T on MERS-S-driven entry was dependent on DPP4 expression levels. Our results show that this is indeed the case: both mutations markedly reduced entry into 293T cells, which expressed low levels of endogenous DPP4 mRNA and protein, but had little effect on entry into Caco-2 cells, which express large amounts of DPP4. Robust expression of DPP4 has been detected in viral target cells in the human respiratory epithelium, type I and type II pneumocytes and alveolar macrophages $(8,32)$, and it is thus conceivable that WT virus and virus bearing D510G or I529T infect these cells with comparable efficiencies in the lung of MERS patients. Finally, one can speculate that engagement of attachment-promoting factors ex- 
pressed in viral target cells in the human respiratory tract but not the cell lines studied here might allow mutants D510G and 1529T to compensate for reduced DPP4 binding and to enter cells with the same efficiency as WT virus.

The proteolytic activation of MERS-S by host cell proteases is essential for MERS-Sdriven entry into target cells (35). Therefore, we addressed whether D510G and I529T might augment viral spread by promoting $S$ protein activation or by changing the choice of $S$ protein-activating protease. Two interconnected routes have been described for MERS-S activation. Upon binding to DPP4, either the virus may be transported into host cell endosomes, where the $\mathrm{S}$ protein is activated by cathepsin $\mathrm{L}$, or the $\mathrm{S}$ protein may be activated at the cell surface by TMPRSS2 $(10,11,24)$. Notably, the choice between CatL and TMPRSS2 might be determined by $S$ protein processing in the infected cell: $S$ protein cleavage by furin in infected cells seems to be indispensable for subsequent DPP4-induced conformational changes in the $S$ protein that are in turn essential for activation by TMPRSS2 (36). The present study demonstrates that D510G and I529T impact neither $\mathrm{S}$ protein cleavage by furin nor S protein activation by TMPRSS2 or CatL. This finding may not be unexpected since both residues are located distant to the two sites believed to be important for S protein processing and activation, R751 (S1/S2 site) and R887 (S2' site).

Several cellular factors can modulate the efficiency of MERS-S-driven entry into cells, raising the question of whether D510G and $1529 \mathrm{~T}$ might alter their effects in a way that promotes viral spread. The DPP4 ligand adenosine deaminase, which is highly expressed in lymphoid tissue and constitutes a component of the purine salvage pathway (37), has been shown to compete with MERS-S for DPP4 binding and to block MERS$\mathrm{S}$-driven entry into target cells (31). Moreover, the IFN-induced transmembrane proteins IFITM2 and, to a lesser degree, IFITM3 were demonstrated to block MERS-S-driven entry, at least upon overexpression (28). Finally, MERS-S has been shown to bind to a coreceptor, sialic acid, which promotes viral entry into target cells (9). Our results indicate that D510G and I529T do not impact the above-named processes, suggesting that both mutations might affect neither viral attachment to cells nor the membrane fusion reaction.

The spike protein is the key target of neutralizing antibodies, and such antibodies are detected with high frequency in convalescent MERS patients who have survived severe disease $(18,38-40)$. Neutralizing antibodies can be directed against the RBD and interfere with viral entry by blocking DPP4/S protein interactions. A previous study conducted with cell culture systems found that MERS-CoV can acquire mutations that allow escape from RBD-targeting neutralizing antibodies but also provided evidence that such mutations might come at the cost of decreased DPP4 binding and viral fitness (30). Such a scenario generally matches our findings that D510G and I529T render the $S$ protein at least partially resistant against neutralization by monoclonal antibodies and sera from MERS patients and reduce DPP4 binding. However, our results also allow the speculation that reduced DPP4 binding might not necessarily translate into reduced viral spread in host cells expressing high levels of DPP4. This possibility awaits confirmation with infectious MERS-CoV and primary target cells. Nevertheless, it would be in keeping with the observation that viruses harboring the 1529T change were robustly transmitted between patients during the MERS outbreak in the Republic of Korea (14), although the 1529T change did not provide the virus with an advantage in the absence of humoral responses. Finally, our finding that single point mutations in MERS-S can increase resistance to antibody-mediated neutralization highlights the need to develop vaccines and therapeutics that simultaneously target multiple epitopes in MERS-S.

Collectively, our findings and previous work suggest that MERS-CoV variants with at least partial resistance to antibody-mediated neutralization can retain high infectivity for cells expressing robust amounts of DPP4 and can spread between humans.

\section{MATERIALS AND METHODS}

Plasmids. We employed expression plasmids encoding the VSV glycoprotein (VSV-G) (41), Machupo virus glycoprotein (MACV-GPC) (42) (kindly provided by M. Farzan), influenza A virus strain A/WSN/33 
(H1N1) hemagglutinin and neuraminidase (WSN-HA/NA) (43), and WT MERS-S (10), which have been described elsewhere. In addition, we employed overlap extension PCR to generate MERS-S mutants harboring single (L411F, F473S, D510G, and I529T) mutations in the RBD (primer sequences and detailed information on the cloning procedure are available upon request). For all $\mathrm{S}$ proteins, we also generated versions containing a C-terminal V5 epitope for detection by immunoblotting. Expression plasmids for TMPRSS2 N-terminally fused to a CMYC epitope and DPP4 N-terminally fused to DsRed (EU827527.1 and DsRed-DPP4) were constructed by amplifying the genetic information from existing expression plasmids and cloning the respective open reading frame (ORF) into the PQCXIP plasmid (kindly provided by A. L. Brass). For the TMPRSS 2 expression vector, we further exchanged the selection marker for puromycin resistance by that for blasticidin resistance, which was taken from plasmid pcDNA6/TR vector $(8,44)$. All PCR-amplified sequences were subjected to automated sequence analysis (Microsynth SeqLab) to verify their integrity.

Cell culture. 293T (human) and Vero E6 (African green monkey) cells were cultivated in Dulbecco's modified Eagle's medium (DMEM; PAN-Biotech). In addition, the human colorectal adenocarcinoma cell line Caco-2 was grown in minimum essential medium (MEM; Thermo Fisher Scientific). 293T cells stably expressing IFITMs or chloramphenicol acetyltransferase (CAT), 293T-IFITM1, 293T-IFITM2, 293T-IFITM3, and 293T-CAT (45), were cultivated as for the parental 293T cell line with the exception that they additionally received $0.5 \mu \mathrm{g} / \mathrm{ml}$ of puromycin (Biomol). All media were supplemented with $10 \%$ fetal additionally received $0.5 \mu \mathrm{g} / \mathrm{ml}$ of puromycin (Biomol). All media were supplemented with $10 \%$ fetal
bovine serum (FBS; PAN-Biotech) as well as $1 \times$ penicillin and streptomycin from a $100 \times$ stock solution bovine serum (FBS; PAN-Biotech) as well as $1 \times$ penicillin and streptomycin from a $100 \times$ stock solution
(PAN-Biotech). All cell lines were cultivated in a humidified atmosphere at $37^{\circ} \mathrm{C}$ and $5 \% \mathrm{CO}_{2}$. Transfection (PAN-Biotech). All cell lines were cultivated in a humidified atmosph
of 293 T cells was performed by calcium phosphate precipitation.

Protease inhibitors. We employed inhibitors targeting cathepsin $L$ and related proteases (MDL28170; Sigma-Aldrich) or TMPRSS2 and related proteases (camostat mesylate; Sigma-Aldrich). Target cells for transduction experiments were treated with the respective inhibitor (specific concentrations are Alictions are indicated in the legends of the respective figures) for $2 \mathrm{~h}$ prior to inoculation with rhabdoviral trans-
duction vectors. uction vectors.

Neuraminidase treatment of target cells. To remove terminal sialic acids from macromolecules on the cell surface, target cells were preincubated with $100 \mathrm{mU}$ of recombinant neuraminidase (SigmaAldrich) for $2 \mathrm{~h}$ before being inoculated with rhabdoviral transduction vectors.

Production of rhabdoviral transduction vectors and transduction of target cells. We employed rhabdoviral transduction vectors (pseudoparticles/pseudotypes) based on a replication-deficient vesicular stomatitis virus that lacks the genetic information for VSV-G but contains ORFs for enhanced green fluorescent protein (eGFP) and firefly luciferase (fLuc), VSV* $\Delta$ G-fLuc (46). For production of VSV-based pseudotypes (VSVpp), 293T cells were transfected with expression plasmids for MERS-S WT, mutant MERS-S harboring RBD polymorphisms, MACV-GPC, H1N1(WSN)-HA/NA, VSV-G (positive control) or empty expression vector (negative control). At $24 \mathrm{~h}$ posttransfection, cells were inoculated with VSV-Gtranscomplemented VSV* $\Delta \mathrm{G}-$ fLuc (Indiana strain, kindly provided by G. Zimmer) at a multiplicity of infection of 3 and incubated for $1 \mathrm{~h}$ at $37^{\circ} \mathrm{C}$ and $5 \% \mathrm{CO}_{2}$. Next the inoculum was removed, cells were washed with phosphate-buffered saline (PBS), and standard culture medium which contained antiVSV-G antibody (11, mouse hybridoma supernatant from CRL-2700: ATCC) was added to neutralize residual input virus (cells transfected with VSV-G expression plasmid received culture medium without anti-VSV-G antibody). The cells were further incubated for $24 \mathrm{~h}$ before the supernatant was harvested, freed from cellular debris by centrifugation $(3,000 \times g$ for $10 \mathrm{~min})$, and either stored at $-80^{\circ} \mathrm{C}$ or used for transduction experiments. For the latter, target cells were grown in 96 -well plates. If necessary, target cells were previously transfected with expression plasmids for DsRed-DPP4 and/or TMPRSS2 ( $24 \mathrm{~h}$ in advance) or were pretreated with protease inhibitors or neuraminidase ( $2 \mathrm{~h}$ in advance). For transduction the culture medium was aspirated and the rhabdoviral transduction vectors were added to the cells. Transduction efficiency was quantified by measuring the virus-encoded fluc activity in cell lysates using commercial kits (Beetle Juice; PJK) and a plate luminometer (Hidex, Turku, Finland) as described elsewhere (47).

Analysis of MERS-S expression and incorporation into VSVpp. 293T cells were transfected with expression plasmids for C-terminally V5-tagged versions of the MERS-S WT or MERS-S mutants or were control transfected with empty plasmid (negative control). At $48 \mathrm{~h}$ posttransfection, the culture supernatant was removed, cells were washed with PBS, and whole cells lysates (WCL) were prepared as follows. First, $2 \times$ SDS sample buffer $(0.03 \mathrm{M}$ Tris- $\mathrm{HCl}, 10 \%$ glycerol, $2 \%$ SDS, $5 \%$ beta-mercaptoethanol, $0.2 \%$ bromophenol blue $1 \mathrm{mM}$ EDTA) was added to the cells, which were then incubated for $10 \mathrm{~min}$ before the sample was transferred to $1.5-\mathrm{ml}$ reaction tubes and heated to $95^{\circ} \mathrm{C}$ for additional $10 \mathrm{~min}$. For analysis of S protein incorporation into VSV particles, the respective culture supernatants were pelleted by high-speed centrifugation $\left(25,000 \times \mathrm{g}, 120 \mathrm{~min}\right.$, and $\left.4^{\circ} \mathrm{C}\right)$ through a $20 \%(\mathrm{wt} / \mathrm{vol})$ sucrose cushion, mixed with $2 \times$ SDS sam ple buffer, and heated to $95^{\circ} \mathrm{C}$ for additional $10 \mathrm{~min}$. Following SDS-PAGE, proteins were transferred onto nitrocellulose membranes (Hartenstein $\mathrm{GmbH}$ ) by immunoblotting. The membranes were then blocked by incubation in 5\% skim milk in PBS-0.5\% Tween 20 (PBS-T) for 30 min at room temperature (RT) and then incubated with primary antibody solution (anti-V5, anti-ACTB, or anti-VSV-M) overnight at $4^{\circ} \mathrm{C}$. Next membranes were washed with PBS-T and further incubated with secondary antibody solution (anti-mouse-horseradish peroxidase [HRP]) for $1 \mathrm{~h}$ at RT. After additional washing steps, the membranes were finally developed using an in house-made chemiluminescence reagent in combination with the ChemoCam imaging system and ChemoStar Professional software (Intas Science Imaging Instruments $\mathrm{GmbH}$ ). For quantification of the signal intensity, the program ImageJ (FIJl distribution) (48) was used. S protein signals detected in the WCL and supernatants were normalized against the respective signals of the loading control, either ACTB or VSV-M. 
Antibodies for protein detection in immunoblot analysis. The following antibodies were used as primary antibodies: anti-V5 (mouse, 1:1,000; Thermo Fisher Scientific), anti- $\beta$-actin (ACTB, mouse, 1:1,000; Sigma-Aldrich), and anti-VSV-M (mouse, 1:1,000; Kerafast). As a secondary antibody, an HRP-coupled anti-mouse antibody was used (goat, 1:5,000; Dianova). All antibodies were diluted in PBS-T (Carl Roth) and $5 \%$ skim milk (Carl Roth).

Analysis of MERS-S/DPP4 interaction and DPP4 surface expression by flow cytometry. For the detection of MERS-S/DPP4 interaction, 293T cells were transfected with expression plasmids for MERS-S WT, MERS-S mutants, or VSV-G or empty plasmid (both negative controls). At $48 \mathrm{~h}$ posttransfection, the cells were washed with PBS and then resuspended in $1 \%$ bovine serum albumin (BSA)-PBS. Next, the cells cells were washed with PBS and then resuspended in $1 \%$ bovine serum albumin (BSA)-PBS. Next, the cells
were pelleted by centrifugation ( 5 min at $600 \times g$ at $4^{\circ} \mathrm{C}$ ) and resuspended in $1 \%$ BSA-PBS containing soluble DPP4 equipped with a C-terminal human FC tag (solDPP4-Fc, 1:200; ACROBiosystems). After incubation for $1 \mathrm{~h}$ at $4^{\circ} \mathrm{C}$, the cells were washed with $1 \%$ BSA-PBS and then resuspended in $1 \%$ BSA-PBS containing an Alexa Fluor 488-conjugated anti-human antibody (1:500; Thermo Fisher Scientific). After another incubation period (as described above), cells were washed with $1 \%$ BSA-PBS, fixed with $4 \%$ paraformaldehyde solution, and analyzed by flow cytometry as described below. For the analysis of DPP4 surface expression by flow cytometry, 293T (untransfected or transfected with expression plasmid for DPP4), Caco-2, and Vero E6 cells were detached by resuspension in 1\% BSA-PBS (293T cells) or by incubation in citric saline (PBS containing $0.135 \mathrm{M}$ potassium chloride and $0.015 \mathrm{M}$ sodium citrate; Caco-2 and Vero E6 cells). Cells were then pelleted and washed as described above, successively incubated with anti-DPP4 (mouse, 1:200; Abcam) and Alexa Fluor 488-conjugated anti-mouse (goat, 1:500; Thermo Fisher Scientific) antibodies, and fixed. Finally, all samples were analyzed using an LSR II flow cytometer and the FACS Diva software (both from BD Biosciences). For further data analysis, FCS Express 4 Flow research software (De Novo software) was employed.

Quantification of DPP4-specific transcript levels by qPCR. Total cellular RNA was extracted from 293T, Caco-2, and Vero E6 cells using the RNeasy minikit (Qiagen) according to the manufacturer's instructions. Then $1 \mu \mathrm{g}$ of RNA was treated with DNase (New England BioLabs) and reverse transcribed into CDNA using the SuperScript III first-strand synthes is system (Thermo Fisher Scientific), both following the manufacturers' specifications. Subsequently, $1 \mu \mathrm{l}$ of each sample was subjected to quantitative PCR (qPCR) using the QuantiTect SYBR green PCR kit (Qiagen) and a Rotor-Gene Q platform (Qiagen). All samples were analyzed for $\beta$-actin (housekeeping gene control) and DPP4 (gene of interest) transcripts in triplicates. Finally, data were analyzed based on the threshold cycle $\left(2^{-\triangle \triangle C}\right)$ method (49) using 293T cells as a reference.

Neutralization experiments. Rhabdoviral transduction vectors harboring MERS-S WT, MERS-S mutants, or VSV-G were normalized for comparable transduction of Caco- 2 cells $\left(\sim 10^{5}\right.$ luminescent counts/s), incubated for $30 \mathrm{~min}$ at RT with increasing concentrations of monoclonal antibodies targeting distinct epitopes within the MERS-S RBD, JC57-14 (targeting an epitope around amino acid residue 535 in MERS-S, isolated from vaccinated nonhuman primates [PDB code $6 \mathrm{C} 6 \mathrm{Y}$ ) ) and $\mathrm{F} 11$ (targeting an epitope around amino acid residue 509 in MERS-S, isolated from vaccinated mice) (29) or with different dilutions of serum from a MERS patient who traveled from the Arabian Peninsula to Germany. Furthermore, sera from two additional MERS patients, CSS16 and CSS23, were tested at a dilution of 1:200 (since the amount of those sera was limited, they were tested at a fixed dilution). Please see Table 1 for further information on the sera and the patient histories. Afterwards, the mixtures of VSVpp and antibodies/ serum were inoculated onto Caco-2 cells that were further incubated at $37^{\circ} \mathrm{C}$ and $5 \% \mathrm{CO}_{2}$. At $18 \mathrm{~h}$ posttransduction, transduction efficiency was quantified (as described above). For normalization, transduction efficiency of rhabdoviral transduction vectors that were incubated in the absence of antibodies/ serum was set as $100 \%$.

Statistical analysis. If not stated otherwise, unpaired or paired, two-tailed Student $t$ tests were performed to test statistical significance of data originating from single representative or multiple combined experiments, respectively. In figures, statistical significance is represented as follows: *, $P \leq 0.05 ;{ }^{* *}, P \leq 0.01 ; * * *, P \leq 0.001$; and ns, not significant.

\section{ACKNOWLEDGMENTS}

We are grateful to M. Farzan, A. L. Brass, and G. Zimmer for providing expression plasmids and reagents.

This work was supported, including the efforts of Stefan Pöhlmann and Christian Drosten, by the Bundesministerium für Bildung und Forschung within the network project RAPID (Risikobewertung bei präpandemischen respiratorischen Infektionserkrankungen; 01KI1723D and 01KI1723A). Furthermore, this work was supported by intramural funding to Barney S. Graham through the National Institutes of Health (NIH).

The funders had no role in study design, data collection and interpretation, or the decision to submit the work for publication.

Charité-Universitätsmedizin Berlin is a corporate member of Freie Universität Berlin, Humboldt-Universität zu Berlin, and Berlin Institute of Health. The German Centre for Infection Research is an associated partner of Charité-Universitätsmedizin Berlin. 


\section{REFERENCES}

1. Lai MMC, Perlman S, Anderson L. 2007. Coronaviridae, p 1305-1336. In Knipe DM, Howley PM, Griffin DE, Lamb RA, Martin MA, Roizman B, Straus SE (ed), Fields virology, 5th ed, vol 1. Lippincott, Williams \& Wilkins, Philadelphia, PA.

2. Haagmans BL, AI Dhahiry SH, Reusken CB, Raj VS, Galiano M, Myers R Godeke GJ, Jonges M, Farag E, Diab A, Ghobashy H, Alhajri F, Al-Thani M, Al-Marri SA, Al Romaihi HE, Al Khal A, Bermingham A, Osterhaus AD, AlHaji MM, Koopmans MP. 2014. Middle East respiratory syndrom coronavirus in dromedary camels: an outbreak investigation. Lancet Infect Dis 14:140-145. https://doi.org/10.1016/S1473-3099(13)70690-X.

3. Reusken CBEM, Haagmans BL, Müller MA, Gutierrez C, Godeke G-J, Meyer B, Muth D, Raj VS, Smits-De Vries L, Corman VM, Drexler J-F, Smits SL, El Tahir YE, De Sousa R, van Beek J, Nowotny N, van Maanen K, HidalgoHermoso E, Bosch B-J, Rottier P, Osterhaus A, Gortázar-Schmidt C, Drosten C, Koopmans MPG. 2013. Middle East respiratory syndrome coronavirus neutralising serum antibodies in dromedary camels: comparative serological study. Lancet Infect Dis 13:859-866. https://do .org/10.1016/S1473-3099(13)70164-6.

4. World Health Organization. 2018. Middle East respiratory syndrom coronavirus (MERS-CoV) - Saudi Arabia. http://www.emro.who.int pandemic-e pidemic-diseases/mers-cov/mers-situation-update-march -2018.html. Accessed 27 July 2018.

5. Assiri A, McGeer A, Perl TM, Price CS, Al Rabeeah AA, Cummings DA Alabdullatif ZN, Assad M, Almulhim A, Makhdoom H, Madani H, Alhakeem R, Al-Tawfiq JA, Cotten M, Watson SJ, Kellam P, Zumla Al, Memish ZA, KSA MERS-CoV Investigation Team. 2013. Hospital outbreak of Middle East respiratory syndrome coronavirus. N Engl J Med 369:407-416. dle East respiratory syndrome coronavirus,

6. Cho SY, Kang JM, Ha YE, Park GE, Lee JY, Ko JH, Lee JY, Kim JM, Kang CI Jo IJ, Ryu JG, Choi JR, Kim S, Huh HJ, Ki CS, Kang ES, Peck KR, Dhong H, Song JH, Chung DR, Kim YJ. 2016. MERS-CoV outbreak following a single patient exposure in an emergency room in South Korea: an epidemiological outbreak study. Lancet 388:994-1001. https://doi.org/10.1016/ S0140-6736(16)30623-7.

7. Oh MD, Park WB, Park SW, Choe PG, Bang JH, Song KH, Kim ES, Kim HB, Kim NJ. 2018. Middle East respiratory syndrome: what we learned from the 2015 outbreak in the Republic of Korea. Korean J Intern Med 33:233-246. https://doi.org/10.3904/kjim.2018.031.

8. Raj VS, Mou H, Smits SL, Dekkers DH, Muller MA, Dijkman R, Muth D, Demmers JA, Zaki A, Fouchier RA, Thiel V, Drosten C, Rottier PJ, Osterhaus AD, Bosch BJ, Haagmans BL. 2013. Dipeptidyl peptidase 4 is functional receptor for the emerging human coronavirus-EMC. Nature 495:251-254. https://doi.org/10.1038/nature12005.

9. Li W, Hulswit RJG, Widjaja I, Raj VS, McBride R, Peng W, Widagdo W, Tortorici MA, van Dieren B, Lang Y, van Lent JWM, Paulson JC, de Haa CAM, de Groot RJ, van Kuppeveld FJM, Haagmans BL, Bosch BJ. 2017. Identification of sialic acid-binding function for the Middle East respiratory syndrome coronavirus spike glycoprotein. Proc Natl Acad Sci U S A tory syndrome coronavirus spike glycoprotein. Proc Natl Acad

10. Gierer S, Bertram S, Kaup F, Wrensch F, Heurich A, Krämer-Kühl A, Welsch K, Winkler M, Meyer B, Drosten C, Dittmer U, von Hahn T, Simmons G, Hofmann H, Pöhlmann S. 2013. The spike protein of the emergin betacoronavirus EMC uses a novel coronavirus receptor for entry, can be activated by TMPRSS2, and is targeted by neutralizing antibodies. J Viro 87:5502-5511. https://doi.org/10.1128/JV.00128-13.

11. Qian Z, Dominguez SR, Holmes KV. 2013. Role of the spike glycoprotein of human Middle East respiratory syndrome coronavirus (MERS-CoV) in virus entry and syncytia formation. PLoS One 8:e76469. https://doi.org/ 10.1371/journal.pone.0076469.

12. Shirato K, Kanou K, Kawase M, Matsuyama S. 2017. Clinical isolates of human coronavirus $229 \mathrm{E}$ bypass the endosome for cell entry. J Viro 91:e01387-16. https://doi.org/10.1128/JVI.01387-16.

13. Kim DW, Kim YJ, Park SH, Yun MR, Yang JS, Kang HJ, Han YW, Lee HS, Kim HM, Kim H, Kim AR, Heo DR, Kim SJ, Jeon JH, Park D, Kim JA, Cheong HM $\mathrm{Nam}$ JG, Kim K, Kim SS. 2016. Variations in spike glycoprotein gene of MERS-CoV, South Korea, 2015. Emerg Infect Dis 22:100-104. https://do .org/10.3201/eid2201.151055.

14. Kim Y, Cheon S, Min CK, Sohn KM, Kang YJ, Cha YJ, Kang Jl, Han SK, Ha NY, Kim G, Aigerim A, Shin HM, Choi MS, Kim S, Cho HS, Kim YS, Cho NH. 2016. Spread of mutant Middle East respiratory syndrome coronavirus with reduced affinity to human CD26 during the South Korean outbreak. mBio 7:e00019-16. https://doi.org/10.1128/mBio.00019-16.

15. Drosten C, Muth D, Corman VM, Hussain R, Al Masri M, HajOmar W, Landt O, Assiri A, Eckerle I, Al Shangiti A, Al-Tawfiq JA, Albarrak A, Zumla A, Rambaut A, Memish ZA. 2015. An observational, laboratory-based study
of outbreaks of Middle East respiratory syndrome coronavirus in Jeddah and Riyadh, Kingdom of Saudi Arabia, 2014. Clin Infect Dis 60:369-377. https://doi.org/10.1093/cid/ciu812.

16. Fagbo SF, Skakni L, Chu DK, Garbati MA, Joseph M, Peiris M, Hakawi AM. 2015. Molecular epidemiology of hospital outbreak of Middle East respiratory syndrome, Riyadh, Saudi Arabia, 2014. Emerg Infect Dis 21: 1981-1988. https://doi.org/10.3201/eid2111.150944.

17. Sabir JS, Lam TT, Ahmed MM, Li L, Shen Y, Abo-Aba SE, Qureshi Ml, Abu-Zeid $M$, Zhang $Y$, Khiyami MA, Alharbi NS, Hajrah NH, Sabir MJ, Mutwakil MH, Kabli SA, Alsulaimany FA, Obaid AY, Zhou B, Smith DK, Holmes EC, Zhu H, Guan Y. 2016. Co-circulation of three camel coronavirus species and recombination of MERS-CoVs in Saudi Arabia. Science 351:81-84. https://doi.org/10.1126/science.aac8608.

18. Corman VM, Albarrak AM, Omrani AS, Albarrak MM, Farah ME, Almasri M, Muth D, Sieberg A, Meyer B, Assiri AM, Binger T, Steinhagen K, Lattwein E, Al-Tawfiq J, Muller MA, Drosten C, Memish ZA. 2016. Viral shedding and antibody response in 37 patients with Middle East respiratory syndrome coronavirus infection. Clin Infect Dis 62:477-483. https://doi .org/10.1093/cid/civ951.

19. Hemida MG, Alnaeem A, Chu DK, Perera RA, Chan SM, Almathen F, Yau E, Ng BC, Webby RJ, Poon LL, Peiris M. 2017. Longitudinal study of Middle East respiratory syndrome coronavirus infection in dromedary camel herds in Saudi Arabia, 2014-2015. Emerg Microbes Infect 6:e56. https://doi.org/10.1038/emi.2017.44

20. Hoffmann M, González Hernández M, Berger E, Marzi A, Pöhlmann S. 2016. The glycoproteins of all filovirus species use the same host factors for entry into bat and human cells but entry efficiency is species dependent. PLoS One 11:e0149651. https://doi.org/10.1371/journal.pone.0149651.

21. Fukuma A, Tani H, Taniguchi S, Shimojima M, Saijo M, Fukushi S. 2015. Inability of rat DPP4 to allow MERS-CoV infection revealed by using a VSV pseudotype bearing truncated MERS-CoV spike protein. Arch Virol 160:2293-2300. https://doi.org/10.1007/s00705-015-2506-z

22. Gierer S, Muller MA, Heurich A, Ritz D, Springstein BL, Karsten CB, Schendzielorz A, Gnirss K, Drosten C, Pohlmann S. 2015. Inhibition of proprotein convertases abrogates processing of the Middle Eastern respiratory syndrome coronavirus spike protein in infected cells but does not reduce viral infectivity. J Infect Dis 211:889-897. https://doi .org/10.1093/infdis/jiu407.

23. Millet JK, Whittaker GR. 2014. Host cell entry of Middle East respiratory syndrome coronavirus after two-step, furin-mediated activation of the spike protein. Proc Natl Acad Sci U S A 111:15214-15219. https://doi spike protein. Proc Natl Acad Sci

24. Shirato K, Kawase M, Matsuyama S. 2013. Middle East respiratory syndrome coronavirus infection mediated by the transmembrane serine protease TMPRSS2. J Virol 87:12552-12561. https://doi.org/10.1128/JVI .01890-13.

25. Yang Y, Liu C, Du L, Jiang S, Shi Z, Baric RS, Li F. 2015. Two mutations were critical for bat-to-human transmission of Middle East respiratory syndrome coronavirus. J Virol 89:9119-9123. https://doi.org/10.1128/JVI .01279-15.

26. Zhou Y, Vedantham P, Lu K, Agudelo J, Carrion R, Jr, Nunneley JW, Barnard D, Pohlmann S, McKerrow JH, Renslo AR, Simmons G. 2015. Protease inhibitors targeting coronavirus and filovirus entry. Antiviral Res 116:76-84. https://doi.org/10.1016/j.antiviral.2015.01.011.

27. Bertram S, Dijkman R, Habjan $M$, Heurich A, Gierer $S$, Glowacka I, Welsch K, Winkler M, Schneider H, Hofmann-Winkler $\mathrm{H}$, Thiel V, Pöhlmann S, 2013. TMPRSS2 activates the human coronavirus $229 \mathrm{E}$ for cathepsinindependent host cell entry and is expressed in viral target cells in the respiratory epithelium. J Virol 87:6150-6160. https://doi.org/10.1128/JVI .03372-12.

28. Wrensch F, Winkler M, Pohlmann S. 2014. IFITM proteins inhibit entry driven by the MERS-coronavirus spike protein: evidence for cholesterol-independent mechanisms. Viruses 6:3683-3698. https:// doi.org/10.3390/v6093683.

29. Wang L, Shi W, Chappell JD, Joyce MG, Zhang Y, Kanekiyo M, Becker MM van Doremalen N, Fischer R, Wang N, Corbett KS, Choe M, Mason RD, Van 
Galen JG, Zhou T, Saunders KO, Tatti KM, Haynes LM, Kwong PD, Modjarrad K, Kong WP, McLellan JS, Denison MR. Munster VJ, Mascola JR, Graham BS. 2018. Importance of neutralizing monoclonal antibodies targeting multiple 2018. Importance of neutralizing monoclonal antibodies targeting multiple
antigenic sites on MERS-CoV spike to avoid neutralization escape. I Viro antigenic sites on MERS-CoV spike to avoid neutra

30. Tang XC, Agnihothram SS, Jiao Y, Stanhope J, Graham RL, Peterson EC, Avnir Y, Tallarico AS, Sheehan J, Zhu Q, Baric RS, Marasco WA. 2014 Identification of human neutralizing antibodies against MERS-CoV and their role in virus adaptive evolution. Proc Natl Acad Sci U S A 111 E2018-E2026. https://doi.org/10.1073/pnas.1402074111.

31. Raj VS, Smits SL, Provacia LB, van den Brand JM, Wiersma L, Ouwendijk WJ, Bestebroer TM, Spronken MI, van Amerongen G, Rottier PJ, Fouchier RA, Bosch BJ, Osterhaus AD, Haagmans BL. 2014. Adenosine deaminase acts as a natural antagonist for dipeptidyl peptidase 4-mediated entry of the Middle East respiratory syndrome coronavirus. J Virol 88:1834-1838. https://doi.org/10.1128/JVI.02935-13.

32. Meyerholz DK, Lambertz AM, McCray PB, Jr. 2016. Dipeptidyl peptidase 4 distribution in the human respiratory tract: implications for the Middle 4 distribution in the human respiratory tract: implications for the Middle
East respiratory syndrome. Am J Pathol 186:78-86. https://doi.org/10 East respiratory syndrome.
$.1016 /$ j.ajpath.2015.09.014.

33. Seys $\sqcup M$, Widagdo W, Verhamme FM, Kleinjan A, Janssens W, Joos GF, Bracke KR, Haagmans BL, Brusselle GG. 2018. DPP4, the Middle East respiratory syndrome coronavirus receptor, is upregulated in lungs of smokers and chronic obstructive pulmonary disease patients. Clin Infect Dis 66:45-53. https://doi.org/10.1093/cid/cix741.

34. Zumla A, Hui DS, Perlman S. 2015. Middle East respiratory syndrome Lancet 386:995-1007. https://doi.org/10.1016/S0140-6736(15)60454-8.

35. Hoffmann M, Hofmann-Winkler H, Pohlmann S. 2018. Priming time: how cellular proteases arm coronavirus spike proteins, $\mathrm{p}$ 71-98. In BöttcherFriebertshäuser E, Garten W, Klenk HD (ed), Activation of viruses by host proteases. Springer International Publishing, Cham, Switzerland.

36. Park JE, Li K, Barlan A, Fehr AR, Perlman S, McCray PB, Jr, Gallagher T. 2016. Proteolytic processing of Middle East respiratory syndrome coronavirus spikes expands virus tropism. Proc Natl Acad Sci U S A 113 navirus spikes expands virus tropism. Proc Natl Acad Sci

37. Cortes A, Gracia E, Moreno E, Mallol J, Lluis C, Canela El, Casado V. 2015 Moonlighting adenosine deaminase: a target protein for drug develop ment. Med Res Rev 35:85-125. https://doi.org/10.1002/med.21324.

38. Choe PG, Perera R, Park WB, Song KH, Bang JH, Kim ES, Kim HB, Ko LWR, Park SW, Kim NJ, Lau EHY, Poon LLM, Peiris M, Oh MD. 2017. MERS-CoV antibody responses 1 year after symptom onset, South Korea, 2015. Emerg Infect Dis 23:1079-1084. https://doi.org/10.3201/eid2307.170310.

39. Arabi YM, Hajeer AH, Luke T, Raviprakash K, Balkhy H, Johani S, AlDawood A, Al-Qahtani S, Al-Omari A, Al-Hameed F, Hayden FG, Fowler R Bouchama A, Shindo N, Al-Khairy K, Carson G, Taha Y, Sadat M, Alahmad M. 2016. Feasibility of using convalescent plasma immunotherapy for MERS-CoV infection, Saudi Arabia. Emerg Infect Dis 22:1554-1561. https://doi.org/10.3201/eid2209.151164.

40. Zhao J, Alshukairi AN, Baharoon SA, Ahmed WA, Bokhari AA, Nehdi AM Layqah LA, Alghamdi MG, Al Gethamy MM, Dada AM, Khalid I, Boujelal M. AI Johan SM, Vogel L Subbar K M Mngalam A, WU C, Ten Eyck P, $M$, Al Johani SM, Vogel $L$, Subbarao $K$, Mangalam $A$, Wu C, Ten Eyck syndrome is associated with antibody and T-cell responses. Sci Immunol 2:eaan5393. https://doi.org/10.1126/sciimmunol.aan5393.
41. Brinkmann C, Hoffmann M, Lübke A, Nehlmeier I, Krämer-Kühl A, Winkler M, Pöhlmann S. 2017. The glycoprotein of vesicular stomatitis virus promotes release of virus-like particles from tetherin-positive cells. PLoS promotes release of virus-like particles from tetherin-positive cells.
One 12:e0189073. https://doi.org/10.1371/journal.pone.0189073.

One 12:e0189073. https://doi.org/10.1371/journal.pone.0189073.
42. Radoshitzky SR, Abraham J, Spiropoulou CF, Kuhn JH, Nguyen D, Li W, Nagel J, Schmidt PJ, Nunberg JH, Andrews NC, Farzan M, Choe H. 2007. Transferrin receptor 1 is a cellular receptor for New World haemorrhagic fever arenaviruses. Nature 446:92-96. https://doi.org/ 10.1038/nature05539.

43. Chaipan C, Kobasa D, Bertram S, Glowacka I, Steffen I, Tsegaye TS, Takeda M, Bugge TH, Kim S, Park Y, Marzi A, PohImann S. 2009. Proteolytic activation of the 1918 influenza virus hemagglutinin. J Virol 83: 3200-3211. https://doi.org/10.1128/JVl.02205-08.

44. Bertram S, Glowacka I, Blazejewska P, Soilleux E, Allen P, Danisch S, Steffen I, Choi SY, Park Y, Schneider H, Schughart K, Pohlmann S. 2010. TMPRSS2 and TMPRSS4 facilitate trypsin-independent spread of influenza virus in Caco-2 cells. J Virol 84:10016-10025. https://doi.org/10 $1128 /$ VI. $00239-10$

45. Wrensch F, Hoffmann M, Gartner S, Nehlmeier I, Winkler M, Pohlmann S. 2017. Virion background and efficiency of virion incorporation determine susceptibility of simian immunodeficiency virus env-driven viral entry to inhibition by IFITM proteins. J Virol 91:e01488-16. https://doi .org/10.1128/JV.01488-16.

46. Berger Rentsch M, Zimmer G. 2011. A vesicular stomatitis virus repliconbased bioassay for the rapid and sensitive determination of multispecies type I interferon. PLoS One 6:e25858. https://doi.org/10.1371/ journal. pone. 0025858 .

47. Hoffmann $M$, Kruger $N$, Zmora $P$, Wrensch F, Herrler G, Pohlmann S. 2016. The hemagglutinin of bat-associated influenza viruses is activated by TMPRSS2 for pH-dependent entry into bat but not human cells. PLoS One 11:e0152134. https://doi.org/10.1371/journal.pone.0152134.

48. Schindelin J, Arganda-Carreras I, Frise E, Kaynig V, Longair M, Pietzsch T, Preibisch S, Rueden C, Saalfeld S, Schmid B, Tinevez JY, White DJ, Hartenstein V, Eliceiri K, Tomancak P, Cardona A. 2012. Fiji: an opensource platform for biological-image analysis. Nat Methods 9:676-682. https://doi.org/10.1038/nmeth.2019.

49. Livak KJ, Schmittgen TD. 2001. Analysis of relative gene expression data using real-time quantitative PCR and the 2(-Delta Delta $C(T)$ ) method. Methods 25:402-408, https://doi.org/10.1006/meth.2001.1262.

50. Guberina H, Witzke O, Timm J, Dittmer U, Muller MA, Drosten C, Bonin F. 2014. A patient with severe respiratory failure caused by novel human coronavirus. Infection 42:203-206. https://doi.org/10.1007/s15010-013 $-0509-9$

51. Drosten C, Seilmaier M, Corman VM, Hartmann W, Scheible G, Sack S, Guggemos W, Kallies R, Muth D, Junglen S, Muller MA, Haas W, Guberina $H$, Rohnisch T, Schmid-Wendtner M, Aldabbagh S, Dittmer U, Gold H, Graf P, Bonin F, Rambaut A, Wendtner CM. 2013. Clinical features and virological analysis of a case of Middle East respiratory syndrome coronavirus infection. Lancet Infect Dis 13:745-751. https://doi.org/10.1016/ S1473-3099(13)70154-3.

52. ProMED. 2015. MERS-COV (31): Saudi Arabia, Germany ex United Arab Emirates, request for information. ProMED mail archive no.
. Prom 20150308.3215456. http://www.promedmail.org/. 
5.3. Third manuscript

\title{
Spike proteins of novel MERS-coronaviruses
}

\author{
isolates from North- and West-African dromedary
}

camels mediate robust viral entry into human target

\section{cells}

Kleine-Weber H, Pöhlmann S, Hoffmann M.

Individual contribution:

In the manuscript, I generated the samples for Figure 1B: "S proteins of North/Westand West-African MERS-CoV isolates from dromedary camels are robustly expressed in human cells and efficiently incorporated into viral particles." and I conducted the experiments for Figure 2: "S proteins of North/West- and West-African MERS-CoV isolates from dromedary camels efficiently bind to DPP4." and Figure 3: "Host cell entry driven by the S proteins of North/West- and West-African MERS-CoV isolates from dromedary camels is robust." 


\section{Spike proteins of novel MERS-coronavirus isolates from North- and West-} African dromedary camels mediate robust viral entry into human target cells

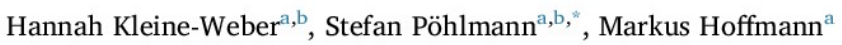

a'Infection Biology Unit, Deutsches Primatenzentrum - Leibniz Institute for Primate Research, Kellnerweg 4, 37077 Göttingen, Germany ${ }^{b}$ Faculty of Biology and Psychology, University Göttingen, Wilhelm-Weber-Str. 2, 37073 Göttingen, Germany

A R T ICLE INFO

\section{Keywords:}

MERS-coronavirus

Spike

Dromedary came

Zoonosis

\begin{abstract}
A B S T R A C T
The highly pathogenic Middle East respiratory syndrome (MERS)-related coronavirus (CoV) is transmitted from dromedary camels, the natural reservoir, to humans. For at present unclear reasons, MERS cases have so far only been observed in the Arabian Peninsula, although MERS-CoV also circulates in African dromedary camels. A recent study showed that MERS-CoV found in North/West- (Morocco) and West-African (Burkina Faso and Nigeria) dromedary camels are genetically distinct from Arabian viruses and have reduced replicative capacity in Nigeria) dromedary camels are genetically distinct from Arabian viruses and have reduced replicative capacity in
human cells, potentially due to amino acid changes in one or more viral proteins. Here, we show that the spike human cells, potentially due to amino acid changes in one or more viral proteins. Here, we show that the spike
(S) proteins of the prototypic Arabian MERS-CoV strain, human betacoronavirus 2c EMC/2012, and the above stated African MERS-CoV variants do not appreciably differ in expression, DPP4 binding and ability to drive entry into target cells. Thus, virus-host-interactions at the entry stage may not limit spread of North- and West-
\end{abstract} African MERS-CoV in human cells.

\section{Introduction}

The Middle East respiratory syndrome-related coronavirus (MERS CoV) causes the severe lung disease MERS (Zaki et al., 2012), which takes a fatal course in roughly $\sim 35 \%$ of infected patients (WHO, 2019). MERS-CoV is endemic in the Middle East, where the virus is transmitted from dromedary camels, the natural reservoir, to humans (Perera et al, 2013; Reusken et al., 2013). Human-to-human transmission is inefficient but resulted in several hospital outbreaks of MERS (Assir et al., 2013; Harriman et al., 2013; Memish et al., 2013), and there is concern that the virus may adapt to humans and cause a pandemic.

Infection of dromedary camels with MERS- $\mathrm{CoV}$ is not limited to the Middle East. African camels are frequently infected with MERS-CoV (Al et al., 2017a, 2017b; Chu et al., 2014, 2015, 2018; Corman et al., 2014; Deem et al., 2015; Kiambi et al., 2018; Miguel et al., 2017; Omme et al., 2018; Perera et al., 2013; Reusken et al., 2013, 2014; van Doremalen et al., 2017) and the responsible viruses are genetically distinct from those circulating in the Middle East (Chu et al., 2018; Kiambi et al., 2018; Ommeh et al., 2018). Moreover, viruses isolated from animals in Morocco, Nigeria and Burkina Faso form a distinct phylogenetic subclade, $\mathrm{C} 1$, and exhibit reduced ability to replicate in human respiratory cells (Chu et al., 2018). In addition, MERS-CoV transmission from camels to humans has not been observed in Northand West-Africa (Munyua et al., 2017; So et al., 2018), although two livestock handlers in Kenya were shown to harbor antibodies against MERS-CoV (Liljander et al., 2016), Moreover, no MERS cases were documented in Africa. At present, the barrier(s) impeding efficient spread of African MERS-CoV in human cells and camel-human transmission of these viruses remain to be identified.

The MERS-CoV spike protein (S) is incorporated into the viral envelope and facilitates viral entry into target cells (Li, 2016). For this, the $S$ protein binds to the cellular receptor dipeptidyl peptidase 4 (DPP4, CD26) (Raj et al., 2013) via its surface unit, S1, and fuses the viral membrane with a target cell membrane via its transmembrane unit, S2 (Li, 2016). Binding of MERS-S to DPP4 is essential for MERS-CoV infection of cells and DPP4 expression and the S protein/DPP4 interface are major determinants of MERS-CoV cell and species tropism (Raj et al., 2013; van Doremalen et al., 2014). The S proteins of North- and West-African MERS-CoV of the C1 clade harbor 6-9 amino acid substitutions relative to MERS-CoV (Fig. 1A, Table 1) and these substitutions might reduce $\mathrm{S}$ protein-driven entry into target cells. However, this possibility has not been examined so far.

\section{Results}

We employed a previously described vesicular stomatitis virus (VSV)-based pseudotyping system to study MERS-S-driven host cell entry (Kleine-Weber et al., 2018, 2019). Pseudotyping systems are

Corresponding author. Infection Biology Unit, Deutsches Primatenzentrum - Leibniz Institute for Primate Research, Kellnerweg 4, 37077 Göttingen, Germany. E-mail address: spoehlmann@dpz.eu (S. Pöhlmann).

https://doi.org/10.1016/j.virol.2019.07.016

Received 14 June 2019; Received in revised form 15 July 2019; Accepted 18 July 2019

Available online 19 July 2019

0042-6822/ (C) 2019 Elsevier Inc. All rights reserved. 
A)

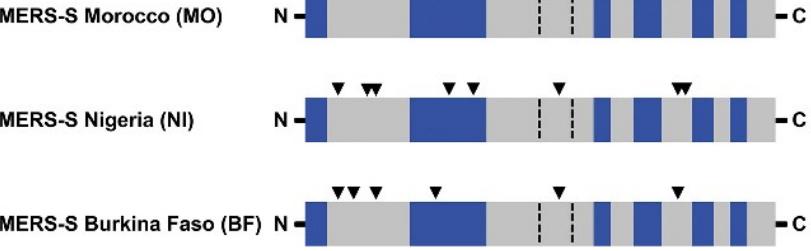

B)

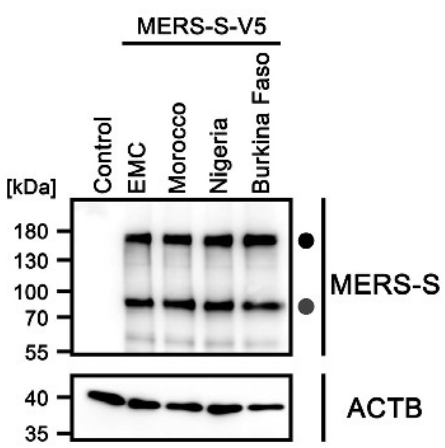

WCL
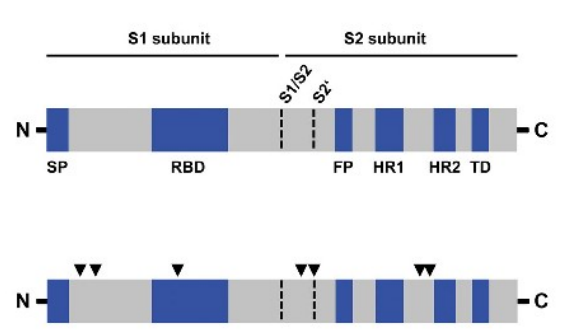

C)

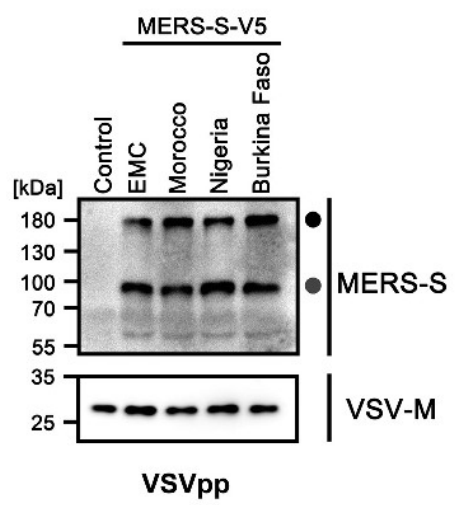

Fig. 1. S proteins of North/West- and WestAfrican MERS-CoV isolates from dromedary camels are robustly expressed in human cells and efficiently incorporated into viral particles. (A) Domain organization of the MERS-S proteins studied here. Black arrowheads indicate amino acid variations found in $\mathrm{S}$ proteins of African viruses as compared to the $S$ protein of the prototypic Arabian MERS-CoV strain, human betacoronavirus 2c EMC/2012 (GenBank: JX869059.2). Abbreviations: SP = signal peptide, $\quad \mathrm{RBD}=$ receptor binding domain, FP = fusion peptide, HR1/HR2 = heptad repeat $1 / 2, \mathrm{TD}=$ transmembrane domain. (B) The indicated $\mathrm{S}$ proteins were transiently expressed in $293 \mathrm{~T}$ cells, whole cell lysates (WCL) were prepared at $48 \mathrm{~h}$ posttransfection and $\mathrm{S}$ protein expression was analyzed via Western blot, using an presiody torgeting the C-terminal V5-tag. Cells antibody targeting the C-terminal V5-tag. Cells expressing no $S$ protein were used as negative control and detection of $\beta$-actin (ACTB) served as loading control. Similar results were obtained in two separate experiments. (C) Rhabdoviral transduction vectors (VSVpp) harboring the indicated $\mathrm{S}$ proteins were concentrated by centrifugation and, following lysis, analyzed by Western blot for S protein incorporation, using Trang Transduction vectors harboring no $S$ protein were used as negative controls and detection of vesicular stomatitis virus matrix protein (VSVM) served as loading control. Similar results were obtained in a separate experiment. Numbers on the left side of each blot indicate the molecular weight in kilodalton (kDa). Further, bands representing the precursor $\mathrm{S}$ protein (SO, black circle) and the $S 2$ subunit of protein (so, black circle) and the $S 2$ subunit of proteolytically processed S protein (grey circle)
are indicated. known to adequately model key aspects of the coronavirus entry process. In order to study host cell entry driven by S proteins from the C1 subclade, we employed PCR-based mutagenesis to generate expression constructs for the S proteins of MERS-CoV from Morocco (camel/Morocco/CIRAD-HKU213/2015, MO), Nigeria (camel/Nigeria/NV1657/ 2016, NI) and Burkina Faso (camel/Burkina Faso/CIRAD-HKU785/ 2015, BF), using a published expression construct for MERS-CoV EMC S protein as template (Kleine-Weber et al., 2018, 2019). Moreover, expression constructs for all $\mathrm{S}$ proteins were generated that encoded a Cterminal v5 antigenic tag. Western blot analysis of cells transfected to express the $\mathrm{S}$ proteins under study revealed that MERS-S EMC, MO, NI and $\mathrm{BF}$ were expressed and proteolytically processed to comparable levels (Fig. 1B). Moreover, these S proteins were incorporated into VSV particles with similar efficiency (Fig. 1C). These results suggest that mutations present in North- and West-African MERS-S of the C1 subclade do not reduce S protein expression and proteolytic processing in human cells.

We next asked whether DPP4 binding of North- and West-African MERS-S was altered. For this, 293T cells transfected to express the S proteins under study were incubated with soluble DPP4 fused to the Fc portion of human immunoglobulin and binding was quantified by flow cytometry, as described previously (Kleine-Weber et al., 2019). The results showed that MERS-S EMC, MO, NI, and BF bound to DPP4 robustly and with comparable efficiency while DPP4 binding to cells expressing no $S$ protein was within the background range (Fig. 2). Finally, we tested whether the robust binding to DPP4 translated into efficient S protein-driven entry. For this, cell lines were selected that were shown to express low levels (293T), intermediate levels (Vero 76) or high levels of DPP4 (Caco-2, 293T + DPP4) (Kleine-Weber et al., 2019). MERS-S MO, NI and BF mediated entry into all cell lines with at least the same efficiency as MERS-S EMC (Fig. 3). Moreover, under conditions of low or medium DPP4 expression, entry mediated by MERS-S $\mathrm{MO}$ and $\mathrm{BF}$ was even more efficient than entry mediated by MERS-S EMC (Fig. 3), although these differences were not statistically significant.

\section{Discussion}

Our results show that amino acid substitutions present in North- and West-African MERS-S proteins relative to MERS-S EMC do not compromise S protein expression in human cells, at least when transfected cells are examined. Similarly, proteolytic processing of the S proteins in the constitutive secretory pathway, which is known to be carried out by furin (Gierer et al., 2015; Millet and Whittaker, 2014), was not 
Table

Amino acid variations between MERS-S EMC and the S proteins of MERS-CoV of North/West- and West-African dromedary camels.

\begin{tabular}{|c|c|c|}
\hline $\mathrm{S}$ protein & Variation $^{n}$ & Localization $^{\mathrm{b}}$ \\
\hline \multirow{7}{*}{$\begin{array}{l}\text { MERS-S MO camel/Morocco/CIRAD-HKU213/2015 } \\
\text { GenBank: MG923469.1 }\end{array}$} & V26A & $\mathrm{S} 1 / \mathrm{n} / \mathrm{a}$ \\
\hline & A89S & $\mathrm{S} 1 / \mathrm{n} / \mathrm{a}$ \\
\hline & T424I & $\mathrm{S} 1 / \mathrm{RBD}$ \\
\hline & S856Y & $\mathrm{S} 2 / \mathrm{n} / \mathrm{a}$ \\
\hline & R884L & $\mathrm{S} 2 / \mathrm{PS}\left(\mathrm{S2}^{\prime}\right)$ \\
\hline & A1158S & $\mathrm{S} 2 / \mathrm{n} / \mathrm{a}$ \\
\hline & V1209L & $\mathrm{S} 2 / \mathrm{n} / \mathrm{a}$ \\
\hline \multirow{8}{*}{$\begin{array}{l}\text { MERS-S NI camel/Nigeria/NV1657/2016 GenBank: } \\
\text { MG 923475.1 }\end{array}$} & V26A & $\mathrm{S} 1 / \mathrm{n} / \mathrm{a}$ \\
\hline & H167Y & $\mathrm{S} 1 / \mathrm{n} / \mathrm{a}$ \\
\hline & H194Y & $\mathrm{s} 1 / \mathrm{n} / \mathrm{a}$ \\
\hline & L495F & $\mathrm{S} 1$ / RBD \\
\hline & L588F & $\mathrm{S} 1 / \mathrm{RBD}$ \\
\hline & S856Y & $\mathrm{S} 2 / \mathrm{n} / \mathrm{a}$ \\
\hline & A1 158L & $\mathrm{S} 2 / \mathrm{n} / \mathrm{a}$ \\
\hline & L1200F & $\mathrm{S} 2 / \mathrm{n} / \mathrm{a}$ \\
\hline \multirow{6}{*}{$\begin{array}{l}\text { MERS-S BF camel/Burkina Faso/CIRAD-HKU785/ } \\
2015 \text { GenBank: MG923471.1 }\end{array}$} & V26A & $\mathrm{S} 1 / \mathrm{n} / \mathrm{a}$ \\
\hline & A89S & $\mathrm{S} 1 / \mathrm{n} / \mathrm{a}$ \\
\hline & H194Y & $\mathrm{S} 1 / \mathrm{n} / \mathrm{a}$ \\
\hline & T424I & $\mathrm{S} 1 / \mathrm{RBD}$ \\
\hline & S856Y & $\mathrm{S} 2 / \mathrm{n} / \mathrm{a}$ \\
\hline & A1158S & $\mathrm{S} 2 / \mathrm{n} / \mathrm{a}$ \\
\hline
\end{tabular}

a Amino acid position (numbering according to MERS-S EMC).

b Subunit / Functional domain (if applicable); Abbreviations: S1 = S1 subunit; $\mathrm{S} 2=\mathrm{S} 2$ subunit; $\mathrm{RBD}=$ receptor binding domain, $\mathrm{PS}\left(\mathrm{S} 2^{\prime}\right)=$ priming site at the S2' position (884-RSAR-887), $\mathrm{n} / \mathrm{a}=$ not applicable.

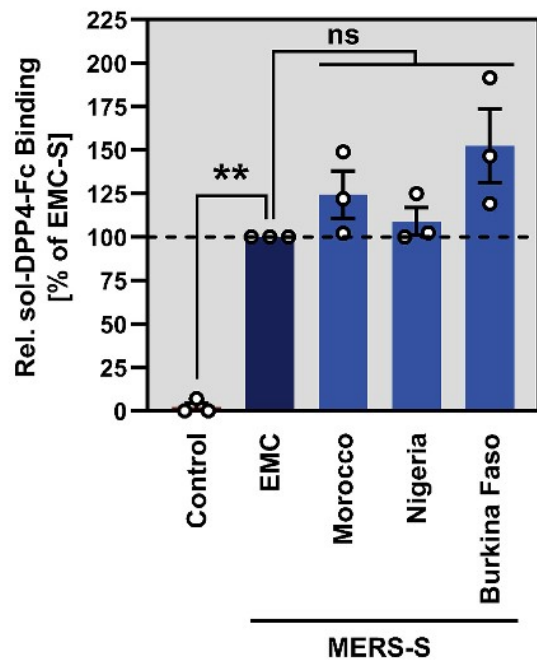

Fig. 2. S proteins of North/West- and West-African MERS-CoV isolates from dromedary camels efficiently bind to DPP4. 293T cells expressing the indicated $\mathrm{S}$ proteins or no $\mathrm{S}$ protein at all (Control) were successively incubated with soluble DPP4 containing a C-terminal Fc tag (sol-DPP4-Fc) and AlexaFluor488conjugated anti-human antibody, before DPP4 binding to the respective S protein was analyzed by flow cytometry. Presented are the combined data of three independent experiments for which sol-DPP4-Fc binding to MERS-S EMC was set as $100 \%$. Error bars indicate the standard error of the mean (SEM). Statistical significance was tested by one-way analysis of variance with Sidak's posttest ( $\mathrm{p}>0.05$, not significant, ns; $\left.\mathrm{p} \leq 0.01,{ }^{* *}\right)$.

appreciably altered. Moreover, binding of North- and West-African S proteins to DPP4 was not diminished as compared to MERS-S EMC, despite the presence of at least one substitution in the receptor binding domain (RBD) in each S protein tested. This finding might not be unexpected since the substituted amino acid residues do not make direct contact with residues in DPP4 (Lu et al., 2013). In keeping with these observations, all African $\mathrm{S}$ proteins mediated robust viral entry into non-human primate (Vero 76) and human cell lines (293T, Caco-2) expressing different levels of DPP4 (Kleine-Weber et al., 2019). In fact, MERS-S MO- and BF-driven entry into cell lines expressing low or intermediate levels of DPP4 was augmented as compared to MERS-S EMC, in keeping with these S proteins showing slightly enhanced DPP4 binding as compared to MERS-S EMC. Finally, it is noteworthy that MERS-S activation in Caco-2 cells mainly depends on the cellular serine protease TMPRSS2 while activation in 293T and Vero 76 cells is mediated by the cellular cysteine protease cathepsin L (Kleine-Weber et al., 2018, 2019). Thus, North- and West-African MERS-S proteins seem to be able to use both pathways available for S protein activation in human cells.

Confirmation of our findings with authentic viruses is pending and we cannot exclude that, for instance, the $\mathrm{S}$ protein modulates recognition of the virus by sensors of the interferon system, which cannot be measured with the assays available to us. Moreover, we note that a recent study examining two MERS-S sequences (C2 subclade) from camels in Ethiopia demonstrated that these sequences, when inserted into MERS-CoV EMC, reduced viral entry and replication and increased sensitivity to antibody-mediated neutralization (Shirato et al., 2019). The reduction in entry was observed for Vero and to a lesser degree for Vero-TMPRSS2 cells and was generally modest. Nevertheless, these results suggest that $\mathrm{S}$ proteins from viruses circulating in Ethiopia might harbor mutations that diminish entry into human cells and that are not present in the MERS-S proteins studied here. Amino acid residues I139, L515, E851 and S1302 in the spike protein are unique to Ethiopian MERS-CoV and warrant further analysis.

Collectively, our results suggest that amino acid substitutions present in the S proteins of North- and West-African MERS-CoV do not compromise the ability of these viruses to enter human cells. Thus, future efforts to understand why North- and West-African MERS-CoV isolates show reduced replicative potential in human cells should be focused on other aspects of the MERS-CoV lifecycle than S proteinmediated host cell entry.

\section{Materials and methods}

\subsection{Plasmids}

Expression plasmids, based on the vector pCAGGS, for VSV-G and MERS-S EMC were previously described (Kleine-Weber et al., 2018, 2019). The MERS-S EMC plasmid was used as template for PCR-based mutagenesis to introduce the mutations found in MERS-S MO (Morocco, camel/Morocco/CIRAD-HKU213/2015, GenBank: MG923469.1), NI (Nigeria, camel/Nigeria/NV1657/2016, GenBank: MG923475.1) and BF (Burkina Faso, camel/Burkina Faso/CIRAD-HKU785/2015, GenBank: MG923471.1) (Table 1). In addition, PCR-based mutagenesis was used to equip the constructs with a C-terminal V5 antigenic tag. The integrity of all sequences was verified using automated sequence analysis.

\subsection{Cell culture}

293T (human embryonal kidney) and Vero 76 (African green monkey kidney) cells were cultivated in Dulbecco's modified Eagle's medium (DMEM; PAN Biotech). The human colorectal adenocarcinoma cell line Caco-2 was grown in Minimum Essential Media (MEM, Life Technologies). All media were supplemented with $10 \%$ fetal bovine serum (FBS, PAN Biotech) and 1 $\mathrm{x}$ penicillin and streptomycin from a 100x stock solution (Pan Biotech). The cells were incubated under humid conditions at $37^{\circ} \mathrm{C}$ and $5 \% \mathrm{CO}_{2}$. For transfection of $293 \mathrm{~T}$ cells the calcium-phosphate precipitation method was used. 
293T

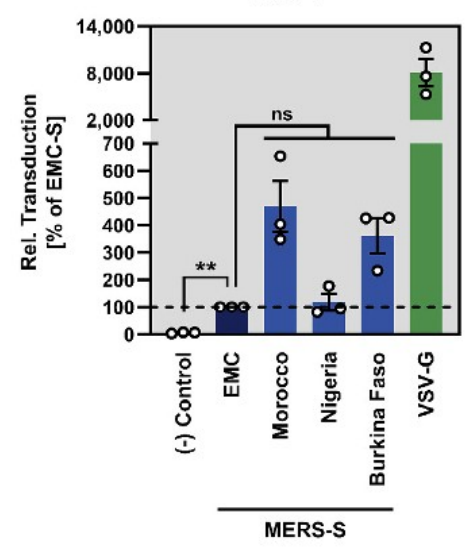

Vero 76

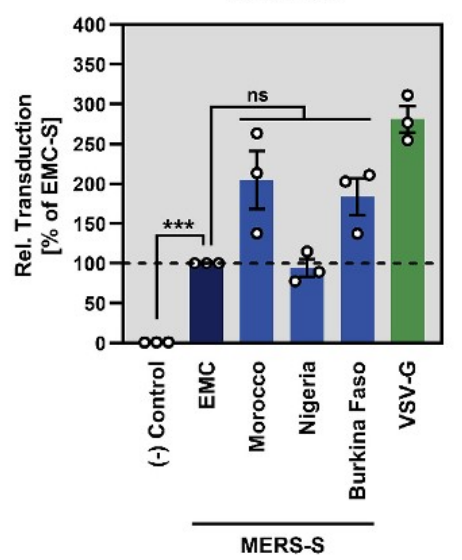

$293 T+$ DPP4

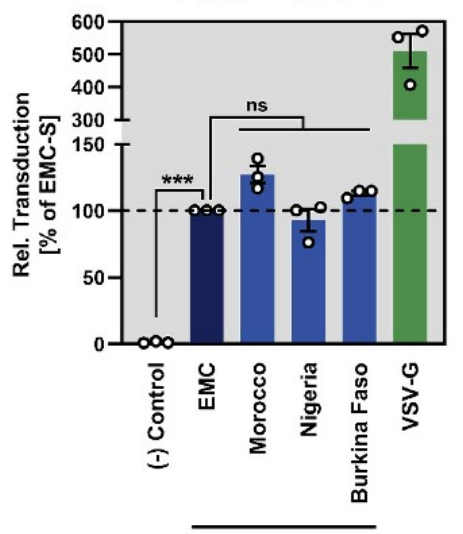

MERS-S

Caco-2

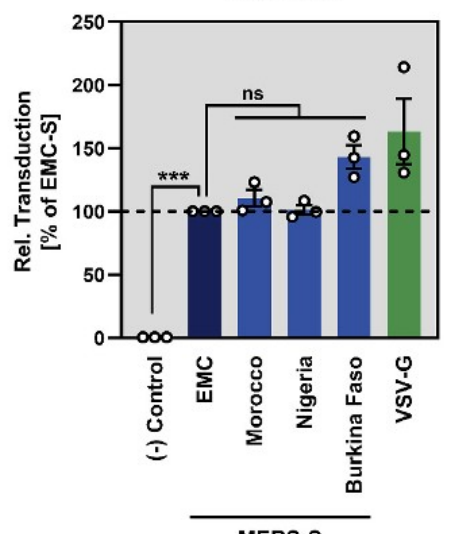

\subsection{Antibodies and DPP4-Fc fusion protein}

For Western blot analysis, anti-V5 (mouse, 1:2,500; ThermoFisher Scientific), anti- $\beta$-actin (mouse, 1:2,500; Sigma-Aldrich), anti-VSV-M (mouse, 1:2,500; Kerafast) were used as primary antibodies and antimouse HRP (horse radish peroxidase) conjugated antibody (goat, 1:2,500; Dianova) was used as secondary antibody. Antibodies were diluted in phosphate buffered saline [PBS] containing 0.5\% Tween 20 [PBS-T] supplemented with $5 \%$ skim milk powder. For flow cytometry, a recombinant fusion protein of the ectodomain of DPP4 fused to the Fc fragment of human immunoglobulin (sol-DPP4-Fc, 1:200, ACROBiosystems) and an AlexaFlour488-conjugated anti-human antibody (goat, 1:500; ThermoFisher Scientific) were used (ligand and antibody were diluted in PBS containing $1 \%$ bovine serum albumin).

4.4. Immunoblot analysis of MERS-S expression and particle incorporation

For analysis of S protein expression, 293T cells were transfected with expression plasmid for MERS-S proteins harboring a C-terminal V5 tag, as described (Kleine-Weber et al., 2018, 2019). To investigate MERS-S incorporation into VSVpp, equal volumes of supernatants
Fig. 3. Host cell entry driven by the $S$ proteins of North/West- and West-African MERS-CoV isolates from dromedary camels is robust. 293T, 293T transfected to express DPP4, Vero 76 and Caco-2 cells were inoculated with equal volumes of rhabdoviral transduction vectors harboring the indicated $\mathrm{S}$ proteins or no $\mathrm{S}$ protein (Control). At $18 \mathrm{~h}$ posttransduction, the activity of the virus-encoded luciferase, which served as an indicator for transduction efficiency, was measured in cell lysates. Presented are the combined data of three independent experiments for which transduction mediated by MERS-S EMC was set as $100 \%$. Error bars indicate SEM. Statistical significance was tested by one-way analysis of variance (ANOVA) with Sidak's posttest $\left(\mathrm{p}>0.05, \mathrm{~ns} ; \mathrm{p} \leq 0.01\right.$, ${ }^{* *}$; $\left.\mathrm{p} \leq 0.005,{ }^{k * k}\right)$.

containing VSVpp bearing S proteins with V5 tag were centrifuged through a $20 \%$ sucrose cushion at $25.000 \mathrm{~g}$ for $120 \mathrm{~min}$. Subsequently, cells and VSVpp pellets were lysed and analyzed by immunoblot, following an established protocol (Kleine-Weber et al., 2018, 2019).

\subsection{Analysis of DPP4 binding efficiency}

DPP4 binding was analyzed as described (Kleine-Weber et al., 2019). In brief, 293T cells were transfected with expression plasmids for MERS-S proteins and empty plasmid as negative control. At $48 \mathrm{~h}$ posttransfection, the cells were washed with PBS, pelleted and resuspended in PBS containing 1\% BSA and soluble human DPP4-Fc fusion protein at a final dilution of $1: 200$. After incubation for $1 \mathrm{~h}$ at $4^{\circ} \mathrm{C}$, the cells were washed and incubated with AlexaFluor488-conjugated anti-mouse antibody at a dilution of 1:500. Finally, the cells were fixed with $4 \%$ paraformaldehyde and analyzed by flow cytometry using an LSR II flow cytometer and the FACS Diva software (both BD Biosciences). 
4.6. Production of VSV pseudoparticles (VSVPp) and transduction of target cells

Transduction vectors based on a replication-deficient VSV (Berger Rentsch and Zimmer, 2011) and pseudotyped with the indicated viral glycoproteins (VSVpp) were generated according to a published protocol (Kleine-Weber et al., 2018, 2019). Target cells were transduced with equal volumes of supernatants containing VSVpp and transduction efficiency was quantified at $16 \mathrm{~h}$ posttransduction by measuring the activity of virus-encoded firefly luciferase in cell lysates as previously described (Kleine-Weber et al., 2018, 2019).

\section{Acknowledgements}

The authors thank Gert Zimmer and Andrea Maisner for providing the replication-deficient VSV vector for pseudotyping and the Vero 76 cell line, respectively. This work was supported, including the efforts of Stefan Pöhlmann, by the Bundesministerium für Bildung und Forschung within the network project RAPID (Risikobewertung bei präpandemischen respiratorischen Infektionserkrankungen; 01KI1723D). The funders had no role in study design, data collection and interpretation, or the decision to submit the work for publication.

\section{References}

Ali, M., El-Shesheny, R., Kandeil, A., Shehata, M., Elsokary, B., Gomaa, M., Hassan, N., El Sayed, A., El-Taweel, A., Sobhy, H., Fasina, F.O., Dauphin, G., El Masry, I, Wolde, A.W., Daszak, P., Miller, M., VonDobschuetz, S., Morzaria, S., Lubroth, J., Makonnen, Y.J., 2017a. Cross-sectional surveillance of Middle East respiratory syndrome cor-
onavirus (MERS-CoV) in dromedary camels and other mammals in Egypt, August 2015 to January 2016. Euro Surveill. 22.

Ali, M.A., Shehata, M.M., Gomaa, M.R., Kandeil, A., El-Shesheny, R., Kayed, A.S., ElTaweel, A.N., Atea, M., Hassan, N., Bagato, O., Moatasim, Y., Mahmoud, S.H., Kutkat, ., Maatouq, A.M., Osman, A., McKenzie, P.P., Webby, R.J., Kayali, G., 2017b.

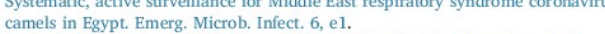

Asiri, A., Mceeer, A., Pert, T.M., Price, C.S., Al Rabeeah, A.A., Cummings, D.A., R. Al-Tawfig, J.A. Cotten, M. Watson, S. J, Kellam, P. Zumla A. Memish, Z.A. Team, K.M.-C.I., 2013. Hospital outbreak of Middle East respiratory syndrome coronavirus. N. Engl. J. Med. 369, 407-416.

Berger Rentsch, M., Zimmer, G., 2011. A vesicular stomatitis virus replicon-based bioassay for the rapid and sensitive determination of multi-species type I interferon PLoS One 6, e25858.

Chu, D.K., Oladipo, J.O., Perera, R.A., Kuranga, S.A., Chan, S.M., Poon, L.L., Peiris, M., 2015. Middle East respiratory syndrome coronavirus (MERS-CoV) in dromedary ca mels in Nigeria, 2015. Euro Surveill. 20.

hu, D.K., Poon, L.L., Gomaa, M.M., Shehata, M.M., Perera, R.A., Abu Zeid, D., El Rifay, A.S., Siu, L.Y., Guan, Y., Webby, R.J., Ali, M.A., Peiris, M., Kayali, G., 2014. M

Chu, D.K.W Hui, K. P. Y, Perera, R, Miguel, E, Niemeyer, D., Zhao, J., Changappan

R., Dudas, G., Oladipo, J.O., Traore, A., Fassi-Fihri, O., Ali, A., Demissie, G.F., Muth, D., Chan, M.C.W., Nicholls, J.M., Meyerholz, D.K., Kuranga, S.A., Mamo, G., Zhou, Z, So, R.T.Y., Hemida, M.G., Webby, R.J., Roger, F., Rambaut, A., Poon, L.L.M., Perlman, S., Drosten, C., Chevalier, V., Peiris, M., 2018. MERS coronaviruses from
camels in Africa exhibit region-dependent genetic diversity. Proc. Natl. Acad. Sci. U. S. A. $115,3144-3149$

Corman, V.M., Jores, J., Meyer, B., Younan, M., Liljander, A., Said, M.Y., Gluecks, I., Lattwein, E., Bosch, B.J., Drexler, J.F., Bornstein, S., Drosten, C., Muller, M.A., 2014 Antibodies against MERS coronavir

Deem, S.L., Fevre, E.M., Kinnaird, M., Browne, A.S., Muloi, D., Godeke, G.J., Koopmans, M., Reusken, C.B., 2015. Serological evidence of MERS-cov antibodies in dromedary camels (Camelus dromedaries) in Laikipia County, Kenya PLoS One 10, 0140125.

Gierer, S., Muller, M.A., Heurich, A., Ritz, D., Springstein, B.L., Karsten, C.B.

Schendzielorz, A., Gnirss, K., Drosten, C., Pöhlmann, S., 2015. Inhibition of proprotein convertases abrogates processing of the middle eastern respiratory syndrome coronavirus spike protein in infected cells but does not reduce viral infectivity. J. Infect. Dis. 211, 889-897.

Harriman, K., Brosseau, L., Trivedi, K., 2013. Hospital-associated Middle East respiratory syndrome coronavirus infections. N. Engl. J. Med. 369, 176

Kiambi, S., Corman, V.M., Sitawa, R., Githinji, J., Ngoci, J., Ozomata, A.S., Gardner, E., von Dobschuetz, S., Morzaria, S., Kimutai, J., Schroeder, S., Njagi, O., Simpkin, P.,
Rugalema, G., Tadesse, Z., Lubroth, J., Makonnen, Y., Drosten, C., Muller, M.A.,
Fasina, F.O., 2018. Detection of distinct MERS-Coronavirus strains in dromedary camels from Kenya, 2017. Emerg. Microb. Infect. 7, 195.

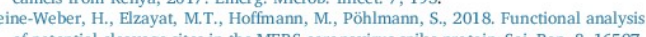
of potential cleavage sites in the MERS-coronavirus spike protein. Sci. Rep. 8, 1659 Meine-Weber, H., Elzayat, M.T., Wang, L,, Graham, B.S., Muiller, M.A., Drosten, C., espor respiratory syndrome coronavirus transmitte

Li, F., 2016. Structure, function, and evolution of coronavirus spike proteins. Annu Rev Virol 3, 237-261.

Liljander, A., Meyer, B., Jores, J., Muller, M.A., Lattwein, E., Njeru, I., Bett, B., Drosten, C., Corman, V.M., 2016. MERS-CoV antibodies in humans, Africa, 2013-2014. Emerg. Infect. Dis. 22, 1086-1089.

Lu, G., Hu, Y., Wang, Q., Qi, J., Gao, F., Li, Y., Zhang, Y., Zhang, W., Yuan, Y., Bao, J., Zhang, B., Shi, Y., Yan, J., Gao, G.F., 2013. Molecular basis of binding between novel human coronavirus MERS-CoV and its receptor CD 26. Nature 500, 227-231.

Memish, Z.A., Al-Tawfiq, J.A., Assiri, A., 2013. Hospital-associated Middle East respiratory syndrome coronavirus infections. N. Engl. J. Med. 369, 1761-1762.

Berbi, Berbri, L, Fassi-Fihri, O., Faye, B., Fekadu, G., Grosbois, V., Ng, B.C., Perera, R.A., So,
T.Y., Traore, A., Roger, F., Peiris, M., 2017. Risk factors for MERS coronavirus infection in dromedary camels in Burkina Faso, Ethiopia, and Morocco, 2015. Euro Surveill. 22.

Millet, J.K., Whittaker, G.R., 2014. Host cell entry of Middle East respiratory syndrome coronavirus after two-step, furin-mediated activation of the spike protein. Proc. Natl. Acad. Sci. U. S. A. 111, 15214-15219.

Munyua, P., Corman, V.M., Bitek, A., Osoro, E., Meyer, B., Muller, M.A., Lattwein, E., Thumbi, S.M., Murithi, R., Widdowson, M.A., Drosten, C., Njenga, M.K., 2017. No serologic evidence of middle East respiratory syndrome coronavirus infection among camel farmers exposed to highly seropositive camel herds: a household linked study,

Ommeh, S., Zhang, W., Zohaib, A., Chen, J., Zhang, H., Hu, B., Ge, X.Y., Yang, X.L., Masika, M., Obanda, V., Lao, Y., Li, S., Waruhn, C., Li, B., Zha, Y., Ouma, D., P. Ngeiywa, K.J., Yan, B., Agwanda, B., Shi, Z.L., 2018. Genetic evidence of Middle East respiratory syndrome coronavirus (MERS-Cov) and widespread seroprevalence among camels in Kenya. Virol. Sin. $33,484-492$

Perera, R.A., Wang, P., Gomaa, M.R., El-Shesheny, R., Kandeil, A., Bagato, O., Siu, L.Y., Shehata, M.M., Kayed, A.S., Moatasim, Y., Li, M., Poon, L.L., Guan, Y., Webby, R.J., Ali, M.A., Peiris, J.S., Kayali, G., 2013. Seroepidemiology for MERS coronavirus using microneutralisation and pseudoparticle virus neutralisation assays reveal a high prevalence of antibody in dromedary camels in Egypt, June 2013. Euro Surveill. 18 pii $=20574$

Raj, V.S., Mou, H., Smits, S.L., Dekkers, D.H., Muller, M.A., Dijkman, R., Muth, D., Demmers, J.A., Zaki, A., Fouchier, R.A., Thiel, V., Drosten, C., Rottier, P.J., functional receptor for the emerging human coronavirus-EMC. Nature 495, 251-254.

Reusken, C.B. Haagmans, B.L, Muller, M.A, Gutierrez, C, Godeke, G.J, Meyer, B, Muth, D., Raj, V.S., Smits-De Vries, L., Corman, V.M., Drexler, J.F., Smits, S.L, El Tahir, Y.E., De Sousa, R., van Beek, J., Nowotny, N., van Maanen, K., Hidalgo-Hermoso, E. Bosch, B.J., Rottier, P., Osterhaus, A., Gortazar-Schmidt, C., Drosten, C., Koopmans, M.P., 2013. Middle East respiratory syndrome coronavirus neutralising serum antibodies in dromedary camels: a comparative serological study. Lancet Infect. Dis. 13, 859-866.

Reusken, C.B., Messadi, L., Feyisa, A., Ularamu, H., Godeke, G.J., Danmarwa, A., Dawo, F., Jemli, M., Melaku, S., Shamaki, D., Woma, Y., Wungak, Y., Gebremedhin, E.Z.,

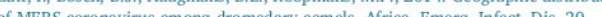
$1370-1374$.

Shirato, K, Melaku, S.K, Kawachi, K, Nao, N. Iwata-Yoshikawa, N, Kawase, M. Kamitani, W., Matsuyama, S., Tessema, T.S., Sentsui, H., 2019. Middle East re spiratory syndrome coronavirus in dromedaries in Ethiopia is Antigenically different from the Middle East isolate EMC. Front. Microbiol. 10, 1326.

So, R.T., Perera, R.A., Oladipo, J.O., Chu, D.K., Kuranga, S.A., Chan, K.H., Lau, E.H., Cheng, S.M., Poon, L.L., Webby, R.J., Peiris, M., 2018. Lack of serological evidence of Middle East respiratory syndrome coronavirus infection in virus exposed came abattoir workers in Nigeria, 2016. Euro Surveill. 23.

van Doremalen, N., Hijazeen, Z.S., Holloway, P., Al Omari, B., McDowell, C., Adney, D., Talafha, H.A., Guitian, J., Steel, J., Amarin, N., Tibbo, M., Abu-Basha, E., Al-Majali, A.M., Munster, V.J., Richt, J.A., 2017. High prevalence of Middle East respiratory 155-159.

van Doremalen, N., Miazgowicz, K.L., Milne-Price, S., Bushmaker, T., Robertson, S., Scott, Middle East respiratory syndrome coronavirus through its receptor, dipeptidyl peptidase 4. Virol. 88, 9220-9232. Who.int/emergencies/mers-cov/en/.

zaki, A.M., van Boheemen, S., Bestebroer, T.M., Osterhaus, A.D., Fouchier, R.A., 2012 Isolation of a novel coronavirus from a man with pneumonia in Saudi Arabia. N. Engl. J. Med. $367,1814-1820$ 


\title{
5.4. Fourth manuscript
}

\section{Polymorphisms in dipeptidyl peptidase 4 reduce}

\section{host cell entry of Middle East respiratory syndrome}

\section{coronavirus}

\author{
Kleine-Weber H, Schroeder S, Krüger N, Prokscha A, Naim HY, Müller MA, Drosten \\ C, Pöhlmann S, Hoffmann M.
}

Individual contribution:

In the manuscript, I conducted the experiment and analysis for Figure 2B: "DPP4 harboring polymorphic amino acid residues at the binding interface with MERS-CoV S are robustly expressed.", Figure 3: "DPP4 harboring polymorphic amino acid residues at the binding interface with MERS-CoV S are efficiently transported to the cell surface.", Figure 4: "Identification of polymorphic amino acid residues in DPP4 that do not support efficient MERS-CoV S-driven host cell entry." and Figure 5C: "Reduced MERS-CoV S-driven host cell entry is caused by inefficient S protein binding to DPP4 harboring polymorphic amino acid residues." 


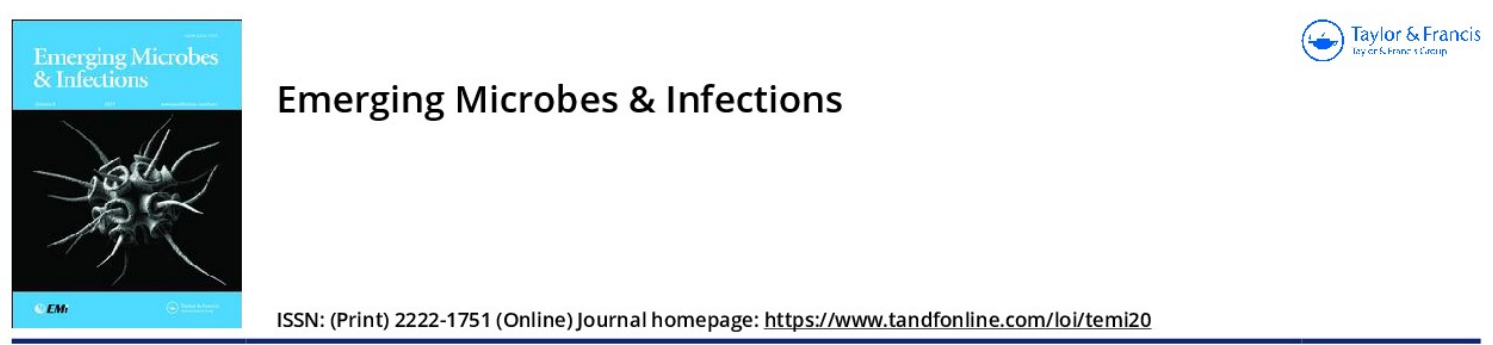

\title{
Polymorphisms in dipeptidyl peptidase 4 reduce host cell entry of Middle East respiratory syndrome coronavirus
}

\author{
Hannah Kleine-Weber, Simon Schroeder, Nadine Krüger, Alexander \\ Prokscha, Hassan Y. Naim, Marcel A. Müller, Christian Drosten, Stefan \\ Pöhlmann \& Markus Hoffmann
}

To cite this article: Hannah Kleine-Weber, Simon Schroeder, Nadine Krüger, Alexander Prokscha Hassan Y. Naim, Marcel A. Müller, Christian Drosten, Stefan Pöhlmann \& Markus Hoffmann (2020) Polymorphisms in dipeptidyl peptidase 4 reduce host cell entry of Middle East respiratory syndrome coronavirus, Emerging Microbes \& Infections, 9:1, 155-168, DOI: 10.1080/22221751.2020.1713705 To link to this article: https://doi.org/10.1080/22221751.2020.1713705
(2) 2020 The Author(s). Published by Informa UK Limited, trading as Taylor \& Francis Group, on behalf of Shanghai Shangyixun Cultural Communication Co., Ltc
Published online: 21 Jan 2020.

Цlll Article views: 3196
+ View supplementary material $[7$

Submit your article to this journal $\sqsubset$

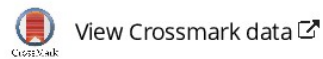




\section{Polymorphisms in dipeptidyl peptidase 4 reduce host cell entry of Middle East respiratory syndrome coronavirus}

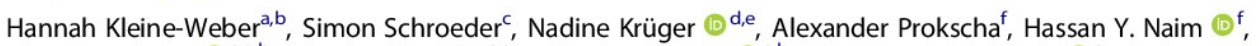

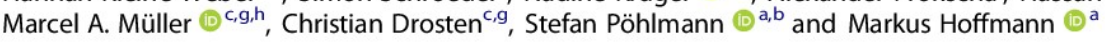

anfection Biology Unit, German Primate Center, Göttingen, Germany; ${ }^{b}$ Faculty of Biology and Psychology, University Göttingen, Göttingen, Germany; ' ${ }^{C}$ Charité-Universitätsmedizin Berlin, corporate member of Freie Universität Berlin, Humboldt-Universität zu Berlin, and Berlin Institute of Health, Institute of Virology, Berlin, Germany; ${ }^{\mathrm{d}}$ Institute of Virology, University of Veterinary Medicine Hannover, Hannover, Germany; ${ }^{e}$ Research Center for Emerging Infections and Zoonoses, University of Veterinary Medicine Hannover, Hannover, Germany; 'Department of Physiological Chemistry, University of Veterinary Medicine Hannover, Hannover, Germany; ${ }^{9}$ German Centre for Infection Department of Physiological Chemistry, University of Veterinary Medicine Hannover, Hannover, Germany; ${ }^{9}$ German Centre for Infection
Research, associated partner Charité, Berlin, Germany; 'Martsinovsky Institute of Medical Parasitology, Tropical and Vector Borne Diseases, Sechenov University, Moscow, Russia

\section{ABSTRACT}

Middle East respiratory syndrome (MERS) coronavirus (MERS-COV) causes a severe respiratory disease in humans. The MERS-CoV spike (S) glycoprotein mediates viral entry into target cells. For this, MERS-CoV $S$ engages the host cell protein dipeptidyl peptidase 4 (DPP4, CD26) and the interface between MERS-CoV S and DPP4 has been resolved on the atomic level. Here, we asked whether naturally-occurring polymorphisms in DPP4, that alter amino acid residues required for MERS-CoV S binding, influence cellular entry of MERS-CoV. By screening of public databases, we identified fourteen such polymorphisms. Introduction of the respective mutations into DPP4 revealed that all except one $(\Delta 346-$ 348 ) were compatible with robust DPP4 expression. Four polymorphisms (K267E, K267N, A291P and $\Delta 346-348$ ) strongly reduced binding of MERS-CoV S to DPP4 and S protein-driven host cell entry, as determined using soluble S protein and S protein bearing rhabdoviral vectors, respectively. Two polymorphisms (K267E and A291P) were analyzed in the context of authentic MERS-CoV and were found to attenuate viral replication. Collectively, we identified naturally-occurring polymorphisms in DPP4 that negatively impact cellular entry of MERS-CoV and might thus modulate MERS development in infected patients.

ARTICLE HISTORY Received 18 August 2019; Revised 17 December 2019; Accepted 1 January 2020

KEYWORDS Middle East respiratory syndrome coronavirus; spike glycoprotein; dipeptidyl peptidase 4; polymorphisms; receptor binding

\section{Introduction}

Middle East respiratory syndrome coronavirus (MERS$\mathrm{CoV}$ ) is an enveloped virus with a single-stranded RNA genome of positive polarity. It belongs to the Coronaviridae family (genus Betacoronavirus), which is part of the order Nidovirales. MERS-CoV was isolated in 2012 from the sputum of a 60 year old man suffering from acute pneumonia and renal failure in Saudi Arabia [1]. Since its discovery, MERS-CoV has caused 2,442 human infections of which $842(34.5 \%)$ had a fatal outcome (as of May, 2019) [2]. Dromedary camels are reservoir hosts of MERS-CoV and display only common cold-like symptoms upon infection but constitute the main source of human infections. Transmission to humans occurs via close contact to animals or contaminated animal products [3-6]. Human-to-human transmissions seem limited and were mainly observed in health care settings, leading to MERS outbreaks in hospitals [7-12]. Finally, differences in the tissue specific expression of the cellular receptor for MERS-CoV, DPP4, were recently suggested to account for the differences in MERS$\mathrm{CoV}$ transmission and disease induction in camels and humans, respectively $[13,14]$.

In order to infect a host (cell) and replicate, MERS$\mathrm{CoV}$ has to deliver its genome into the cellular cytoplasm for gene translation and genome replication. This process is facilitated by the viral spike (S) glycoprotein, a type-I transmembrane protein embedded in the viral envelope. For host cell entry, the surface unit, S1, of MERS-CoV S binds to the cellular type-II transmembrane protein dipeptidyl peptidase 4 (DPP4, CD26) [15]. The structure of the interface between DPP4 and MERS-CoV-S was resolved on the atomic level and fifteen residues in DPP4 were found to make direct contact with residues in the viral S protein [16]. Upon DPP4 engagement, MERS$\mathrm{CoV} S$ undergoes proteolytic activation through the

CONTACT Markus Hoffmann 0 mhoffmann@dpz.eu 20 Infection Biology Unit, German Primate Center, Göttingen, Germany; Stefan Pöhlmann (2) spoehlmann@dpz.eu 20 Infection Biology Unit, German Primate Center, Göttingen, Germany; Faculty of Biology and Psychology, University Göttingen, Göttingen, Germany

(4) Supplemental data for this article can be accessed https://doi.org/10.1080/22221751.2020.1713705

- 2020 The Author(s). Published by Informa UK Limited, trading as Taylor \& Francis Group, on behalf of Shanghai Shangyixun Cultural Communication Co., Ltd This is an Open Access article distributed under the terms of the Creative Commons Attribution License (http://creativecommonsorg/icenses/by/40/) which permits unrestricted use, distribution, and reproduction in any medium, provided the original work is properly cited.
und 
cellular serine protease TMPRSS2 or the endosomal cysteine protease cathepsin L [17-19], which allows the transmembrane unit, S2, of MERS-CoV S to fuse the viral membrane with cellular membranes.

DPP4 is a prolyl oligopeptidase that is expressed in various tissues [20] and involved in multiple biological processes including T-cell activation [21], control of the activity of growth factors, chemokines and bioactive peptides [22-24], and regulation of the glucose metabolism [25]. Mature DPP4 is embedded in the plasma membrane as a homodimer and each monomer consists of an N-terminal cytoplasmic domain, followed by a transmembrane domain and a large ectodomain, which can be further subdivided into a short stalk domain, a glycosylation-rich and a cysteine-rich region as well as the $\mathrm{C}$-terminal catalytic domain ( $\alpha$ / $\beta$-hydrolase domain) [26]. Polymorphisms in the DPP4 gene were implicated in several diseases and conditions, including diabetes $[27,28]$ and myocardial infarction [29] but their potential impact on MERS$\mathrm{CoV}$ infection has not been analyzed.

We asked whether naturally-occurring amino acid polymorphisms in DPP4 residues making contact with MERS-CoV S have an impact on MERS-CoV entry. We identified fourteen polymorphisms by screening public databases and introduced the respective mutations into a DPP4 expression plasmid. We identified four mutations that reduced MERS-CoV S binding to DPP4 and MERS-CoV S-driven host cell entry without affecting DPP4 expression at the cell surface.

\section{Materials and methods}

\section{Analysis of total DPP4 expression by SDS-PAGE} and immunoblot

293T cells were transfected with expression vectors for WT or mutant DPP4, or empty expression vector (negative control). At $16 \mathrm{~h}$ post transfection, the culture medium was replaced and the cells were further incubated for additional $32 \mathrm{~h}$. Then, the cells were washed with PBS and mixed with $2 \mathrm{x}$ SDS-sample buffer (0.03 M Tris- $\mathrm{HCl}, 10 \%$ glycerol, $2 \%$ SDS, $0.2 \%$ bromophenol blue, $1 \mathrm{mM}$ EDTA). Cell lysis was achieved by incubating the samples for $10 \mathrm{~min}$ at room temperature followed by incubation at $96{ }^{\circ} \mathrm{C}$ for an additional $10 \mathrm{~min}$. The samples were further loaded on polyacrylamide gels and SDS-PAGE (sodium dodecyl sulfate-polyacrylamide gel electrophoresis) was performed. Next, the proteins were transferred onto nitrocellulose membranes (Hartenstein $\mathrm{GmbH}$ ) by immunoblotting. The membranes were further blocked by incubation in PBS-T (PBS containing $0.5 \%$ Tween 20 and $5 \%$ skim milk powder) for $30 \mathrm{~min}$ at room temperature. Afterwards, the membranes were incubated overnight at $4{ }^{\circ} \mathrm{C}$ with undiluted supernatant of a hybridoma cell line secreting anticMYC antibody 9E10 (for DPP4 detection) or PBS-T containing anti- $B$-actin (ACTB) antibody (mouse, 1:1,000, Sigma Aldrich). Following three washing intervals with PBS-T, the membranes were further incubated with PBS-T containing horseradish peroxidaseconjugated anti-mouse antibody (goat, 1:5,000, Dianova) for $1 \mathrm{~h}$ at room temperature before an in house-prepared enhanced chemiluminescent solution (0.1 M Tris- $\mathrm{HCl}$ [pH 8.6], $250 \mu \mathrm{g} / \mathrm{ml}$ luminol, $1 \mathrm{mg} /$ $\mathrm{ml}$ para-hydroxycoumaric acid, $\left.0.3 \% \quad \mathrm{H}_{2} \mathrm{O}_{2}\right)$ was added and signals were recorded using the ChemoCam imaging system and the ChemoStar Professional software (Intas Science Imaging Instruments $\mathrm{GmbH}$ ).

In order to quantify the signal intensity of the protein bands, the program ImageJ (FIJI distribution) [30] was used. To account for differences in the total protein content of the samples and variations, we normalized the DPP4 signals against the respective signals of the loading control (ACTB).

\section{Cell culture}

293T (human kidney cells, DSMZ no. ACC 635), BHK21 (hamster kidney cells, DSMZ no. ACC 61) and Vero 76 (African green monkey kidney cells, kindly provided by Andrea Maisner, Philipps-University Marburg) were cultivated in Dulbecco's modified Eagle medium (PAN-Biotech) while Caco-2 cells (human colorectal adenocarcinoma cells) were cultivated in Minimum Essential Medium (ThermoFisher Scientific). The media were supplemented with $10 \%$ fetal bovine serum (Biochrom), $100 \mathrm{U} / \mathrm{ml}$ of penicillin and $0.1 \mathrm{mg} / \mathrm{ml}$ of streptomycin (PAN-Biotech). All cell lines were incubated at $37{ }^{\circ} \mathrm{C}$ and $5 \% \mathrm{CO} 2$ in a humidified atmosphere. For subcultivation and seeding, cells were washed with phosphate-buffered saline (PBS) and detached by incubation with trypsin/ EDTA solution (PAN-Biotech) (BHK-21, Vero 76 and Caco-2) or by resuspending the cells in culture medium (293T). Transfection of 293T and BHK-21 cells was carried out by calcium-phosphate precipitation or with the help of ICAFectin-441 (In-CellArt) or FuGENE HD (Promega).

\section{Plasmids and generation of DPP4 mutants}

All DPP4 mutants were generated based on a pcDNA3.1/Zeo(+)-based expression vector in which the coding sequence for human DPP4 (GenBank: XM_005246371.3) containing an C-terminal cMYC epitope was inserted into via BamHI/EcoRI restriction sites. The following aa (amino acid) substitutions were introduced via overlap-extension PCR: K267E, K267N, Q286K, T288I, T288S, A289V, A291P, A291V, R317K $\mathrm{Y} 322 \mathrm{H}, \mathrm{I} 346 \mathrm{~T}, \mathrm{I} 346 \mathrm{~V}$ and K392N. In addition, a deletion mutant was generated that lacks aa residues 
346-348 ( $\triangle 346-348)$. Information on DPP4 polymorphisms was retrieved from the Ensembl database (https://www.ensembl.org/index.html) [31] and the Single Nucleotide Polymorphism Database (dbSNP) of the National Center for Biotechnology Information (NCBI) (https://www.ncbi.nlm.nih.gov/snp) [32], and is based on data provided by the gnomAD database (Genome Aggregation database, https://gnomad. broadinstitute.org/), TOPMed program (Trans-Omics for Precision Medicine, https://www.nhlbiwgs.org/), ExAC consortium (Exome Aggregation Consortium, http://exac.broadinstitute.org/) [33] and the 1000G project $(1,000$ genomes project, http://www. internationalgenome.org/) [34] (For detailed information see Supplementary Table 1).

We further utilized pCAGGS-based expression vectors for vesicular stomatitis virus (VSV) glycoprotein (G), MERS-CoV S wildtype (WT) and MERS-CoV S (D510G) (the latter two either untagged or equipped with a C-terminal V5 epitope) that have been described elsewhere [35-37]. In addition, a previously described expression vector for angiotensin converting enzyme 2 was employed [38]. Similar to the strategy used for the generation of DPP4 mutants, we employed the overlap-extension PCR technique to introduce a single mutation into the MERS-CoV S open reading frame, thus generating untagged and V5-tagged MERS-CoV S (D539N).

Soluble S comprising the S1 subdomain of MERSCoV S (aa residues: 1-747) fused to a human IgG Fc tag was generated by inserting the PCR-amplified S1 sequences into the pCG1Fc vector [39] (kindly provided by Georg Herrler, University of Veterinary Medicine Hannover) making use of the BamHI/SalI restriction sites. In addition, we generated an expression vector for the enhanced green fluorescent protein (eGFP) by inserting the eGFP coding sequence, which was PCR-amplified from the $\mathrm{PEGFP}-\mathrm{C1}$ vector (Clontech), into the pCAGGS plasmid using the EcoRI/XhoI restriction sites.

All PCR-amplified sequences were subjected to automated sequence analysis (Microsynth SeqLab) to verify their integrity. Sequences of primers used for cloning of the different constructs are available upon request.

\section{Analysis of DPP4 surface expression by immunofluorescence analysis}

BHK-21 cells were grown on coverslips and transfected with the different DPP4 constructs or empty expression vector using ICAFectin-441 (In-Cell-Art) at $24 \mathrm{~h}$ post seeding according to the manufacturer's instructions. After changing the culture medium at $4 \mathrm{~h}$ post transfection, the cells were incubated for additional $20 \mathrm{~h}$. Then, the culture medium was aspirated and the cells were washed with PBS, before they were fixed by incubated with PBS containing 4\% paraformaldehyde (PBS/PFA) for $15 \mathrm{~min}$ at room temperature. Subsequently, the cells were washed with $0.1 \mathrm{M}$ glycine/ PBS solution followed by a washing step with PBS. Next, the coverslips were incubated with anti-DPP4 antibody (mouse, diluted 1:200 in PBS containing 1\% bovine serum albumin [PBS/BSA], Abcam) for $1 \mathrm{~h}$ at $4{ }^{\circ} \mathrm{C}$. For this, the coverslip was put on a drop $(20 \mu \mathrm{l})$ of antibody solution that was added on a sheet of parafilm inside a humidity chamber (a glass dish in which the parafilm was placed on wet paper tissue). Thereafter, the cells were washed $3 \mathrm{x}$ with PBS before incubation with AlexaFluor568-conjugated antimouse antibody (goat, 1:1000, diluted in PBS/BSA, ThermoFisher Scientific) for $30 \mathrm{~min}$ at $4{ }^{\circ} \mathrm{C}$ was performed. Subsequently, the cells were washed $3 \mathrm{x}$ with PBS. Finally, the cells were incubated with DAPI (4',6-diamidino-2-phenylindole, Carl Roth) and mounted in ProLong Gold Antifade Mountant (ThermoFisher Scientific) before they were analyzed using a Zeiss LSM800 (Zeiss) confocal laser scanning microscope and the ZEN imaging software (Zeiss).

\section{Analysis of DPP4 surface expression by flow cytometry}

BHK-21 cells were transfected with expression vectors for WT or mutant DPP4, or empty expression vector (negative control). At $16 \mathrm{~h}$ post transfection, the culture medium was replaced and the cells were further incubated for additional $32 \mathrm{~h}$. Then, the cells were washed with PBS, resuspended in PBS/ BSA and pelleted by centrifugation $(600 \mathrm{x}$ g, $5 \mathrm{~min}$, $4{ }^{\circ} \mathrm{C}$ ). After aspiration of the supernatant, the cells were resuspended in PBS/BSA containing anti-DPP4 antibody (mouse, diluted 1:100, Abcam) and incubated for $1 \mathrm{~h}$ at $4{ }^{\circ} \mathrm{C}$. Next, the cells were pelleted, washed with PBS/BSA, pelleted again, resuspended in PBS/BSA containing AlexaFluor488-conjugated anti-mouse antibody (donkey, diluted 1:500, ThermoFisher Scientific) and incubated for $1 \mathrm{~h}$ at $4{ }^{\circ} \mathrm{C}$. Subsequently, the cells were washed (as described above) and resuspended in PBS/PFA for $2 \mathrm{~h}$ at $4{ }^{\circ} \mathrm{C}$ for fixation. Finally, the cells were washed (as described above) and resuspended in PBS/BSA for flow cytometric analysis using an LSR II flow cytometer and the FACS Diva software (both BD Biosciences). Additional data analysis was carried out using the FCS Express 4 Flow research software (De Novo software). For quantification of DPP4 surface expression, the mean fluorescence intensity (MFI) value of the negative control was subtracted from all samples. For normalization of DPP4 surface expression, values obtained for cells expressing DPP4 WT were set as $100 \%$ and the relative surface expression of the respective DPP4 mutants was calculated accordingly. 


\section{Production of soluble MERS-CoV S and binding studies}

In order to generate soluble MERS-CoV S for binding studies, 293T cells were transfected with an expression vector for the S1 subunit of MERS-CoV S fused to the Fc fragment of human immunoglobulin G (solMERS$\mathrm{S} 1-\mathrm{Fc})$. At $24 \mathrm{~h}$ post transfection, the culture medium was exchanged and the cells were further incubated for $24 \mathrm{~h}$ before culture supernatants were harvested and freed from cellular debris by centrifugation $\left(4,700 \mathrm{x} \mathrm{g}, 10 \mathrm{~min}, 4{ }^{\circ} \mathrm{C}\right)$. The clarified supernatants were loaded on Vivaspin protein concentrator columns with a molecular weight cut-off of $30 \mathrm{kDa}$ (Sartorius) and centrifuged at $4,700 \mathrm{x}$ g at $4{ }^{\circ} \mathrm{C}$ until the sample was 10 -fold concentrated.

\section{Analysis of MERS-CoV S / DPP4 interaction with soluble MERS-CoV $s 1$ by flow cytometry}

For the binding studies with solMERS-S1-Fc, a similar protocol was followed as described for the analysis of DPP4 surface expression with the exceptions that solMERS-S1-Fc was used instead of the primary antibody ( $1: 10$ dilution in PBS/BSA) and that an AlexaFluor488conjugated anti-human antibody (goat, 1:500 dilution in PBS/BSA, ThermoFisher Scientific) was employed as the secondary antibody. BHK-21 cells transfected with expression vectors for WT or mutant DPP4, ACE2 or empty expression vector (both negative controls) were analyzed by flow cytometry for solMERSS1-Fc binding using an LSR II flow cytometer and the FACS Diva software (both BD Biosciences). Additional data analysis was carried out using the FCS Express 4 Flow research software (De Novo software). For quantification of solMERS-S1-Fc binding, the MFI value obtained for cells transfected with empty expression vector was subtracted from all samples. Further, binding of solMERS-S1-Fc to cells expressing DPP4 WT was set as $100 \%$ and the relative binding efficiencies to cells expressing the respective DPP4 mutants or ACE2 were calculated accordingly.

\section{Analysis of MERS-CoV S / DPP4 interaction by co- immunoprecipitation}

$293 \mathrm{~T}$ cells (grown in 6-well plates) were cotransfected with expression plasmids coding for solMERS-S1-Fc and WT or mutant DPP4. Cells transfected with empty expression vector instead of DPP4 or solMERS-S1-Fc (or both) served as controls. At $48 \mathrm{~h}$ posttransfection, cells were washed with PBS and lysed with $500 \mu \mathrm{l} /$ well NP40 lysis buffer $(50 \mathrm{mM}$, Tris- $\mathrm{HCl}[\mathrm{pH}$ 8.0 ], $150 \mathrm{mM} \mathrm{NaCl}, 1.0 \%$ [v/v] NP-40, 1 tablet/ $100 \mathrm{ml}$ of Complete protease inhibitor cocktail [Roche]) by incubation for $45 \mathrm{~min}$ on ice. Lysates were centrifuged for $30 \mathrm{~min}$ at $16,400 \mathrm{x}$ g at $4{ }^{\circ} \mathrm{C}$, before $400 \mu \mathrm{l}$ of the supernatant were mixed with $50 \mu \mathrm{l}$ of protein A-sepharose (1 g protein A-sepharose [Sigma-Aldrich] in $4 \mathrm{ml}$ PBS) while the residual $100 \mu \mathrm{l}$ of the cell lysate were mixed with $100 \mu \mathrm{l} 2 \mathrm{x}$ SDS-sample buffer and incubated for $15 \mathrm{~min}$ at $96^{\circ} \mathrm{C}$ (These samples were later analyzed to confirm comparable total protein levels [via detection of ACTB] as well as comparable DPP4 and solMERS-S1-Fc levels before the co-immunoprecipitation [co-IP] step.). Following incubation of the lysate/protein A-sepharose mixtures for $2 \mathrm{~h}$ at $4{ }^{\circ} \mathrm{C}$ in an overhead shaker, the samples were centrifuged for $5 \mathrm{~min}$ at $16,400 \mathrm{x}$ g at $4{ }^{\circ} \mathrm{C}$ to pellet the protein A-sepharose/solMERS-S1-Fc/DPP4-complexes. After aspiration of the supernatant, $500 \mu \mathrm{l}$ of NP40 lysis buffer (without protease inhibitors) were added and the cells were mixed by vortexing, before being centrifuged again. This washing routine was repeated three times, before finally $50 \mu \mathrm{l}$ of $2 \mathrm{x}$ SDSsample buffer were added to the pelleted complexes and the samples were further incubated for $15 \mathrm{~min}$ at $96{ }^{\circ} \mathrm{C}$. Thereafter, the samples were subjected to SDSPAGE and Western blot analysis (see above). Detection of DPP4 (lysate and co-IP samples) and ACTB (lysate samples) was carried out as described above. solMERSS1-Fc was detected (lysate and co-IP samples) by incubation with a peroxidase-conjugated anti-human antibody (goat, 1:5,000, Dianova).

Signal intensities of the protein bands were quantified as described above. Further, signals obtained for DPP4 were normalized against the respective signals for solMERS-S1-Fc in order to account for variations in transfection efficiency and sample processing.

\section{Analysis of MERS-CoV S / DPP4 interaction using soluble DPP4 Ligand}

For the binding studies with soluble DPP4, a similar protocol was followed as described for the analysis of binding of solMERS-S1-Fc with the exceptions that a soluble DPP4 fused to the $\mathrm{Fc}$ region of human IgG (solDPP4-Fc, Acro Biosystems) was used instead of solMERS-S1-Fc (1:200 dilution in PBS/BSA) and that an AlexaFluor488-conjugated anti-human antibody (goat, 1:500 dilution in PBS/BSA, ThermoFisher Scientific) was employed as the secondary antibody. 293T cells transfected with expression vectors for WT or mutant (D510G and D539N) MERS-CoV S, or empty expression vector (negative control) were analyzed by flow cytometry for solDPP4-Fc binding using an LSR II flow cytometer and the FACS Diva software (both BD Biosciences). Additional data analysis was carried out using the FCS Express 4 Flow research software (De Novo software). For quantification of solDPP4Fc binding, the MFI value obtained for cells transfected with empty expression vector was subtracted from all samples. Further, binding of solDPP4-Fc to cells expressing MERS-CoV S WT was set as $100 \%$ and the relative binding efficiencies to cells expressing the 
respective MERS-CoV S mutants were calculated accordingly.

\section{Generation of rhabdoviral pseudotypes and transduction studies}

We employed a previously described protocol for the generation of VSV pseudotype particles (VSVpp) that is based on a replication-deficient VSV vector that lacks the genetic information for VSV-G but instead contains the genetic information for eGFP and firefly luciferase (fLuc) as reporters of transduction efficiency $\left(\mathrm{VSV}^{*} \Delta \mathrm{G}\right.$-fLuc, kindly provided by Gert Zimmer, Institute of Virology and Immunology, Mittelhäusern/Switzerland) $[37,40]$. In brief, 293T cells transfected with expression vectors for MERS-CoV S, VSV-G (positive control) or empty expression vector (negative control) were inoculated with $\mathrm{VSV}^{*} \Delta \mathrm{G}$ fLuc for $1 \mathrm{~h}$ before being washed with PBS and further incubated for $16 \mathrm{~h}$ with culture medium that was supplemented with anti-VSV-G antibody (I1, mouse hybridoma supernatant from CRL-2700; ATCC) (except for cells expressing VSV-G). The produced VSVpp were inoculated onto BHK-21 cells expressing WT or mutant DPP4, or no DPP4 (empty expression vector, negative control) and incubated for 16-18 h before fluc activity in cell lysates was quantified as an indicator for transduction efficiency using the Beetle-Juice kit (PJK) and a plate luminometer (Hidex) [41]

\section{MERS-CoV infection and quantification of viral titers}

BHK-21 cells were transfected with expression vectors for wildtype or mutant DPP4 (K267E or A291P), or empty expression vector (negative control) using FuGENE HD (Promega) according to the manufacturer's instructions. At $24 \mathrm{~h}$ posttransfection, the cells were infected with MERS-CoV (Human betacoronavirus 2c EMC/2012, MERS-CoV EMC-2012, GenBank accession number: JX869059) at a multiplicity of infection of 0.01 for $1 \mathrm{~h}$. Thereafter, the inoculum was removed and the cells were washed $3 \mathrm{x}$ with PBS before fresh medium was added and the first sample (time point $0 \mathrm{~h}$ postinfection) was taken. The cells were further incubated and additional samples were taken at 24 and $48 \mathrm{~h}$ postinfection. Viral titers in the culture supernatant were analyzed by quantitative reversetranscriptase PCR, using the upE assay according to a published protocol [42]. In brief, viral RNA was isolated from cell culture supernatant using the NucleoSpin RNA Virus kit (Macherey-Nagel), reversetranscribed into cDNA using the Superscript III one step RT-PCR system (ThermoFisher Scientific) and analyzed on a LightCycler 480 qPCR cycler platform (Roche) with primers and conditions as specified for the upE assay [42]. In vitro-transcribed standard samples containing defined amounts of MERS-CoV fragments $(10,100,1,000$ and 10,000 copies) were included for absolute quantification as genome equivalents (GE).

\section{Protein structure visualization}

The DPP4 protein structure (4PV7) [43] and the structure of the complex formed by the MERS-CoV S receptor binding domain bound to DPP4 (4L72) [16] were retrieved from the Research Collaboratory for Structural Bioinformatics Protein Database (RSCB PDB, https://www.rcsb.org/). Structure visualization and colorization was performed using the YASARA software (http://www.yasara.org/index.html) [44] and UCSF Chimera version 1.14 (developed by the Resource for Biocomputing, Visualization, and Informatics at the University of California, San Francisco) [45].

\section{Statistical analysis}

One-way or two-way analysis of variance (ANOVA) with Dunnett's posttest was used to test for statistical significance. Only $p$ values of 0.05 or lower were considered statistically significant ( $p>0.05$ [ns, not significant $\left.], p \leq 0.05\left[^{*}\right], p \leq 0.01\left[{ }^{* *}\right], p \leq 0.001\left[^{* * *}\right]\right)$. For all statistical analyses, the GraphPad Prism 7 software package was used (GraphPad Software).

\section{Results}

Identification of polymorphisms in DPP4 that alter amino acid residues which make contact with MERS-CoV S

The binding interface between MERS-CoV S and the cellular receptor DPP4 was resolved by Wang and colleagues using crystallography, revealing the interacting amino acid residues for each binding partner [16]: Fourteen residues of MERS-CoV S (Y499, N501, K502, L506, D510, R511, E513, D537 G538, D539, Y540, R542, W553 and V555) interact with a total of fifteen residues in DPP4 (K267, F269, Q286, T288, A289, A291，L294，I295, H298，R317，Y322，R336, Q344, I346 and K392) [16], which are distributed over the glycosylation-rich domain and the cysteinerich domain (Figure 1A-C).

In order to identify polymorphic residues in DPP4 that contact MERS-CoV S, we screened public databases that provide information on polymorphic amino acid residues based on data derived from different bio projects (i.e. gnomAD, TOPMed, ExAC, $1000 \mathrm{G}$; more information is given in the Materials and Methods section). By this method we found that nine out of the fifteen DPP4 residues interacting with MERS-CoV S are polymorphic (K267, Q286, T288, 
A

DPP4 (CD26)

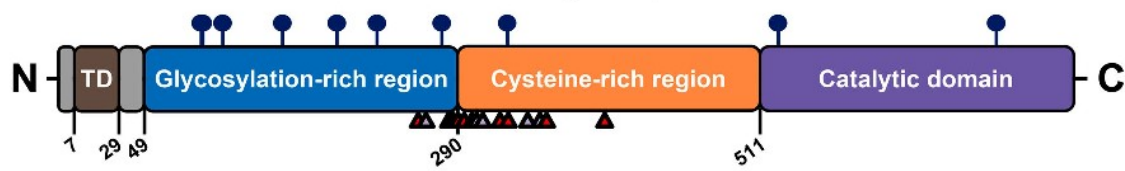

B

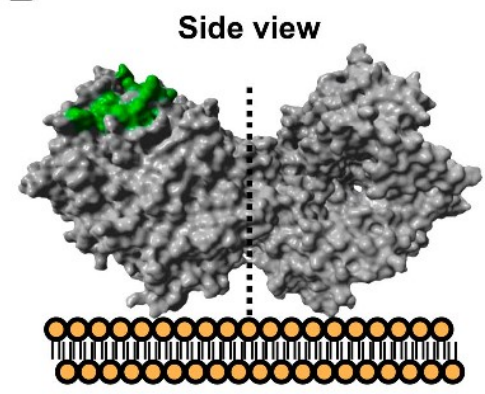

Top view

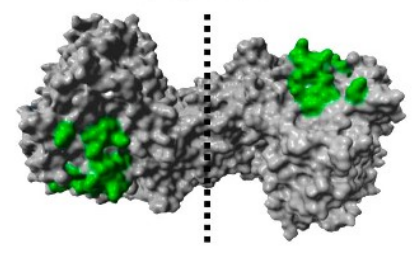

C

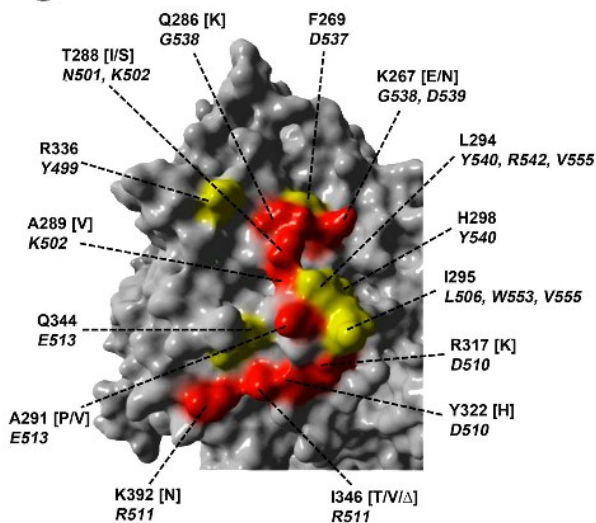

D

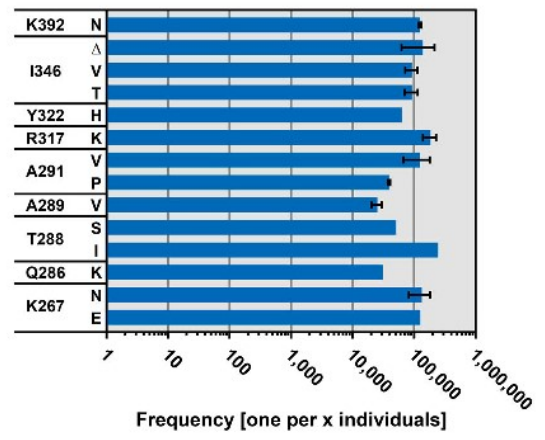

Figure 1. Identification of polymorphic amino acid residues in DPP4 at the binding interface with MERS-CoV S. (A) Schematic representation of DPP4 (CD26). Highlighted are the transmembrane domain (TD, brown), glycosylation-rich (blue) and cysteine-rich (orange) regions, and the catalytic domain (purple). Circles with sticks represent glycosylation sites, while small numbers indicate the amino acid residues. Triangles below the domains highlight the positions of amino acid residues that directly interact with MERS-CoV S (grey triangles mark residues for which no polymorphism has been reported, while red triangles indicate polymorphic residues). (B) Side (left) and top (right) view of homodimeric DPP4 (the dotted line indicates the border between the two monomers and the cellular plasma membrane is schematically depicted below the side view model of DPP4). The protein model was constructed on the published crystal structure (4PV7) deposited in RSCB PDB and the binding interface with MERS-CoV S has been highlighted (green). (C) Close-up on the DPP4 residues that directly interact with MERS-CoV S and for which no polymorphic (yellow) or polymorphic (red) residues have been reported. In addition, the specific residues in DPP4 (regular letters and numbers), including the respective polymorphic residues (letters in brackets), and the corresponding interacting residues in MERS-CoV S (italicized letters and numbers) are indicated. (D) Frequency of polymorphic DPP4 residues in the human population. Public databases (see Supplementary Table 1 and the materials and methods section for detailed information) were screened for the frequency of the polymorphic residues under study (y-axis). Error bars indicate standard error of the mean (SEM) and refer to polymorphic residues found in more than one database.

A289, A291, R317, Y322, I346 and K392) (Figure 1C). While five of these residues can be replaced by only a single different amino acid residue (Q286[K], A289
[V], R317[K], Y322[H] and $\mathrm{K} 392[\mathrm{~N}])$ the remaining four residues can be replaced by two different amino acid residues (K267[E/N], T288[I/S], A291[P/V] and 
I346[T/V]) or can even be absent from DPP4 (I346 $\Delta$ ) (Figure 1C-D and Supplementary Table 1). Finally, the frequency of these polymorphisms in the human population is low, ranging roughly from 1:19,000 (A289V) to $1: 245,000$ (T288I) (Figure 1D and Supplementary Table 1).

\section{DPP4 polymorphisms are compatible with robust DPP4 expression and localization at the cell surface}

We next introduced the polymorphisms in a DPP4 expression plasmid. Western blot analysis and signal quantification revealed that all resulting DPP4 variants were robustly expressed and total expression levels were comparable (Figure 2A-B). As DPP4 needs to be transported to the plasma membrane to be engaged by MERS-CoV S for host cell entry, we next investigated whether the presence of the polymorphic DPP4 residues has an impact on DPP4 cell surface localization. For this, we performed flow cytometry and confocal laser scanning microscopy, using transfected BHK-21 cells and an antibody targeting the DPP4 ectodomain. We found that all DPP4 variants but one, a deletion variant lacking amino acid residues 346-348 ( $\triangle 346-348)$, displayed comparable cell surface expression levels (Figure 3A-B).

\section{Polymorphisms at positions 267 and 291 in DPP4 reduce $S$ protein-driven host cell entry and replication of authentic MERS-CoV}

We next investigated whether polymorphic DPP4 residues impact MERS-CoV host cell entry. For this, we made use of vesicular stomatitis virus (VSV) pseudotypes (VSVpp) bearing MERS-CoV S or VSV G, which does not bind to DPP4 and served as negative control [46]. As expected, VSVpp harboring VSV G were able to efficiently transduce BHK-21 target cells irrespective of DPP4 expression. In contrast, transduction of BHK-21 cells mediated by MERS-CoV S critically depended on ectopic expression of human DPP4, in accordance with published findings [47] (Figure 4). Notably, four DPP4 polymorphisms K267E, K267N, A291P and $\Delta 346-348$ - severely reduced MERS-CoV S-driven transduction compared to DPP4 WT (Figure 4). In order to analyze whether the reduction in MERS-CoV S-driven host cell entry would translate into attenuated MERS-CoV replication, we next investigated two DPP4 polymorphisms (K267E and A291P) in the context of infection with authentic MERS-CoV. When followed over a period of two days post infection it was observed that MERS-CoV replication in BHK-21 cells expressing human DPP4 was significantly reduced when DPP4 contained either K267E or A291P (Figure 5).
DPP4 polymorphisms K267E, K267N and A291P reduce MERS-CoV S binding efficiency to DPP4

After the identification of DPP4 polymorphisms that reduce S-driven cellular entry of rhabdoviral vectors as well as MERS-CoV replication, we next sought to investigate whether the attenuating phenotype was due to reduced binding of MERS-CoV S to DPP4. For this, we used soluble MERS-CoV S, produced by fusing the S1 subunit, which contains the DPP4 binding domain, to the Fc portion of human immunoglobulin $\mathrm{G}$ (solMERS-S1-Fc). Co-immunoprecipitation analysis demonstrated that DPP4 variants harboring polymorphisms K267E, K267N or A291P, which were not compatible with efficient MERS-CoV S-driven host cell entry, displayed significantly reduced ability to interact with MERS-CoV S as indicated by weaker DPP4 signals upon protein A-sepharosemediated pull-down of DPP4/solMERS-S1-Fc (as compared to DPP4 WT, Figure 6A-B). Notably, DPP4 variant $\Delta 346-348$ could be as efficiently coimmunoprecipitated as DPP4 WT, indicating that its inefficient receptor function was solely due to its defect in proper surface transport. The findings obtained by co-IP analysis were confirmed by flow cytometry. It was revealed that polymorphisms that reduced MERS-CoV S-driven host cell entry (K267E, K267N, A291P and $4346-348)$ and spread of authentic MERS-CoV (K267E and A291P) also reduced MERSCoV S binding to cells expressing DPP4 on the cell surface (Figure 6C). In addition, polymorphism A289V, which decreased MERS-CoV S-driven transduction to a lesser extent than the aforementioned polymorphisms (Figure 4), also reduced MERS-CoV S binding to DPP4. Thus, DPP4 polymorphisms K267E, K267N and A291P reduce MERS-CoV S-driven host cell entry and MERS-CoV infection by diminishing MERS-CoV S binding to DPP4.

\section{Discussion}

Host cell entry of MERS-CoV critically depends on the interaction between the viral $\mathrm{S}$ protein and the cellular receptor DPP4. A link between obesity or underlying diseases like diabetes mellitus, which both can affect DPP4 expression levels [48], and the risk of fatal outcome of MERS-CoV infection has been made [49] Moreover, alanine scanning mutagenesis identified DPP4 residues critical for MERS-CoV entry, including K267, L294, I295, R317 and R336 [50,51]. However, the impact of natural-occurring variations on host cell entry of MERS-CoV has not been addressed so far We identified DPP4 polymorphisms that reduce S protein-driven host cell entry and replication of authentic MERS-CoV by lowering the binding efficiency of MERS-CoV S to DPP4, suggesting that the DPP4 phenotype may impact the course of MERS-CoV infection. 

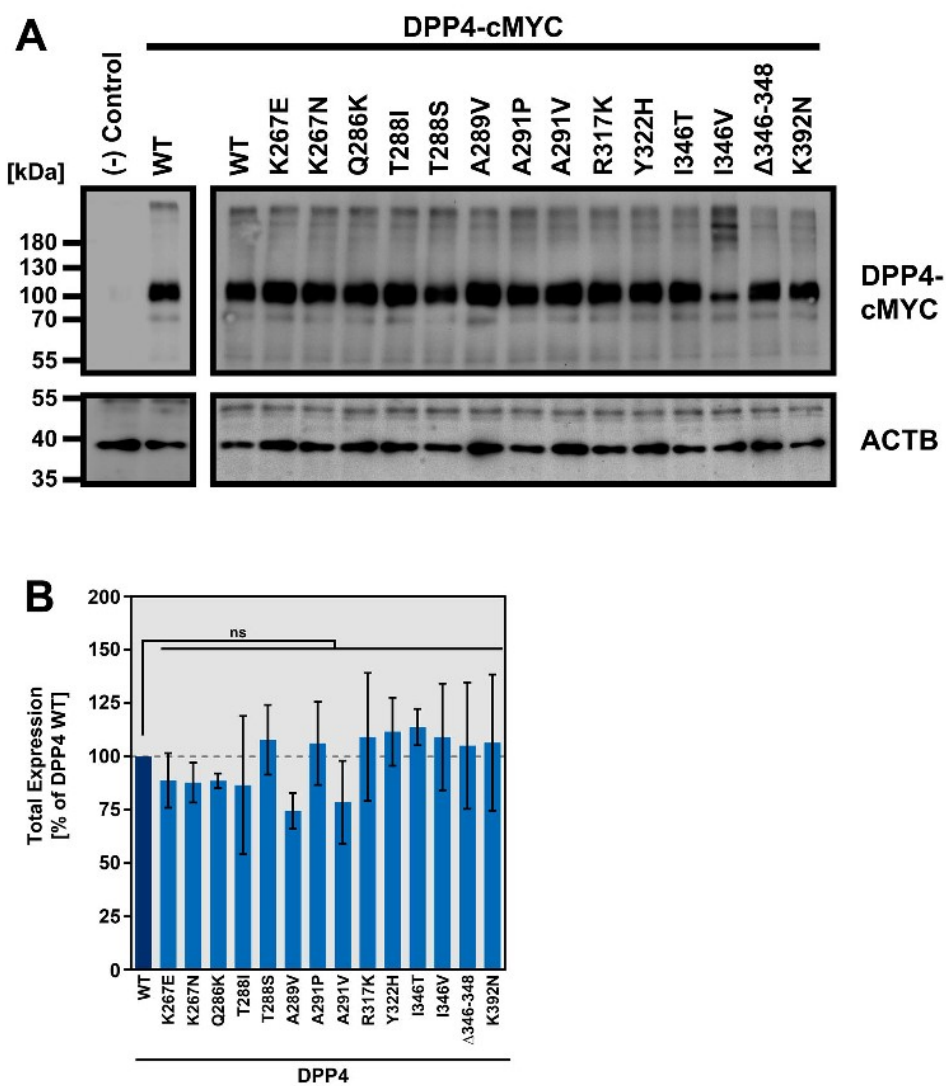

Figure 2. DPP4 harboring polymorphic amino acid residues at the binding interface with MERS-CoV $S$ are robustly expressed. (A) Wildtype (WT) and mutant DPP4 were expressed in $293 \mathrm{~T}$ cells (cells transfected with empty expression vector served as negative control). Whole cell lysates (WCL) were prepared and analyzed for DPP4 expression by SDS-PAGE under non-reducing conditions and WB using a primary antibody targeting the C-terminal CMYC epitope and a peroxidase-conjugated secondary antibody. Further, expression of beta-actin (ACTB) was analyzed as a loading control. Shown are the expression data from a representative experiment. Numbers at the left indicate the molecular weight in kilodalton $(\mathrm{kDa})$. (B) Quantification of total DPP4 expression in WCL. After normalization of DPP4 band intensities with that of the corresponding ACTB bands. DPP4 WT expression was set as 100\% and the relative expression of mutant DPP4 was calculated accordingly. Presented are the combined data of three independent experiments with error bars indicating the SEM. No statistical significance for differences in total expression between WT and mutant DPP4 was observed by one-way analysis of variance with Dunnett's posttest ( $p>0.05$, not significant [ns]).

Western blot analysis, flow cytometry and confocal laser scanning microscopy revealed that none of the polymorphisms studied, except deletion of amino acids 346-348, had a significant impact on total or cell surface expression of DPP4, at least in the context of DPP4 transfected cells. Four polymorphisms located at three different sites in DPP4 (K267E, K267N, A291P and $\Delta 346-348$ ) severely reduced $S$ protein-driven host cell entry. As DPP4 $\Delta 346-348$ was shown to be incompatible with robust cell surface transport but able to interact with MERS-CoV S in co-IP analysis, we conclude that the reduction in entry efficiency is solely due to insufficient DPP4 surface levels. In contrast, reduction of host cell entry by K267E, K267N and A291P could not be explained by reduced DPP4 expression and these polymorphisms were thus further investigated. MERS-CoV infection of BHK-21 cells transfected to express DPP4 WT and variants K267E or A291P revealed that $\mathrm{K} 267 \mathrm{E}$ or A291P were not compatible with robust MERS-CoV replication. Finally, coIP analyses and binding studies with soluble MERS$\mathrm{CoV} \mathrm{S}$ showed that these DPP4 polymorphisms reduced S protein binding to DPP4.

When looking at the crystal structure of the complex consisting of the MERS-CoV $\mathrm{S}$ receptor binding domain bound to DPP4, these observations do not come as a surprise. DPP4 residue K267 has been reported to contact MERS-CoV S residues G538 and D539, including a salt bridge interaction with D539 [16]. The exchange of K267 to either glutamate (E) 


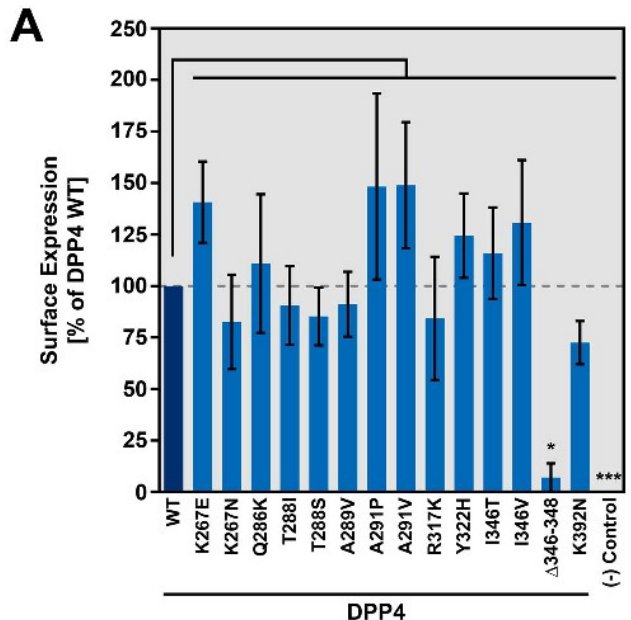

B
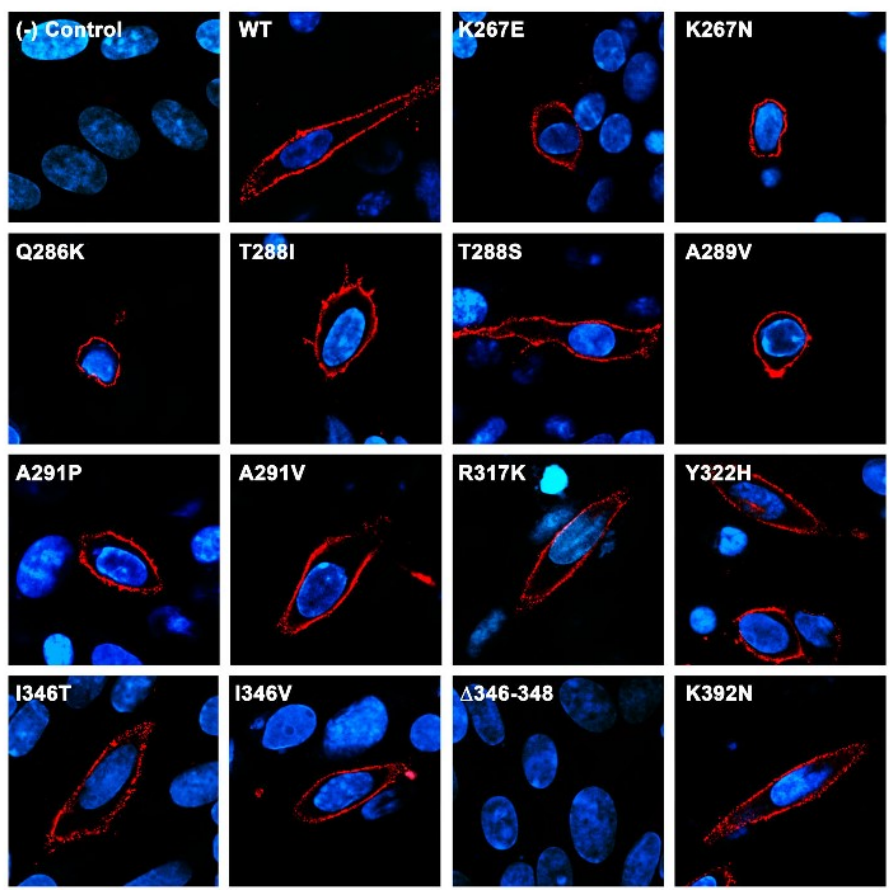

Figure 3. DPP4 harboring polymorphic amino acid residues at the binding interface with MERS-CoV S are efficiently transported to the cell surface. (A) Wildtype (WT) and mutant DPP4 were expressed in BHK-21 cells (cells transfected with empty expression vector served as negative control). Surface expressed DPP4 was stained by subsequent incubation of the non-permeabilized cells with a primary antibody that targets the DPP4 ectodomain and an AlexaFluor488-conjugated secondary antibody. Fluorescent signals representing surface-expressed DPP4 were analyzed by flow cytometry and the mean fluorescence intensity (MFI) values for each sample were calculated. For normalization, the MFI value of the negative control was subtracted from all samples. Further, surface expression of DPP4 WT was set as 100\% and the relative surface expression of the DPP4 mutants was calculated accordingly. Shown are the combined data of three experiments with error bars indicating the SEM. Statistical significance for differences in surface expression between WT and mutant DPP4 was tested by one-way analysis of variance with Dunnett's posttest ( $p>0.05$, not significant; $\left.p \leq 0.05,{ }^{*}\right)$. (B) DPP4 surface expression was further analyzed by immunofluorescence analysis. For this, DPP4 WT or DPP4 mutants were expressed in BHK-21 cells grown on coverslips (cells transfected with empty expression vector served as negative control). After fixation of the cells, surface expressed DPP4 was stained by subsequent incubation of non-permeabilized cells with a primary antibody that targets the DPP4 ectodomain and an AlexaFluor568-conjugated secondary antibody. In addition, cellular nuclei were stained with DAPI. Finally, images were taken using a confocal laser scanning microscope at a magnification of $80 x$. 


\section{VSVpp(MERS-CoV S)}

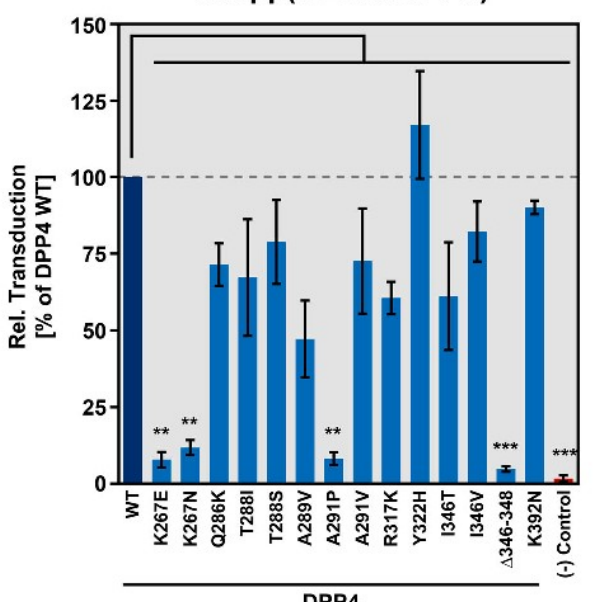

VSVpp(VSV G)

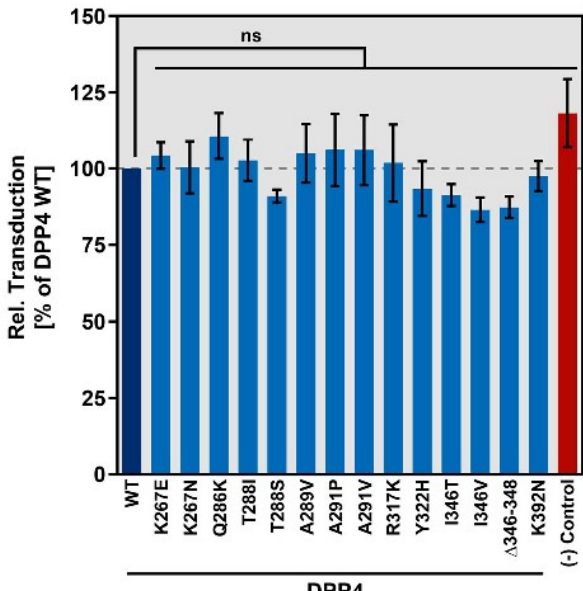

Figure 4. Identification of polymorphic amino acid residues in DPP4 that do not support efficient MERS-CoV S-driven host cell entry. (A) To investigate whether mutant DPP4 support host cell entry driven by MERS-CoV S, we produced vesicular stomatitis virus pseudotype particles (VSVpp) harboring MERS-CoV S (left) or VSV G (control, right). VSVpp were further inoculated on BHK-21 cells expressing wildtype (WT) or mutant DPP4, or cells that were transfected with empty expression vector. At $16 \mathrm{~h}$ posttransduction, transduction efficiency was analyzed by measuring the activity of virus-encoded firefly luciferase. Shown are the combined data from three independent experiments (each performed in quadruplicates) for which transduction efficiency of cells expressing DPP4 WT was set as $100 \%$. Error bars indicate the SEM. Statistical significance of differences in transduction efficiency of cells expressing WT or mutant DPP4 was analyzed by one-way analysis of variance with Dunnett's posttest $(p>0.05$, not significant $\left.[\mathrm{ns}] ; p \leq 0.05,{ }^{*} ; p \leq 0.01,{ }^{* *} ; p \leq 0.001,{ }^{* * *}\right)$.

or asparagine (N) likely abolishes/decreases the interaction with MERS-S due to the different biochemical properties of K267 (positively charged, basic) versus E267 (negatively charged, acidic) and N267 (not charged, acidic) (Supplementary Figure 1). For DPP4 residue $\mathrm{A} 291$, which has been reported to contact the MERS-CoV S residue E513, no information on the type of interaction is available [16]. Here, we speculate that the bulky and distorted side chain of proline (in comparison to the small side chain of alanine) abolishes/decreases interaction with MERS-CoV S residue E513 (Supplementary Figure 1). In contrast to that, valine contains a small side chain and also has identical biochemical properties as alanine and thus might be efficiently contacted by E513 of MERS-CoV S, which is why we did not observe any impact of polymorphisms A291V on MERS-CoV S-driven entry and MERS-CoV S MERS-CoV S binding/interaction (Supplementary Figure 1).

The observation that certain polymorphisms in DPP4 reduced MERS-CoV S binding and viral entry triggered the question whether residues in MERS-CoV $\mathrm{S}$ that are in direct contact with the respective DPP4 residues are also polymorphic. Indeed, we obtained initial evidence to support such a concept. Thus, we found that residue 539 in MERS-CoV S which contacts DPP4 residue 267 is polymorphic, with certain MERS$\mathrm{CoV}$ variants harboring an asparagine instead of an

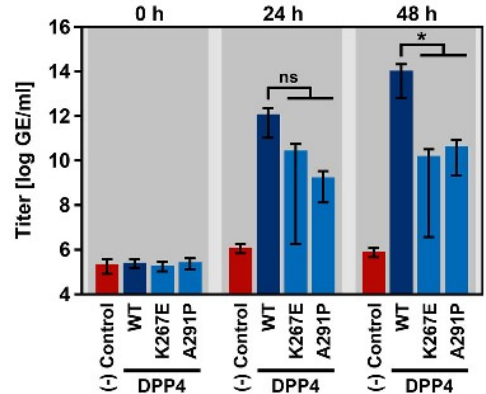

Figure 5. DPP4 harboring polymorphic amino acid residues at the binding interface with MERS-CoV S poorly support replication of live MERS-CoV. Two DPP4 mutants that showed reduced compatibility for MERS-CoV S-driven host cell entry (K267E and A291P) were analyzed in the context of infection and replication of authentic MERS-CoV. For this, BHK-21 cells expressing wildtype (WT) or mutant DPP4, or no DPP4 at all (negative control) were inoculated with MERS-CoV. At $1 \mathrm{~h}$ postinfection, the inoculum was removed and the cells were washed before they received fresh culture medium and were further incubated. MERS-CoV replication was analyzed at 0,24 and $48 \mathrm{~h}$ postinfection by determining MERS-CoV genome equivalents (GE) in the culture supernatant (given as $\mathrm{GE} / \mathrm{ml}$ ) by quantitative reversetranscriptase PCR. Shown are the combined results of three independent experiments (each performed in triplicates). Error bars indicate the SEM. Statistical significance of differences in MERS-CoV replication in cells expressing WT or mutant DPP4 was analyzed by two-way analysis of variance with Dunnett's posttest $\left(p>0.05, \mathrm{~ns} ; p \leq 0.05,{ }^{*}\right)$. 
A

DPP4-cMYC
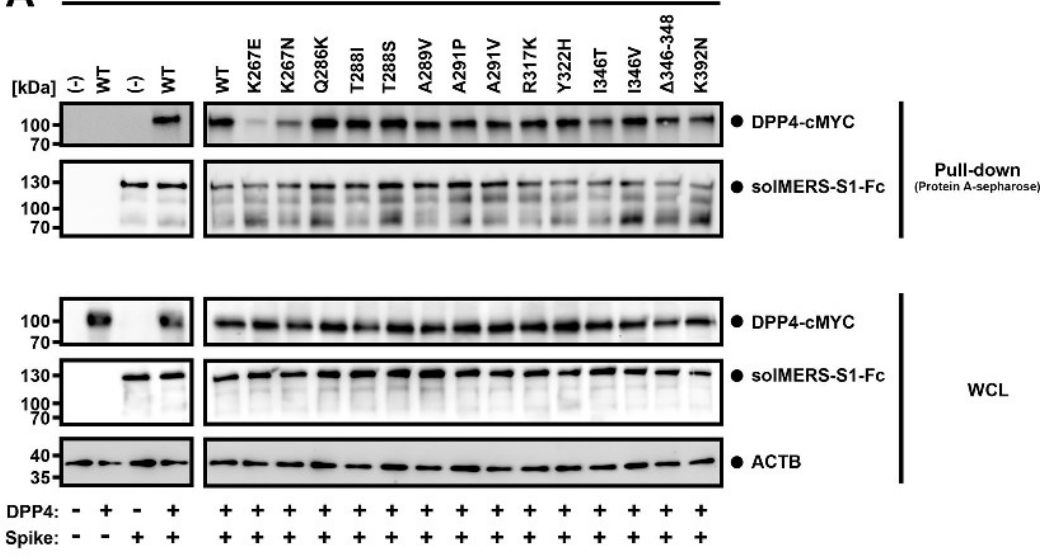

WCL

B

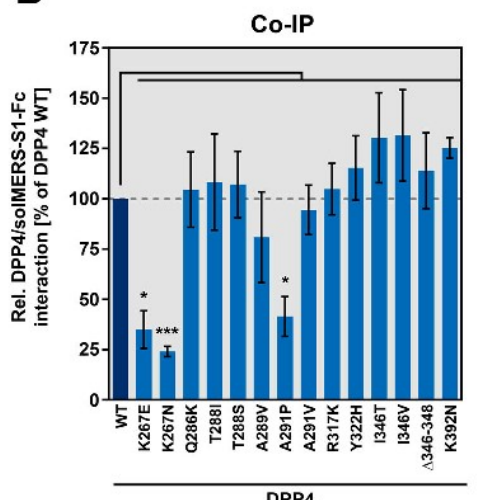

C

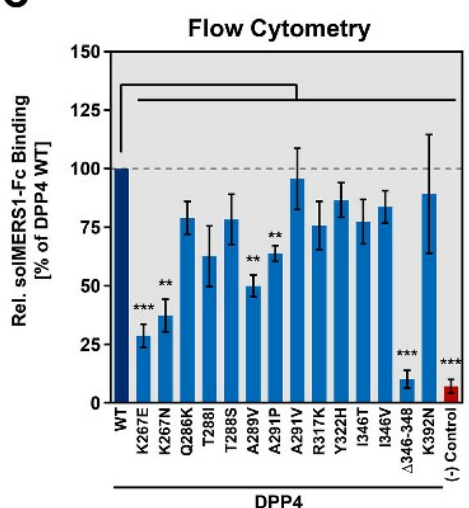

Figure 6. Reduced MERS-CoV S-driven host cell entry is caused by inefficient S protein binding to DPP4 harboring polymorphic amino acid residues. In order to investigate whether reduced MERS-CoV S-driven host cell entry and MERS-CoV replication is due to inefficient MERS-CoV S binding to DPP4 harboring amino acid polymorphisms at the binding interface, we performed co-immunoprecipitation (co-IP) as well as binding experiments with a soluble S protein comprising the S1 subunit of MERS-CoV $S$ fused to the Fc region of human IgG. (A) 293T cells were cotransfected with expression plasmids coding for soluble, Fc-tagged MERS-CoV S1 (solMERS-S1-Fc) and the indicated DPP4 variant containing a C-terminal CMYC-tag. Cells that were transfected only with empty expression vector alone, or empty expression vector instead of either solMERS-S1-Fc or DPP4 served as controls. At $48 \mathrm{~h}$ posttransduction, cells were lysed and incubated with protein A sepharose. Next, samples were subjected to SDS-PAGE and Western blot analysis. DPP4 levels were detected via antibodies specific for the CMYC-tag, whereas solMERS-S1-Fc was detected using a peroxidase-coupled anti-human antibody. Similar results were obtained in three individual experiments. Analysis of whole cell lysates (WCL) for expression of solMERS-S1-Fc, DPP4 and B-actin confirmed comparable ß-actin levels in each sample and comparable expression levels for solMERS-S1-Fc and DPP4. (B) For quantification of MERS-CoV S/DPP4 interaction we first normalized the DPP4 signals against the respective solMERS-S1-Fc signals. Then, MERS-CoV S/DPP4 interaction was set as 100\% for wildtype (WT) DPP4 and the relative interaction efficiency for each DPP4 mutant was calculated accordingly. Presented are the mean data from three independent experiments. Error bars indicate the SEM. Statistical significance of differences in MERS-CoV S/DPP4 interaction between WT and mutant DPP4 was analyzed by one-way analysis of variance with Dunnett's posttest $\left(p>0.05, \mathrm{~ns} ; p \leq 0.05,{ }^{*} ; p \leq\right.$ $\left.0.001{ }^{* * *}\right)$. (C) Soluble MERS-CoV S1-Fc was incubated with BHK-21 cells expressing wildtype (WT) or mutant DPP4, or cells transfected with empty expression vector or an ACE2-expression plasmid (controls). To detect bound S protein, the cells were subsequently incubated with an AlexaFluor488-conjugated anti-human antibody directed against the Fc-tag. Fluorescent signals representing bound solMERS-S1-Fc were analyzed by flow cytometry and MFI values for each sample were calculated. For normalization, the MFI value of the negative control (empty expression vector) was subtracted from all samples. Further, binding of solMERS-S1-Fc to cells expressing DPP4 WT was set as $100 \%$ and the relative binding to cells expressing the DPP4 mutants was calculated accordingly. Shown are the combined data of five independent experiments with error bars indicating the SEM. Statistical significance of differences in solMERS-S1-Fc binding to cells expressing WT or mutant DPP4 was analyzed by one-way analysis of variance with Dunnett's posttest ( $\left.p>0.05, \mathrm{~ns} ; p \leq 0.05,{ }^{*} ; p \leq 0.01,{ }^{* *} ; p \leq 0.001,{ }^{* * *}\right)$. 
aspartate residue at this position. D539N reduced entry into cells expressing relatively low amounts of DPP4 but had no effect on entry into cells expressing high amounts of DPP4 (Supplementary Figure 2). Moreover, and more interestingly, D539N slightly rescued MERSCoV S-driven entry from the negative effect exerted by DPP4 polymorphism K267N (Supplementary Figure 2). Similarly, residue 510 in MERS-CoV S, which is known to interact with DPP4 residues 317 and 322, was found to be polymorphic, and previous studies demonstrated that polymorphism D510G reduced DPP4 binding but also increased resistance to neutralizing antibodies [37]. Notably, D510G slightly increased entry via DPP4 harboring polymorphism $\mathrm{Y} 322 \mathrm{H}$ and allowed MERS-CoV S to use DPP4 with polymorphism R317K with the same efficiency as WT DPP4. It should be stated that none of these effects was statistically significant and that DPP4 and MERS-CoV S polymorphisms occur with low frequency. Although it is unlikely that the DPP4 polymorphisms have emerged as a result of evolutionary pressure from MERS-CoV infections, our results suggest that certain existing DPP4 polymorphism(s) might foster the emergence of MERS$\mathrm{CoV}$ variants with altered biological properties.

The polymorphisms studied here occur with relatively low frequencies of one per $\sim 19,000$ (A289V) to $\sim 245,000$ (T288I) individuals. However, detailed information on the geographic distribution or incidence in certain ethnical groups is largely missing. Thus, DPP4 polymorphisms could contribute to the perplexing absence of MERS cases in Africa, where the virus circulates in camels [52-57]. However, recent evidence suggests that sequence variations between African and Arabian MERS-CoV might be a factor $[53,57]$. More importantly, it remains to be analyzed how frequent DPP4 polymorphisms that affect S protein binding occur in the Middle East and whether they are associated with the clinical course of MERS.

\section{Acknowledgements}

We are grateful to thank G. Herrler, A. Maisner and G. Zimmer for providing plasmids and reagents. We further thank A.-S. Moldenhauer for excellent technical support.

\section{Disclosure statement}

No potential conflict of interest was reported by the authors.

\section{Funding}

This work was supported, including the efforts of Stefan Pöhlmann and Christian Drosten, by the Bundesministerium für Bildung und Forschung [grant numbers $01 \mathrm{KI} 1723 \mathrm{D}$ and $01 \mathrm{KI} 1723 \mathrm{~A}]$, network project RAPID (Risikobewertung bei präpandemischen respiratorischen Infektionserkrankungen). The funders had no role in study design, data collection and interpretation, or the decision to submit the work for publication.

\section{ORCID}

Nadine Krüger (1) https://orcid.org/0000-0002-4413-8699 Hassan Y. Naim (1) https://orcid.org/0000-0003-4884-8425 Marcel A. Müller (1) https://orcid.org/0000-0003-2242-5117 Stefan Pöhlmann (1) http://orcid.org/0000-0001-6086-9136 Markus Hoffmann (1) http://orcid.org/0000-0003-4603-7696

\section{References}

[1] Zaki AM, van Boheemen S, Bestebroer TM, et al Isolation of a novel coronavirus from a man with pneumonia in Saudi Arabia. N Engl J Med. 2012 Nov 8;367(19):1814-1820.

[2] WHO. MERS situation update http://www.emro.who. int/health-topics/mers-cov/mers-outbreaks.html2019 [updated 2019-05]. Available from: https://www.who. int/emergencies/mers-cov/en/.

[3] Adney DR, van Doremalen N, Brown VR, et al. Replication and shedding of MERS-CoV in upper respiratory tract of inoculated dromedary camels. Emerg Infect Dis. 2014 Dec;20(12):1999-2005.

[4] Azhar EI, El-Kafrawy SA, Farraj SA, et al. Evidence for camel-to-human transmission of MERS coronavirus. N Engl J Med. 2014 Jun 26;370(26):2499-2505.

[5] Haagmans BL, Al Dhahiry SH, Reusken CB, et al. Middle East respiratory syndrome coronavirus in dromedary camels: an outbreak investigation. Lancet Infect Dis. 2014 Feb;14(2):140-145.

[6] Raj VS, Farag EA, Reusken CB, et al. Isolation of MERS coronavirus from a dromedary camel, Qatar, 2014. Emerg Infect Dis. 2014 Aug;20(8):1339-1342.

[7] Al-Abdallat MM, Payne DC, Alqasrawi S, et al Hospital-associated outbreak of Middle East respiratory syndrome coronavirus: a serologic, epidemiologic, and clinical description. Clin Infect Dis. 2014 Nov 1;59 (9):1225-1233.

[8] Assiri A, McGeer A, Perl TM, et al. Hospital outbreak of Middle East respiratory syndrome coronavirus. N Engl J Med. 2013 Aug 1;369(5):407-416.

[9] Fagbo SF, Skakni L, Chu DK, et al. Molecular epidemiology of hospital outbreak of Middle East respiratory syndrome, Riyadh, Saudi Arabia, 2014. Emerg Infect Dis. 2015 Nov:21(11):1981-1988.

[10] Korea Centers for Disease Control Prevention. Middle East respiratory syndrome coronavirus outbreak in the Republic of Korea, 2015. Osong Public Health Res Perspect. 2015 Aug;6(4):269-278.

[11] Oboho IK, Tomczyk SM, Al-Asmari AM, et al. 2014 MERS-CoV outbreak in Jeddah-a link to health care facilities. N Engl J Med. 2015 Feb 26;372(9):846-854.

[12] Park HY, Lee EJ, Ryu YW, et al. Epidemiological investigation of MERS-CoV spread in a single hospital in South Korea, May to June 2015. Euro Surveill. 2015 Jun 25;20(25):1-6.

[13] Drosten C, Meyer B, Muller MA, et al. Transmission of MERS-coronavirus in household contacts. N Engl J Med. 2014 Aug 28;371(9):828-835.

[14] Widagdo W, Raj VS, Schipper D, et al. Differential expression of the Middle East respiratory syndrome coronavirus receptor in the upper respiratory tracts of humans and dromedary camels. J Virol. 2016 May;90(9):4838-4842.

[15] Raj VS, Mou H, Smits SL, et al. Dipeptidyl peptidase 4 is a functional receptor for the emerging human coronavirus-EMC. Nature. 2013 Mar 14;495(7440):251254. 
[16] Wang N, Shi X, Jiang L, et al. Structure of MERS-CoV spike receptor-binding domain complexed with human receptor DPP4. Cell Res. 2013 Aug;23 (8):986-993.

[17] Gierer S, Bertram S, Kaup F, et al. The spike protein of the emerging betacoronavirus EMC uses a novel coronavirus receptor for entry, can be activated by TMPRSS2, and is targeted by neutralizing antibodies. J Virol. 2013 May;87(10):5502-5511.

[18] Qian Z, Dominguez SR, Holmes KV. Role of the spike glycoprotein of human Middle East respiratory syndrome coronavirus (MERS-CoV) in virus entry and syncytia formation. PLoS One. 2013;8(10):e76469.

[19] Shirato K, Kawase M, Matsuyama S. Middle East respiratory syndrome coronavirus infection mediated by the transmembrane serine protease TMPRSS2. J Virol. 2013 Dec;87(23):12552-12561.

[20] Deacon CF. Physiology and pharmacology of DPP-4 in glucose Homeostasis and the treatment of type 2 diabetes. Front Endocrinol (Lausanne). 2019;10:80.

[21] Ohnuma K, Dang NH, Morimoto C. Revisiting an old acquaintance: CD26 and its molecular mechanisms in T cell function. Trends Immunol. 2008 Jun;29(6):295301.

[22] Mentlein R. Dipeptidyl-peptidase IV (CD26)-role in the inactivation of regulatory peptides. Regul Pept. 1999 Nov 30;85(1):9-24

[23] Mortier A, Gouwy M, Van Damme J, et al. CD26/ dipeptidylpeptidase IV-chemokine interactions: double-edged regulation of inflammation and tumor biology. J Leukoc Biol. 2016 Jun;99(6):955-969.

[24] Reinhold D, Bank U, Buhling F, et al. Inhibitors of dipeptidyl peptidase IV (DP IV, CD26) induces secretion of transforming growth factor-beta 1 (TGF-beta 1) in stimulated mouse splenocytes and thymocytes. Immunol Lett. 1997 Jun;58(1):29-35.

[25] Barnett A. DPP-4 inhibitors and their potential role in the management of type 2 diabetes. Int J Clin Pract. 2006 Nov;60(11): 1454-1470.

[26] Klemann C, Wagner L, Stephan M, et al. Cut to the chase: a review of CD26/dipeptidyl peptidase-4's (DPP4) entanglement in the immune system. Clin Exp Immunol. 2016 Jul;185(1):1-21.

[27] Ahmed RH, Huri HZ, Al-Hamodi Z, et al. Association of DPP4 gene polymorphisms with type 2 diabetes mellitus in Malaysian Subjects. PLoS One. 2016;11 (4):e0154369.

[28] Xing X, Han Y, Zhou X, et al. Association between DPP4 gene polymorphism and serum lipid levels in Chinese type 2 diabetes individuals. Neuropeptides. 2016 Dec;60:1-6.

[29] Aghili N, Devaney JM, Alderman LO, et al. Polymorphisms in dipeptidyl peptidase IV gene are associated with the risk of myocardial infarction in patients with atherosclerosis. Neuropeptides. 2012 Dec;46(6):367-371.

[30] Schindelin J, Arganda-Carreras I, Frise E, et al. Fiji: an open-source platform for biological-image analysis. Nat Methods. 2012 Jun 28;9(7):676-682.

[31] Hunt SE, McLaren W, Gil L, et al. Ensembl variation resources. Database (Oxford). 2018 Jan 1;2018:1-13.

[32] Sherry ST, Ward MH, Kholodov M, et al. dbSNP: the NCBI database of genetic variation. Nucleic Acids Res. 2001 Jan 1;29(1):308-311.

[33] Lek M, Karczewski KJ, Minikel EV, et al. Analysis of protein-coding genetic variation in 60,706 humans. Nature. 2016 Aug 18;536(7616):285-291.
[34] Genomes Project Consortium, Auton A, Brooks LD, et al. A global reference for human genetic variation. Nature. 2015 Oct 1;526(7571):68-74.

[35] Brinkmann C, Hoffmann M, Lubke A, et al. The glycoprotein of vesicular stomatitis virus promotes release of virus-like particles from tetherin-positive cells. PLoS One. 2017;12(12):e0189073

[36] Hofmann H, Hattermann K, Marzi A, et al. S protein of severe acute respiratory syndrome-associated coronavirus mediates entry into hepatoma cell lines and is targeted by neutralizing antibodies in infected patients. J Virol. 2004 Jun;78(12):6134-6142.

[37] Kleine-Weber H, Elzayat MT, Wang L, et al. Mutations in the spike protein of Middle East respiratory syndrome coronavirus transmitted in Korea increase resistance to antibody-mediated Neutralization. Virol. 2019 Jan 4;93(2):e01381-18. doi:10.1128/JVI. 01381-18.

[38] Hoffmann M, Muller MA, Drexler JF, et al. Differential sensitivity of bat cells to infection by enveloped RNA viruses: coronaviruses, paramyxoviruses, filoviruses, and influenza viruses. PLoS One. 2013;8(8):e72942.

[39] Shahwan K, Hesse M, Mork AK, et al. Sialic acid binding properties of soluble coronavirus spike (S1) proteins: differences between infectious bronchitis virus and transmissible gastroenteritis virus. Viruses. 2013 Jul 26;5(8):1924-1933.

[40] Rentsch MB, Zimmer G. A vesicular stomatitis virus replicon-based bioassay for the rapid and sensitive determination of multi-species type I interferon. PLoS One. 2011;6(10):e25858.

[41] Hoffmann M, Kruger N, Zmora P, et al. The Hemagglutinin of bat-associated Influenza Viruses is activated by TMPRSS2 for $\mathrm{pH}$-dependent entry into bat but not human cells. PLoS One. 2016;11(3):e0152134.

[42] Corman VM, Eckerle I, Bleicker T, et al. Detection of a novel human coronavirus by real-time reverse-transcription polymerase chain reaction. Euro Surveill. 2012 Sep 27;17(39):3-8.

[43] Xiao P, Guo R, Huang S, et al. Discovery of dipeptidyl peptidase IV (DPP4) inhibitors based on a novel indole scaffold. Chin Chem Lett. 2014 May;25(5):673-676.

[44] Land H, Humble MS. YASARA: a tool to obtain structural guidance in Biocatalytic investigations. Methods Mol Biol. 2018;1685:43-67.

[45] Pettersen EF, Goddard TD, Huang CC, et al. UCSF Chimera-a visualization system for exploratory research and analysis. J Comput Chem. 2004 Oct;25 (13): 1605-1612.

[46] Finkelshtein D, Werman A, Novick D, et al. LDL receptor and its family members serve as the cellular receptors for vesicular stomatitis virus. Proc Natl Acad Sci U S A. 2013 Apr 30;110(18):7306-7311.

[47] van Doremalen N, Miazgowicz KL, Milne-Price S, et al. Host species restriction of Middle East respiratory syndrome coronavirus through its receptor, dipeptidyl peptidase 4. J Virol. 2014 Aug;88(16):9220-9232.

[48] Anoop S, Misra A, Bhatt SP, et al. High circulating plasma dipeptidyl peptidase- 4 levels in non-obese Asian Indians with type 2 diabetes correlate with fasting insulin and LDL-C levels, triceps skinfolds, total intra-abdominal adipose tissue volume and presence of diabetes: a case-control study. BMJ Open Diabetes Res Care. 2017;5(1):e000393.

[49] Assiri A, Al-Tawfiq JA, Al-Rabeeah AA, et al. Epidemiological, demographic, and clinical characteristics of 47 cases of Middle East respiratory 
syndrome coronavirus disease from Saudi Arabia: a descriptive study. Lancet Infect Dis. 2013 Sep;13 (9):752-761.

[50] Song W, Wang Y, Wang N, et al. Identification of residues on human receptor DPP4 critical for MERS-CoV binding and entry. Virology. 2014 Dec;471-473:49-53.

[51] Valerio CM, de Almeida JS, Moreira RO, et al. Dipeptidyl peptidase-4 levels are increased and partially related to body fat distribution in patients with familial partial lipodystrophy type 2. Diabetol Metab Syndr. 2017;9(26):1-5.

[52] Chu DK, Oladipo JO, Perera RA, et al. Middle East respiratory syndrome coronavirus (MERS-CoV) in dromedary camels in Nigeria, 2015. Euro Surveill. 2015;20(49):11-17.

[53] Chu DKW, Hui KPY, Perera R, et al. MERS coronaviruses from camels in Africa exhibit region-dependent genetic diversity. Proc Natl Acad Sci U S A. 2018 Mar 20;115(12):3144-3149.
[54] Corman VM, Jores J, Meyer B, et al. Antibodies against MERS coronavirus in dromedary camels, Kenya, 1992-2013. Emerg Infect Dis. 2014 Aug;20 (8):1319-1322.

[55] Muller MA, Corman VM, Jores J, et al. MERS coronavirus neutralizing antibodies in camels, Eastern Africa, 1983-1997. Emerg Infect Dis. 2014 Dec;20(12):20932095.

[56] Perera RA, Wang P, Gomaa MR, et al Seroepidemiology for MERS coronavirus using microneutralisation and pseudoparticle virus neutralisation assays reveal a high prevalence of antibody in dromedary camels in Egypt, June 2013. Euro Surveill. 2013 Sep 5;18(36):20574

[57] Shirato K, Melaku SK, Kawachi K, et al. Middle East respiratory syndrome coronavirus in Dromedaries in Ethiopia Is Antigenically different from the Middle East Isolate EMC. Front Microbiol. 2019;10:1326. 
5.5. Fifth manuscript

\section{SARS-CoV-2 cell Entry Depends on ACE-2 and TMPRSS2 and Is Blocked by Clinically Proven}

\section{Protease Inhibitor}

Hoffmann M, Kleine-Weber H, Schroeder S, Krüger N, Herrler T, Erichsen S, Schiergens TS, Herrler G, Wu NH, Nitsche A, Müller MA, Drosten C, Pöhlmann S.

Individual contribution:

In the manuscript, I conducted experiments and analysis for Figure 1B: "SARS-2-S and SARS-S Facilitate Entry into a Similar Panel of Mammalian Cell Lines" and Figure 5: "Sera from Convalescent SARS Patients Cross-Neutralize SARS-2-SDriven Entry". 
Cell

\section{SARS-CoV-2 Cell Entry Depends on ACE2 and TMPRSS2 and Is Blocked by a Clinically Proven Protease Inhibitor}

Graphical Abstract

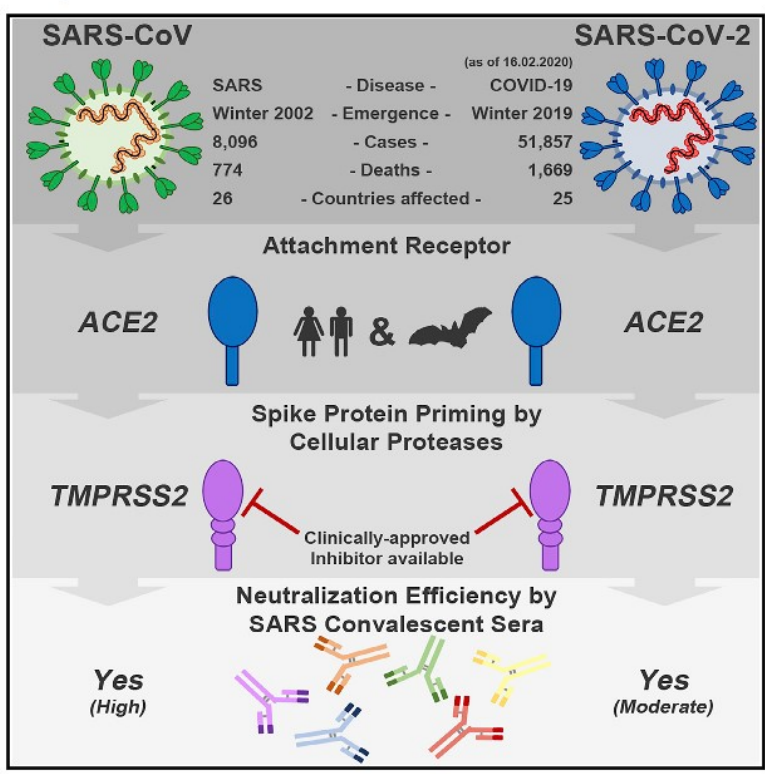

Highlights

- SARS-CoV-2 uses the SARS-CoV receptor ACE2 for host cell entry

- The spike protein of SARS-CoV-2 is primed by TMPRSS2

- Antibodies against SARS-CoV spike may offer some protection against SARS-CoV-2
Authors

Markus Hoffmann, Hannah Kleine-Weber, Simon Schroeder, ..., Marcel A. Müller, Christian Drosten, Stefan PöhImann

\section{Correspondence}

mhoffmann@dpz.eu (M.H.), spoehlmann@dpz.eu (S.P.)

In Brief

The emerging SARS-coronavirus 2 (SARS-CoV-2) threatens public health. Hoffmann and coworkers show that SARS-CoV-2 infection depends on the host cell factors ACE2 and TMPRSS2 and can be blocked by a clinically proven protease inhibitor. These findings might help to establish options for prevention and treatment. 


\title{
SARS-CoV-2 Cell Entry Depends on ACE2 and TMPRSS2 and Is Blocked by a Clinically Proven Protease Inhibitor
}

\author{
Markus Hoffmann, ${ }^{1,13,{ }^{*}}$ Hannah Kleine-Weber, ${ }^{1,2,13}$ Simon Schroeder, ${ }^{3,4}$ Nadine Krüger, ${ }^{5,6}$ Tanja Herrler, ${ }^{7}$ \\ Sandra Erichsen, ${ }^{8,9}$ Tobias S. Schiergens, ${ }^{10}$ Georg Herrler, ${ }^{5}$ Nai-Huei Wu, ${ }^{5}$ Andreas Nitsche, ${ }^{11}$ Marcel A. Müller, $, 3,4,12$ \\ Christian Drosten, ${ }^{3,4}$ and Stefan Pöhlmann ${ }^{1,2,14, *}$ \\ 'Infection Biology Unit, German Primate Center - Leibniz Institute for Primate Research, Göttingen, Germany \\ ${ }^{2}$ Faculty of Biology and Psychology, University Göttingen, Göttingen, Germany \\ ${ }^{3}$ Charité-Universitätsmedizin Berlin, corporate member of Freie Universität Berlin, Humboldt-Universität zu Berlin, and Berlin Institute of \\ Health, Institute of Virology, Berlin, Germany \\ ${ }^{4}$ German Centre for Infection Research, associated partner Charité, Berlin, Germany \\ 5 Institute of Virology, University of Veterinary Medicine Hannover, Hannover, Germany \\ ${ }^{6}$ Research Center for Emerging Infections and Zoonoses, University of Veterinary Medicine Hannover, Hannover, Germany \\ ${ }^{7}$ BG Unfallklinik Murnau, Murnau, Germany \\ 8Institute for Biomechanics, BG Unfallklinik Murnau, Murnau, Germany \\ 9 Institute for Biomechanics, Paracelsus Medical University Salzburg, Salzburg, Austria \\ ${ }^{10}$ Biobank of the Department of General, Visceral, and Transplant Surgery, Ludwig-Maximilians-University Munich, Munich, Germany \\ ${ }^{11}$ Robert Koch Institute, ZBS 1 Highly Pathogenic Viruses, WHO Collaborating Centre for Emerging Infections and Biological Threats, Berlin \\ Germany \\ ${ }^{12}$ Martsinovsky Institute of Medical Parasitology, Tropical and Vector Borne Diseases, Sechenov University, Moscow, Russia \\ ${ }^{13}$ These authors contributed equally \\ 14Lead Contact \\ *Correspondence: mhoffmann@dpz.eu (M.H.), spoehlmann@dpz.eu (S.P.) \\ https://doi.org/10.1016/J.cell.2020.02.052
}

\section{SUMMARY}

The recent emergence of the novel, pathogenic SARS-coronavirus 2 (SARS-CoV-2) in China and its rapid national and international spread pose a global health emergency. Cell entry of coronaviruses depends on binding of the viral spike (S) proteins to cellular receptors and on $\mathrm{S}$ protein priming by host cell proteases. Unravelling which cellular factors are used by SARS-CoV-2 for entry might provide in sights into viral transmission and reveal therapeutic targets. Here, we demonstrate that SARS-CoV-2 uses the SARS-CoV receptor ACE2 for entry and the serine protease TMPRSS2 for S protein priming. A TMPRSS2 inhibitor approved for clinical use blocked entry and might constitute a treatment option. Finally, we show that the sera from convalescent SARS patients cross-neutralized SARS-2S-driven entry. Our results reveal important commonalities between SARS-CoV-2 and SARS-CoV infection and identify a potential target for antivira intervention.

\section{INTRODUCTION}

Several members of the family Coronaviridae constantly circulate in the human population and usually cause mild respiratory disease (Corman et al., 2019). In contrast, the severe acute res piratory syndrome coronavirus (SARS-CoV) and the Middle Eas respiratory syndrome coronavirus (MERS-CoV) are transmitted from animals to humans and cause severe respiratory diseases in afflicted individuals, SARS and MERS, respectively (Feh et al., 2017). SARS emerged in 2002 in Guangdong province, China, and its subsequent global spread was associated with 8,096 cases and 774 deaths (de Wit et al., 2016; WHO, 2004). Chinese horseshoe bats serve as natural reservoir hosts fo SARS-CoV (Lau et al., 2005; Li et al., 2005a). Human transmission was facilitated by intermediate hosts like civet cats and raccoon dogs, which are frequently sold as food sources in Chinese wet markets (Guan et al., 2003). At present, no specific an tivirals or approved vaccines are available to combat SARS, and the SARS pandemic in 2002 and 2003 was finally stopped by conventional control measures, including travel restrictions and patient isolation.

In December 2019, a new infectious respiratory disease emerged in Wuhan, Hubei province, China (Huang et al., 2020; Wang et al., 2020; Zhu et al., 2020). An initial cluster of infections was linked to Huanan seafood market, potentially due to animal contact. Subsequently, human-to-human transmission occurred (Chan et al., 2020) and the disease, now termed coronavirus disease 19 (COVID-19) rapidly spread within China. A novel coronavirus, SARS-coronavirus 2 (SARS-CoV-2), which is closely related to SARS-CoV, was detected in patients and is believed to be the etiologic agent of the new lung disease (Zhu et al., 2020). On February 12, 2020, a total of 44,730 laboratoryconfirmed infections were reported in China, including 8,204 
A
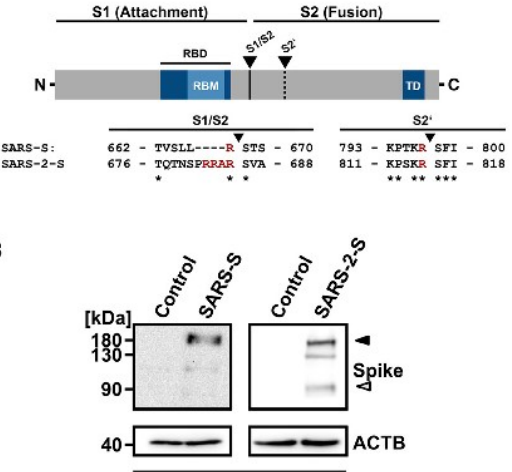

Cell Lysate

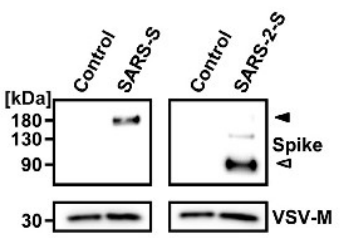

Pseudotype

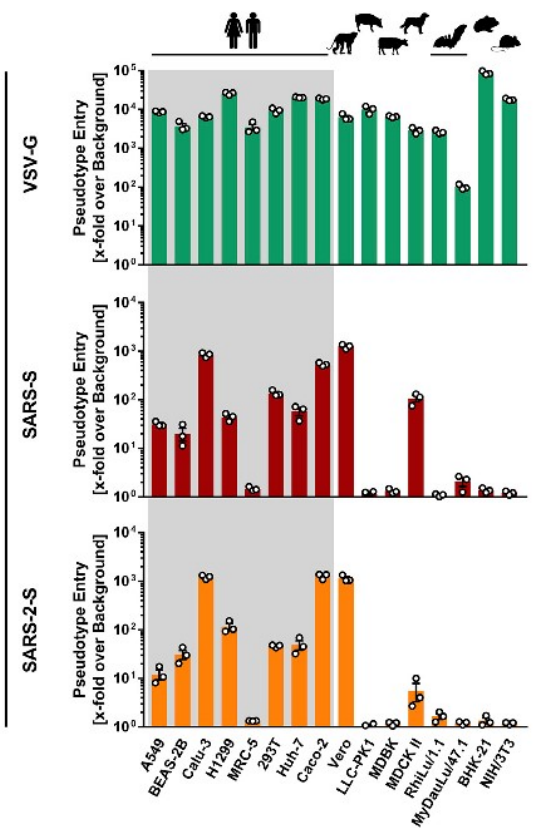

Figure 1. SARS-2-S and SARS-S Facilitate Entry into a Similar Panel of Mammalian Cell Lines

(A) Schematic illustration of SARS-S including functional domains (RBD, receptor binding domain; RBM, receptor binding motif; TD, transmembrane domain) and proteolytic cleavage sites (S1/S2, S2'). Amino acid sequences around the two protease recognition sites (red) are indicated for SARS-S and SARS-2-S (asterisks indicate conserved residues). Arrow heads indicate the cleavage site.

(B) Analysis of SARS-2-S expression (upper panel) and pseudotype incorporation (lower panel) by western blot using an antibody directed against the C-terminal hemagglutinin served as loading contros (M, matrix protein). Black anow heads indicate bands corresponding to uncleaved S proteins (S0) whereas gray arrow heads indicate ands corresponding to the $\mathbf{S} 2$ subunit.

(C) Cell lines of human and animal origin were inoculated with pseudotyped VSV harboring VSV-G, SARS-S, or SARS-2-S. At 16 h postinoculation, pseudotype entry was analyzed by determining luciferase activity in cell lysates. Signals obtained for particles bearing no envelope protein were used for normalization. The average of three independent experiments is shown. Error bars indicate SEM. Unprocessed data from a single experiment are presented in Figure S1.

severe cases and 1,114 deaths (WHO, 2020). Infections were also detected in 24 countries outside China and were associated with international travel. At present, it is unknown whether the sequence similarities between SARS-CoV-2 and SARS-CoV translate into similar biological properties, including pandemic potential (Munster et al., 2020)

The spike (S) protein of coronaviruses facilitates viral entry into target cells. Entry depends on binding of the surface unit, S1, of the $S$ protein to a cellular receptor, which facilitates viral attachment to the surface of target cells. In addition, entry requires $S$ protein priming by cellular proteases, which entails $S$ protein cleavage at the S1/S2 and the S2' site and allows fusion of vira and cellular membranes, a process driven by the S2 subunit (Fig ure $1 A$ ). SARS-S engages angiotensin-converting enzyme 2 (ACE2) as the entry receptor (Li et al., 2003) and employs the

272 Cell 181, 271-280, April 16, 2020 cellular serine protease TMPRSS2 for S protein priming (Glowacka et al., 2011; Matsuyama et al., 2010; Shulla et al., 2011). The SARS-S/ACE2 interface has been elucidated at the atomic level, and the efficiency of ACE2 usage was found to be a key determinant of SARS-CoV transmissibility (Li et al., 2005a, 2005b). SARS-S und SARS-2-S share $\sim 76 \%$ amino acid identity. However, it is unknown whether SARS-2-S like SARS-S employs ACE2 and TMPRSS2 for host cell entry.

\section{RESULTS}

Evidence for Efficient Proteolytic Processing

of SARS-2-S

The goal of our study was to obtain insights into how SARS-2-S facilitates viral entry into target cells and how this process can be 
blocked. For this, we first asked whether SARS-2-S is robustly expressed in a human cell line, 293T, commonly used for experimentation because of its high transfectability. Moreover, we analyzed whether there is evidence for proteolytic processing of the $\mathrm{S}$ protein because certain coronavirus $\mathrm{S}$ proteins are cleaved by host cell proteases at the S1/S2 cleavage site in infected cells (Figure 1A). Immunoblot analysis of 293T cells expressing SARS-2-S protein with a C-terminal antigenic tag revealed a band with a molecular weight expected for unprocessed S protein (S0) (Figure 1B). A band with a size expected for the S2 subunit of the S protein was also observed in cells and, more prominently, in vesicular stomatitis virus (VSV) particles bearing SARS-2-S (Figure 1B). In contrast, an S2 signal was largely absent in cells and particles expressing SARS-S (Figure 1B), as previously documented (Glowacka et al., 2011; Hofmann et al., 2004b). These results suggest efficient proteolytic processing of SARS-2-S in human cells, in keeping with the presence of several arginine residues at the $\mathrm{S} 1 / \mathrm{S} 2$ cleavage site of SARS-2-S but not SARS-S (Figure 1A). In contrast, the S2' cleavage site of SARS-2-S was similar to that of SARS-S.

SARS-2-S and SARS-S Mediate Entry into a Similar Spectrum of Cell Lines

Replication-defective VSV particles bearing coronavirus S proteins faithfully reflect key aspects of coronavirus host cell entry (Kleine-Weber et al., 2019). We employed VSV pseudotypes bearing SARS-2-S to study cell entry of SARS-CoV-2. Both SARS-2-S and SARS-S were robustly incorporated into VSV particles (Figure 1B), allowing a meaningful side-by-side comparison; although, formally, comparable particle incorporation of the $\mathrm{S} 1$ subunit remains to be demonstrated. We first asked which cell lines were susceptible to SARS-2-S-driven entry, using a panel of well-characterized cell lines of human and animal origin, respectively. All cell lines were readily susceptible to entry driven by the glycoprotein of the pantropic VSV (VSV-G) (Figure 1C; Figure S1), as expected. Most human cell lines and the animal cell lines Vero and MDCKII were also susceptible to entry driven by SARS-S (Figure 1C). Moreover, SARS-2-S facilitated entry into an identical spectrum of cell lines as SARS-S (Figure $1 C$ ), suggesting similarities in choice of entry receptors.

SARS-CoV-2 Employs the SARS-CoV Receptor for Host Cell Entry

In order to elucidate why SARS-S and SARS-2-S mediated entry into the same cell lines, we next determined whether SARS-2-S harbors amino acid residues required for interaction with the SARS-S entry receptor ACE2. Sequence analysis revealed that SARS-CoV-2 clusters with SARS-CoV-related viruses from bats (SARSr-CoV), of which some but not all can use ACE2 for host cell entry (Figure 2A; Figure S2). Analysis of the receptor binding motif (RBM), a portion of the receptor binding domain (RBD) that makes contact with ACE2 (Li et al., 2005a), revealed that most amino acid residues essential for ACE2 binding by SARS-S were conserved in SARS-2-S (Figure 2B). In contrast, most of these residues were absent from $S$ proteins of SARSr$\mathrm{CoV}$ previously found not to use ACE2 for entry (Figure 2B) (Ge et al., 2013; Hoffmann et al., 2013; Menachery et al., 2020). In agreement with these findings, directed expression of human and bat (Rhinolophus alcyone) ACE2 but not human DPP4, the entry receptor used by MERS-CoV (Raj et al., 2013), or human APN, the entry receptor used by HCoV-229E (Yeager et al., 1992), allowed SARS-2-S- and SARS-S-driven entry into otherwise non-susceptible BHK-21 cells (Figure 3A). Moreover, antiserum raised against human ACE2 blocked SARS-S- and SARS-2-S- but not VSV-G- or MERS-S-driven entry (Figure 3B). Finally, authentic SARS-CoV-2 infected BHK-21 cells trans fected to express ACE2 cells but not parental BHK-21 cells with high efficiency (Figure $3 C$ ), indicating that SARS-2-S, like SARS-S, uses ACE2 for cellular entry.

The Cellular Serine Protease TMPRSS2 Primes SARS-2$S$ for Entry, and a Serine Protease Inhibitor Blocks SARS-CoV-2 Infection of Lung Cells

We next investigated protease dependence of SARS-CoV-2 entry. SARS-CoV can use the endosomal cysteine proteases cathepsin B and L (CatB/L) (Simmons et al., 2005) and the serine protease TMPRSS2 (Glowacka et al., 2011; Matsuyama et al., 2010; Shulla et al., 2011) for S protein priming in cell lines, and inhibition of both proteases is required for robust blockade of viral entry (Kawase et al., 2012). However, only TMPRSS2 activity is essential for viral spread and pathogenesis in the infected host whereas CatB/L activity is dispensable (lwata-Yoshikawa et al., 2019; Shirato et al., 2016; Shirato et al., 2018; Zhou et al., 2015).

In order to determine whether SARS-CoV-2 can use CatB/L for cell entry, we initially employed ammonium chloride, which elevates endosomal $\mathrm{pH}$ and thereby blocks CatB/L activity. 293T cells (TMPRSS2 ${ }^{-}$, transfected to express ACE2 for robust S protein-driven entry) and Caco-2 cells (TMPRSS2 ${ }^{+}$) were used as targets. Ammonium chloride blocked VSV-G-dependent entry into both cell lines whereas entry driven by Nipah virus $F$ and $G$ proteins was not affected (Figure S3A; data not shown), consistent with Nipah virus but not VSV being able to fuse directly with the plasma membrane (Bossart et al.,2002). Ammonium chloride treatment strongly inhibited SARS-2-S- and SARS-S-driven entry into TMPRSS2 ${ }^{-}$293T cells (Figure S3 A), suggesting CatB/L dependence. Inhibition of entry into TMPRSS2 ${ }^{+}$Caco- 2 cells was less efficient compared to 293T cells (Figure S3 A), which would be compatible with SARS-2-S priming by TMPRSS2 in Caco- 2 cells. Indeed, the clinically proven serine protease inhibitor camostat mesylate, which is active against TMPRSS2 (Kawase et al., 2012), partially blocked SARS-2-S-driven entry into Caco-2 (Figure S3 B) and Vero-TMPRSS2 cells (Figure 4A). Ful inhibition was attained when camostat mesylate and E-64d, an inhibitor of CatB/L, were added (Figure 4A; Figure S3B), indicating that SARS-2-S can use both $C$ at $B / L$ as well as TMPRSS2 for priming in these cell lines. In contrast, camostat mesylate did not interfere with SARS-2-S-driven entry into the TMPRSS2 ${ }^{-}$cell lines 293T (Figure S3B) and Vero (Figure 4A), which was efficiently blocked by E-64d and therefore is CatB/L dependent. Moreover, directed expression of TMPRSS2 rescued SARS-2S-driven entry from inhibition by E-64d (Figure 4B), confirming that SARS-2-S can employ TMPRSS2 for S protein priming.

We next analyzed whether TMPRSS2 usage is required for SARS-CoV-2 infection of lung cells. Indeed, camostat mesylate significantly reduced MERS-S-, SARS-S-, and SARS-2-S- but 
A

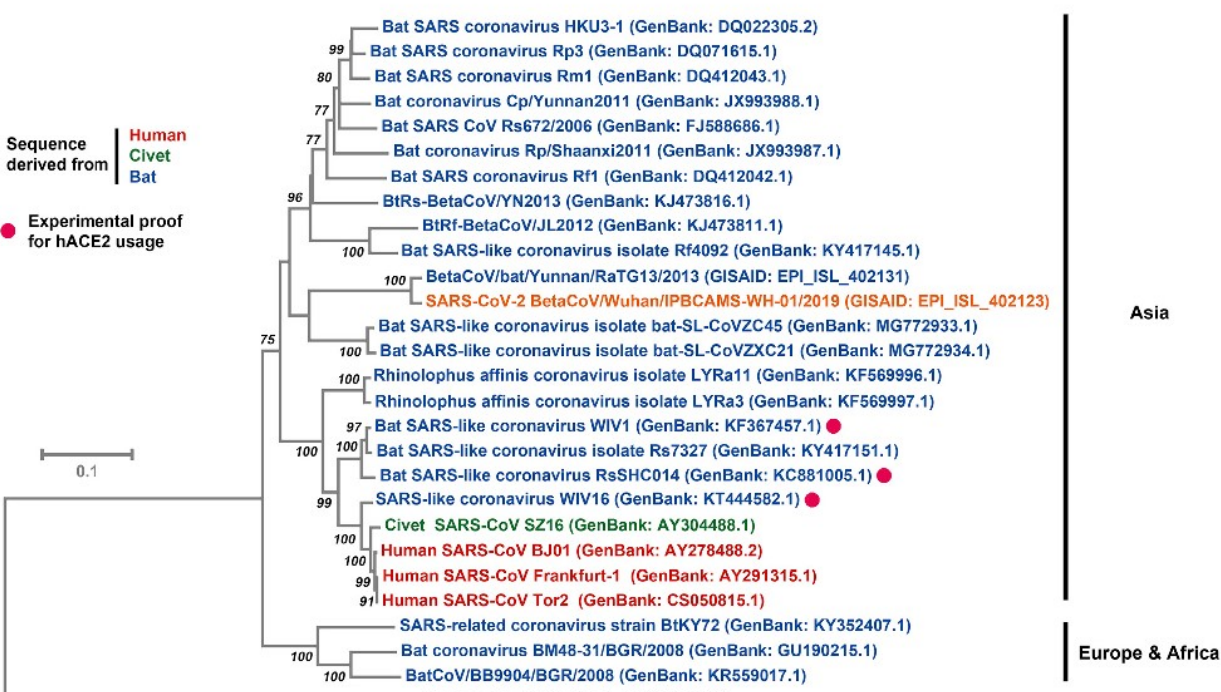

B

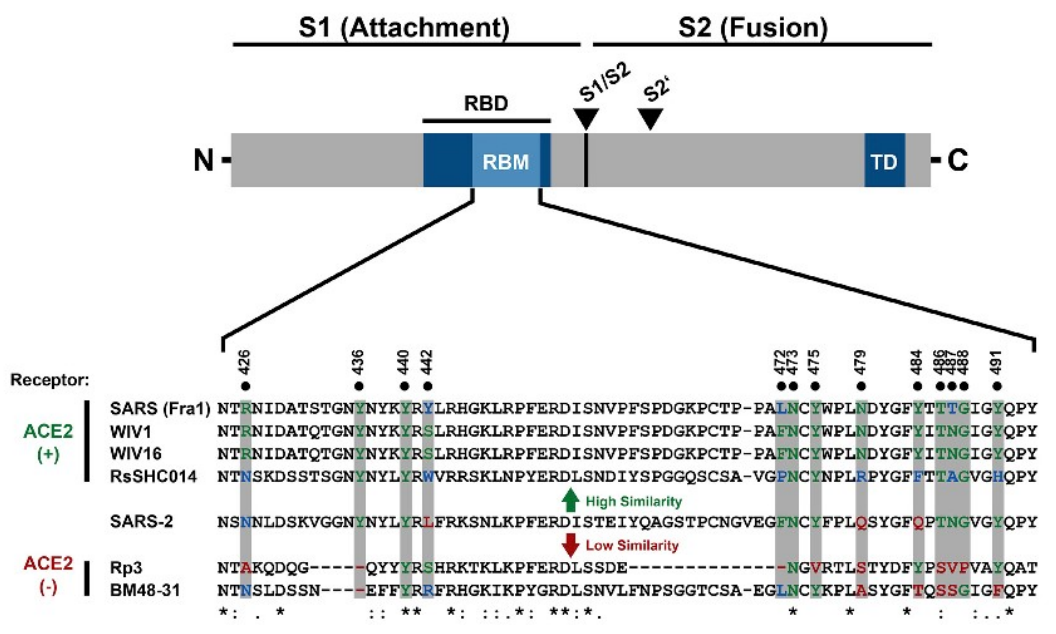

Figure 2. SARS-2-S Harbors Amino Acid Residues Critical for ACE2 Binding

(A) The S protein of SARS-CoV-2 clusters phylogenetically with S proteins of known bat-associated betacoronavinuses (see Figure S2 for more details). (B) Alignment of the receptor binding motif of SARS-S with corresponding sequences of bat-associated betacoronavirus S proteins, which are able or unable to use ACE2 as cellular receptor, reveals that SARS-CoV-2 possesses crucial amino acid residues for ACE2 binding.

not VSV-G-driven entry into the lung cell line Calu-3 (Figure 4C) and exerted no unwanted cytotoxic effects (Figure S3 C). Similarly, camostat mesylate treatment significantly reduced Calu-3

274 Cell 181, 271-280, April 16, 2020 infection with authentic SARS-CoV-2 (Figure 4D). Finally, camostat mesylate treatment inhibited SARS-S- and SARS-2-S- but not VSV-G-driven entry into primary human lung cells (Figure 4E). 
A
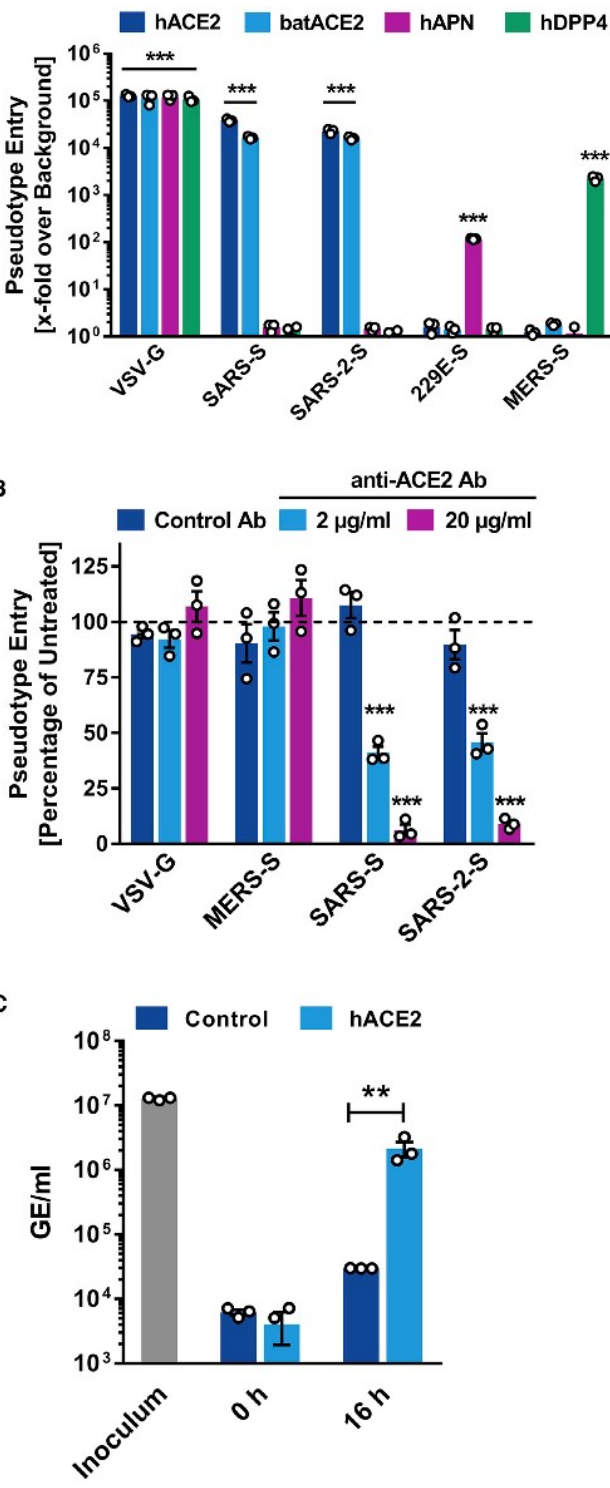

Figure 3. SARS-2-S Utilizes ACE2 as Cellular Receptor

(A) BHK-21 cells transiently expressing ACE2 of human or bat origin, huma APN, or human DPP4 were inoculated with pseudotyped VSV harboring VSVG, SARS-S, SARS-2-S, MERS-S, or 229E-S. At $16 \mathrm{~h}$ postinoculation, pseu-
Collectively, SARS-CoV-2 can use TMPRSS2 for S protein priming and camostat mesylate, an inhibitor of TMPRSS2, blocks SARS-CoV-2 infection of lung cells.

Evidence that Antibodies Raised against SARS-CoV Will Cross-Neutralize SARS-CoV-2

Convalescent SARS patients exhibit a neutralizing antibody response directed against the viral S protein (Liu et al., 2006). We investigated whether such antibodies block SARS-2-Sdriven entry. Four sera obtained from three convalescent SARS patients inhibited SARS-S- but not VSV-G-driven entry in a concentration-dependent manner (Figure 5). In addition, these sera also reduced SARS-2-S-driven entry, although with lower efficiency compared to SARS-S (Figure 5). Similarly, rabbit sera raised against the $\mathrm{S} 1$ subunit of SARS-S reduced both SARS-S- and SARS-2-S-driven entry with high efficiency, and again inhibition of SARS-S-driven entry was more efficient. Thus, antibody responses raised against SARS-S during infection or vaccination might offer some level of protection against SARS-CoV-2 infection.

DISCUSSION

The present study provides evidence that host cell entry of SARSCoV-2 depends on the SARS-CoV receptor ACE2 and can be blocked by a clinically proven inhibitor of the cellular serine protease TMPRSS2, which is employed by SARS-CoV-2 for S protein priming. Moreover, it suggests that antibody responses raised against SARS-CoV could at least partially protect against SARSCoV-2 infection. These results have important implications for our understanding of SARS-CoV-2 transmissibility and pathogenesis and reveal a target for therapeutic intervention.

The finding that SARS-2-S exploits ACE2 for entry, which was also reported by Zhou and colleagues (Zhou et al., 2020) while the present manuscript was in revision, suggests that the virus might target a similar spectrum of cells as SARS-CoV. In the lung, SARS-CoV infects mainly pneumocytes and macrophages (Shieh et al., 2005). However, ACE2 expression is not limited to the lung, and extrapulmonary spread of SARS-CoV in ACE2 ${ }^{+}$tissues was observed (Ding et al., 2004; Gu et al., 2005; Hamming et al., 2004). The same can be expected for SARS-CoV-2, although affinity of SARS-S and SARS-2-S for ACE2 remains

dotype entry was analyzed (normalization against particles without viral envelope protein).

(B) Untreated Vero cells as well as Vero cells pre-incubated with 2 or $20 \mu \mathrm{g} / \mathrm{mL}$ of anti-ACE2 antibody or unrelated control antibody (anti-DC-SIGN, $20 \mu \mathrm{g} / \mathrm{mL}$ ) were inoculated with pseudotyped VSV harboring VSV-G, SARS-S, SARS-2$\mathrm{S}$, or MERS-S. At $16 \mathrm{~h}$ postinoculation, pseudotype entry was analyzed (normalization against untreated cells).

(C) BHK-21 cells transfected with ACE2-encoding plasmid or control trans-

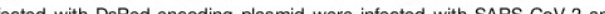
wected wh DsRod-encoding plasmid were infected with SARS-COV-2 and washed, and genome equivalonts in all quantitative RT-PCR.

The average of three independent experiments conducted with triplicate samples is shown in (A-C). Error bars indicate SEM. Statistical significance was tested by two-way ANOVA with Dunnett posttest. Cells transfected with empty vector served as reference in (A) whereas cells that were not treated with antibody served as reference in (B). 

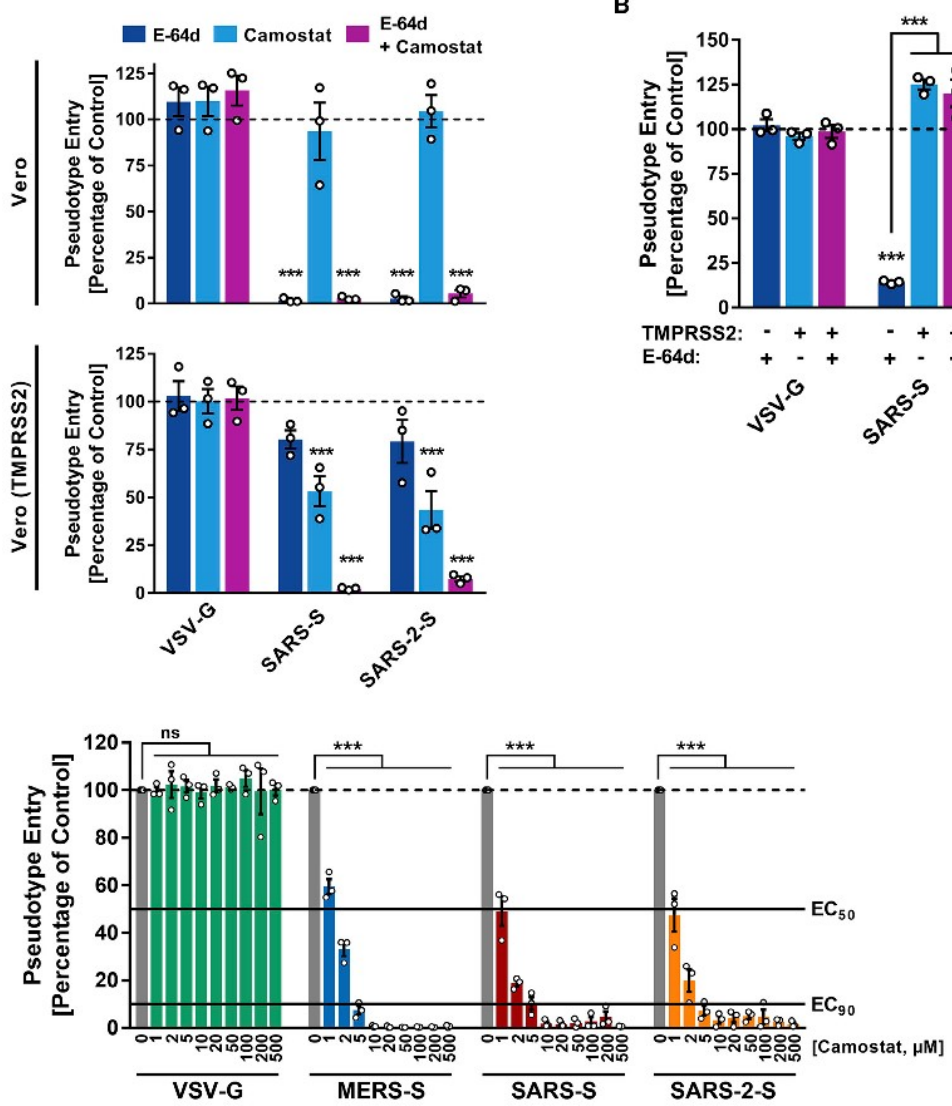

D
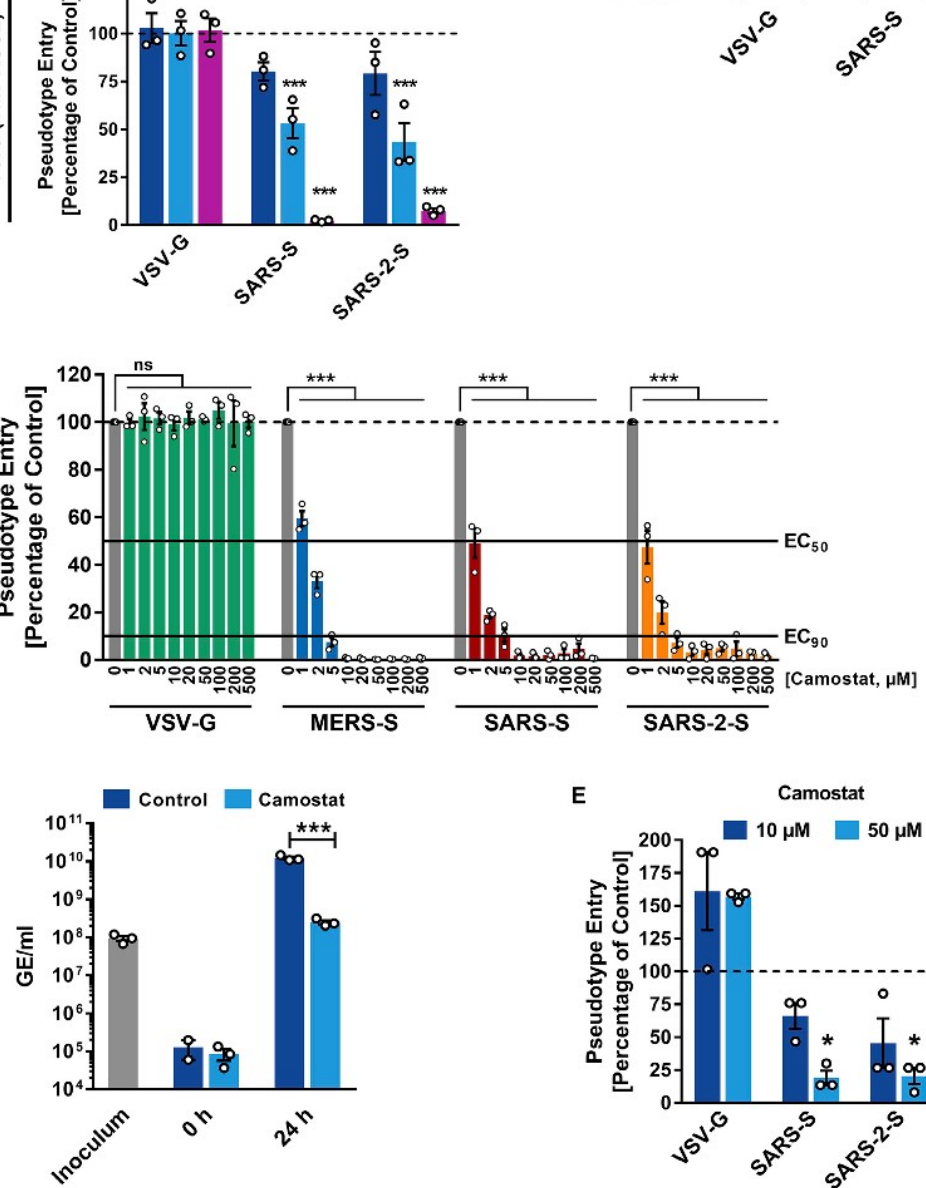
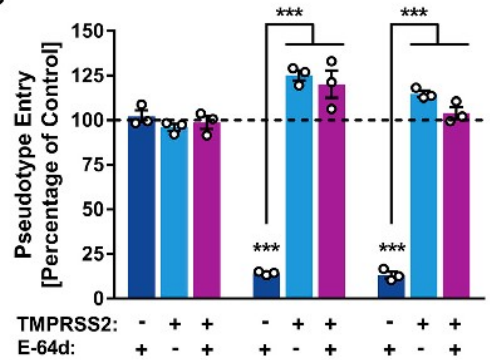

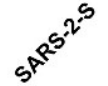

276 Cell 181, 271-280, April 16, 2020 
to be compared. It has been suggested that the modest ACE2 expression in the upper respiratory tract (Bertram et al., 2012; Hamming et al., 2004) might limit SARS-CoV transmissibility. In light of the potentially increased transmissibility of SARS CoV-2 relative to SARS-CoV, one may speculate that the new virus might exploit cellular attachment-promoting factors with higher efficiency than SARS-CoV to ensure robust infection of ACE2 ${ }^{+}$cells in the upper respiratory tract. This could compris binding to cellular glycans, a function ascribed to the $\mathrm{S} 1$ domain of certain coronaviruses ( $L$ i et al., 2017; Park et al., 2019). Finally, it should be noted that ACE2 expression protects from lung injury and is downregulated by SARS-S (Haga et al., 2008; Imai et al., 2005; Kuba et al., 2005), which might promote SARS. It will thus be interesting to determine whether SARS-CoV-2 also interferes with ACE2 expression.

Priming of coronavirus $\mathrm{S}$ proteins by host cell proteases is essential for viral entry into cells and encompasses $S$ protein cleavage at the S1/S2 and the S2' sites. The S1/S2 cleavage site of SARS-2-S harbors several arginine residues (multibasic), which indicates high cleavability. Indeed, SARS-2-S was efficiently cleaved in cells, and cleaved S protein was incorporated into VSV particles. Notably, the cleavage site sequence can determine the zoonotic potential of coronaviruses (Menachery et al., 2020; Yang et al., 2014, 2015), and a multibasic cleavage site was not present in RaTG13, the coronavirus most closely related to SARS-CoV-2. It will thus be interesting to determine whether the presence of a multibasic cleavage site is required for SARS-CoV-2 entry into human cells and how this cleavage site was acquired.

The $\mathrm{S}$ proteins of SARS-CoV can use the endosomal cysteine proteases CatB/L for S protein priming in TMPRSS2- cells (Simmons et al., 2005). However, S protein priming by TMPRSS2 but not $C a t B / L$ is essential for viral entry into primary target cells and for viral spread in the infected host (Iwata-Yoshikawa et al., 2019; Kawase et al., 2012; Zhou et al., 2015). The present study indicates that SARS-CoV-2 spread also depends on TMPRSS2 activity, althoug h we note that SARS-CoV- 2 infection of Calu- 3 cells was inhibited but not abrogated by camostat mesylate, likely reflecting residual $S$ protein priming by CatB/L. One can speculate that furin-mediated precleavage at the $\mathrm{S} 1 / \mathrm{S} 2$ site in infected cell might promote subsequent TMPRSS2-dependent entry into target cells, as reported for MERS-CoV (Kleine-Weber et al.
2018. Park et al. 2016). Collectively, our present findings and previous work highlight TMPRSS2 as a host cell factor that is critical for spread of several clinically relevant viruses, including influenza A viruses and coronaviruses (Gierer et al., 2013; Glowacka et al., 2011; Iwata-Yoshikawa et al., 2019; Kawase et al., 2012; Matsuyama et al., 2010; Shulla et al., 2011; Zhou et al., 2015). In contrast, TMPRSS2 is dispensable for development and homeostasis (Kim et al., 2006) and thus constitutes an attractive drug target. In this context, it is noteworthy that the serine protease inhibitor camostat mesylate, which blocks TMPRSS2 activity (Kawase et al., 2012; Zhou et al., 2015), has been approved in Japan for human use, but for an unrelated indication. This compound or related ones with potentially increased antiviral activity (Yamamoto et al., 2016) could thus be considered for off-labe treatment of SARS-CoV-2-infected patients.

Convalescent SARS patients exhibit a neutralizing antibody response that can be detected even 24 months after infection (Liu et al., 2006) and that is largely directed against the S protein. Moreover, experimental SARS vaccines, including recombinan $\mathrm{S}$ protein (He et al., 2006) and inactivated virus (Lin et al., 2007), induce neutralizing antibody responses. Although confirmation with infectious virus is pending, our results indicate that neutralizing antibody responses raised against SARS-S could offer some protection against SARS-CoV-2 infection, which may have implications for outbreak control.

In sum, this study provided key insights into the first step of SARS-CoV-2 infection, viral entry into cells, and defined potential targets for antiviral intervention.

\section{STAR $\star M E T H O D S$}

Detailed methods are provided in the online version of this paper and include the following:

- KEY RESOURCES TABLE

- IEAD CONTACT AND MATERIALS AVAllabILITY

- EXPERIMANTAL MODEL AND SUBJECT DETAILS O Cell cultures, primary cells, viral strains

- METHOD DETAILS

O Plasmids

Pseudotyping of VSV and transduction experiments

○ Quantification of cell viability

Figure 4. SARS-2-S Employs TMPRSS2 for S Protein Priming in Human Lung Cells

(A) Importance of activity of CatB/L or TMPRSS2 for host cell entry of SARS-CoV-2 was evaluated by adding inhibitors to target cells prior to transduction. E-64d and camostat mesylate block the activity of CatB/L and TMPRSS2, respectively (additional data for 293T cells transiently expressing ACE2 and Caco-2 cells are shown in Figure S3).

(B) To analyze whether TMPRSS2 can rescue SARS-2-S-driven entry into cells that have low CatB/L activity, 293T cells transiently expressing ACE2 alone or in combination with TMPRSS2 were incubated with CatB/L inhibitor E-64d or DMSO as control and inoculated with pseudotypes bearing the indicated viral surface proteins.

(C) Calu-3 cells were pre-incubated with the indicated concentrations of camostat mesylate and subsequently inoculated with pseudoparticles harboring the indicated viral glycoproteins.

indicated (D) Calu-3 cells wore pre-incubated with camostat mesylate and inter culture supernatants were determined by quantitative RT-PCR.

(E) In order to investigate whether serine protease activity is required for SARS-2-S-driven entry into human lung cells, primary human airway epithelial cells were incubated with camostat mesylate prior to transduction.

The average of three independent experiments conducted with triplicate or quadruplicate samples is shown in (A-E). Error bars indicate SEM. Statistical significance was tested by two-way ANOVA with Dunnett posttest. Cells that did not receive inhibitor served as reference in (A), (C), (D), and (E) whereas cells transfected with empty vector and not treated with inhibitor served as reference in (B). 

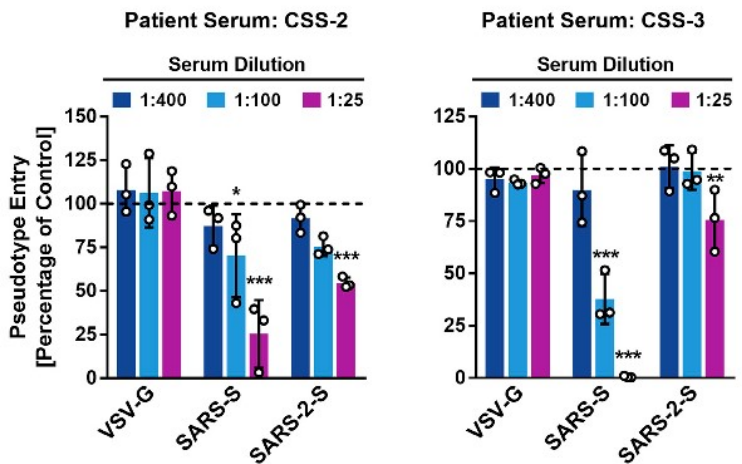

Patient Serum: CSS-4
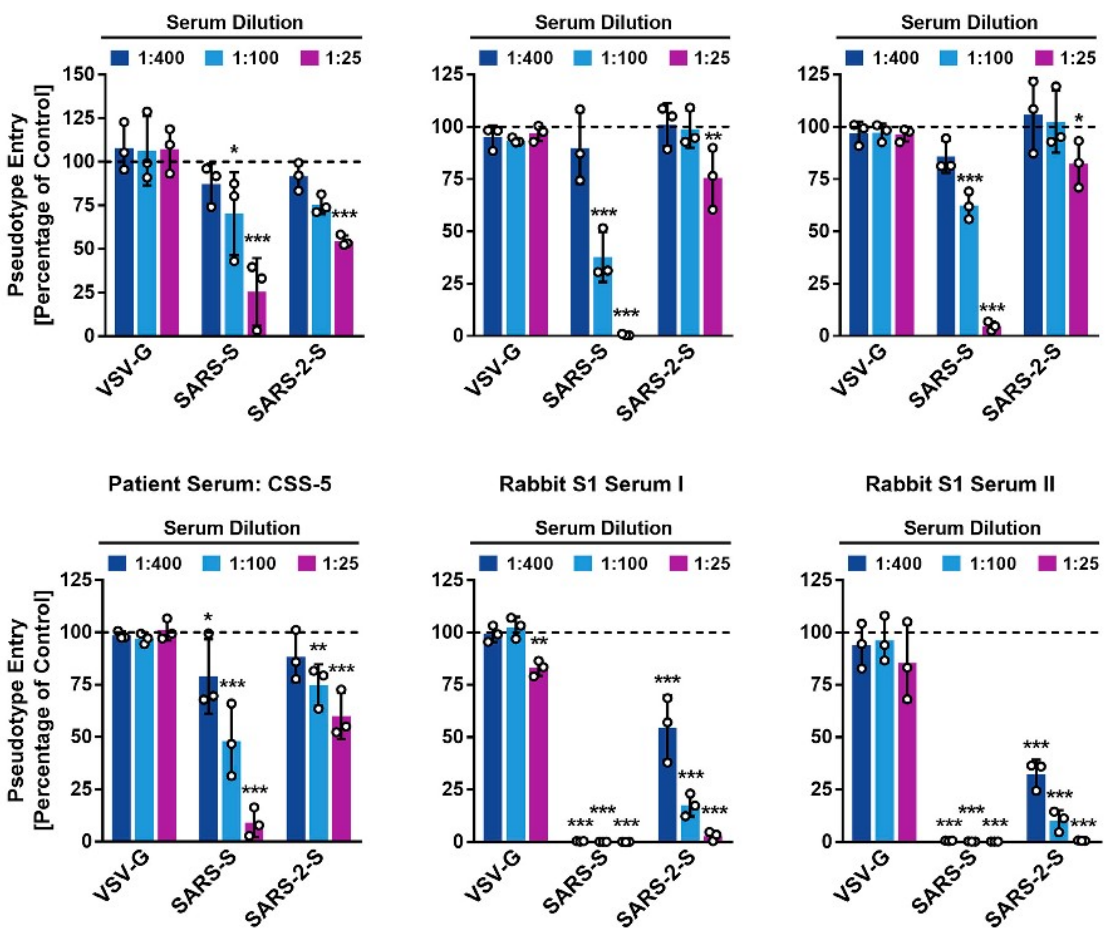

Figure 5. Sera from Convalescent SARS Patients Cross-Neutralize SARS-2-S-Driven Entry

Pseudotypes harboring the indicated viral surface proteins were incubated with different dilutions of sera from three convalescent SARS patients or sera from rabbits immunized with the S1 subunit of SARS-S and subsequently inoculated onto Vero cells in order to evaluate cross-neutral ization potential. The average of three independent experiments performed with triplicate samples is shown. Error bars indicate SEM. Statistical significance was tested by two-way ANOVA with three independentex

Analysis of SARS-2-S expression and particle incorporation

o Infection with authentic SARS-CoV-2

○ Sera

Phylogenetic analysis

- QUANTIFICATION AND STATISTICAL ANALYSIS

- DATA AND CODE AVAILABILITY

\section{ACKNOWLEDGMENTS}

We thank Heike Hofmann-Winkler for discussion, Andrea Maisner for Nipah F and $\mathrm{G}$ expression plasmids, Anette Teichmann for technical assistance, and Roberto Cattaneo for plasmid pCG1. We acknowledge the support of the non-profit foundation HTCR, which holds human tissue on trust, making it broadly available for research on an ethical and legal basis. We gratefully acknowledge the authors and the originating and submitting laboratories for their sequence and metadata shared through GISAID, on which this research is based. This work was supported by BMBF (RAPID Consortium, 01KI1723D

278 Cell 181, 271-280, April 16, 2020 and $01 \mathrm{KI} 1723 \mathrm{~A}$ to C.D. and S.P.) and German Research Foundation (DFG) (WU 929/1-1 to N.-H.W.).

AUTHOR CONTRIBUTIONS

Conceptualization, M.H. and S.P.; Formal analysis, M.H., H.K.-W. M.A.M. and S.P.; Investigation, M.H., H.K.-W., S.S., N.K., T.H., N.-H.W., and M.A.M.; Resources, T.H., S.E., T.S.S., G.H., A.N., M.A.M., and C.D.; Writing - Original Draft, M.H. and S.P.; Writing - Review \& Editing, all authors; Funding acquisition, S.P., N.-H.W., and C.D.

DECLARATION OF INTERESTS

The authors declare no competing interests.

Received: February 6, 2020

Revised: February 13, 2020

Accepted: February 25, 2020

Published: March 5, 2020 


\section{REFERENCES}

Berger Rentsch, M., and Zimmer, G. (2011). A vesicular stomatitis virus replcon-based bioassay for the rapid and sensitive determination of multi-species type I interferon. PLoS ONE 6, e25858.

Bertram, S., Glowacka, I., Blazejewska, P., Soilleux, E., Allen, P., Danisch, S. Steffen, I., Choi, S.Y., Park, Y., Schneider, H., et al. (2010). TMPRSS2 and TMPRSS facilita Inpsin. Y. Sclependent spread of influenza virus in Caco-2 TMPRSS4 facilitate trypsin-indep
cells. J. Virol. 84, 10016-10025.

Bertram, S., Heurich, A., Lavender, H., Gierer, S., Danisch, S., Perin, P., Lucas, J.M., Nelson, P.S., Pöhlmann, S., and Soilleux, E.J. (2012). Influenza and SARS-coronavirus activating proteases TMPRSS2 and HAT are expressed at multiple sites in human respiratory and gastrointestinal tracts. PLOS ONE 7, e35876.

Bossart, K.N., Wang, L.F., Flora, M.N., Chua, K.B., Lam, S.K., Eaton, B.T., and Broder, C.C. (2002). Membrane fusion tropism and heterotypic functional activities of the Nipah virus and Hendra virus envelope glycoproteins. J. Virol. 76, 11186-11198.

Brinkmann, C., Hoffmann, M., Lübke, A., Nehlmeier, I., Krämer-Kühl, A., Winkler, M., and Pöhlmann, S. (2017). The glycoprotein of vesicular stomatitis vinus promotes release of virus-like particles from tetherin-positive cells. PLOS ONE 12, e0189073.

Buchholz, U., Müller, M.A., Nitsche, A., Sanewski, A., Wevering, N., BauerBalci, T., Bonin, F., Drosten, C., Schweiger, B., Wolff, T., et al. (2013). Contact investigation of a case of human novel coronavirus infection treated in a German hospital, October-November 2012. Euro Surveill. 18, 20406.

Chan, J.F., Yuan, S., Kok, K.H., To, K.K., Chu, H., Yang, J., Xing, F., Liu, J., Yip, C.C., Poon, R.W., et al. (2020). A familial cluster of pneumonia associated with the 2019 novel coronavirus indicating person-to-person transmission: a study of a family cluster. Lancet 395, 514-523.

Corman, V.M., Lienau, J., and Witzenrath, M. (2019). [Coronaviruses as the cause of respiratory infections]. Internist (Berl.) 60, 1136-1145.

Corman, V.M., Landt, O., Kaiser, M., Molenkamp, R., Meijer, A., Chu, D.K, Bleicker, T., Brünink, S., Schneider, J., Schmidt, M.L., et al. (2020). Detection of 2019 novel coronavirus (2019-nCoV by real-time RT-PCR. Euro Surveill. 25 https://doi.org/10.2807/1560-7917.ES. 2020.25.3.2000045.

de Wit, E., van Doremalen, N., Falzarano, D., and Munster, V.J. (2016). SARS and MERS: recent insights into emerging coronaviruses. Nat. Rev. Microbio. 14, 523-534.

Ding, Y., He, L., Zhang, Q., Huang, Z., Che, X., Hou, J., Wang, H., Shen, H., Qiu, Ding, Y. He L. Zhang, Q. Huang, Z, Che,X., Hou, J.,Wang, H, Shen, H, Qu, (SARS) associated) (SARS) associated coronavirus (SARS-CoV) in SARS patients: implications
pathogenesis and virus transmission pathways. J. Pathol. 203, 622-630. pathogenesis and virus transmission pathways. J. Pathol. 203, 622-630. Fehr, A.R., Channappanavar, R., and Perlman, S. (2017). Middle East Respiratory Syndrome: Emergence of a Pathogenic Human Coronavirus. Annu. Rev. Med. 68, 387-399.

Ge, X.Y., Li, J.L., Yang, X.L., Chmura, A.A., Zhu, G., Epstein, J.H., Mazet, J.K. Hu, B., Zhang, W., Peng, C., et al. (2013). Isolation and characterization of a b. SARS-like coronavirus that uses the ACE2 receptor. Nature 503, 535-538.

Gierer, S., Bertram, S., Kaup, F., Wrensch, F., Heurich, A., Krämer-Kühl, A. Welsch, K., Winkler, M., Meyer, B., Drosten, C., et al. (2013). The spike protein of the emerging betacoronavirus EMC uses a novel coronavirus receptor for entry, can be activated by TMPRSS2, and is targeted by neutralizing antientry, can be activated by TM
bodies. J. Virol. $87,5502-5511$.

Glowacka, I., Bertram, S., Müller, M.A., Allen, P., Soilleux, E., Pfefferle, S., Steffen, I., Tsegaye, T.S., He, Y, Gnirss, K., et al. (2011). Evidence that TMPRSS activates the severe acute respiratory syndrome coronavirus spike protein for membrane fusion and reduces viral control by the humoral immune response. J. Virol. $85,4122-4134$.

Gu, J., Gong, E., Zhang, B., Zheng, J., Gao, Z., Zhong, Y., Zou, W., Zhan, J. Wang, S., Xie, Z, et al. (2005). Multiple organ infection and the pathogenesis of SARS. J. Exp. Med. 202, 415-424.
Guan, Y., Zheng, B.J., He, Y.Q., Liu, X.L., Zhuang, Z.X., Cheung, C.L., Luo, S.W., Li, P.H., Zhang, L.J., Guan, Y.J., et al. (2003). Isolation and characterizaion of viruses related to the SARS coronavirus from animals in southern China. Science 302, 276-278.

Haga, S., Yamamoto, N., Nakai-Murakami, C., Osawa, Y., Tokunaga, K., Sata, T., Yamamoto, N., Sasazuki, T., and Ishizaka, Y. (2008). Modulation of TNFalpha-converting enzyme by the spike protein of SARS-COV and ACE2 induces TNF-alpha production and facilitates viral entry. Proc. Natt. Acad. Sci. USA 105, 7809-7814.

Hamming, I., Timens, W., Bulthuis, M.L., Lely, A.T., Navis, G., and van Goor, H. (2004). Tissue distribution of ACE2 protein, the functional receptor for SARS coronavirus. A first step in understanding SARS pathogenesis. J. Pathol. 203, 631-637.

He, Y., Li, J., Heck, S., Lustigman, S., and Jiang, S. (2006). Antigenic and immunogenic characterization of recombinant baculovins-expressed severe acute respiratory syndrome coronavirus spike protein: implication for vaccine design. J. Virol. 80, 5757-5767.

Hoffmann, M., Müller, M.A., Drexler, J.F., Glende, J., Erdt, M., Gützkow, T., Losemann, C., Binger, T., Deng, H., Schwegmann-Weßels, C., et al. (2013). Differential sensitivity of bat cells to infection by enveloped RNA viruses: coronaviruses, paramyxovinuses, filoviruses, and influenza viruses. PLOS ONE 8 , e72942.

Hofmann, H., Geier, M., Marzi, A., Krumbiegel, M., Peipp, M., Fey, G.H., Gramberg, T., and Pöhlmann, S. (2004a). Susceptibility to SARS coronavirus S protein-driven infection correlates with expression of angiotensin converting enzyme 2 and infection can be blocked by soluble receptor. Biochem. Biophys. Res. Commun. 319, 1216-1221.

Hofmann, H., Hattermann, K., Marzi, A., Gramberg, T., Geier, M., Krumbiegel, M. Kuate, S., Uberla, K., Niedrig, M., and Pöhlmann, S. (2004b). S protein of severe acute respiratory syndrome-associated coronavirus mediates entry into hepatoma cell lines and is targeted by neutralizing antibodies in infected patients. J. Virol. 78, 6134-6142.

Hofmann, H., Pyrc, K., van der Hoek, L., Geier, M., Berkhout, B., and Pöhlmann, S. (2005). Human coronavirus NL63 employs the severe acute respiralony syndrome coronavirus receptor for cellutar entry. Proc. Nath Acad. Sci. USA 102, 7988-7993.

Huang, C., Wang, Y., Li, X., Ren, L., Zhao, J., Hu, Y., Zhang, L., Fan, G., Xu, J. $\mathrm{Gu}, \mathrm{X}$., et al. (2020). Clinical features of patients infected with 2019 novel coronavirus in Wuhan (China: Lancet).

Imai, Y., Kuba, K., Rao, S., Huan, Y., Guo, F., Guan, B., Yang, P., Sarao, R., Wada, T., Leong-Poi, H., et al. (2005). Angiotensin-converting enzyme 2 protects from severe acute lung failure. Nature 436, 112-116.

Iwata-Yoshikawa, N., Okamura, T., Shimizu, Y., Hasegawa, H., Takeda, M. and Nagata, N. (2019). TMPRSS2 Contributes to Virus Spread and Immunopathology in the Airways of Murine Models after Coronavirus Infection. J. Virol. 93 https://doi.org/10.1128/JVI.01815-18.

Kawase, M. Shirato, K, van der Hoek, L, Taguchi, F, and Matsuyama, S. (2012). Simultaneous treatment of human bronchial epithelial cells with serine and cysteine protease inhibitors prevents severe acute respiratory syndrome coronavirus entry. J. Virol. 86, 6537-6545.

Kim, T.S., Heinlein, C., Hackman, R.C., and Nelson, P.S. (2006). Phenotypic analysis of mice lacking the Tmprss2-encoded protease. Mol. Cell. Biol. 26 , 965-975.

Kleine-Weber, H., Elzayat, M.T., Hoffmann, M., and Pöhlmann, S. (2018). Functional analysis of potential cleavage sites in the MERS-coronavirus spike protein. Sci. Rep. 8, 16597.

Kleine-Weber, H., Elzayat, M.T., Wang, L., Graham, B.S., Müller, M.A., Drosten, C. Pöhlmann, S. and Hoffmann, M. (2019). Mutations in the Spike Prote of Middle East Respiratory Syndrome Coronavirus Transmitted in Korea inMiddlo East Respiration Transmitted in Korea InVirol. 93 https:/ .

Kuba, K., Imai, Y., Rao, S., Gao, H., Guo, F., Guan, B., Huan, Y., Yang, P. Zhang, Y., Deng, W., et al. (2005). A crucial role of angiotensin converting 
enzyme 2 (ACE2) in SARS coronavirus-induced lung injury. Nat. Med. 11 $875-879$.

Kumar, S., Stecher, G., Li, M., Knyaz, C., and Tamura, K. (2018). MEGA X: Molecular Evolutionary Genetics Analysis across Computing Platforms. Mol Bid Evol 35, 1547-1549.

Lau, S.K., Woo, P.C., Li, K.S., Huang, Y., Tsoi, H.W., Wong, B.H., Wong, S.S. Leung, S.Y., Chan, K.H., and Yuen, K.Y. (2005). Severe acute respiratory syndrome coronavirus-like virus in Chinese horseshoe bats. Proc. Natl. Acad. Sci. USA 102, 14040-14045.

Li, W., Moore, M.J., Vasilieva, N., Sui, J., Wong, S.K., Berne, M.A., Somasurdaran, M., Sullivan, J.L., Luzuriaga, K., Greenough, T.C., et al. (2003). Angiotensin-converting enzyme 2 is a functional receptor for the SARS coronavirus. Nature 426, 450-454.

Li, F., Li, W., Farzan, M., and Harrison, S.C. (2005a). Structure of SARS coronavirus spike receptor-binding domain complexed with receptor. Science 309 1864-1868.

Li, W., Zhang, C., Sui, J., Kuhn, J.H., Moore, M.J., Luo, S., Wong, S.K., Huang, I.C., Xu, K., Vasilieva, N., et al. (2005b). Receptor and viral determinants SARS-coronavirus adaptation to human ACE2. EMBO J. 24, 1634-1643.

Li, W., Hulswit, R.J.G., Widjaja, I., Raj, V.S., McBride, R., Peng, W., Widagdo, W. Tortorici, M.A., van Dieren, B., Lang, Y., et al. (2017). Identification of sialic acid-binding function for the Middle East respiratory syndrome coronavirus spike glycoprotein. Proc. Natt. Acad. Sci. USA 114, E8508-E8517.

Lin, J.T., Zhang, J.S., Su, N., Xu, J.G., Wang, N., Chen, J.T., Chen, X., Liu, Y.X, Gao, H., Jia, Y.P., et al. (2007). Safety and immunogenicity from a phase I tria of inactivated severe acute res piratory syndrome coronavirus vaccine. Antivir. Ther. (Lond.) 12,1107-1113.

Liu, W. Fontanet, A., Zhang, P.H., Zhan, L., Xin, Z.T., Baril, L., Tang, F., Lv, H. and Cao, W.C. (2006). Two-year prospective study of the humoral immune response of patients with severe acute respiratory syndrome. J. Infect. Dis. 193, 792-795

Matsuyama, S., Nagata, N., Shirato, K., Kawase, M., Takeda, M., and Taguchi, F. (2010). Efficient activation of the severe acute respiratory syndrome coronavirus spike protein by the transmembrane protease TMPRSS2. J. Virol. 84, 12658-12664.

Menachery, V.D., Dinnon, K.H., III, Yount, B.L., Jr., McAnarney, E.T., Gralinski, L.E., Hale, A., Graham, R.L., Scobey, T., Anthony, S.J., Wang, L., et al. (2020) Trypsin treatment unlocks barier for zoonotic bat coronaviruses infection. J. Virol. 94 https://doi.org/10.1128/JVI.01774-19.

Munster, V.J., Koopmans, M., van Doremalen, N., van Riel, D., and de Wit, E. (2020). A Novel Coronavirus Emerging in China - Key Questions for Impact Assessment. N. Engl. J. Med. 382, 692-694.

Park, J.E., Li, K., Barlan, A., Fehr, A.R., Perlman, S., McCray, P.B., Jr., and Gallagher, T. (2016). Proteolytic processing of Middle East respiratory syndrome coronavirus spikes expands virus tropism. Proc. Natt. Acad. Sci. USA 113 12262-12267.

Park, Y.J., Walls, A.C., Wang, Z, Sauer, M.M., Li, W., Tortorici, M.A., Bosch, B.J., DiMaio, F., and Veesler, D. (2019). Structures of MERS-CoV spike glycoprotein incomplex with siabside attachment receptors. Nat. Struct Mot. Bio26, 1151-1157.

Raj, V.S., Mou, H., Smits, S.L., Dekkers, D.H., Müller, M.A., Dijkman, R., Muth, D., Demmers, J.A., Zaki, A., Fouchier, R.A., et al. (2013). Dipeptidyl peptidase is a functional receptor for the emerging human coronavirus-EMC. Nature 495 251-254

Shieh, W.J., Hsiao, C.H., Paddock, C.D., Guarner, J., Goldsmith, C.S., Tatt, K. Packard, M., Mueller, L., Wu, M.Z., Rollin, P., et al. (2005). Immunohisto- chemical, in situ hybridization, and ultrastructural localization of SARS-associted coronavirus in lung of a fatal case of severe acute respiratory syndrome in Taiwan. Hum. Pathol. 36, 303-309.

Shirato, K., Kanou, K., Kawase, M., and Matsuyama, S. (2016). Clinical Isolates of Human Coronavirus 229E Bypass the Endosome for Cell Entry. J. Virol. 91 https://doi. org/10.1128/JVI. 01387-16.

Shirato, K., Kawase, M., and Matsuyama, S. (2018). Wild-type human coronaviruses prefer cell-surface TMPRSS2 to endosomal cathepsins for cell entry. Virology 517, 9-15.

Shulla, A., Heald-Sargent, T., Subramanya, G. Zhao, J., Perlman, S., and Gallagher, T. (2011). A transmembrane serine protease is linked to the severe acute respiratory syndrome coronavirus receptor and activates virus entry. J. Virol. 85, 873-882.

Simmons, G., Gosalia, D.N., Rennekamp, A.J., Reeves, J.D., Diamond, S.L., and Bates, P. (2005). Inhibitors of cathepsin L prevent severe acute respirator syndrome coronavirus entry, Proc. Natl. Acad. Sci. USA 102, 11876-11881.

Wang, C., Horby, P.W., Hayden, F.G., and Gao, G.F. (2020). A novel coronavirus outbreak of global health concern. Lancet 395, 470-473.

WHO (2004). Summary of probable SARS cases with onset of illness from November 2002 to 31 July 2003. https:/wwww who.int/csr/sars/country/ table2004_04_21/en/.

WHO (2020). Novel Coronavirus(2019-nCoV) Situation Report 23. https:/ www.who.int/docs/default-source/coronaviruse/situation-reports/

20200212-sitrep-23-ncov.pdf?sfvrsn\&equals;41e9fb78_4.

Wu, N.H., Yang, W., Beineke, A., Dijkman, R., Matrosovich, M., Baumgärtner, W., Thiel, V., Valentin-Weigand, P., Meng, F., and Herrler, G. (2016). The differentiated airway epithelium infected by influenza viruses maintains the barrier function despite a dramatic loss of ciliated cells. Sci. Rep. 6, 39668.

Yamamoto, M., Matsuyama, S., Li, X., Takeda, M., Kawaguchi, Y., Inoue, J.I., and Matsuda, Z. (2016). Identification of Nafamostat as a Potent Inhibitor o Middle East Respiratory Syndrome Coronavirus S Protein-Mediated Membrane Fusion Using the Split Protein-Based Cell-Cell Fusion Assay. AntimiCrob. Agents Chemother 60, 6532-6539.

Yang, Y., Du, L., Liu, C., Wang, L., Ma, C., Tang, J., Baric, R.S., Jiang, S., and $\mathrm{Li}$, F. (2014). Receptor usage and cell entry of bat coronavirus HKU4 provide insight into bat-to-human transmission of MERS coronavirus. Proc. Natt. Acad. Sci. USA 111, 12516-12521.

Yang, Y., Liu, C., Du, L., Jiang, S., Shi, Z., Baric, R.S., and Li, F. (2015). Two Mutations Were Critical for Bat-to-Human Transmission of Middle East Respiratory Syndrome Coronavirus. J. Virol. 89, 9119-9123.

Yeager, C.L., Ashmun, R.A., Williams, R.K., Cardellichio, C.B., Shapiro, L.H. Yook, A. T, and Holmes, KV (1992). Human aminopeptidase N is a receptor for human coronavirus 229E. Nature 357, 420-422.

Zhou, Y., Vedantham, P., Lu, K., Agudelo, J., Carrion, R., J., Nunneley, J.W. Barnard, D., Pöhlmann, S., McKerrow, J.H., Renslo, A.R., and Simmons, G. (2015). Protease inhibitors targeting coronavirus and filovirus entry. Antiviral Res. 116, 76-84.

Zhou, P., Yang, X.L., Wang, X.G., Hu, B., Zhang, L., Zhang, W., Si, H.R., Zhu, Y., Li, B., Huang, C.L., et al. (2020). A pneumonia outbreak associated with a new coronavirus of probable bat origin. Nature. https://doi.org/10.1038/ s41586-020-2012-7.

Zhu, N., Zhang, D., Wang, W., Li, X., Yang, B., Song, J., Zhao, X., Huang, B. Shi, W. Lu, R. D. Wan, W in China, 2019. N Engl J Med. 382, 727-733. 
Manuscripts

STAR $\star M E T H O D S$

KEY RESOURCES TABLE

\begin{tabular}{|c|c|c|}
\hline REAGENT or RESOURCE & SOURCE & IDENTIFIER \\
\hline \multicolumn{3}{|l|}{ Antibodies } \\
\hline Monoclonal anti-HA antibody produced in mouse & Sigma-Aldrich & $\begin{array}{l}\text { Cat.\#: H3663; } \\
\text { RRID: AB_262051 }\end{array}$ \\
\hline Monoclonal anti- $\beta$-actin antibody produced in mouse & Sigma-Aldrich & $\begin{array}{l}\text { Cat.\#: A5441; } \\
\text { RRID: AB_476744 }\end{array}$ \\
\hline Monoclonal anti-VSV-M $(23 \mathrm{H} 12)$ antibody & KeraFast & $\begin{array}{l}\text { Cat.\#: EB0011; } \\
\text { RRID: AB_2734773 }\end{array}$ \\
\hline Polyclonal anti-ACE2 antibody & R\&D Systems & $\begin{array}{l}\text { Cat.\#: AF933; } \\
\text { RRID: AB_355722 }\end{array}$ \\
\hline Polyclonal anti-DC-SIGN antibody & Santa Cruz & Cat.\#: sc-11038; RRID:AB_639038 \\
\hline Monoclonal anti-mouse, peroxidase-coupled & Dianova & $\begin{array}{l}\text { Cat.\#: } 115-035-003 \\
\text { RRID:AB_10015289 }\end{array}$ \\
\hline $\begin{array}{l}\text { Anti-VSV-G antibody (11, produced from CRL-2700 mouse } \\
\text { hybridoma cells) }\end{array}$ & ATCC & $\begin{array}{l}\text { Cat.\# CRL-2700; } \\
\text { RRID:CVCL_G654 }\end{array}$ \\
\hline \multicolumn{3}{|l|}{ Bacterial and Virus Strains } \\
\hline$V_{S V}^{*} \Delta G-F L u c$ & (Berger Rentsch and Zimmer, 2011) & N/A \\
\hline SARS-CoV-2 isolate Munich 929 & Laboratory of Christian Drosten & N/A \\
\hline One Shot ${ }^{\mathrm{TM}}$ OmniMAX'M 2 T1R Chemically Competent $E$. coli & ThermoFisher Scientific & Cat.\#: C854003 \\
\hline \multicolumn{3}{|l|}{ Biological Samples } \\
\hline Patient serum, CSS-2 & Laboratory of Christian Drosten & N/A \\
\hline Patient serum, CSS-3 & Laboratory of Andreas Nitsche & $\mathrm{N} / \mathrm{A}$ \\
\hline Patient serum, CSS-4 & Laboratory of Andreas Nitsche & N/A \\
\hline Patient serum, CSS- 5 & Laboratory of Andreas Nitsche & $\mathrm{N} / \mathrm{A}$ \\
\hline Rabbit serum, anti-SARS-S1 rabbit I & Laboratory of Stefan Pöhlmann & N/A \\
\hline Rabbit serum, anti-SARS-S1 rabbit II & Laboratory of Stefan Pöhlmann & $\mathrm{N} / \mathrm{A}$ \\
\hline \multicolumn{3}{|l|}{ Chemicals, Peptides, and Recombinant Proteins } \\
\hline Camostat mesylate & Sigma-Aldrich & SML0057 \\
\hline$E-64 d$ & Sigma-Aldrich & E8640 \\
\hline Ammonium chloride & Carl Roth & Cat.\#: 5050.2 \\
\hline \multicolumn{3}{|l|}{ Critical Commercial Assays } \\
\hline Beetle-Juice Kit & PJK & Cat.\#: 102511 \\
\hline CellTiter-Glo (Buminescent Cell Viability Assay & Promega & Cat.\#: G7570 \\
\hline \multicolumn{3}{|l|}{ Experimental Models: Cell Lines } \\
\hline A549 & Laboratory of Georg Herrler & $\begin{array}{l}\text { ATCC Cat\# CRM-CCL-185; } \\
\text { RRID:CVCL_0023 }\end{array}$ \\
\hline BEAS-2B & Laboratory of Stefan Pöhlmann & $\begin{array}{l}\text { ATCC Cat\# CRL-9609; } \\
\text { RRID:CVCL_0168 }\end{array}$ \\
\hline Calu-3 & Laboratory of Stephan Ludwig & $\begin{array}{l}\text { ATCC Cat\# HTB-55; } \\
\text { RRID:CVCL_0609 }\end{array}$ \\
\hline $\mathrm{NCl}-\mathrm{H} 1299$ & Laboratory of Stefan Pöhlmann & $\begin{array}{l}\text { ATCC Cat\# CRL-5803; } \\
\text { RRID:CVCL_0060 }\end{array}$ \\
\hline Huh-7 & Laboratory of Thomas Pietschmann & $\begin{array}{l}\text { JCRB Cat\# JCRB0403; } \\
\text { RRID:CVCL_0336 }\end{array}$ \\
\hline Caco-2 & Laboratory of Stefan Pöhlmann & $\begin{array}{l}\text { ATCC Cat\# HTB-37; } \\
\text { RRID:CVCL_0025 }\end{array}$ \\
\hline
\end{tabular}




\begin{tabular}{|c|c|c|}
\hline \multicolumn{3}{|l|}{ Continued } \\
\hline REAGENT or RESOURCE & SOURCE & IDENTIFIER \\
\hline Vero & Laboratory of Andrea Maisner & $\begin{array}{l}\text { ATCC Cat\# CRL-1586; } \\
\text { RRID:CVCL_0574 }\end{array}$ \\
\hline Vero-TMPRSS2 & This paper & N/A \\
\hline LLC-PK1 & Laboratory of Georg Herrler & $\begin{array}{l}\text { ATCC Cat\# CRL-1392; } \\
\text { RRID:CVCL_0391 }\end{array}$ \\
\hline MDBK & Laboratory of Georg Herrler & $\begin{array}{l}\text { ATCC Cat\# CCL-22; } \\
\text { RRID:CVCL_0421 }\end{array}$ \\
\hline MDCKII & Laboratory of Georg Herrler & $\begin{array}{l}\text { ATCC Cat\# CRL-2936; } \\
\text { RRID:CVCL_B034 }\end{array}$ \\
\hline RhiLw/1.1 & $\begin{array}{l}\text { Laboratory of Christian Drosten, } \\
\text { Laboratory of Marcel A. Müller }\end{array}$ & $\begin{array}{l}\text { N/A; } \\
\text { RRID: CVCL_RX22 }\end{array}$ \\
\hline MyDauLu/47.1 & $\begin{array}{l}\text { Laboratory of Christian Drosten, } \\
\text { Laboratory of Marcel A. Müller }\end{array}$ & $\begin{array}{l}\text { N/A; } \\
\text { RRID: CVCL_RX18 }\end{array}$ \\
\hline BHK-21 & Laboratory of Georg Herrler & $\begin{array}{l}\text { ATCC Cat\# CCL-10; } \\
\text { RRID:CVCL_1915 }\end{array}$ \\
\hline $\mathrm{NIH} / 3 \mathrm{~T} 3$ & Laboratory of Stefan Pöhlmann & $\begin{array}{l}\text { ATCC Cat\# CRL-1658; } \\
\text { RRID:CVCL_0594 }\end{array}$ \\
\hline HAE & $\begin{array}{l}\text { HTCR Foundation (Human Tissue } \\
\text { and Cell Research) }\end{array}$ & N/A \\
\hline 293T & DSMZ & $\begin{array}{l}\text { Cat.\#: ACC-635; } \\
\text { RRID: CVCL_0063 }\end{array}$ \\
\hline \multicolumn{3}{|l|}{ Oligonucleotides } \\
\hline $\begin{array}{l}\text { SARS-2-S (BamHI) F AAGGCCGGATCCGCCACCATGTTTCT } \\
\text { GCTGACCACCAAGC }\end{array}$ & Sigma-Aldrich & N/A \\
\hline $\begin{array}{l}\text { SARS-2-S (Xbal) R AAGGCCTCTAGATTAGGTGTAGTGCAG } \\
\text { TITCACG }\end{array}$ & Sigma-Aldrich & N/A \\
\hline $\begin{array}{l}\text { SARS-2-S-HA (Xbal) R AAGGCCTCTAGATTACGCATAATCC } \\
\text { GGCACATCATACGGATAGGTGTAGTGCAGTTTCACG }\end{array}$ & Sigma-Aldrich & N/A \\
\hline WH-Ssyn 651F CAAGATCTACAGCAAGCACACC & Sigma-Aldrich & N/A \\
\hline WH-Ssyn 1380F GTCGGCGGCAACTACAATTAC & Sigma-Aldrich & N/A \\
\hline WH-Ssyn 1992F CTGTCTGATCGGAGCCGAGCAC & Sigma-Aldrich & N/A \\
\hline WH-Ssyn 2648F TGAGATGATCGCCCAGTACAC & Sigma-Aldrich & N/A \\
\hline WH-Ssyn 3286F GCCATCTGCCACGACGGCAAAG & Sigma-Aldrich & N/A \\
\hline \multicolumn{3}{|l|}{ Recombinant DNA } \\
\hline Synthetic, codon-optimized (humanized) SARS-2-S & ThermoFisher Scientific (GeneArt) & N/A \\
\hline Plasmid: pCG1-SARS-S & (Hoffmann et al., 2013) & N/A \\
\hline Plasmid:pCG1-SARS-S-HA & This paper & N/A \\
\hline Plasmid: pCG1-SARS-2-S & This paper & N/A \\
\hline Plasmid: pCG1-SARS-2-S-HA & This paper & N/A \\
\hline Plasmid: pCAGGS-229E-S & (Hofmann et al., 2005) & N/A \\
\hline Plasmid: pCAGGS-MERS-S & (Gierer et al., 2013) & N/A \\
\hline Plasmid: pCAGGS-VSV-G & (Brinkmann et al., 2017) & N/A \\
\hline Plasmid: pCAGGS-NiV-F & Laboratory of Andrea Maisner & N/A \\
\hline Plasmid: pCAGGS-NiV-G & Laboratory of Andrea Maisner & N/A \\
\hline Plasmid: pCG1-hACE2 & (Hoffmann et al., 2013) & N/A \\
\hline Plasmid: pCG1-batACE2 & (Hoffmann et al., 2013) & N/A \\
\hline Plasmid: pCG1-hAPN & (Hofmann et al., 2004a) & N/A \\
\hline Plasmid: pQCXIP-DsRed-hDPP4 & (Kleine-Weber et al., 2018) & N/A \\
\hline Plasmid: pQCXIBL-hTMPRSS2 & (Kleine-Weber et al., 2018) & N/A \\
\hline Plasmid: pCG1 & Laboratory of Roberto Cattaneo & N/A \\
\hline Plasmid: pCAGGS-DsRed & Laboratory of Stefan Pöhlmann & $\mathrm{N} / \mathrm{A}$ \\
\hline
\end{tabular}

e2 Cell 181, 271-280.e1-e5, April 16, 2020 


\begin{tabular}{lll}
\hline Continued & & \\
\hline REAGENT or RESOURCE & SOURCE & IDENTIFIER \\
\hline Plasmid: pCAGGS-eGFP & Laboratory of Stefan Pöhlmann & N/A \\
\hline Software and Algorithms & & \\
\hline Hidex Sense Microplate Reader Software & Hidex Deutschland Vertrieb GmbH & https://www.hidex.de/ \\
ChemoStar Imager Software (version v.0.3.23) & Intas Science Imaging Instruments & https://www.intas.de/ \\
& GmbH & https://www.megasoftware.net \\
MEGA 7.0.26 & Kumar et al., 2018 & https://www.adobe.com/ \\
Adobe Photoshop CS5 Extended (version 12.0 x 32) & Adobe & https://www.graphpad.com/ \\
GraphPad Prism (version 8.3.0(538)) & GraphPad Software & https://products.office.com/ \\
Microsoft Office Standard 2010 (version 14.0.7232.5000) & Microsoft Corporation &
\end{tabular}

\section{LEAD CONTACT AND MATERIALS AVAILABILITY}

Requests for material can be directed to Markus Hoffmann (mhoffmann@dpz.eu) and the lead contact, Stefan Pöhlmann (spoehlmann@dpz.eu). All materials and reagents will be made available upon installment of a material transfer agreement (MTA).

\section{EXPERIMANTAL MODEL AND SUBJECT DETAILS}

Cell cultures, primary cells, viral strains

All cell lines were incubated at $37^{\circ} \mathrm{C}$ and $5 \% \mathrm{CO}_{2}$ in a humidified atmosphere. 293T (human, kidney), BHK-21 (Syrian hamster, kidney cells), Huh-7 (human, liver), LLC-PK1 (pig, kidney), MRC-5 (human, lung), MyDauLu/47.1 (Daubenton's bat [Myotis daubentonii], lung), NIH/3T3 (Mouse, embryo), RhiLu/1.1 (Halcyon horseshoe bat [Rhinolophus alcyone], lung) and Vero (African green monkey, kidney) cells were incubated in Dulbecco's' modified Eagle medium (PAN-Biotech). Calu-3 (human, lung), Caco-2 (human, colon), MDBK (cattle, kidney) and MDCKII (Dog, kidney) cells were incubated in Minimum Essential Medium (ThermoFisher Scientific). A549 (human, lung), BEAS-2B (human, bronchus) and NCI-H1299 (human, lung) cells were incubated in DMEM/F-12 Medium with Nutrient Mix (ThermoFisher Scientific). Vero cells stably expressing human TMPRSS2 were generated by retroviral transduction and blasticidin-based selection. All media were supplemented with $10 \%$ fetal bovine serum (Biochrom), $100 \mathrm{U} / \mathrm{mL}$ of penicillin and $0.1 \mathrm{mg} / \mathrm{mL}$ of streptomycin (PAN-Biotech), 1x non-essential amino acid solution (10x stock, PAA) and $10 \mathrm{mM}$ sodium pyruvate (ThermoFisher Scientific). For seeding and subcultivation, cells were first washed with phosphate buffered saline (PBS) and then incubated in the presence of trypsin/EDTA solution (PAN-Biotech) until cells detached. Transfection was carried out by calciumphosphate precipitation. Lung tissue samples were obtained and experimental procedures were performed within the framework of the non-profit foundation HTCR, including the informed patient's consent.

For preparation of human airway epithelial cells, bronchus tissue was derived from patients undergoing pulmonary resection and was provided by the Biobank of the Department of General, Visceral, and Transplant Surgery, Ludwig-Maximilians- University Munich. Primary human airway epithelial cells were subsequently isolated as described (Wu et al., 2016). In brief, tissue with a length of approximately $10 \mathrm{~mm}$ and a diameter of $8 \mathrm{~mm}$ was collected and incubated for $24 \mathrm{~h}$ at $4{ }^{\circ} \mathrm{C}$ with DMEM (GIBCO) containing $1 \mathrm{mg} / \mathrm{mL}$ protease type XIV and $10 \mu \mathrm{g} / \mathrm{mL}$ DNase I, 100 units $/ \mathrm{mL}$ penicillin and $100 \mu \mathrm{g} / \mathrm{mL}$ streptomycin, $2.5 \mu \mathrm{g} / \mathrm{mL}$ amphotericin $\mathrm{B}$, and $50 \mu \mathrm{g} / \mathrm{mL}$ gentamicin (GIBCO). The epithelial cells were then harvested from the mucosal surface using the scalpel and were resuspended in growth medium. After incubation at $37^{\circ} \mathrm{C}, 5 \% \mathrm{CO}_{2}$ for $2 \mathrm{~h}$ to remove adherent fibroblast cells, non-adherent cells were seeded on a collagen I coated flask and maintained at $37^{\circ} \mathrm{C}, 5 \% \mathrm{CO}_{2}$. The growth medium was refreshed every 2 days and consisted of a 1:1 mixture of DMEM (GIBCO) and Airway Epithelial Cell basal medium (Promocell, Heidelberg, Germany) supplemented with $52 \mu \mathrm{g} / \mathrm{mL}$ bovine pituitary extract, $15 \mathrm{ng} / \mathrm{mL}$ retinoic acid, $5 \mu \mathrm{g} / \mathrm{mL}$ insulin, $0.5 \mu \mathrm{g} / \mathrm{mL}$ hydrocortisone, $0.5 \mu \mathrm{g} / \mathrm{mL}$ epinephrine, $10 \mu \mathrm{g} / \mathrm{mL}$ transferrin, $1 \mathrm{ng} / \mathrm{mL}$ human epidermal growth factor (Corning), $1.5 \mathrm{ng} / \mathrm{mL}$ bovine serum albumin, $100 \mathrm{units} / \mathrm{mL}$ penicillin and $100 \mu \mathrm{g} / \mathrm{mL}$ streptomycin, with or without $5 \mu \mathrm{M}$ Rho-associated protein kinase inhibitor (Y-27632), as previously described (Wu et al., 2016). If not stated otherwise all materials were purchased from Sigma-Aldrich.

For infection experiments with SARS-CoV-2, the SARS-CoV-2 isolate Munich 929 was propagated in VeroE6 cells (passage 1) after primary isolation from patient material on Vero-TMPRSS2 cells (passage 0).

\section{METHOD DETAILS}

\section{Plasmids}

Expression plasmids for vesicular stomatitis virus (VSV, serotype Indiana) glycoprotein (VSV-G), Nipah virus (NiV) fusion ( $F$ and attachment glycoprotein (G), SARS-S (derived from the Frankfurt-1 isolate) with or without a C-terminal HA epitope tag, HCoV-229E-S, MERS-S, human and bat angiotensin converting enzyme 2 (ACE2), human aminopeptidase N (APN), human 
dipeptidyl-peptidase 4 (DPP4) and human TMPRSS2 have been described elsewhere (Bertram et al., 2010; Brinkmann et al., 2017; Gierer et al., 2013; Hoffmann et al., 2013; Hofmann et al., 2005; Kleine-Weber et al., 2019). For generation of the expression plasmids for SARS-2-S with or without a C-terminal HA epitope tag we PCR-amplified the coding sequence of a synthetic, codon-optimized (for human cells) SARS-2-S DNA (GeneArt Gene Synthesis, ThermoFisher Scientific) based on the publicly available protein sequence in the National Center for Biotechnology Information database (NCBI Reference Sequence: YP_009724390.1) and cloned in into the pCG1 expression vector via BamHI and Xbal restriction sites.

Pseudotyping of VSV and transduction experiments

For pseudotyping, VSV pseudotypes were generated according to a published protocol (Berger Rentsch and Zimmer, 2011). In brief, $293 T$ transfected to express the viral surface glycoprotein under study were inoculated with a replication-deficient VSV vector that contains expression cassettes for eGFP (enhanced green fluorescent protein) and firefly luciferase instead of the VSV-G open reading frame, VSV* $\Delta G$-fLuc (kindly provided by Gert Zimmer, Institute of Virology and Immunology, Mittelhäusern/Switzerland). After an incubation period of $1 \mathrm{~h}$ at $37^{\circ} \mathrm{C}$, the inoculum was removed and cells were washed with PBS before medium supplemented with antiVSV-G antibody (11, mouse hybridoma supernatant from CRL-2700; ATCC) was added in order to neutralize residual input virus (no antibody was added to cells expressing VSV-G). Pseudotyped particles were harvested $16 \mathrm{~h}$ postinoculation, clarified from cellular debris by centrifugation and used for experimentation.

For transduction, target cells were grown in 96 -well plates until they reached $50 \%-75 \%$ confluency before they were inoculated with respective pseudotyped VSV. For experiments addressing receptor usage, cells were transfected with expression plasmids $24 \mathrm{~h}$ before transduction. In order to block ACE2 on the cell surface, cells were pretreated with 2 or $20 \mu \mathrm{g} / \mathrm{mL}$ anti-ACE2 antibody (R\&D Systems, goat, AF933). As control, an unrelated anti-DC-SIGN antibody (Serotec, goat, $20 \mu \mathrm{g} / \mathrm{mL}$ ) was used. For experiments involving ammonium chloride (final concentration $50 \mathrm{mM}$ ) and protease inhibitors ( $\mathrm{E}-64 \mathrm{~d}, 25 \mu \mathrm{M}$; camostat mesylate, 1-500 $\mu \mathrm{M}$ ), target cells were treated with the respective chemical $2 \mathrm{~h}$ before transduction. For neutralization experiments, pseudotypes were pre-incubated for $30 \mathrm{~min}$ at $37^{\circ} \mathrm{C}$ with different serum dilutions. Transduction efficiency was quantified $16 \mathrm{~h}$ posttransduction by measuring the activity of firefly luciferase in cell lysates using a commercial substrate (Beetle-Juice, PJK) and a Hidex Sense plate luminometer (Hidex).

Quantification of cell viability

Cell viability following treatment of Calu- 3 cells with camostat mesylate was analyzed using the CellTiter-Glo® Luminescent Cel Viability Assay (Promega). In brief, Calu-3 cells grown to $50 \%$ confluency in 96-well plates were incubated for $24 \mathrm{~h}$ in the absence or presence of different concentrations $(1-500 \mu \mathrm{M})$ of camostat mesylate. Next, the culture medium was aspirated and $100 \mu \mathrm{l}$ of fresh culture medium was added before an identical volume of the assay substrate was added. Wells containing only culture medium served as a control to determine the assay background. After 2 min of incubation on a rocking platform and additional 10 min without movement, samples were transferred into white opaque-walled 96-well plates and luminescent signal were recorded using a Hidex Sense plate luminometer (Hidex).

Analysis of SARS-2-S expression and particle incorporation

To analyze S protein expression in cells, 293T cells were transfected with expression vectors for HA-tagged SARS-2-S or SARS-S or empty expression vector (negative control). The culture medium was replaced at $16 \mathrm{~h}$ posttransfection and the cells were incubated for an additional $24 \mathrm{~h}$. Then, the culture medium was removed and cells were washed once with PBS before $2 \times$ SDS-sample buffer $(0.03 \mathrm{M}$ Tris- $\mathrm{HCl}, 10 \%$ glycerol, $2 \%$ SDS, $0.2 \%$ bromophenol blue, $1 \mathrm{mM}$ EDTA) was added and cells were incubated for $10 \mathrm{~min}$ at room temperature. Next, the samples were heated for $15 \mathrm{~min}$ at $96^{\circ} \mathrm{C}$ and subjected to SDS-PAGE and immunoblotting.

For analysis of $\mathrm{S}$ protein incorporation into pseudotyped particles, $1 \mathrm{~mL}$ of the respective VSV pseudotypes were loaded onto a $20 \%(\mathrm{w} / \mathrm{v})$ sucrose cushion (volume $50 \mu \mathrm{l})$ and subjected to high-speed centrifugation $\left(25.000 \mathrm{~g}\right.$ for $120 \mathrm{~min}$ at $4^{\circ} \mathrm{C}$ ). Thereafter, $1 \mathrm{~mL}$ of supernatant was removed and the residual volume was mixed with $50 \mu \mathrm{l}$ of $2 \times \mathrm{SDS}$-sample buffer, heated for $15 \mathrm{~min}$ at $96^{\circ} \mathrm{C}$ and subjected to SDS-PAGE and immunoblotting. After protein transfer, nitrocellulose membranes were blocked in $5 \%$ skim milk solution ( $5 \%$ skim milk dissolved in PBS containing $0.05 \%$ Tween-20, PBS-T) for $1 \mathrm{~h}$ at room temperature and then incubated over night at $4{ }^{\circ} \mathrm{C}$ with the primary antibody (diluted in in skim milk solution)). Following three washing intervals of $10 \mathrm{~min}$ in PBS-T the membranes were incubated for $1 \mathrm{~h}$ at room temperature with the secondary antibody (diluted in in skim milk solution), before the membranes were washed and imaged using an in in house-prepared enhanced chemiluminescent solution $(0.1 \mathrm{M} \mathrm{Tris}-\mathrm{HCl}[\mathrm{pH} 8.6], 250 \mu \mathrm{g} / \mathrm{mL}$ luminol, $1 \mathrm{mg} / \mathrm{mL}$ para-hydroxycoumaric acid, $0.3 \% \mathrm{H}_{2} \mathrm{O}^{2}$ ) and the ChemoCam imaging system along with the ChemoStar Professional software (Intas Science Imaging Instruments $\mathrm{GmbH}$ ). The following primary antibodies were used: Mouse anti-HA tag (Sigma-Aldrich, H3663, 1:2,500), mouse anti- $\beta$-actin (Sigma-Aldrich, A5441, 1:2,000), mouse anti-VSV matrix protein (Kerafast, EB0011, 1:2,500). As secondary antibody we used a peroxidase-coupled goat anti-mouse antibody (Dianova, 115-035-003, 1:10000).

Infection with authentic SARS-CoV-2

BHK-21 cells $\left(1.6 \times 10^{5}\right.$ cells $\left./ \mathrm{mL}\right)$ were transfected with ACE2 and DsRed as a negative control. After $24 \mathrm{~h}$, cells were washed with PBS and infected with $8 \times 10^{7}$ genome equivalents (GE) per 24-well of SARS-CoV-2 isolate Munich 929 for $1 \mathrm{~h}$ at $37^{\circ} \mathrm{C}$. Calu- 3 cells $\left(5 \times 10^{5} \mathrm{celll} / \mathrm{mL}\right.$ ) were mock treated or treated with $100 \mu \mathrm{M}$ camostat mesylate (Sigma Aldrich) $2 \mathrm{~h}$ prior to infection with SARS-CoV-2

e4 Cell 181, 271-280.e1-e5, April 16, 2020 
Manuscripts

isolate Munich 929 at a multiplicity of infection (MOI) of 0.001 for $1 \mathrm{~h}$ at $37^{\circ} \mathrm{C}$. After infection, cells were washed three times with PBS before $500 \mu \mathrm{l}$ of DMEM medium was added. At 16 or $24 \mathrm{~h}$ post infection, $50 \mu \mathrm{l}$ culture supernatant was subjected to viral RNA extraction using a viral RNA kit (Macherey-Nagel) according to the manufacturer's instructions. GE per ml were detected by real time RTPCR using a previously reported protocol (Corman et al., 2020).

\section{Sera}

The convalescent human anti-SARS-CoV sera (CSS-2 to CSS-5) stemmed from the serum collection of the national consiliary laboratory for coronavirus diagnostics at Charité, Berlin, Germany or the Robert Koch Institute, Berlin, Germany. All sera were previously tested positive using a recombinant S-based immunofluorescence test (Buchholz et al., 2013). CSS-2 was taken from a SARS patient 3.5 years post onset of disease. CSS-3 and CSS- 4 originated from a second SARS patient 24 and 36 days post onset of disease. CSS- 5 was collected from a third SARS patient 10 days post onset of disease. Rabbit sera were obtained by immunizing rabbits with purified SARS-S1 protein fused to the Fc portion of human immunoglobulin.

Phylogenetic analysis

Phylogenetic analysis (neighbor-joining tree, bootstrap method with 5,000 iterations, Poisson substitution model, uniform rates among sites, complete deletion of gaps/missing data) was performed using the MEGA7.0.26 software. Reference sequences were obtained from the National Center for Biotechnology Information and GISAID (Global Initiative on Sharing All Influenza Data) databases. Reference numbers are indicated in the figures.

\section{QUANTIFICATION AND STATISTICAL ANALYSIS}

One-way or two-way analysis of variance (ANOVA) with Dunnett posttest was used to test for statistical significance. Only $p$ values of 0.05 or lower were considered statistically significant $\left(\mathrm{p}>0.05\right.$ [ns, not significant], $\mathrm{p}<0.05$ [^], $\left.\mathrm{p}<0.011^{[\star *}\right], \mathrm{p} \leq 0.001$ [**]). For al statistical analyses, the GraphPad Prism 7 software package was used (GraphPad Software).

\section{DATA AND CODE AVAILABILITY}

The study did not generate unique datasets or code. 

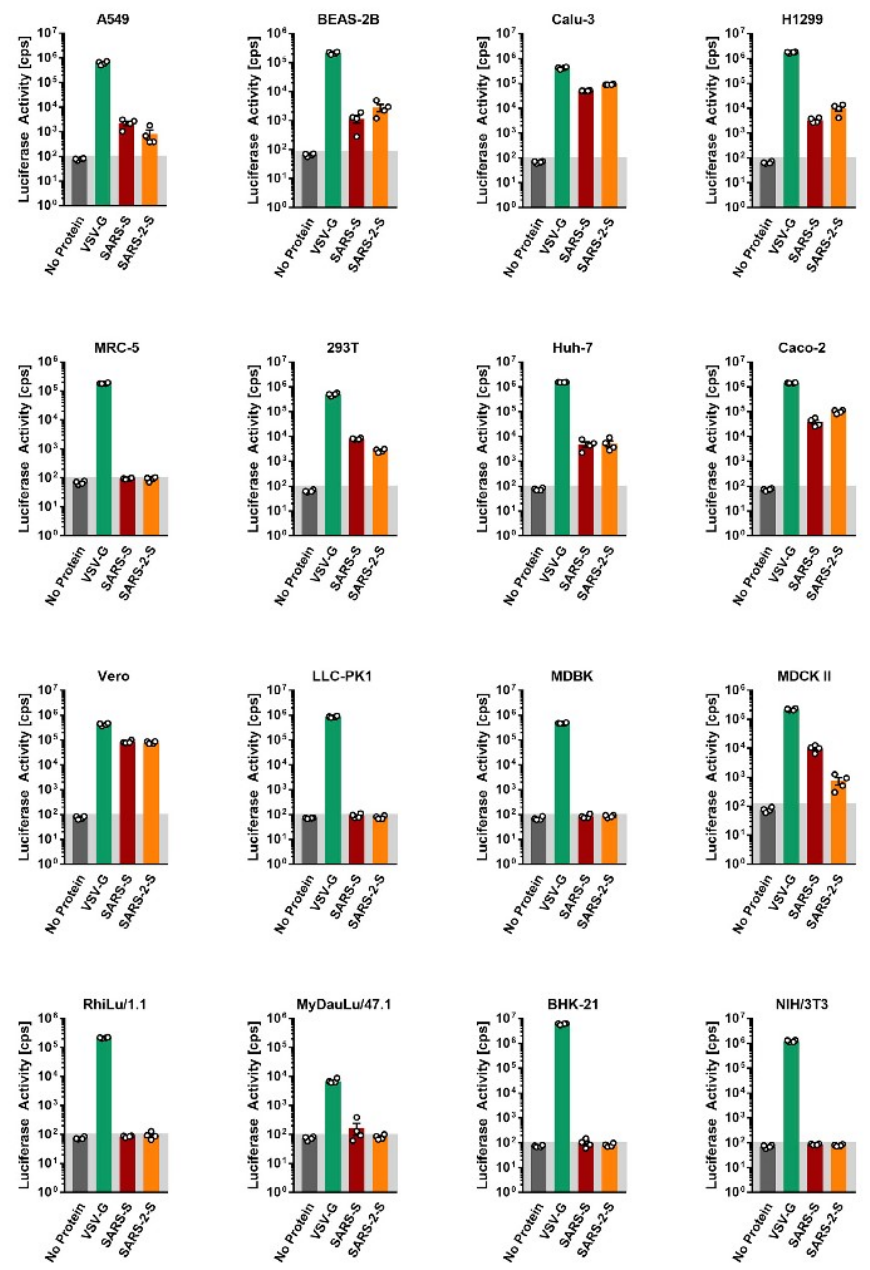

Figure S1. Representative Experiment Included in the Average, Related to Figure 1C

The indicated cells lines were inoculated with pseudoparticles harboring the indicated viral glycoprotein or harboring no glycoprotein (no protein) and luciferase activities in cell lysates were determined at $16 \mathrm{~h}$ posttransduction. The experiment was performed with quadruplicate samples, the average \pm SD is shown. 


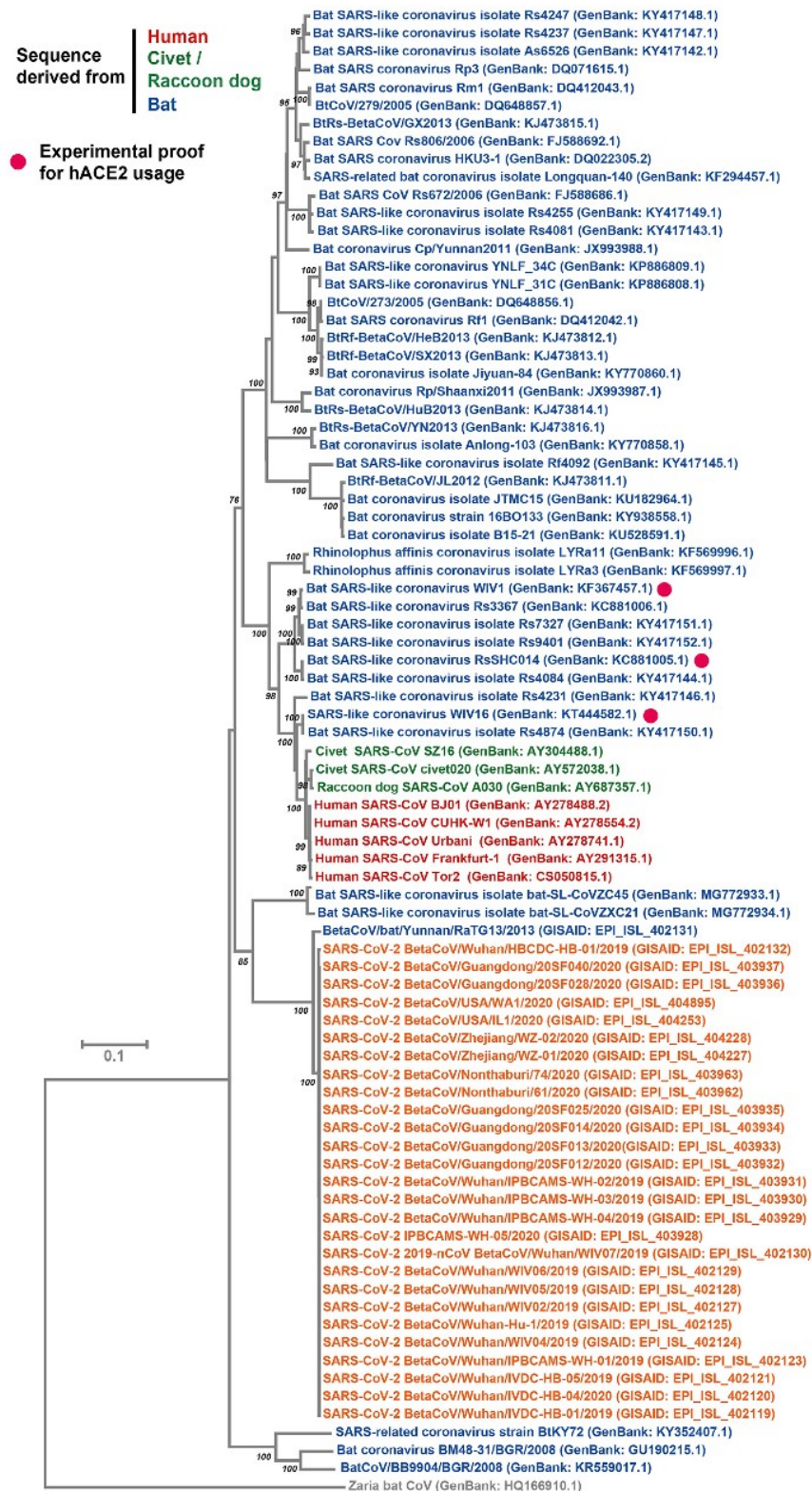

Asia

Europe \& Africa

Figure S2. Extended Version of the Phylogenetic Tree, Related to Figure 2B 
A

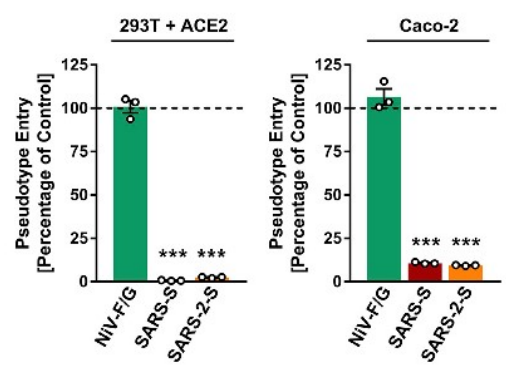

C

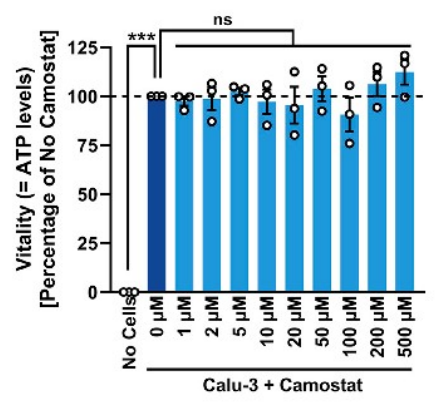

B
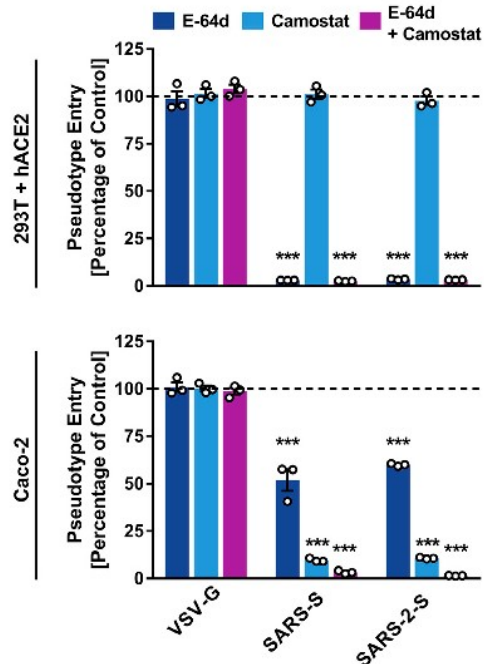

Figure S3. Protease Requirement for SARS-2-S-Driven Entry and Absence of Unwanted Cytotoxicity of Camostat Mesylate, Related to Figure 4

(A and B) Importance of endosomal low pH (A) and activity of CatB/L or TMPRSS2 (B) for host cell entry of SARS-CoV-2 was evaluated by adding inhibitors to target cells prior to transduction. Ammonium chloride (A) blocks endosomal acidification while E-64d and camostat mesylate (B) block the activity of CatB/L and TMPRSS2, respectively. Entry into cells not treated with inhibitor was set as $100 \%$.

(C) Absence of cytotoxic effects of camostat mesylate. Calu-3 cells were treated with camostat mesylate identically as for infection experiments and cell viability was measured using a commercially available assay (CellTiter-Glo, Promega). 
5.6. Sixth manuscript

\section{A multibasic cleavage site in the spike protein of}

\section{SARS-CoV-2 is essential for infection of human lung \\ cells}

Hoffmann M, Kleine-Weber H, Pöhlmann S.

Individual contribution:

In the manuscript, I generated samples for the Western Blot analysis of Figure 2:

"The Multibasic S1/S2 Site of SARS-2-S Is Cleaved by Furin, and Cleavage Is Required for Syncytium Formation and Entry into Human Lung Cells“. 


\section{Molecular Cell}

\section{A Multibasic Cleavage Site in the Spike Protein of SARS-CoV-2 Is Essential for Infection of Human Lung Cells}

Graphical Abstract

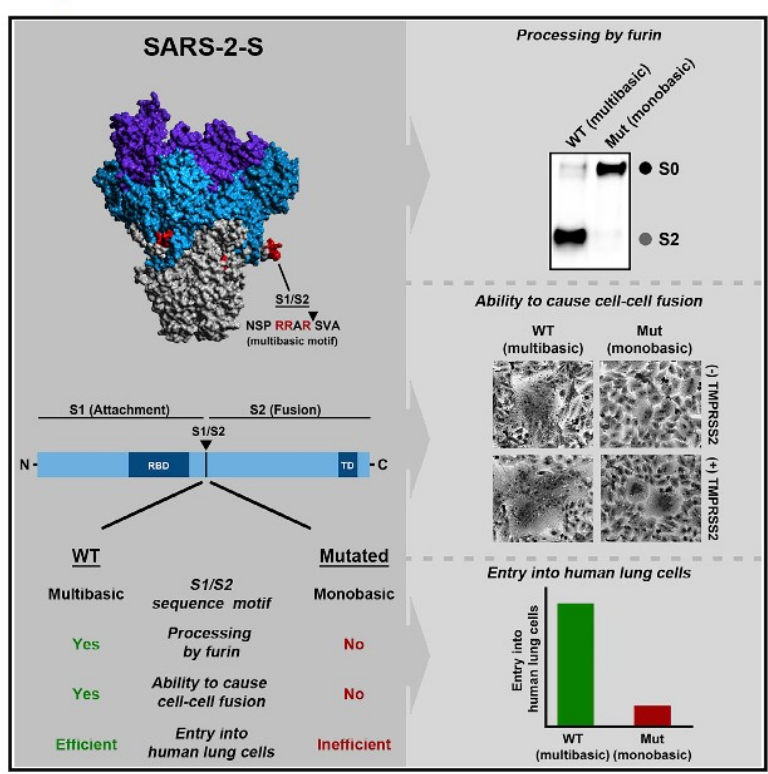

Highlights

- The spike protein of SARS-CoV-2 harbors a multibasic S1/ S2 site

- The host cell protease furin cleaves the SARS-CoV-2 spike protein at the $\mathrm{S} 1 / \mathrm{S} 2$ site

- Cleavage at the $\mathrm{S} 1 / \mathrm{S} 2$ site is essential for spike-driven viral entry into lung cells

\section{Authors}

Markus Hoffmann,

Hannah Kleine-Weber,

Stefan Pöhlmann

\section{Correspondence}

mhoffmann@dpz.eu (M.H.),

spoehlmann@dpz.eu (S.P.)

In Brief

Coronavirus spike proteins are activated by host cell proteases. Hoffmann and colleagues show that the pandemic SARS-CoV-2 harbors a highly cleavable $\mathrm{S} 1 / \mathrm{S} 2$ cleavage site not found in closely related coronaviruses. Cleavage at this site is mediated by furin and is required for viral entry into human lung cells. 


\section{Short Article \\ A Multibasic Cleavage Site in the Spike Protein of SARS-CoV-2 Is Essential for Infection of Human Lung Cells}

Markus Hoffmann, ${ }^{1, *}$ Hannah Kleine-Weber, ${ }^{1,2}$ and Stefan Pöhlmann ${ }^{1,2,3, *}$

'Deutsches Primatenzentrum - Leibniz Institut für Primatenforschung, Göttingen, Germany

${ }^{2}$ Faculty of Biology and Psychology, University Göttingen, Göttingen, Germany

${ }^{3}$ Lead Contact

*Correspondence: mhoffmann@dpz.eu (M.H.), spoehlmann@dpz.eu (S.P.)

https://doi.org/10.1016/..molcel.2020.04.022

\section{SUMMARY}

The pandemic coronavirus SARS-CoV-2 threatens public health worldwide. The viral spike protein mediates SARS-CoV-2 entry into host cells and harbors a S1/S2 cleavage site containing multiple arginine residues (multibasic) not found in closely related animal coronaviruses. However, the role of this multibasic cleavage site in SARS-CoV-2 infection is unknown. Here, we report that the cellular protease furin cleaves the spike protein at the S1/S2 site and that cleavage is essential for S-protein-mediated cell-cell fusion and entry into human lung cells. Moreover, optimizing the S1/S2 site increased cell-cell, but not virus-cell, fusion, suggesting that the corresponding viral variants might exhibit increased cell-cell spread and potentially altered virulence. Our results suggest that acquisition of a S1/S2 multibasic cleavage site was essential for SARSCoV-2 infection of humans and identify furin as a potential target for therapeutic intervention.

\section{INTRODUCTION}

It is believed that the severe acute respiratory syndrome coronavirus 2 (SARS-CoV-2, previously termed nCoV-2019) was introduced into the human population from a poorly characterized animal reservoir in late 2019 (Ge et al., 2013; Wang et al., 2020; Zhou et al., 2020b; Zhu et al., 2020). The epicenter of the subsequent SARS-CoV-2 spread was Wuhan, Hubei province, China, with more than 65,000 cases occurring in this area $\mathrm{WHO}$, 2020a). However, infections have now been detected in more than 110 countries and massive outbreaks are currently ongoing in the United States, Italy, and Spain (WHO, 2020a, 2020b). Understanding which features of SARS-CoV-2 are essential for infection of human cells should provide insights into viral transmissibility and pathogenesis and might reveal targets for intervention.

The spike protein of coronaviruses is incorporated into the viral envelope and facilitates viral entry into target cells. For this, the surface unit $\mathrm{S} 1$ binds to a cellular receptor while the transmembrane unit S2 facilitates fusion of the viral membrane with a cellular membrane (Hoffmann et al., 2018; Hulswit et al., 2016; Millet and Whittaker, 2018). Membrane fusion depends on S protein cleavage by host cell proteases at the $\mathrm{S} 1 / \mathrm{S} 2$ and the $\mathrm{S} 2$ ' site (Figure 1A), which results in S protein activation (Hoffmann et al., 2018; Hulswit et al., 2016; Millet and Whittaker, 2018). Cleavage of the $\mathrm{S}$ protein can occur in the constitutive secretory pathway of infected cells or during viral entry into target cells and is essen- tial for viral infectivity. Therefore, the responsible enzymes constitute potential targets for antiviral intervention.

Our previous work revealed that the activity of the cellula serine protease TMPRSS2, which activates several coronaviruses (Bertram et al., 2013; Gierer et al., 2013; Glowacka et al., 2011; Matsuyama et al., 2010; Shirato et al., 2013, 2016; Shulla et al., 2011), is also required for robust SARS-CoV-2 infection o human lung cells (Hoffmann et al., 2020). However, it is conceivable that the activity of other cellular proteases is also necessary. Thus, the Middle East respiratory syndrome coronavirus spike protein (MERS-S) is activated by a two-step process: MERS-S is first cleaved by furin at the S1/S2 site in infected cells, which is required for subsequent TMPRSS2-mediated cleavage at the $\mathrm{S} 2$ ' site (Figure 1A) during viral entry into lung cells (KleineWeber et al., 2018; Park et al., 2016; Millet and Whittaker 2014). A cathepsin B/L-dependent auxiliary activation pathway is operative in many TMPRSS2 ${ }^{-}$cell lines but seems not to be available in viral target cells in the lung because TMPRSS2 dependent activation of the $S$ protein is essential for robus MERS-CoV and SARS-CoV spread and pathogenesis in the infected host (Iwata-Yoshikawa et al., 2019; Simmons et al., 2005; Zhou et al., 2015).

The S1/S2 site in SARS-CoV-2 forms an exposed loop (Figure 1B) that harbors multiple arginine residues (multibasic) Walls et al., 2020; Wrapp et al., 2020) that are not found in SARS-CoV-related coronaviruses (SARSr-CoV) but are present in the human coronaviruses OC43, HKU1, and MERS-CoV 
Please cite this article in press as: Hoffmann et al., A Multibasic Cleavage Site in the Spike Protein of SARS-CoV-2 Is Essential for Infection of Human Lung Cells, Molecular Cell (2020), https://doi.org/10.1016/..molcel.2020.04.022

\section{$\infty$ CellPress}

A
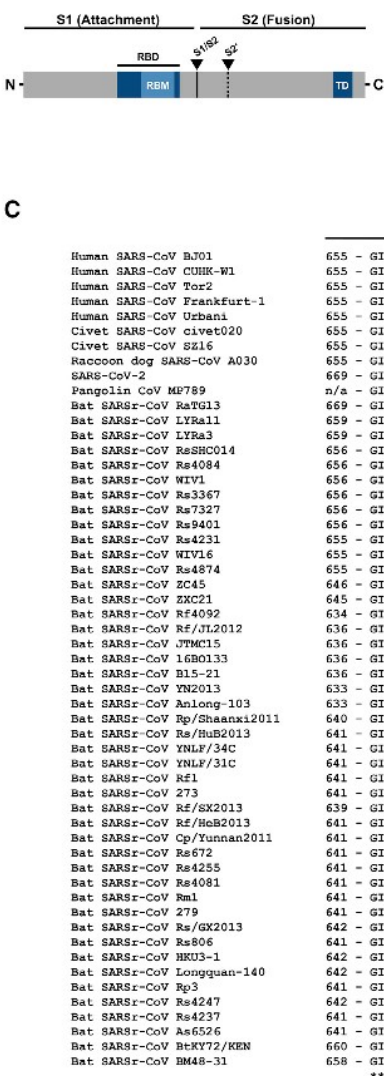

D

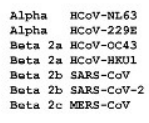

B

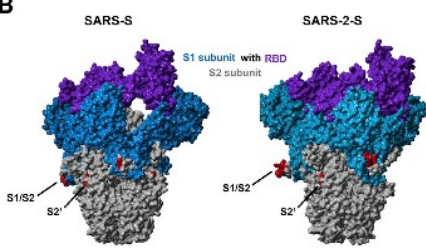

Figure 1. The Multibasic Motif at the S1/S2 Cleavage Site of SARS-2-S Is Unique among Related Group 2b Betacoronaviruses

(A) Schematic illustration of a coronavirus spike glycoprotein in which functional domains and cleavage sites are highlighted (RBD, receptorbinding domain; RBM, receptor-binding motif; TD, transmembrane domain).

(B) Protein models for SARS-S and SARS-2-S based on the PDB: 5X5B structure (Yuan et al., 2017) as a template. Colored in red are the $S 1 / S 2$ and $\mathrm{S}^{\prime}$ clo sites. Further, the $\mathrm{S} 1$ S1/S (blue), including the RBD (purple), and the S2 subunit (gray) are depicted.

( $C$ and D) Amino acid sequence alignment of resi( $C$ and $\mathrm{D}$ ) Amino acid sequence alignment of resi-
dues around the $\mathrm{S} 1 / \mathrm{S} 2$ and $\mathrm{S} 2$ cleavage sites of dues around the $\mathrm{S} 1 / \mathrm{S} 2$ and $\mathrm{S}^{\prime}$ cleavage sites of
group $2 \mathrm{~b}$ betacoronaviruses found in humans, group $2 \mathrm{~b}$ betacoronavinuses found in humans,
civet cats, raccoon dog, pangolin, and bats (C) or coronaviruses that are able to infect humans (D). Basic amino acid residues are highlighted in red, while gray boxes mark the presence of multibasic motifs. Numbers refer to amino acid residues (n/a, no information available). The symbol "*” refers to amino acid residues that areconserved among amino acid residues that are conserved among al tested sequences, whilo ho symbols "." and ":" indicate positions with heterogenoous amino acid residues that share highly similar or similar biochemical properties.

altered S1/S2 cleavage sites (Figure 2A). In particular, we exchanged the multibasic cleavage site against its monobasic counterparts present in SARS-S or RaTG13-S (Figure 2A, RaTG13 is a bat coronavirus closely related to SARSCoV-2 [Zhou et al., 2020b]). This resulted in mutants SARS-2-S (SARS) and SARS2-S (RaTG). Moreover, we either deleted all arginines in the S1/S2 site of SARS-2$S$ or inserted an additional arginine residue (jointly with an alanine to lysine exchange), giving rise to mutants SARS-2$S$ (delta) and SARS-2-S (opt), respectively. Finally, we introduced the S1/S2 sites of SARS-2-S and RaTG13-S into the background of SARS-S (Figure 2A), which yielded the mutants SARS-S (SARS-2) and SARS-S (RaTG).

The effects of the above described $\mathrm{S} 1 /$

(Figure 1C). However, the contribution of this multibasic cleavage site to SARS-CoV-2 infection of human cells is unknown and was in the focus of the present study.

RESULTS

The Multibasic S1/S2 Site in the Spike Protein of SARSCoV-2 Is Required for Efficient Proteolytic Cleavage of the Spike Protein

In order to address the role of the multibasic S1/S2 cleavage site in SARS-CoV-2 infection, we generated S protein mutants with

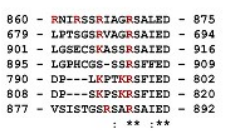

S2 mutations on viral entry were examined using vesicular stomatitis virus (VSV) particles bearing $S$ proteins because these particles are safe and adequately reflect coronavirus entry into target cells. Immunoblot of VSV particles bearing S proteins with a C-terminal antigenic tag revealed that all $S$ proteins were readily incorporated into VSV particles. SARS-2-S WT (wild type) was efficiently cleaved at the S1/S2 site (Figure 2B), in keeping with published data (Hoffmann et al., 2020; Walls et al., 2020). Exchange of the S1/S2 site of SARS-2-S against those of SARS-S and RaTG13-S abrogated cleavage, and this effect was also seen when the multibasic motif was deleted

2 Molecular Cell 78, 1-6, May 21, 2020 
Molecular Cell

Short Article
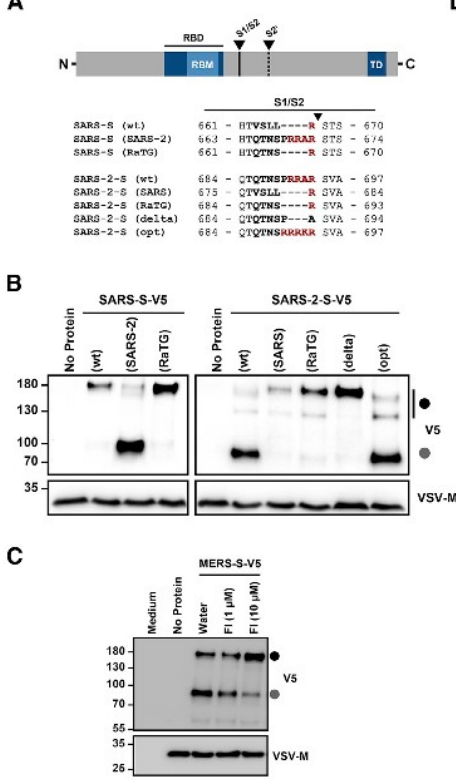

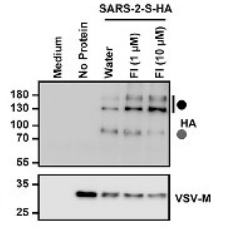

D

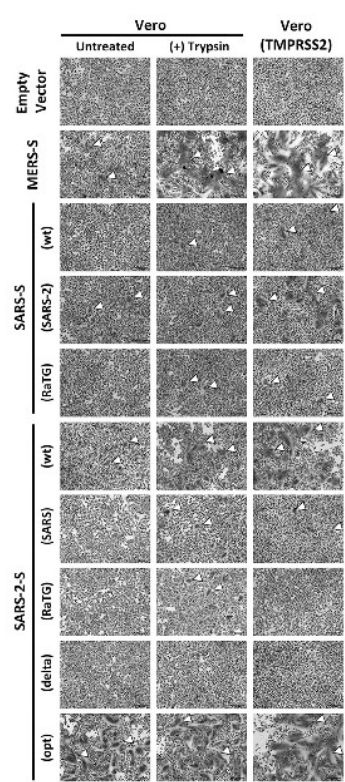

E

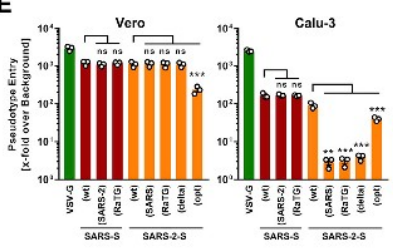

CellPress

Figure 2. The Multibasic S1/S2 Site of SARS-2-S Is Cleaved by Furin, and Cleavage Is Required for Syncytium Formation and Entry into Human Lung Cells

(A) Overview of the SARS-S and SARS-2-S S1/S2 mutants analyzed.

(B) Analysis of furin-mediated S protein priming Rhabdoviral particles harboring the indicated $\mathrm{S}$ proteins containing a C-terminal V5 tag for detection were lysed and subjected to western blot analysis. Detection of vesicular stomatitis virus matrix protein (NSV-M) served as control.

(C) Rhabdoviral particles bearing MERS-S, SARSS, or SARS-2-S equipped with a V5 or HA epitope tag at their $\mathrm{C}$ terminus (or no glycoprotein at all, control) were produced in the absence or presence of furin inhibitor (FI, decanoyl-RVKR-CMK; $1 \mu \mathrm{M}$ or $10 \mu \mathrm{M}$ ) and analyzed for $\mathrm{S}$ protein processing by western blot analysis. Detection of VSV-M served as control.

(D) Syncytium formation assay: Vero or VeroTMPRSS2 cells were transfected to express the indicated S proteins (or no S protein, empty vector, control). At 24 h post transfection, cells were cont 24 post tran incubated in the prosence or absence of trypsin $(1 \mu \mathrm{g} / \mathrm{mL})$ for an additional $24 \mathrm{~h}$ before they were fixed, stained with May-Gruenwald and Giems solution, and analyzed by bright field microscopy (scale bars, $200 \mu \mathrm{m})$. White arrowheads indicat syncytia. For (B)-(D), representative data from three $(B$ and $C$ ) or four $(D)$ independent experiments are shown.

(E) Transduction of Vero (TMPRSS2) and Calu-3 (TMPRSS2+) cells with rhabdoviral particles bearing the indicated $S$ proteins or vesicular stomatitis virus glycoprotein (NSV-G). At 16 h post matis vition, virus transduction, vins quanticod in cell lysates. Presented are the mean data from three independent experiments. Transduction efficiency is shown relative to that measured for particles not bearing a vira glycoprotein. Error bars indicate the standard erro of the mean. Statistical significance was tested by one-way analysis of variance with Dunnett's post test $\left(p>0.05, n s ;{ }^{* * *} p \leq 0.001\right)$
(Figure 2B). Moreover, insertion of an additional arginine residue jointly with an alanine-to-lysine exchange at the S1/S2 site did not appreciably increase cleavability. Finally, insertion of the S1/S2 site of SARS-2-S into SARS-S increased S protein cleavability while insertion of the RaTG13 S1/S2 site did not (Fig ure $2 \mathrm{~B}$ ). These results indicate that the presence of several arginine residues at the S1/S2 site is required for efficient SARS-2-S proteolytic processing in human cells and also confers high cleavability to SARS-S.

Furin Cleaves the SARS-CoV-2 Spike Protein at the S1/ S2 Site, and Cleavage Is Required for Efficient Cell-Cell Fusion

We next investigated which protease is required for $\mathrm{S}$ protein processing at the S1/S2 site. The S1/S2 motif matches the minimal furin sequence RXXR and is closely related to the furin consensus sequence RX[K/R]R. Therefore, we analyzed whether decanoyl-RVKR-CMK, a furin inhibitor, blocks SARS-2-S pro- cessing at the S1/S2 site. Decanoyl-RVKR-CMK inhibited processing of MERS-S, which is known to depend on furin (Giere et al., 2015; Millet and Whittaker, 2014), in a concentrationdependent manner and had no effect on SARS-S expression (Figure 2C), as expected. Processing of SARS-2-S was also inhibited, indicating that furin cleaves SARS-2-S at the S1/S2 site. In order to determine whether cleavage at the S1/S2 site is required for SARS-2-S-driven cell-cell fusion, we studied S-protein-dependent formation of multinucleated giant cells (syncytia). No syncytia were observed in the absence of S protein expression while MERS-S WT expression resulted in syncytium formation, which was increased upon addition of trypsin or expression of TMPRSS2 (Figure 2D). Expression of SARS-S WT or SARS-S harboring the S1/S2 site of RaTG13-S did not induce syncytium formation in the absence of protease, but modest multikaryon formation was detected in the presence of trypsin or TMPRSS2. In contrast, SARS-S harboring the SARS-2-S S1/S2 site induced syncytia in the absence of 
Please cite this article in press as: Hoffmann et al., A Multibasic Cleavage Site in the Spike Protein of SARS-CoV-2 Is Essential for Infection of Human Lung Cells, Molecular Cell (2020), https://doi.org/10.1016/j.molcel.2020.04.022

\section{$\infty$ CellPress}

protease, and syncytium formation was markedly increased by trypsin and, particularly, TMPRSS2. SARS-2-S expression trig gered syncytium formation that was strongly increased by trypsin and TMPRSS2. Syncytium formation was clearly less prominent and required the presence of trypsin or TMPRSS when the SARS-2-S S1/S2 site was replaced by that of SARS $\mathrm{S}$ or RaTG13-S. Moreover, deletion of the multibasic motif resulted in a spike protein that was no longer able to induce syncytium formation even in the presence of trypsin or TMPRSS2. Finally, the addition of an arginine residue to the S1/S2 site of SARS-2-S jointly with alanine-to-lysine exchange strongly increased syncytium formation, indicating that viral variants with optimized S1/S2 sites might show augmented cell-ce spread and potentially altered pathogenicity. Thus, the S1/S2 site of SARS-2-S is required for cell-cell fusion, and this process can be augmented by adding basic residues to the S1/S2 site.

Cleavage of the SARS-CoV-2 Spike Protein at the S1/S2 Site Is Required for Viral Entry into Human Lung Cells We finally examined the importance of the S1/S2 site for S-protein-mediated virus-cell fusion. Blockade of SARS-2-S cleavage at the S1/S2 site (mutants SARS-2-S (SARS), SARS-2-S (RaTG), and SARS-2-S (delta)) abrogated entry into the TMPRSS2 ${ }^{+}$human lung cell line Calu-3 (Figure 2E), in which the cathepsin B/ $\mathrm{L}$-dependent $\mathrm{S}$ protein activation pathway is not sufficiently available (Park et al., 2016). In contrast, entry into TMPRSS2 Vero cells, which is known to be cathepsin $B / L$ dependent, was not affected by these mutations (Figure 1E), in keeping with results reported by Walls and colleagues (Walls et al. 2020). Optimization of the S1/S2 site did not increase entry into the cell lines tested; it slightly decreased entry into both Vero and Calu-3 cells, for, at present, unclear reasons. Finally, alterations of the S1/S2 site of SARS-S did not augment entry efficiency. Collectively, these results demonstrate that a multibasic S1/S2 site is essential for SARS-2-S-driven entry into human lung cells while a monobasic site is sufficient for SARS-S.

\section{DISCUSSION}

Our results reveal commonalities between the proteolytic activation of SARS-CoV-2 and MERS-CoV. Both viruses depend on furin-mediated pre-cleavage of their $S$ proteins at the $S 1 / S 2$ site for subsequent $S$ protein activation by TMPRSS2 in lung cells, which fail to express robust levels of cathepsin L (Park et al., 2016). Thus, inhibitors of furin and TMPRSS2 might be considered as a treatment option for COVID-19, and a TMPRSS2 inhibitor that blocks SARS-CoV-2 infection has recently been described (Hoffmann et al., 2020). Regarding furin inhibition, must be taken into account that furin, unlike TMPRSS2, is required for normal development (Roebroek et al., 1998). Blockade of this enzyme for prolonged time periods might thus be associated with unwanted toxic effects. In contrast, a brief treatment might be well tolerated and still associated with a therapeutic benefit (Sarac et al., 2002, 2004).

For avian influenza A viruses, a multibasic cleavage site in the viral hemagglutinin protein is a central virulence factor (Lucz et al., 2015). Thus, viruses with a monobasic cleavage site are activated by TMPRSS2 or related proteases with an expression profile confined to the aerodigestive tract. As a consequence, vira replication is limited to these organs and does not result in severe disease. In contrast, viruses with a multibasic cleavage site are activated by ubiquitously expressed proprotein convertases, including furin, and can thus spread systemically and cause massive disease. In the context of coronavirus infection, S protein cleavability has been identified as a determinant of zoonotic potential (Menachery et al., 2020; Yang et al., 2014). The presence of a highly cleavable $\mathrm{S} 1 / \mathrm{S} 2$ site in SARS-2-S may therefore not have been unexpected. However, it is noteworthy that al SARS-CoV-2-related coronaviruses of bats and pangolins identified today harbor a monobasic cleavage site (Lam et al., 2020; L et al., 2020; Zhang et al., 2020). It will thus be interesting to determine how the multibasic motif was acquired by SARS-CoV-2, and a recent study suggested that a recombination event might have been responsible (Zhang et al., 2020; Zhou et al., 2020a).

Limitations of the Study

Our results demonstrate that the multibasic S1/S2 cleavage site is essential for SARS-2-S-driven entry into TMPRSS2 ${ }^{+}$lung cells. It will be interesting to extend these studies to primary human respiratory epithelial cells and to authentic SARS-CoV-2, which requires a reverse genetics system not available to the present study.

\section{STAR $\star M E T H O D S$}

Detailed methods are provided in the online version of this paper and include the following:

- KEY RESOURCES TABLE

- RESOURCE AVAILABILITY

- Lead Contact

- Materials Availability

O Data and Code Availability

- METHOD DETAILS

O Cell cultures

- Plasmids

- Preparation of pseudotyped particles and transduction experiments

- Western blot analysis

- Syncytium formation assay

- Sequence analysis and protein models

- QUANTIFICATION AND STATISTICAL ANALYSIS

\section{ACKNOWLEDGMENTS}

We thank Inga Nehlmeier for technical assistance. We gratefully acknowledge the authors and the originating and submitting laboratories for their sequence and metadata shared through GISAID, on which this research is based. This work was supported by the Bundesministerium für Bildung und Forschung (BMBF, RAPID Con (BMME, RAPID Consortium, 01 KI1723D to S.P.). We further like to thank Andrea Maisner and Stephan Ludwig for providing the Vero cells and Calu- 3 cells,
respectively.

\section{AUTHOR CONTRIBUTIONS}

Conceptualization, M.H. and S.P.; Formal Analysis, M.H. and S.P.; Investigation, M.H. and H.K.-W; Writing-Original Draft, M.H. and S.P.; Writing-Review \& Editing, all authors; Funding Acquisition, S.P. 


\section{Molecular Cell}

\section{Short Article}

\section{DECLARATION OF INTEREST}

The authors declare not competing interests

\section{Received: March 15, 2020 \\ Revised: April 14, 2020 \\ Accepted: April 17, 2020 \\ Published: May 1, 2020}

\section{REFERENCES}

Berger Rentsch, M., and Zimmer, G. (2011). A vesicular stomatitis virus replcon-based bioassay for the rapid and sensitive determination of multi-specie type I interferon. PLoS ONE 6, e25858.

Bertram, S., Dijkman, R., Habjan, M., Heurich, A., Gierer, S., Glowacka, Welsch, K., Winkler, M., Schneider, H., Hofmann-Winkler, H., et al. (2013) TMPRSS activates the human cor $\mathrm{H}$. Hovirus $220 \mathrm{E}$. host cellentry and is expres J. Virol. $87,6150-6160$.

Brinkmann, C., Hoffmann, M., Lübke, A., Nehlmeier, I., Krämer-Kühl, A. Winkler, M., and Pöhlmann, S. (2017). The glycoprotein of vesicular stomatitis virus promotes release of virus-like particles from tetherin-positive cells. PLOS ONE 12, e0189073.

Ge, X.Y., Li, J.L., Yang, X.L., Chmura, A.A., Zhu, G., Epstein, J.H., Mazet, J.K. Hu, B., Zhang, W., Peng, C., et al. (2013). Isolation and characterization of a bat SARS-like coronavirus that uses the ACE2 receptor. Nature 503, 535-538.

Gierer, S., Bertram, S., Kaup, F., Wrensch, F., Heurich, A., Krämer-Kühl, A. Welsch, K., Winkler, M., Meyer, B., Drosten, C., et al. (2013). The spike protein of the emerging betacoronavirus EMC uses a novel coronavirus receptor for entry, can be activated by TMPRSS2, and is targeted by neutralizing antientry, can be activated by TMPR
bodies. J. Virol. $87,5502-5511$

Gierer, S., Müller, M.A., Heurich, A., Ritz, D., Springstein, B.L., Karsten, C.B., Schendzielorz, A., Gnirß, K., Drosten, C., and Pöhlmann, S. (2015). Inhibition of proprotein convertases abrogates processing of the middle eastern respiratory syndrome coronavirus spike protein in infected cells but does not reduce viral infectivity, J. Infect. Dis. 211, 889-897.

Glowacka, I., Bertram, S., Müller, M.A., Allen, P., Soilleux, E., Pfefferle, S. Steffen, I., Tsegaye, T.S., He, Y., Gnirss, K., et al. (2011). Evidence that TMPRSS2 activates the severe acute respiratory syndrome coronavirus spike protein for membrane fusion and reduces viral control by the humoral immune response. J. Virol. 85, 4122-4134.

Hoffmann, M., Hofmann-Winkler, H., and Pöhlmann, S. (2018). Priming Time: How Cellular Proteases Arm Coronavirus Spike Proteins, In Activation of Viruses by Host Proteases, E. Böttcher-Friebertshäuser, W. Garten, and H. Klenk, eds. (Springer), pp. 71-98.

Hoffmann, M., Müller, M.A., Drexler, J.F., Glende, J., Erdt, M., Gützkow, T., Losemann, C., Binger, T., Deng, H., Schwegmann-Weßels, C., et al. (2013) Differential sensitivity of bat cells to infection by enveloped RNA viruses: coronaviruses, paramyxoviruses, filoviruses, and influenza viruses. PLOS ONE 8 e72942.

Hoffmann, M., Kleine-Weber, H., Schroeder, S., Krüger, N., Herrler, T. Enchsen, S., Schiergens, T.S., Hernler, G., Wu, N.H., Nitsche, A., et (2020). SARS-CoV-2 Cell Entry Depends on ACE2 and TMPRSS2 and $1 \mathrm{~s}$ Blocked by a Clinically Proven Protease Inhibitor. Cell 181, 271-280.e8.

Hulswit, R.J., de Haan, C.A., and Bosch, B.J. (2016). Coronavirus Spike Protein and Tropism Changes. Adv. Virus Res. 96, 29-57.

Iwata-Yoshikawa, N., Okamura, T., Shimizu, Y., Hasegawa, H., Takeda, M. and Nagata, N. (2019). TMPRSS2 Contributes to Virus Spread and Immunopathology in the Airways of Murine Models after Coronavirus Infection. J. Virol. 93, 93.

Kleine-Weber, H., Elzayat, M.T., Hoffmann, M., and Pöhlmann, S. (2018) Functional analysis of potential cleavage sites in the MERS-coronavirus spike protein. Sci. Rep. 8, 16597
CellPress

Kleine-Weber, H., Elzayat, M.T. Wang, L, Graham, B.S., Müller, M.A. Prosten, C. Pöhlmann, S., and Hoffmann, M. (2019). Mutations in the Spike Protein of Middle East Respiratory Syndrome Coronavirus Transmitted in Korea Increase Resistance to Antibody-Mediated Neutralization. J. Virol. 93,93

Krieger, E., and Vriend, G. (2014). YASARA View - molecular graphics for all devices - from smartphones to workstations. Bioinformatics 30, 2981-2982. Lam, T.T., Shum, M.H., Zhu, H.C., Tong, Y.G., Ni, X.B., Liao, Y.S., Wei, W Cheung, W.Y., Li, W.J., Li, L.F., et al. (2020). Identifying SARS-CoV-2 related coronaviruses in Malayan pangolins. Nature. Published online March 26, 2020. https://doi.org/10.1038/s41586-020-2169-0.

Li, X., Zai, J., Zhao, Q., Nie, Q., Li, Y., Foley, B.T., and Chaillon, A. (2020). Evolutionary history, potential intermediate animal host, and cross-species analyses of SARS-CoV-2. J. Med. Virol.

Luczo, J.M., Stambas, J., Durr, P.A., Michalski, W.P., and Bingham, J. (2015). Molecular pathogenesis of $\mathrm{H} 5$ highly pathogenic avian influenza: the role of the haemagglutinin cleavage site motif. Rev. Med. Virol. 25, 406-430.

Madeira, F., Park, Y.M., Lee, J., Buso, N., Gur, T., Madhusoodanan, N. Basutkar, P. Tivey, A.R.N.. Potter, S.C., Finn, R.D., and Lopez, R. (2019). The EMBL-EBI search and sequence analysis tools APIs in 2019. Nucleic Acids Res. 47 (W1), W636-W641.

Matsuyama, S., Nagata, N., Shirato, K., Kawase, M., Takeda, M., and Taguchi, F. (2010). Efficient activation of the severe acute respiratory syndrome coronavirus spike protein by the transmembrane protease TMPRSS 2 . V Virol. 84, 12658-12664.

Menachery, V.D., Dinnon, K.H., 3rd, Yount, B.L., Jr., McAnarney, E.T. Gralinski, L.E., Hale, A., Graham, R.L., Scobey, T., Anthony, S.J., Wang, L., et al. (2020). Trypsin Treatment Unlocks Barrier for Zoonotic Bat Coronaviruses Infection. J. Virol. 94, e01774-19.

Millet, J.K. and Whittaker, G.R. (2014). Host cell entry of Middle East respiratory syndrome coronavins after two-step, furin-mediated activation of the spike protein. Proc. Natt. Acad. Sci. USA 111, 15214-15219.

Millet, J.K., and Whittaker, G.R. (2018). Physiological and molecular triggers for SARS-CoV membrane fusion and entry into host cells. Virology 517, 3-8. Park, J.E., Li, K. Barlan, A., Fehr, A.R., Perlman, S., McCray, P.B., Jr., and Gallagher, T. (2016). Proteolytic processing of Middle East respiratory syndrome coronavirus spikes expands virus tropism. Proc. Natt. Acad. Sci. USA 113, 12262-12267.

Roebroek, A.J., Umans, L., Pauli, I.G., Robertson, E.J., van Leuven, F., Van de Ven, W.J., and Constam, D.B. (1998). Failure of ventral closure and axial rotalion in embryos lacking the proprotein convertase Furin. Development 125, 4863-4876.

Sarac, M. S., Cameron, A., and Lindberg, I. (2002). The furin inhibitor hexa-Darginine blocks the activation of Pseudomonas aeruginosa exotoxin $\mathrm{A}$ in vivo. Infect. Immun. 70, 7136-7139.

Sarac, MS. Peinado, J.R., Leppla, S.H., and Lindberg. I (2004). Protection against anthrax toxemia by hexa-D-arginine in vitro and in vivo. Infect. Immun. 72, 602-605.

Schwegmann-Weßels, C., Glende, J., Ren, X., Qu, X., Deng, H., Enjuanes, L., and Herler, G. (2009). Comparison of vesicular stomatitis virus pseudotyped with the $\mathrm{S}$ proteins from a porcine and a human coronavirus. J. Gen. Virol. $90,1724-1729$

Shirato, K., Kawase, M., and Matsuyama, S. (2013). Middle East respiratory syndrome coronavirus infection mediated by the transmembrane serine protease TMPRSS2. J. Virol. 87, 12552-12561.

Shirato, K., Kanou, K., Kawase, M., and Matsuyama, S. (2016). Clinical Isolates of Human Coronavirus 229E Bypass the Endosome for Cell Entry, J. Virol. $91,91$.

Shulla, A., Heald-Sargent, T., Subramanya, G., Zhao, J., Perlman, S., and Gallagher, T. (2011). A transmembrane serine protease is linked to the severe acute respiratory syndrome coronavirus receptor and activates virus entry. J. Virol. 85, 873-882. 
Please cite this article in press as: Hoffmann et al., A Multibasic Cleavage Site in the Spike Protein of SARS-CoV-2 Is Essential for Infection of Human Lung Cells, Molecular Cell (2020), https://doi.org/10.1016/j.molcel.2020.04.022

\section{$\infty$ CellPress}

\section{Molecular Cell}

Short Article

Simmons, G., Gosalia, D.N., Rennekamp, A.J., Reeves, J.D., Diamond, S.L., and Bates, P. (2005). Inhibitors of cathepsin L prevent severe acute respiratory syndrome coronavirus entry. Proc. Natl. Acad. Sci. USA 102, 11876-11881. Walls, A.C., Park, Y.J., Tortorici, M.A., Wall, A., McGuire, A.T., and Veesler, D. (2020). Structure, Function, and Antigenicity of the SARS-CoV-2 Spike Glycoprotein. Cell 181, 281-292.e6.

Wang, C., Horby, P.W., Hayden, F.G., and Gao, G.F. (2020). A novel coronavirus outbreak of global health concern. Lancet $395,470-473$.

WHO (2020a). Novel Coronavirus(2019-nCoV) Situation Report 52. https: www.who.int/docs/default-source/coronaviruse/situation-reports/20200312 sitrep-52-covid-19.pdf?sfirsn=e2bfc9c0_4.

WHO (2020b). Coronavins disease 2019 (COVD-19) Situation Report - 81, https: www.who.int/docs/default-source/coronaviruse/situation-reports/20200410-sitrep81-covid-19.pdi? sfvrsn=ca96eb84_2

Wrapp, D., Wang, N., Corbett, K.S., Goldsmith, J.A., Hsieh, C.L., Abiona, O. Graham, B.S., and McLellan, J.S. (2020). Cryo-EM structure of the 2019 nCoV spike in the prefusion conformation. Science 367, 1260-1263.

Yang, Y., Du, L., Liu, C., Wang, L., Ma, C., Tang, J., Baric, R.S., Jiang, S., and Y Y. F. (2014) L, Receptor usage and cell entry of bat coronavirus HKU4 provide Acad. Sci. USA 111, 12516-12521.
Yuan, Y., Cao, D., Zhang, Y., Ma, J., Qi, J., Wang, Q., Lu, G., Wu, Y., Yan, J., Shi, Y., et al. (2017). Cryo-EM structures of MERS-CoV and SARS-CoV spike glycoproteins reveal the dynamic receptor binding domains. Nat. Commun 8,15092 .

Zhang, T., Wu, Q., and Zhang, Z. (2020). Probable Pangolin Origin of SARSCoV-2 Associated with the COVID-19 Outbreak. Curr. Biol. 30, 1346-1351.e2. Zhou, Y., Vedantham, P., Lu, K., Agudelo, J., Carrion, R., Jr., Nunneley, J.W. Barnard, D., Pöhlmann, S., McKerrow, J.H., Renslo, A.R., and Simmons, G. (2015). Protease inhibitors targeting coronavirus and filovirus entry. Antiviral Res. 116, 76-84.

Zhou, H., Chen, X., Hu, T., Li, J., Song, H., Liu, Y., Wang, P., Liu, D., Yang, J. Holmes, E.C., et al. (2020a). A novel bat coronavinus reveals natural insertions at the $\mathrm{S} 1 / \mathrm{S} 2$ cleavage site of the Spike protein and a possible recombinant origin of HCoV-19. bioRxiv. https://doi. org/10.1101/2020.03.02.974139.

Zhou, P., Yang, X.L., Wang, X.G., Hu, B., Zhang, L., Zhang, W., Si, H.R., Zhu, Y., Li, B., Huang, C.L., et al. (2020b). A pneumonia outbreak associated with new coronavirus of probable bat origin. Nature $579,270-273$.

Zhu, N., Zhang, D., Wang, W., Li, X., Yang, B., Song, J., Zhao, X., Huang, B., Shi, W. Lu, R. et al. China Novel Coronavirus Investigating and Research Team (2020). A Novel Coronavinus from Patients with Pneumonia in China, 2019. N. Engl. J. Med. 382, 727-733.

6 Molecular Cell 78, 1-6, May 21, 2020 
Please cite this article in press as: Hoffmann et al., A Multibasic Cleavage Site in the Spike Protein of SARS-CoV-2 Is Essential for Infection of Human Lung Cells, Molecular Cell (2020), https://doi.org/10.1016/j.molcel.2020.04.022

Molecular Cell

$\infty$ CellPress

Short Article

STAR $\star$ METHODS

KEY RESOURCES TABLE

\begin{tabular}{|c|c|c|}
\hline REAGENT or RESOURCE & SOURCE & IDENTIFIER \\
\hline \multicolumn{3}{|l|}{ Antibodies } \\
\hline Monoclonal anti-HA antibody produced in mouse & Sigma-Aldrich & Cat.\#: H3663; RRID: AB_262051 \\
\hline Monoclonal anti- $\beta$-actin antibody produced in mouse & Sigma-Aldrich & Cat.\#: A5441; RRID: AB_476744 \\
\hline Monoclonal anti-VSV-M (23H12) antibody & KeraFast & Cat.\#: EB0011; RRID: AB_2734773 \\
\hline Monoclonal anti-mouse, peroxidase-coupled & Dianova & $\begin{array}{l}\text { Cat.\#: 115-035-003; RRID: } \\
\text { AB_10015289 }\end{array}$ \\
\hline $\begin{array}{l}\text { Anti-VSV-G antibody (11, produced from CRL-2700 } \\
\text { mouse hybridoma cells) }\end{array}$ & ATCC & Cat.\# CRL-2700; RRID: CVCL_G654 \\
\hline \multicolumn{3}{|l|}{ Bacterial and Virus Strains } \\
\hline $\mathrm{VSV}^{*} \Delta \mathrm{G}-\mathrm{FLuc}$ & $\begin{array}{l}\text { Berger Rentsch and } \\
\text { Zimmer, } 2011\end{array}$ & N/A \\
\hline One Shot ${ }^{\mathrm{TM}}$ OmniMAX ${ }^{\mathrm{TM}} 2 \mathrm{~T} 1 \mathrm{R}$ Chemically Competent $E$. coli & Thermo Fisher Scientific & Cat.\#: C854003 \\
\hline \multicolumn{3}{|l|}{ Chemicals, Peptides, and Recombinant Proteins } \\
\hline Lipofectamine LTX with Plus Reagent & Thermo Fisher Scientific & Cat.\#: 15338100 \\
\hline Furin inhibitor, decanoyl-RVKR-CMK & Tocris & Cat.\#: 3501 \\
\hline May-Grünwald solution & Sigma-Aldrich & Cat.\#: 63590 \\
\hline Giemsa solution & Sigma-Aldrich & Cat.\#: GS500 \\
\hline \multicolumn{3}{|l|}{ Critical Commercial Assays } \\
\hline Beetle-Juice Kit & PJK & Cat.\#: 102511 \\
\hline \multicolumn{3}{|l|}{ Experimental Models: Cell Lines } \\
\hline $293 \mathrm{~T}$ & DSMZ & Cat.\#: ACC-635; RRID: CVCL_0063 \\
\hline Calu-3 & $\begin{array}{l}\text { Laboratory of Stephan } \\
\text { Ludwig }\end{array}$ & $\begin{array}{l}\text { ATCC Cat\# HTB-55; RRID: } \\
\text { CVCL_0609 }\end{array}$ \\
\hline Vero & $\begin{array}{l}\text { Laboratory of Andrea } \\
\text { Maisner }\end{array}$ & $\begin{array}{l}\text { ATCC Cat\# CRL-1586; RRID: } \\
\text { CVCL_0574 }\end{array}$ \\
\hline Vero-TMPRSS2 & Hoffmann et al., 2020 & N/A \\
\hline \multicolumn{3}{|l|}{ Oligonucleotides } \\
\hline $\begin{array}{l}\text { SARS-S (BamHI) F CTTGGATCCGCCACCATGTTTATITC } \\
\text { TTATATITC }\end{array}$ & Sigma-Aldrich & N/A \\
\hline $\begin{array}{l}\text { SARS-S } \triangle 18 \text { (Xbal) R CTTCTAGACTACTTGCAGCAAGAA } \\
\text { CCACAAGAGC }\end{array}$ & Sigma-Aldrich & N/A \\
\hline $\begin{array}{l}\text { SARS-S } 18 \text { (-)STOP (Xbal) R CTTCTAGACTTGCAGCAAG } \\
\text { AACCACAAGAGC }\end{array}$ & Sigma-Aldrich & $\mathrm{N} / \mathrm{A}$ \\
\hline $\begin{array}{l}\text { SARS-2-S (BamHI) F GAATTCGGATCCGCCACCATGTTCGT } \\
\text { GTITCTGGTGCTGC }\end{array}$ & Sigma-Aldrich & N/A \\
\hline $\begin{array}{l}\text { SARS-2-S } \triangle 18 \text { (Xbal) R AAGGCCTCTAGACTACTTGCAGCA } \\
\text { GCTGCCACAGC }\end{array}$ & Sigma-Aldrich & N/A \\
\hline $\begin{array}{l}\text { SARS-2-S } 18 \text { (-)STOP (Xbal) R AAGGCCTCTAGACTTGCA } \\
\text { GCAGCTGCCACAGC }\end{array}$ & Sigma-Aldrich & N/A \\
\hline $\begin{array}{l}\text { SARS-S (SARS) F CAGACAAACAGCCCCAGACGGGCCAG } \\
\text { AAGTACTAGCCAAAAATCTATTG }\end{array}$ & Sigma-Aldrich & N/A \\
\hline $\begin{array}{l}\text { SARS-S (SARS) R TCTGGCCCGTCTGGGGCTGTTTGTCT } \\
\text { GTGTATGGTAACTAGCACAAATGC }\end{array}$ & Sigma-Aldrich & N/A \\
\hline $\begin{array}{l}\text { SARS-S (RaTG) F CAGACAAACAGCAGAAGTACTAGCCA } \\
\text { AAAATC }\end{array}$ & Sigma-Aldrich & $\mathrm{N} / \mathrm{A}$ \\
\hline $\begin{array}{l}\text { SARS-S (RaTG) R TCTGCTGTTIGTCTGTGTATGGTAACTA } \\
\text { GCACAAATGC }\end{array}$ & Sigma-Aldrich & N/A \\
\hline
\end{tabular}


Please cite this article in press as: Hoffmann et al., A Multibasic Cleavage Site in the Spike Protein of SARS-CoV-2 Is Essential for Infection of Human Lung Cells, Molecular Cell (2020), https://doi.org/10.1016/..molcel.2020.04.022

\section{CellPress}

Molecular Cell

Short Article

\begin{tabular}{|c|c|c|}
\hline \multicolumn{3}{|l|}{ Continued } \\
\hline REAGENT or RESOURCE & SOURCE & IDENTIFIER \\
\hline $\begin{array}{l}\text { SARS-2-S (SARS) F GTTTCTTATTACGTTCTGTGGCCAGC } \\
\text { CAGAGCATC }\end{array}$ & Sigma-Aldrich & N/A \\
\hline $\begin{array}{l}\text { SARS-2-S (SARS) R ACGTAATAAAGAAACTGTCTGGTAGC } \\
\text { TGGCACAGATG }\end{array}$ & Sigma-Aldrich & N/A \\
\hline $\begin{array}{l}\text { SARS-2-S (RaTG) F CAGACAAACAGCAGATCTGTGGCCAGC } \\
\text { CAGAGCATC }\end{array}$ & Sigma-Aldrich & N/A \\
\hline $\begin{array}{l}\text { SARS-2-S (RaTG) R GCTGGCCACAGATCTGCTGTTTGTCTG } \\
\text { TGTCTGGTAGC }\end{array}$ & Sigma-Aldrich & N/A \\
\hline $\begin{array}{l}\text { SARS-2-S (delta) F CAAACAGCCCCGCATCTGTGGCCAGCC } \\
\text { AGAGCATC }\end{array}$ & Sigma-Aldrich & N/A \\
\hline $\begin{array}{l}\text { SARS-2-S (delta) R GCTGGCCACAGATGCGGGGCTGTTTGTC } \\
\text { TGTGTCTGGTAGC }\end{array}$ & Sigma-Aldrich & N/A \\
\hline $\begin{array}{l}\text { SARS-2-S (opt) F CGAAGACGAAAAAGATCTGTGGCCAGCCA } \\
\text { GAGCATC }\end{array}$ & Sigma-Aldrich & N/A \\
\hline $\begin{array}{l}\text { SARS-2-S (opt) R TCTIITTCGTCTTCGGCTGTTTGTCTGTGT } \\
\text { CTGG }\end{array}$ & Sigma-Aldrich & N/A \\
\hline pCG1 Seq F CCTGGGCAACGTGCTGGT & Sigma-Aldrich & N/A \\
\hline pCG1 Seq R GTCAGATGCTCAAGGGGCTTCA & Sigma-Aldrich & $\mathrm{N} / \mathrm{A}$ \\
\hline SARS-S 387F TGTTATACGAGCATGTAAC & Sigma-Aldrich & $\mathrm{N} / \mathrm{A}$ \\
\hline SARS-S 790F AAGCCAACTACATTTATGC & Sigma-Aldrich & N/A \\
\hline SARS S 1194F TGATGTAAGACAAATAGCG & Sigma-Aldrich & N/A \\
\hline SARS S 1575F TATTAAGAACCAGTGTGTC & Sigma-Aldrich & $\mathrm{N} / \mathrm{A}$ \\
\hline SARS S 1987F GTGCTAGTTACCATACAG & Sigma-Aldrich & $\mathrm{N} / \mathrm{A}$ \\
\hline SARS S 2391F CTAAAGCCAACTAAGAGG & Sigma-Aldrich & N/A \\
\hline SARS S 2787F TCAACTGCATTGGGCAAG & Sigma-Aldrich & N/A \\
\hline SARS-2-S 651F CAAGATCTACAGCAAGCACACC & Sigma-Aldrich & N/A \\
\hline SARS-2-S 1380F GTCGGCGGCAACTACAATTAC & Sigma-Aldrich & $\mathrm{N} / \mathrm{A}$ \\
\hline SARS-2-S 1992F CTGTCTGATCGGAGCCGAGCAC & Sigma-Aldrich & N/A \\
\hline SARS-2-S 2648F TGAGATGATCGCCCAGTACAC & Sigma-Aldrich & N/A \\
\hline SARS-2-S 3286F GCCATCTGCCACGACGGCAAAG & Sigma-Aldrich & $\mathrm{N} / \mathrm{A}$ \\
\hline $\begin{array}{l}\text { pCG1-V5 F TCCCTAACCCTCTCCTCGGTCTCGATTCTACGTG } \\
\text { AAAGCTGATCTIITCCCTCTGCC }\end{array}$ & Sigma-Aldrich & N/A \\
\hline $\begin{array}{l}\text { pCG1-V5 R GACCGAGGAGAGGGTTAGGGATAGGCTTACCG } \\
\text { CATGCCTGCAGGTTAAACAGTCG }\end{array}$ & Sigma-Aldrich & N/A \\
\hline pCG1-Xhol R CTCCTCGAGTTCATAAGAGAAGAGGG & Sigma-Aldrich & N/A \\
\hline \multicolumn{3}{|l|}{ Recombinant DNA } \\
\hline Plasmid: pCG1-SARS-S & Hoffmann et al., 2013 & $\mathrm{~N} / \mathrm{A}$ \\
\hline Plasmid: pCG1-SARS-S-HA & Hoffmann et al., 2020 & N/A \\
\hline Plasmid: pCG1-SARS-2-S & Hoffmann et al., 2020 & $\mathrm{~N} / \mathrm{A}$ \\
\hline Plasmid: pCG1-SARS-2-S-HA & Hoffmann et al., 2020 & $\mathrm{~N} / \mathrm{A}$ \\
\hline Plasmid: pCG1-SARS-S $\Delta 18$ & Hoffmann et al., 2013 & N/A \\
\hline Plasmid: pCG1-SARS-S $\Delta 18-V 5$ & This paper & N/A \\
\hline Plasmid: pCG1-SARS-2-SA18 & This paper & $\mathrm{N} / \mathrm{A}$ \\
\hline Plasmid: pCG1-SARS-2-SA18-V5 & This paper & $\mathrm{N} / \mathrm{A}$ \\
\hline Plasmid: pCG1-SARS-SA18 (SARS-2) & This paper & N/A \\
\hline Plasmid: pCG1-SARS-SA18-V5 (SARS-2) & This paper & N/A \\
\hline Plasmid: pCG1-SARS-S $\Delta 18$ (RaTG) & This paper & $\mathrm{N} / \mathrm{A}$ \\
\hline Plasmid: pCG1-SARS-SA18-V5 (RaTG) & This paper & $\mathrm{N} / \mathrm{A}$ \\
\hline Plasmid: pCG1-SARS-2-SA18 (SARS) & This paper & N/A \\
\hline Plasmid: pCG1-SARS-2-SA18-V5 (SARS) & This paper & N/A \\
\hline Plasmid: pCG1-SARS-2-SA18 (RaTG) & This paper & $\mathrm{N} / \mathrm{A}$ \\
\hline
\end{tabular}

e2 Molecular Cell 78, 1-6.e1-e5, May 21, 2020 
Please cite this article in press as: Hoffmann et al., A Multibasic Cleavage Site in the Spike Protein of SARS-CoV-2 Is Essential for Infection of Human Lung Cells, Molecular Cell (2020), https://doi.org/10.1016/j.molcel.2020.04.022

Molecular Cell

$\$$ CellPress

Short Article

\begin{tabular}{|c|c|c|}
\hline \multicolumn{3}{|l|}{ Continued } \\
\hline REAGENT or RESOURCE & SOURCE & IDENTIFIER \\
\hline Plasmid: pCG1-SARS-2-S $\Delta 18-V 5$ (RaTG) & This paper & N/A \\
\hline Plasmid: pCG1-SARS-2-S $\Delta 18$ (delta) & This paper & N/A \\
\hline Plasmid: pCG1-SARS-2-S $\Delta 18-V 5$ (delta) & This paper & N/A \\
\hline Plasmid: pCG1-SARS-2-S $\Delta 18$ (opt) & This paper & N/A \\
\hline Plasmid: pCG1-SARS-2-SA18-V5 (opt) & This paper & N/A \\
\hline Plasmid: pCAGGS-MERS-S-V5 & Gierer et al., 2013 & N/A \\
\hline Plasmid: pCAGGS-VSV-G & Brinkmann et al., 2017 & N/A \\
\hline Plasmid: pCAGGS-DsRed & Hoffmann et al., 2013 & N/A \\
\hline Plasmid: pCG1 & $\begin{array}{l}\text { Laboratory of Roberto } \\
\text { Cattaneo }\end{array}$ & N/A \\
\hline Plasmid: pCG1-V5 & This paper & N/A \\
\hline \multicolumn{3}{|l|}{ Software and Algorithms } \\
\hline Hidex Sense Microplate Reader Software & $\begin{array}{l}\text { Hidex Deutschland Vertrieb } \\
\text { GmbH }\end{array}$ & https://www.hidex.de/ \\
\hline ChemoStar Imager Software (version v.0.3.23) & $\begin{array}{l}\text { Intas Science Imaging } \\
\text { Instruments GmbH }\end{array}$ & https://www.intas.de/ \\
\hline ZEN imaging software & Carl Zeiss & https://www.zeiss.com/ \\
\hline Clustal Omega & $\begin{array}{l}\text { European Molecular Biology } \\
\text { Laboratory - European } \\
\text { Bioinformatics Institute (EMBL-EBI) }\end{array}$ & $\begin{array}{l}\text { https://www.ebi.ac.uk/Tools/msa/ } \\
\text { clustalo/; Madeira et al., } 2019\end{array}$ \\
\hline Adobe Photoshop CS5 Extended (version 12.0332 ) & Adobe & https://www.adobe.com/ \\
\hline GraphPad Prism (version 8.3.0(538)) & GraphPad Software & https://www.graphpad.com/ \\
\hline YASARA (version 19.1.27) & $\begin{array}{l}\text { YASARA Biosciences } \\
\text { GmbH }\end{array}$ & $\begin{array}{l}\text { http://www.yasara.org/; Krieger } \\
\text { and Vriend, } 2014\end{array}$ \\
\hline Microsoft Office Standard 2010 (version 14.0 .7232 .5000 ) & Microsoft Corporation & https://products.office.com/home \\
\hline \multicolumn{3}{|l|}{ Other } \\
\hline Prefusion structure of SARS-CoV spike glycoprotein (5X5B) & Yuan et al., 2017 & https://www.rcsb.org/structure/5X5B \\
\hline
\end{tabular}

RESOURCE AVAILABILITY

Lead Contact

Further information and requests for resources and reagents should be directed to and will be fulfilled by the Lead Contact, Stefan Pöhlmann (spoehlmann@dpz.eu).

Materials Availability

All unique/stable reagents generated in this study are available from the Lead Contact with a completed Materials Transfer Agreement.

Data and Code Availability

The study did not generate unique datasets or code.

METHOD DETAILS

Cell cultures

293T (human, kidney) and Vero (African green monkey, kidney) cells were cultivated in Dulbecco's Modified Eagle Medium (PANBiotech) supplemented with $10 \%$ fetal bovine serum (Biochrom), $100 \mathrm{U} / \mathrm{mL}$ of penicillin and $0.1 \mathrm{mg} / \mathrm{mL}$ of streptomycin (PANBiotech). Vero cells that stably express human TMPRSS2 have been described previously (Hoffmann et al., 2020) and were cultivated in the presence of $10 \mu \mathrm{g} / \mathrm{mL}$ blasticidin (Invivogen). Calu-3 (human, lung; kindly provided by Stephan Ludwig, Westfälische WilhelmsUniversität, Muenster/Germany) cells were cultivated in Minimum Essential Medium (Thermo Fisher Scientific) supplemented with $10 \%$ fetal bovine serum (Biochrom), $100 \mathrm{U} / \mathrm{mL}$ of penicillin and $0.1 \mathrm{mg} / \mathrm{mL}$ of streptomycin (PAN-Biotech), $1 \times$ non-essential amino acid solution (from 100x stock, PAA) and $10 \mathrm{mM}$ sodium pyruvate (Thermo Fisher Scientific). All cell lines were incubated at $37^{\circ} \mathrm{C}$ and $5 \% \mathrm{CO}_{2}$ in a humidified atmosphere. 


\section{$\infty$ CellPress}

Plasmids

Expression plasmids for full-length vesicular stomatitis virus (VSV) glycoprotein (VSV-G), Middle-East respiratory syndrome coronavirus spike glycoprotein (MERS-S) containing a C-terminal V5 epitope tag, severe acute respiratory syndrome coronavirus spike glycoprotein (SARS-S) and severe acute respiratory syndrome coronavirus 2 spike glycoprotein (SARS-2-S) both equipped with a C-terminal hemagglutinin (HA) epitope tag have been described previously (Brinkmann et al., 2017; Hoffmann et al., 2020). Empty pCG1 expression vector was kindly provided by Roberto Cattaneo, Mayo Clinic, Rochester, MN/USA). Based on the SARS-S and SARS-2-S expression plasmids we cloned mutated versions with alterations at the S1/S2 cleavage site: We generated SARS-S containing the cleavage site of SARS-2-S, SARS-S (SARS-2), or BetaCoV/bat/Yunnan/RaTG13/2013 (RaTG; GISAID: EPI_ISL_402131), SARS-S (RaTG). Further, we generated SARS-2-S harboring the S1/S2 cleavage site of SARS-S, SARS-2-S (SARS) or RaTG-S, SARS-2-S (RaTG). Finally, we constructed SARS-2-S variants in which either the multibasic motif was deleted, SARS-2-S (delta), or in which the proline residue preceding the multibasic motif was mutated to arginine and the alanine residue within the minimal furin motif was changed to lysine in order to increase the basic environment at the S1/S2 site, SARS-2-S (opt). All newly cloned spike protein constructs further contained a deletion of 18 amino acids at their respective $\mathrm{C}$ terminus as this has been shown to improve coronavirus spike protein incorporation into VSV particles and thus transduction (Schwegmann-Weßels et al., 2009). Further, for each construct an untagged variant as well as a version containing a C-terminal V5 epitope tag was constructed.

Preparation of pseudotyped particles and transduction experiments

A previously published protocol was employed to produce VSV pseudotype particles (VSVpp) carrying foreign viral glycoproteins in their envelope (Berger Rentsch and Zimmer, 2011; Kleine-Weber et al., 2019). First, 293T cells were transfected with expression plasmid for the respective spike glycoprotein or VSV-G or empty expression vector by calcium-phosphate precipitation. At $16 \mathrm{~h}$ posttransfection, the cells were inoculated with VSV* $\Delta$ G-fLuc (kindly provided by Gert Zimmer, Institute of Virology and Immunology, Mittelhäusern/Switzerland), a replication-deficient VSV vector that lacks the genetic information for VSV-G and encodes for eGFP and firefly luciferase (fLuc), at a multiplicity of infection of 3 . After $1 \mathrm{~h}$ of incubation, the inoculum was removed and cells were washed with phosphate-buffered saline (PBS) before medium containing anti-VSV-G antibody (11, mouse hybridoma supernatant from CRL-2700; ATCC) was added to all cells except for those expressing VSV-G (here, medium without antibody was added). Cells were further incubated for $16 \mathrm{~h}$, before the VSVpp containing supernatants were harvested, freed from cellular debris by centrifugation and used for experiments.

For transduction, target cells were grown in 96 -well plates until they reached $50 \%-80 \%$ confluency. The culture supernatant was removed by aspiration and $100 \mu \mathrm{l} /$ well of the respective pseudotype were added (quadruplicate samples). At $16 \mathrm{~h}$ posttransduction, culture supematants were aspirated and cells lysed in $1 \mathrm{x}$ cell culture lysis reagent (prepared from $5 \mathrm{x}$ stock, Promega) for 20 min at room temperature. The lysates were then transferred to white, opaque-walled 96 -well plates and luciferase activity was quantified by measuring luminescence upon addition of a substrate (PJK) using a Hidex Sense plate luminometer (Hidex).

Western blot analysis

For the analysis of S protein processing, we subjected VSVpp harboring V5- or HA-tagged S proteins to SDS-PAGE and western blot analysis. For this, we loaded $1 \mathrm{~mL}$ VSVpp onto $50 \mu \mathrm{l}$ of a $20 \%(\mathrm{w} / \mathrm{v})$ sucrose cushion and performed high-speed centrifugation $\left(25.000 \mathrm{~g}\right.$ for $120 \mathrm{~min}$ at $4^{\circ} \mathrm{C}$ ). Next, we removed $1 \mathrm{~mL}$ of supernatant, added $50 \mu \mathrm{l}$ of $2 x$ SDS-sample buffer and incubated the samples for $15 \mathrm{~min}$ at $96^{\circ} \mathrm{C}$. Thereafter, the samples were subjected to SDS-PAGE and protein transfer to nitrocellulose membranes by western blot. The membranes were subsequently blocked in $5 \%$ skim milk solution (PBS containing $0.05 \%$ Tween-20 [PBS-T] and $5 \%$ skim milk powder) for $1 \mathrm{~h}$ at room temperature. The blots were then incubated over night at $4{ }^{\circ} \mathrm{C}$ with primary antibody solution (all antibodies were diluted in PBS-T containing $5 \%$ skim milk; mouse anti-HA tag [Sigma-Aldrich, H3663, 1:2,500], mouse anti-V5 tag [Thermo Fisher Scientific, R960-25, 1:2,500] or VSV matrix protein [Kerafast, EB0011, 1:2,500]). Following this incubation, the blots were washed $3 \mathrm{x}$ with PBS-T before they were incubated for $1 \mathrm{~h}$ at room temperature with peroxidase-coupled goat anti-mouse antibody (Dianova, 115-035-003, 1:10,000). Finally, the blots were again washed and imaged. For this, an in house-prepared enhanced chemiluminescent solution ( $0.1 \mathrm{M}$ Tris- $\mathrm{HCl}$ [pH 8.6], $250 \mu \mathrm{g} / \mathrm{mL}$ luminol, $1 \mathrm{mg} / \mathrm{mL}$ para-hydroxycoumaric acid, $0.3 \% \mathrm{H}_{2} \mathrm{O}_{2}$ ) and the ChemoCam imaging system along with the ChemoStar Professional software (Intas Science Imaging Instruments $\mathrm{GmbH}$ ) were used.

Syncytium formation assay

Vero or Vero-TMPRSS2 cells were grown on coverslips seeded in 24-well plates and transfected with S protein expression plasmids ( $1 \mu \mathrm{g} /$ well) using Lipofectamine 2000 LTX with Plus reagent (Thermo Fisher Scientific) and OptiMEM medium (GIBCO). After $6 \mathrm{~h}$ the transfection solutions were aspirated and the cells further incubated for $24 \mathrm{~h}$ in standard culture medium. Next, the medium was changed to serum free medium $\pm 1 \mu \mathrm{g} / \mathrm{mL}$ bovine trypsin (Sigma-Aldrich) and the cells were incubated for additional $24 \mathrm{~h}$. Then, the cells were washed with PBS, fixed with $4 \%$ paraformaldehyde solution for $20 \mathrm{~min}$ at room temperature, washed again, air-dried and incubated for $30 \mathrm{~min}$ with May-Gruenwald solution (Sigma-Aldrich). Thereafter, the cells were washed three times with deionized water, air-dried and incubated for 30 min with 1:10 diluted Giemsa solution (Sigma-Aldrich). After an additional washing interval with deionized water, the samples were air-dried and analyzed by bright-field microscopy using a Zeiss LSM800 confocal laser scanning microscope and the ZEN imaging software (both from Zeiss). 


\section{Molecular Cell}

Short Article

Sequence analysis and protein models

Sequence alignments were performed using the Clustal Omega online tool (https://www.ebi.ac.uk/Tools/msa/clustalo/). Protein models were designed using the YASARA software (http://www.yasara.org/index.html). For the generation of the SARS-2-S protein model the protein sequence was first modeled on a SARS-S template (PDB: 5X5B, (Yuan et al.,2017)) using the SWISS-MODEL online tool (https://swissmodel.expasy.org/). The following sequences information were obtained from National Center for Biotechnology Information (NCBI) database: SARS-CoV BJ01 (GenBank: AY278488.2), SARS-CoV CUHK-W1 (GenBank: AY278554.2), SARS-CoV Frankfurt-1 (GenBank: AY291315.1), SARS-CoV Tor2 (GenBank: CS050815.1), SARS-CoV Urbani (GenBank: AY278741.1), civet SARS-CoV SZ16 (GenBank: AY304488.1), civet SARS-CoV civet020 (GenBank: AY572038.1), raccoon dog SARS-CoV A030 (GenBank: AY687357.1), bat SARSr-CoV BtKY72/KEN (GenBank: KY352407.1), bat SARSr-CoV BM48-31/BGR/ 2008 (GenBank: GU190215.1), bat SARSr-CoV Rs4231 (GenBank: KY417146.1), bat SARSr-CoV WIV16 (GenBank: KT444582.1) bat SARSr-CoV Rs4874 (GenBank: KY417150.1), bat SARSr-CoV SL-CoVZC45 (GenBank: MG772933.1), bat SARSr-CoV SLCoVZXC21 (GenBank: MG772934.1), bat SARSr-CoV LYRa11 (GenBank: KF569996.1), bat SARSr-CoV LYRa3 (GenBank: KF569997.1), bat SARSr-CoV WIV1 (GenBank: KF367457.1), bat SARSr-CoV RsSHC014 (GenBank: KC881005.1), bat SARSrCoV Rs3367 (GenBank: KC881006.1), bat SARSr-CoV Cp/Yunnan2011 (GenBank: JX993988.1), bat SARSr-CoV Rp/Shaanxi2011 (GenBank: JX993987.1), bat SARSr-CoV HKU3-1 (GenBank: DQ022305.2), bat SARSr-CoV Rm1 (GenBank: DQ412043.1), bat SARSr-CoV Rp3 (GenBank: DQ071615.1), bat SARSr-CoV Rf1 (GenBank: DQ412042.1), bat SARSr-CoV 279 (GenBank: DQ648857.1), bat SARSr-CoV 273 (GenBank: DQ648856.1), bat SARSr-CoV YN2013 (GenBank: KJ473816.1), bat SARSr-CoV Rs/HuB2013 (GenBank: KJ473814.1), bat SARSr-CoV Rs/GX2013 (GenBank: KJ473815.1), bat SARSr-CoV Rf/SX2013 (GenBank: KJ473813.1), bat SARSr-CoV Rf/JL2012 (GenBank: KJ473811.1), bat SARSr-CoV Rf/HeB2013 (GenBank: KJ473812.1), bat SARSrCoV YNLF/34C (GenBank: KP886809.1), bat SARSr-CoV YNLF/31C (GenBank: KP886808.1), bat SARSr-CoV Rs672 (GenBank: FJ588686.1), bat SARSr-CoV Rs7327 (GenBank: KY417151.1), bat SARSr-CoV Rs4084 (GenBank: KY417144.1), bat SARSr-CoV Rs9401 (GenBank: KY417152.1), bat SARSr-CoV Rs4247 (GenBank: KY417148.1), bat SARSr-CoV Rs4255 (GenBank: KY417149.1), bat SARSr-CoV Rs4081 (GenBank: KY417143.1), bat SARSr-CoV Rs4237 (GenBank: KY417147.1), bat SARSr-CoV As6526 (GenBank: KY417142.1), bat SARSr-CoV Rf4092 (GenBank: KY417145.1), bat SARSr-CoV Longquan-140 (GenBank: KF294457.1), bat SARSr-CoV Rs806 (GenBank: FJ588692.1), bat SARSr-CoV Anlong-103 (GenBank: KY770858.1), bat SARSrCoV JTMC15 (GenBank: KU182964.1), bat SARSr-CoV 16BO133 (GenBank: KY938558.1), bat SARSr-CoV B15-21 (GenBank: KU528591.1), pangolin coronavirus MP789 (GenBank: MT084071.1). In addition the following sequences information were obtained from the Global Initiative on Sharing All Influenza Data (GISAID) database: SARS-CoV-2 (GISAID: EPI_ISL_404895), bat SARSr-CoV RaTG13 (GISAID: EPI_ISL_402131).

\section{QUANTIFICATION AND STATISTICAL ANALYSIS}

If not stated otherwise, statistical significance was tested by one-way analysis of variance with Dunnet's posttest (GraphPad Prism 7.03). Only $p$ values of 0.05 or lower were considered statistically significant $\left(p>0.05\right.$ [ns, not significant], $p \leq 0.05\left[{ }^{\star}\right], p \leq 0.01\left[{ }^{\star \star}\right]$, $\mathrm{p} \leq 0.001\left[{ }^{\star \star}\right]$ ). For all statistical analyses, the GraphPad Prism 7 software package was used (GraphPad Software). 


\section{Discussion}

MERS-CoV and SARS-CoV-2 pose a severe threat to human health. Both coronaviruses have a zoonotic origin and recently spilled over into the human population. MERS-CoV emerged in 2012 in the KSA and, since then, has been sporadically transmitted from dromedary camels to humans with only limited local spread mainly restricted to the Middle-East (Mackay and Arden, 2015; Killerby et al., 2020). In contrast, SARS-CoV-2 infections have been first noticed in the winter of 2019 the city of Wuhan in China from where the virus has subsequently been disseminated all over the world causing an ongoing pandemic with more than four million infections and over 280,000 deaths (WHO, 2020). This work demonstrates, that MERS-CoV and SARS-CoV-2 share striking commonalities with respect to proteolytic priming of their respective surface glycoprotein, S protein, a step that is crucial for viral entry into target cells of the human lung.

The investigation and in-depth understanding of the host cell entry process, including virus attachment to host cells trough interaction of the viral S protein and its cellular receptor molecule as well as the proteolytic priming of the $S$ protein by host cell proteases provide the basis for the development of antiviral intervention strategies (Gao et al., 2013; Du et al., 2017).

Transduction vectors like vesicular stomatitis virus-based pseudotype particles bearing coronavirus $S$ proteins faithfully mirror the cellular entry process of coronaviruses and thus provide a save platform to study S-driven host cell entry in absence of the infectious authentic coronavirus and are thus powerful toll to study the early events of the viral lifecycle (Tani, Morikawa and Matsuura, 2012). 


\subsection{Functional characterization of host cell factors required for cellular entry driven by the S protein of MERS-CoV}

\subsubsection{Analysis of molecular requirements for $S$ protein priming revels cell type specific priming strategies for MERS-S}

MERS-S harbors two multibasic cleavage sites, the S1/S2 and the S2' sites, that are important for proteolytic priming and thus viral entry into target cells, I could demonstrate that the requirement for proteolytic priming as the MERS-S S1/S2 site is cell type dependent while priming at the S2' site is universally required for S protein activation. Thus the viral entry driven by a mutant MERS-S variant was strongly reduced for TMPRSS2-positive Caco-2 cells, while entry into TMPRSS2-negative Vero cells was at the same level as for wildtype MERS-S. In contrast, mutation of the S2' site in MERS-S caused decreased S protein-driven cellular entry for all cell lines tested (Kleine-Weber et al., 2018). It is now generally believed that a pre-priming event at the S1/S2 site is mediated by the PPC furin during S protein transport along the secretory pathway in the infected cell (Gierer et al., 2013), which enables a second priming event at the S2' site that is performed by TMPRSS2 after attachment to new target cells (Park et al., 2016; Kleine-Weber et al., 2018). MERS-S further harbors an additional cleavage site for CTSL near the S1/S2 site, which was shown to be required for $S$ protein priming within endosomal vesicles after endocytosis of receptor-bound virus in TMPRSS2-negative cells (Gierer et al., 2013; Yang et al., 2015; Park et al., 2016; Kleine-Weber et al., 2018). In this context, a study by Yang and coworkers showed that introduction of a glycosylation site at the CTSL priming site in MERS-S severely attenuated S protein-driven host cell entry (Yang et al., 2015) 
However, the role of CTSL-mediated MERS-S priming is controversially discussed and there are several lines of evidence, which suggest that it might represent a cell culture adaptation and has no biological relevance in vivo. In contrast, $\mathrm{S}$ protein priming by TMPRSS2 seems to be crucial for cellular entry driven by the S protein of MERS-CoV and other coronaviruses in vivo. TMPRSS2 is known to play a crucial role in activation of S proteins of related coronaviruses such as SARS-CoV or HCoV229E, as well as the HA of several IAV strains (Ebara, Fukuda and Saisho, 2003; Hatesuer et al., 2013; Shirato, Kawase and Matsuyama, 2013, 2018b; Zmora et al., 2015; Shirato et al., 2016). Further, it is reported that clinical isolates of HCoV-229E, HCoV-OC43 and HCoV-HKU1 preferentially enter human cells following S protein priming through TMPRSS2, while the CTSL-mediated S protein priming was mainly observed for viruses that have been previously passaged in cell culture (Shirato et al., 2016; Shirato, Kawase and Matsuyama, 2018a). With respect to the availability of CTSL and TMPRSS2 for priming of coronavirus S proteins in the human lung cells, a study by Park and colleagues demonstrated that CTSL expression in these cells is low, while TMPRSS2 expression is high (Park et al., 2016). The latter finding could further be confirmed and extended to the lung as a whole organ by my own work (Kleine-Weber et al., 2018). Lack of in vivo relevance for CTSL-mediated S protein priming has been demonstrated by Zhou and colleagues, who showed that treatment of SARS-CoV infected mice with a CTSL inhibitor did not protect from fatal disease (9 out of 10 succumbed to infection), while inhibition of serine proteases like TMPRSS2 by administration of camostat mesylate allowed 6/10 mice to survive (Zhou et al., 2020). 
Given the overwhelming scientific evidence, which indicates that TMPRSS2 is the main activating protease of the $\mathrm{S}$ proteins of $\mathrm{HCoV}$ in the human lung a major focus of my work was dedicated to the in-depth analysis of TMPRSS2-mediated MERS-S priming.

Similar to trypsin, TMPRSS2 requires only a single basic amino acid residue (arginine or lysine) for the cleavage of polypeptides (Hooper et al., 2001; Szabo and Bugge, 2008). Using a mutational approach, in which I exchanged individual or multiple arginine residues by alanine residues, I could show that the S2' site is a substrate for TMPRSS2-mediated MERS-S priming (Kleine-Weber et al., 2018). Moreover, I found out that only the second arginine (R887) of the multibasic motif at the S2' site of MERS-S is crucial for efficient S protein priming by TMPRSS2 (KleineWeber et al., 2018). With respect to the MERS-S S1/S2 priming site I further demonstrated that removal of either of the two arginine residues abolished MERS-S pre-priming and, as a consequence, abrogates subsequent MERS-S priming by TMPRSS2 and thus S protein-driven entry into TMPRSS2-positive target cells. It can thus be concluded that the MERS-S S1/S2 site is cleaved by proteases that require a multibasic motif e.g. furin, while the $S 2$ ' site is a substrate for proteases that can cleave at a monobasic motif e.g. TMPRSS2 (Fuller, Brake and Thorner, 1989; Seidah and Chretien, 1999; Yang et al., 2014; Kleine-Weber et al., 2018). Further, my work revealed that the expression level of the MERS-CoV receptor DPP4 has an impact on the dependence of MERS-S priming at the S2' site. Thus, cellular entry of viral transduction vectors harboring a MERS-S variant with a mutated S2' site was almost at background level for wildtype 293T cells whereas the same S protein variant allowed for robust viral entry into 293 T cells transiently overexpressing DPP4 (Kleine-Weber et al., 2018) 


\subsubsection{Natural sequence variations in the $S$ protein of MERS-CoV isolates or the cellular receptor DPP4 affect viral entry and viral resistance against antibody-mediated neutralization}

The efficacy of $S$ protein binding with its cellular receptor can be influenced by natural sequence polymorphisms of the $S$ protein. Thus, sequence variations at $S$ protein residues directly interacting with residues of the receptor molecule might enhance or decrease binding efficiency. The emergence of polymorphic residues in coronavirus S proteins can happen spontaneously due to the high mutation rate of RNA viruses (Elena and Sanjua, 2005; Duffy, 2018). Alternatively, sequence variations can develop as a consequence of a selective pressure.

During the MERS outbreak in 2015 in the Republic of Korea, which was started by single infected traveler returning from the Middle East, two particular polymorphisms in the receptor binding domain of MERS-S, D510G and I529T, emerged in several patients (Kim et al., 2016). I529T was found in $72 \%$ of sequences and was passed on during transmission events. In contrast, D510G was less frequent (Kim et al., 2016). It was further shown, that both polymorphisms were associated with a reduced ability of the S protein to bind to DPP4 and polymorphism I529T was shown to be less efficient in mediating cellular entry of viral particles (Kim et al., 2016). However, besides this "negative" effect for the virus no functional benefit was revealed that could be a selective force to drive emergence of these two polymorphisms.

In front of this background, I investigated the consequences of the two Korean polymorphisms on $\mathrm{S}$ protein-driven host cell entry and evasion of the adaptive immune response. I could confirm lower binding efficiency for MERS-S harboring either polymorphism D510G or I529T. However, this "defect" was only associated 
with reduced viral entry into target cells expressing low levels of DPP4, whereas for cells expressing high amounts of DPP4, S protein-driven entry was as or almost as efficient as for wildtype MERS-S (Kleine-Weber et al., 2019). These results indicate that infection of target cells expressing high DPP4 levels by MERS-CoV variants bearing S protein polymorphisms D510G or I529T would not be compromised. More importantly, I revealed that both polymorphisms provided the $S$ protein with some resistance against neutralization mediated by antibodies present in sera from MERS patients (Kleine-Weber et al., 2019). This observation fits well to the previous study by Tang and colleagues who reported that MERS-CoV can acquire mutations that can allow the virus to escape from neutralizing antibodies and that these mutations could affect receptor binding (Tang et al., 2014).

In sum, these findings are of high importance for vaccine design, as this suggests that MERS-CoV, and likely other (emerging) coronaviruses, could have the potential to rapidly escape from neutralizing antibodies that target only a single epitope on the $S$ protein. It should therefore be a focus to design vaccines that elicit antibodies against multiple epitopes or administer a combination of monoclonal antibodies with different targets.

As mentioned before, DPP4, is highly expressed in the human respiratory tract, which has been also reported for ACE2 (Tipnis et al., 2000; Vliegen et al., 2017). Besides the presence of sufficient amounts of receptor molecules on the cell surface also the efficiency of $S$ protein/receptor-interaction is a key factor that defines whether a coronavirus can successfully enter a target cell. The binding efficiency of the coronaviral $S$ protein to its respective receptor can be affected by naturaloccurring polymorphisms present in either the $S$ protein or in the receptor molecule, especially at the binding interface. Naturally-occurring polymorphisms can be found 
in all proteins. In most cases these polymorphisms are not associated with a phenotype for the host, however, in some cases, single nucleotide polymorphisms (SNPs) can cause amino acid changes and thereby affect protein function, which itself can induce diseases including different types of cancer or metabolic disorders (e.g. diabetes) (Böhm et al., 2017; Hoppe et al., 2018). Diabetes, like obesity and heart conditions, is an underlying condition (comorbidity) in MERS or COVID-19 patients that is associated with increased risk for severe disease and mortality (Guery et al., 2013; Al-Tawfiq et al., 2014; Memish, Cotten, Watson, et al., 2014; Rabeeah et al., 2014; Guan et al., 2020; Guo et al., 2020). The coronavirus receptors DPP4 and ACE2 have been shown to be involved in metabolic processes (e.g. glucose metabolism, blood pressure regulation) that are often disturbed in patients suffering from severe coronavirus infection (Crowley et al., 2005; Demuth, Mclntosh and Pederson, 2005; Memish, Cotten, Watson, et al., 2014; Guo et al., 2020). DPP4 plays a crucial role for the glucose metabolism and ACE2 plays an important role on the insulin secretion in pancreatic islets and the homeostasis of vascular function including the blood pressure (Crowley et al., 2005; Demuth, Mclntosh and Pederson, 2005; Tikellis and Thomas, 2012). Further, polymorphisms in ACE2 have already been shown to play a role in systemically arterial hypertension and diabetes (Liu et al., 2018; Pinheiro et al., 2019).

Whether naturally-occurring polymorphism in the MERS-CoV receptor DPP4 may have an impact on MERS-S-driven cell entry - and thus susceptibility to MERS-CoV infection - had not been investigated before. Therefore, I analyzed natural sequence variations in DPP4 at the MERS-S/DPP4 binding interface and found that some of them were associated with reduced S protein-driven host cell entry and replication of authentic MERS-CoV. Further, I could reveal that this phenotype was caused due to 
a less efficient binding of MERS-S to the respective DPP4 variants (Kleine-Weber et al., 2020).

Based on these findings it would be interesting to expand this kind of study to ACE2 and to screen MERS and COVID-19 patients for the presence of polymorphisms in DPP4 or ACE2, respectively, in order to investigate whether particular polymorphisms are associated with mild or severe disease. Further, it could be analyzed if particular populations, ethnic groups or people with chronic medical conditions possess unique polymorphisms that make them less/higher susceptible to infection and/or development of severe disease. A straight-forward study could comparatively analyze populations in Africa and the Arabia Peninsula regarding the presence and distribution of DPP4 polymorphisms. This would be interesting as the vast majority of MERS cases is attributed to Saudi-Arabia while MERS-CoV-positive dromedary camels are present through-out the Western and Eastern part of NorthAfrica as indicated by several studies (Chu et al., 2014; Müller et al., 2014; Reusken et al., 2014; Mohd, Al-Tawfiq and Memish, 2016).

\subsubsection{S proteins of MERS-CoV isolates that were recently found in dromedary camels in Africa enable efficient viral entry into human cells}

Shortly after the emergence of MERS-CoV in 2012 in Saudi-Arabia and the identification of dromedary camels as the main source of human infections, several studies have shown that also African camels harbor MERS-CoV (Chu et al., 2014; Müller et al., 2014; Reusken et al., 2014; Mohd, Al-Tawfiq and Memish, 2016). However, although there are ongoing MERS-CoV infections reported for the Arabian Peninsula since 2012 (WHO, 2019) only limited evidence has been obtained for 
MERS-CoV infections in humans with camel-contact in Africa (Abbad et al., 2019; Kiyong'a et al., 2020; Sayed, Malek and Abushahba, 2020). It was thus speculated that MERS-CoV variants present in African dromedaries might differ with respect to their potential to infect humans from MERS-CoV variants prevalent in the Arabian Peninsula (H. Chu et al., 2018). Moreover, two studies suggest that African camel MERS-CoV variants are less efficient in entering and replicating in human cells $(\mathrm{H}$. Chu et al., 2018; Shirato et al., 2019).

In the light of these results, I investigated whether the $S$ proteins from MERS-CoV variants circulating in dromedary camels in North- and West-Africa differ in their potential to drive viral entry into human cells compared to $S$ proteins from MERSCoV variants found in the Middle East. I found out that there were no differences in the cellular entry efficiency by viral particles harboring either the prototype Arabian MERS-S or S proteins related to MERS-CoV variants from African dromedaries. I could further show that all S proteins tested displayed the same potential to bind to DPP4 (Kleine-Weber, Pöhlmann and Hoffmann, 2019). A plausible explanation for the different findings could be that host cell entry might not be different for African and Arabian MERS-CoV variants and that post-entry events are the reason for the different extent of human infections in the two regions. Nevertheless, it should also be taken into account that it might as well possible that human MERS-CoV infections are severely underreported in Africa due to lack of diagnostic tests and/or an insufficient capacities in the infrastructure of the health care system in most African countries. 


\subsection{Identification of ACE2, furin and TMPRSS2 as host cell factors required for cellular entry of SARS-CoV-2}

With respect to the novel coronavirus SARS-CoV-2, I participated in a collaborative study, which identified ACE2 as the cellular receptor for SARS-CoV-2 and TMPRSS2 as the cellular protease required for SARS-2-S priming in order to enable infection of human lung cells (Hoffmann, Kleine-Weber, et al., 2020). Most importantly, this study showed that inhibition of TMPRSS2 provides a promising antiviral therapy and identified a clinically-approved TMPRSS2 inhibitor (camostat mesylate) as a potential treatment option (Hoffmann, Kleine-Weber, et al., 2020). Like MERS-S, SARS-2-S also harbors a multibasic motif at the S1/S2 site, which is different from SARS-S, which contains a monobasic motif at the S1/S2 site. With respect to the S2' site, only MERS-S harbors a multibasic motif while SARS-2-S and SARS-S each have monobasic motifs at their S2' sites (Gierer et al., 2013; Reinke et al., 2017; Hoffmann, Kleine-Weber, et al., 2020). Based on my findings on the proteolytic priming of MERS-S, it was expected that proteolytic priming of SARS-2-S might also follow a two-step process, including pre-priming at the $\mathrm{S} 1 / \mathrm{S} 2$ site by a protease that requires a multibasic motif (e.g. furin) (Nakayama, 1997) and a second priming event at the S2' site involving a protease that requires only a monobasic motif (e.g. TMPRSS2) (Kleine-Weber et al., 2018). My work could demonstrate that similar to MERS-S, also SARS-2-S undergoes a proteolytic cleavage event in $S$ protein expressing cells before a new host cell entry event is started (Hoffmann, KleineWeber and Pöhlmann, 2020; Hoffmann, Kleine-Weber, et al., 2020). Furthermore, I was able to verify that SARS-2-S priming at the S1/S2 site is achieved by the cellular protease furin and that this pre-cleavage is required for a subsequent priming event by TMPRSS2 at the S2' during host cell entry into human lung cells (Hoffmann, Kleine-Weber and Pöhlmann, 2020). 


\subsection{Inhibition of $S$ protein priming by the cellular protease TMPRSS2} provides a strategy for antiviral therapy

The importance of TMPRSS2-mediated priming of $S$ proteins of human coronaviruses suggests that interfering with this step could provide a promising strategy for antiviral therapy. Camostat mesylate is a serine protease inhibitor and is approved for the treatment of pancreatitis in Japan. Previous work including my own, could demonstrate that camostat mesylate-mediated inhibition of TMPRSS2 can block MERS-S, SARS-2-S and SARS-S protein-driven host entry into human lung (Kleine-Weber et al., 2018; Hoffmann, Kleine-Weber, et al., 2020; Hoffmann, Schroeder, et al., 2020). Likewise, it was shown that camostat mesylate also inhibits viral replication of authentic MERS-CoV and SARS-CoV-2 in TMPRSS2-positive target cells (Kawase et al., 2012; Zhou et al., 2015; Shirato, Kawase and Matsuyama, 2018a; Hoffmann, Kleine-Weber, et al., 2020). Besides camostat mesylate also other serine protease inhibitors could serve as treatment options for patients infected with emerging coronaviruses. In this context, nafamostat mesylate, an FDA (U.S. Food and Drug Administration)-approved serine protease inhibitor was identified to be highly effective in inhibiting entry driven by the S proteins of SARSCoV, SARS-CoV-2 and MERS-CoV as well as replication of authentic SARS-CoV-2 in human lung cells (Hoffmann, Schroeder, et al., 2020). The ability of nafasmostat mesylate to block replication of MERS-CoV has also been demonstrated by others (Yamamoto et al., 2016). Although, serine protease inhibitors appear to be promising therapeutics against coronavirus infections in vitro data from clinical studies for their use as treatment options for patients infected with MERS-CoV or SARS-CoV are currently missing. 
It has been claimed that presence or acquisition of a multibasic cleavage site in coronavirus S protein, like that found in MERS-S or SARS-2-S, is a crucial factor defining the zoonotic potential of animal coronaviruses (Yang et al., 2014; Menachery et al., 2019). Analysis of SARS-2-S-related $S$ protein sequences from other betacoronaviruses found in bats and other animals revealed that only SARS-2-S harbors a multibasic cleavage site at the junction of the S1 and S2 subunits (Coutard et al., 2020; Hoffmann, Kleine-Weber, et al., 2020; Jaimes et al., 2020; Walls et al., 2020). In case of MERS-S it was shown that furin-mediated cleavage at this site enables subsequent TMPRSS2-mediated MERS-S priming during host cell entry at the S2' site (Park et al., 2016), as mentioned before. The presence of multi- or monobasic motifs might also be important for the disease development as furin is ubiquitously expressed, while TMPRSS2 is mainly found in the aerodigestive tract (Vaarala et al., 2001). In case of avian IAV, infections of poultry by viruses harboring monobasic motifs in their HA are mostly limited to the intestinal and respiratory tract, whereas infections by viruses harboring multibasic motifs in their HA can lead to systemic viral spread (Luczo et al., 2009; Yang et al., 2014; Menachery et al., 2019).

Whether the presence of a multibasic motif at the S1/S2 site of SARS-2-S is processed by furin in infected cells and whether this proteolytic cleavage is required for infection of new target cells and efficient viral spread within the host was so far unknown. Using SARS-2-S variants with altered S1/S2 cleavage motifs and protease inhibitors I revealed that SARS-2-S is indeed proteolytically processed by the cellular protease furin in S protein expressing cells. Moreover, I was able to show that this priming event is necessary for subsequent $\mathrm{S}$ protein processing by TMPRSS2 and efficient viral entry into human lung cells (Hoffmann, Kleine-Weber and Pöhlmann, 2020). Finally, I also obtained evidence for the potential of SARS-CoV-2 to be spread 
from cell to cell by inducing the fusion of SARS-2-S-expressing cells with neighboring cells even in the absence of TMPRSS2, a phenotype that is also observed for MERS-S (contains a multibasic motif at the S1/S2 site) but not SARS-S (contains a monobasic motif at the S1/S2 site) (Hoffmann, Kleine-Weber and Pöhlmann, 2020). This finding could explain why SARS-CoV-2 is efficiently spread among the human population, as the virus could initially infect ACE2-expressing cells in the upper respiratory tract and subsequently be amplified into his region by inducing cell-cell fusion. As a result, high concentrations of virus would be present in the upper respiratory tract and could thus be disseminated by coughing or exhaling.

\subsection{Concluding remarks}

Receptor engagement and proteolytic priming of the coronaviral S protein are crucial events in the entry process of coronaviruses and especially the latter displays a potential target for antiviral treatment. The existence of natural polymorphisms in both the $S$ proteins of coronaviruses and their respective host cell receptors indicate that virus variant- or patient-specific polymorphisms can have an impact on the viral infectivity and the host's susceptibility to infection and (possibly) development of severe disease. The different studies presented here, which have been conducted as part of my thesis, provide important insights on the proteolytic activation of coronavirus $\mathrm{S}$ proteins and host cell entry of emerging coronaviruses, and thus might help to develop new or improve existing strategies for the design of vaccine and antiviral compounds. 


\section{Outlook}

Before the beginning of this century, coronaviruses have been largely neglected as they were "only" associated with mild, self-resolving upper respiratory tract infections. However, since the emergence of SARS-CoV in 2002, the research interest in coronaviruses has increased and let to fundamental discoveries in the biology of coronaviruses including their replication, the proteolytic activation of their S proteins and the zoonotic of human coronaviruses. Recent research studies identified important points for the molecular understanding of MERS-CoV and SARS-CoV-2 and the development of vaccines and antiviral therapeutics. Nevertheless, the ongoing SARS-CoV-2 pandemic emphasizes that even today animal coronaviruses can spill over from an animal reservoir to the human population and cause devastating consequences for our health and economics. Therefore, there is the urgent need further increase research capacities on coronaviruses addressing points like:

1) How to develop effective and broadly-active vaccines and therapies against known (and presently unknown) coronaviruses?

2) How and how frequent do animal coronavirus recombine in nature and what kind of recombination events can drive the emergence of a zoonotic coronavirus and allow the virus to cross the species barriers?

3) With respect to MERS-CoV, why are some regions like the Middle East are more affected than others (Africa) despite similar virus prevalence in dromedary camels?

4) How can zoonotic coronaviruses escape the human immune response after spillover events from an animal reservoir? 
Hopefully, this study provides some insights on the proteolytic activation of coronavirus $S$ proteins, which might help to design antiviral therapeutics against coronaviruses like MERS-CoV and SARS-CoV-2 in the future. 


\section{References}

Abbad, A. et al. (2019) 'Middle East respiratory syndrome coronavirus (MERS-CoV) neutralising antibodies in a high-risk human population, Morocco, November 2017 to January 2018', Eurosurveillance, 24(48), pp. 1-8. doi: 10.2807/15607917.ES.2019.24.48.1900244.

Afar, D. E. H. et al. (2001) 'Catalytic cleavage of the androgen-regulated TMPRSS2 protease results in its secretion by prostate and prostate cancer epithelia', Cancer Research, 61(4), pp. 1686-1692.

Al-abdallat, M. M. et al. (2016) 'Hospital-Associated Outbreak of Middle East respiratory Syndrome Coronavirus: A Serologic, Epidemiologic, and Clinical Description', 59(9), pp. 1225-1233. doi: 10.1093/cid/ciu359.Hospital-Associated. Al-Tawfiq, J. A. et al. (2014) 'Middle east respiratory syndrome coronavirus: A casecontrol study of hospitalized patients', Clinical Infectious Diseases, 59(2), pp. 160165. doi: $10.1093 / \mathrm{cid} / \mathrm{ciu} 226$.

Al-Tawfiq, J. A. and Memish, Z. A. (2014) 'Middle East respiratory syndrome coronavirus: Epidemiology and disease control measures', Infection and Drug Resistance, 7, pp. 281-287. doi: 10.2147/IDR.S51283.

Alagaili, A. N. et al. (2014) 'Middle east respiratory syndrome coronavirus infection in dromedary camels in Saudi Arabia', mBio, 5(2), pp. 1-6. doi: 10.1128/mBio.0088414.

Alexandersen, S. et al. (2014) 'Middle east respiratory syndrome coronavirus antibody reactors among camels in Dubai, United Arab Emirates, in 2005', Transboundary and Emerging Diseases, 61(2), pp. 105-108. doi: 10.1111/tbed.12212.

Almazán, F. et al. (2013) ‘Engineering a Replication-Competent, PropagationDefective Middle East Respiratory Syndrome Coronavirus as a Vaccine Candidate', 
mBIO, 4(5), pp. 1-11. doi: 10.1128/mBio.00650-13.Editor.

Almazan, F., Galan, C. and Enjuanes, L. (2004) 'The Nucleoprotein Is Required for

Efficient Coronavirus Genome Replication', Journal of Virology, 78(22), pp. 1268312688. doi: 10.1128/jvi.78.22.12683-12688.2004.

Alshukairi, A. N. et al. (2018) 'High Prevalence of MERS-CoV Infection in Camel Workers in Saudi Arabia', 9(5), pp. 1-10.

Anderson, R. M. et al. (2004) 'Epidemiology, transmission dynamics and control of SARS: The 2002-2003 epidemic', Philosophical Transactions of the Royal Society B:

Biological Sciences, 359(1447), pp. 1091-1105. doi: 10.1098/rstb.2004.1490.

Assiri, A., Al-Tawfiq, J. A., et al. (2013) 'Epidemiological, demographic, and clinical characteristics of 47 cases of Middle East respiratory syndrome coronavirus disease from Saudi Arabia: A descriptive study', The Lancet Infectious Diseases, 13(9), pp. 752-761. doi: 10.1016/S1473-3099(13)70204-4.

Assiri, A., McGeer, A., et al. (2013) 'Hospital outbreak of middle east respiratory syndrome coronavirus', New England Journal of Medicine, 369(5), pp. 407-416. doi: 10.1056/NEJMoa1306742.

Azhar, E. I. et al. (2014) ‘Evidence for camel-to-human transmission of MERS coronavirus', New England Journal of Medicine, 370(26), pp. 2499-2505. doi: 10.1056/NEJMoa1401505.

Bakkers, M. J. G. et al. (2017) 'Betacoronavirus Adaptation to Humans Involved Progressive Loss of Hemagglutinin-Esterase Lectin Activity', Cell Host and Microbe. Elsevier Inc., 21(3), pp. 356-366. doi: 10.1016/j.chom.2017.02.008.

Baseler, L., de Wit, E. and Feldmann, H. (2016) 'A Comparative Review of Animal Models of Middle East Respiratory Syndrome Coronavirus Infection', Veterinary Pathology, 53(3), pp. 521-531. doi: 10.1177/0300985815620845.

Bermingham, A. et al. (2012) 'Severe respiratory illness caused by a novel 
coronavirus, in a patient transferred to the United Kingdom from the Middle East, September 2012', Eurosurveillance, 17(40), pp. 1-5. doi: 10.2807/ese.17.40.20290en.

Bertram, S. et al. (2012) 'Influenza and SARS-coronavirus activating proteases TMPRSS2 and HAT are expressed at multiple sites in human respiratory and gastrointestinal tracts', PLoS ONE, 7(4), pp. 1-8. doi: 10.1371/journal.pone.0035876. Boheemen, S. Van, Graaf, M. De and Lauber, C. (2013) 'Syndrome in Humans Genomic Characterization of a Newly Discovered Coronavirus', 3(6), pp. 1-9. doi: 10.1128/mBio.00473-12.Editor.

Böhm, A. et al. (2017) 'DPP4 gene variation affects GLP-1 secretion, insulin secretion, and glucose tolerance in humans with high body adiposity', PLoS ONE, 12(7), pp. 1-13. doi: 10.1371/journal.pone.0181880.

Brierley, I., Digard, P. and Inglis, S. C. (1989) 'Characterization of an efficient coronavirus ribosomal frameshifting signal: Requirement for an RNA pseudoknot', Cell, 57(4), pp. 537-547. doi: 10.1016/0092-8674(89)90124-4.

Bugge, T. H., Antalis, T. M. and Wu, Q. (2009) 'Type II transmembrane serine proteases', Journal of Biological Chemistry, 284(35), pp. 23177-23181. doi: 10.1074/jbc.R109.021006.

Cascella, M. et al. (2020) 'Features, Evaluation and Treatment Coronavirus (COVID19)', StatPearls, pp. 1-15. Available at:

http://www.ncbi.nlm.nih.gov/pubmed/32150360.

Chang, C.-Y. et al. (2020) 'Middle East respiratory syndrome coronavirus nucleocapsid protein suppresses type I and type III interferon induction by targeting RIG-I signaling', Journal of Virology, (1). doi: 10.1128/jvi.00099-20.

Chen, Y. et al. (2013) 'Crystal Structure of the Receptor-Binding Domain from Newly Emerged Middle East Respiratory Syndrome Coronavirus', Journal of Virology, 
87(19), pp. 10777-10783. doi: 10.1128/jvi.01756-13.

Choi, J. Y. (2015) 'An unexpected outbreak of middle east respiratory syndrome coronavirus infection in the republic of Korea, 2015', Infection and Chemotherapy, 47(2), pp. 120-122. doi: 10.3947/ic.2015.47.2.120.

Chu, D. et al. (2018) 'MERS coronaviruses from camels in Africa exhibit regiondependent genetic diversity', Proceedings of the National Academy of Sciences of the United States of America, 115(12), pp. 3144-3149. doi:

10.1073/pnas.1718769115.

Chu, D. K. W. et al. (2014) 'MERS coronaviruses in dromedary camels, Egypt', Emerging Infectious Diseases, 20(6), pp. 1049-1053. doi: 10.3201/eid2006.140299. Chu, H. et al. (2018) 'Middle East respiratory syndrome coronavirus and bat coronavirus HKU9 both can utilize GRP78 for attachment onto host cells', Journal of Biological Chemistry, 293(30), pp. 11709-11726. doi: 10.1074/jbc.RA118.001897.

Chung, K. M. et al. (2010) 'The dimeric transmembrane domain of prolyl dipeptidase DPP-IV contributes to its quaternary structure and enzymatic activities', Protein Science, 19(9), pp. 1627-1638. doi: 10.1002/pro.443.

Conarello, S. L. et al. (2003) 'Mice lacking dipeptidyl peptidase IV are protected against obesity and insulin resistance', Proceedings of the National Academy of Sciences of the United States of America, 100(11), pp. 6825-6830. doi: 10.1073/pnas.0631828100.

Conzade, R. et al. (2018) 'Reported direct and indirect contact with dromedary camels among laboratory-confirmed MERS-CoV cases', Viruses, 10(8), pp. 1-10. doi: 10.3390/v10080425.

Coutard, B. et al. (2020) 'The spike glycoprotein of the new coronavirus 2019-nCoV contains a furin-like cleavage site absent in CoV of the same clade', Antiviral Research. Elsevier, 176(February), p. 104742. doi: 10.1016/j.antiviral.2020.104742. 
Crowley, S. D. et al. (2005) 'Distinct roles for the kidney and systemic tissues in blood pressure regulation by the renin-angiotensin system', Journal of Clinical Investigation, 115(4), pp. 1092-1099. doi: 10.1172/JCI23378.

Darmoul, D. et al. (no date) 'Regional expression epithelial DPP4 in the human intestines'.

Demuth, H. U., Mclntosh, C. H. S. and Pederson, R. A. (2005) 'Type 2 diabetes Therapy with dipeptidyl peptidase IV inhibitors', Biochimica et Biophysica Acta Proteins and Proteomics, 1751(1), pp. 33-44. doi: 10.1016/j.bbapap.2005.05.010. Donaldson, S. H. et al. (2002) 'Regulation of the epithelial sodium channel by serine proteases in human airways', Journal of Biological Chemistry, 277(10), pp. 83388345. doi: 10.1074/jbc.M105044200.

Donoghue, M. et al. (2000) 'UltraRapid Communication A Novel AngiotensinConverting Enzyme - Related to Angiotensin 1-9', Circ Res, 87, pp. e1-e9.

Drosten, C. et al. (2003) 'Identification of a novel coronavirus in patients with severe acute respiratory syndrome', New England Journal of Medicine, 348(20), pp. 19671976. doi: 10.1056/NEJMoa030747.

Drosten, C. et al. (2014) 'Transmission of MERS-coronavirus in household contacts', New England Journal of Medicine, 371(9), pp. 828-835. doi:

10.1056/NEJMoa1405858.

Du, L. et al. (2017) 'MERS-CoV spike protein: a key target for antivirals', Expert Opinion on Therapeutic Targets, 21(2), pp. 131-143. doi:

10.1080/14728222.2017.1271415.

Duckert, P., Brunak, S. and Blom, N. (2004) 'Prediction of proprotein convertase cleavage sites', Protein Engineering, Design and Selection, 17(1), pp. 107-112. doi: 10.1093/protein/gzh013.

Duffy, S. (2018) 'Why are RNA virus mutation rates so damn high?', PLoS Biology, 
16(8), pp. 1-6. doi: 10.1371/journal.pbio.3000003.

Durai, P. et al. (2015a) 'Middle East respiratory syndrome coronavirus: transmission, virology and therapeutic targeting to aid in outbreak control', Experimental \& molecular medicine. Nature Publishing Group, 47(July), p. e181. doi:

10.1038/emm.2015.76.

Durai, P. et al. (2015b) 'Middle East respiratory syndrome coronavirus: transmission, virology and therapeutic targeting to aid in outbreak control', Experimental \& molecular medicine. Nature Publishing Group, 47(8), p. e181. doi:

10.1038/emm.2015.76.

Ebara, M., Fukuda, H. and Saisho, H. (2003) 'The copper/zinc ratio in patients with hepatocellular carcinoma', Journal of Gastroenterology, pp. 104-105. doi: $10.1007 / \mathrm{s} 005350300016$.

Elena, S. F. and Sanjua, R. (2005) 'GUEST COMMENTARY Adaptive Value of High Mutation Rates of RNA Viruses : Separating Causes from Consequences', Society, 79(18), pp. 11555-11558. doi: 10.1128/JVI.79.18.11555.

Escors, D., Camafeita, E., et al. (2001) 'Organization of Two Transmissible Gastroenteritis Coronavirus Membrane Protein Topologies within the Virion and Core', Journal of Virology, 75(24), pp. 12228-12240. doi: 10.1128/jvi.75.24.1222812240.2001.

Escors, D., Ortego, J., et al. (2001) 'The Membrane M Protein Carboxy Terminus Binds to Transmissible Gastroenteritis Coronavirus Core and Contributes to Core Stability', Journal of Virology, 75(3), pp. 1312-1324. doi: 10.1128/jvi.75.3.13121324.2001.

Falzarano, D. et al. (2013) 'Treatment with interferon- $\alpha 2 b$ and ribavirin improves outcome in MERS-CoV-infected rhesus macaques', Nature Medicine. Nature Publishing Group, 19(10), pp. 1313-1317. doi: 10.1038/nm.3362. 
Falzarano, D., de Wit, E., et al. (2014) 'Infection with MERS-CoV Causes Lethal Pneumonia in the Common Marmoset', PLoS Pathogens, 10(8). doi:

10.1371/journal.ppat.1004250.

Falzarano, D., Wit, E. De, et al. (2014) 'Interferon-alpha2b and ribavirin treatment improves outcome in MERS-CoV-infected rhesus macaques', 19(10), pp. 13131317. doi: 10.1038/nm.3362.Interferon-.

Fehr, A. R. and Perlman, S. (2015) 'Coronaviruses: An Overview of Their Replication and Pathogenesis', Coronaviruses: Methods and Protocols, pp. 1-282. doi: 10.1007/978-1-4939-2438-7.

Fischer, F. et al. (1998) 'Analysis of constructed E gene mutants of mouse hepatitis: Virus confirms a pivotal role for E protein in coronavirus assembly', Journal of Virology, 72(10), pp. 7885-7894.

Fouchier, R. A. M. et al. (2004) 'A previously undescribed coronavirus associated with respiratory disease in humans', Proceedings of the National Academy of Sciences of the United States of America, 101(16), pp. 6212-6216. doi: 10.1073/pnas.0400762101.

Fuller, R. S., Brake, A. J. and Thorner, J. (1989) 'Intracellular targeting and structural conservation of a prohormone-processing endoprotease', Science, 246(4929), pp. 482-486. doi: 10.1126/science.2683070.

Gamblin, S. J. and Skehel, J. J. (2010) 'Influenza hemagglutinin and neuraminidase membrane glycoproteins', Journal of Biological Chemistry, 285(37), pp. 2840328409. doi: 10.1074/jbc.R110.129809.

Gao, J. et al. (2013) 'Structure of the Fusion Core and Inhibition of Fusion by a Heptad Repeat Peptide Derived from the S Protein of Middle East Respiratory Syndrome Coronavirus', Journal of Virology, 87(24), pp. 13134-13140. doi: 10.1128/jvi.02433-13. 
Gierer, S. et al. (2013) 'The Spike Protein of the Emerging Betacoronavirus EMC Uses a Novel Coronavirus Receptor for Entry, Can Be Activated by TMPRSS2, and Is Targeted by Neutralizing Antibodies', Journal of Virology, 87(10), pp. 5502-5511. doi: 10.1128/jvi.00128-13.

Glowacka, I. et al. (2011) 'Evidence that TMPRSS2 Activates the Severe Acute Respiratory Syndrome Coronavirus Spike Protein for Membrane Fusion and Reduces Viral Control by the Humoral Immune Response', Journal of Virology, 85(9), pp. 4122-4134. doi: 10.1128/jvi.02232-10.

Gonzalez, M. E. and Carrasco, L. (2003) 'Viroporins', FEBS Letters, 552(1), pp. 2834. doi: 10.1016/S0014-5793(03)00780-4.

Gorbalenya, A. E. et al. (2006) 'Nidovirales: Evolving the largest RNA virus genome', Virus Research, 117(1), pp. 17-37. doi: 10.1016/j.virusres.2006.01.017.

Gorbalenya, A. E. et al. (2020) 'The species Severe acute respiratory syndromerelated coronavirus: classifying 2019-nCoV and naming it SARS-CoV-2', Nature Microbiology, 5(4), pp. 536-544. doi: 10.1038/s41564-020-0695-z.

Gorrell, M. D. (2005) 'Dipeptidyl peptidase IV and related enzymes in cell biology and liver disorders', Clinical Science, 108(4), pp. 277-292. doi: 10.1042/CS20040302. de Groot, R. et al. (2012) 'Part II - The Positive Sense Single Stranded RNA Viruses Family Coronaviridae', Virus taxonomy: ninth report of the International Committee on Taxonomy of Viruses, (Figure 1), pp. 806-828. doi: 10.1016/B978-0-12-3846846.00068-9.

Guan, W.-J. et al. (2020) 'Clinical Characteristics of Coronavirus Disease 2019 in China.', The New England journal of medicine, pp. 1-13. doi:

10.1056/NEJMoa2002032.

Guan, Y. et al. (2003) 'Isolation and characterization of viruses related to the SARS coronavirus from animals in Southern China', Science, 302(5643), pp. 276-278. doi: 
10.1126/science.1087139.

Guery, B. et al. (2013) 'Clinical features and viral diagnosis of two cases of infection with Middle East Respiratory Syndrome coronavirus: A report of nosocomial transmission', The Lancet, 381(9885), pp. 2265-2272. doi: 10.1016/S0140$6736(13) 60982-4$

Guo, Y.-R. et al. (2020) 'The origin, transmission and clinical therapies on coronavirus disease 2019 (COVID-19) outbreak - an update on the status', Military Medical Research. Military Medical Research, 7(1), pp. 1-10. doi: 10.1186/s40779020-00240-0.

de Haan, C. A. M. and Rottier, P. J. M. (2005) 'Molecular Interactions in the Assembly of Coronaviruses', Advances in Virus Research, 64(05), pp. 165-230. doi: 10.1016/S0065-3527(05)64006-7.

Hamre, D. and Procknow, J. J. (1962) 'A New Virus Isolated from the Human respiratory Tract', (30734), pp. 190-193.

Hatesuer, B. et al. (2013) 'Tmprss2 Is Essential for Influenza H1N1 Virus

Pathogenesis in Mice', PLoS Pathogens, 9(12), pp. 1-10. doi:

10.1371/journal.ppat.1003774.

Henrich, S. et al. (2003) 'The crystal structure of the proprotein processing proteinase furin explains its stringent specificity (Nature Structural Biology (2003) 10 (520-526))', Nature Structural Biology, 10(8), p. 669. doi: 10.1038/nsb0803-669b.

Van Der Hoek, L. et al. (2004) 'Identification of a new human coronavirus', Nature Medicine, 10(4), pp. 368-373. doi: 10.1038/nm1024.

Van Der Hoek, L. (2007) 'Human coronaviruses: What do they cause?', Antiviral Therapy, 12(4 B), pp. 651-658.

Hoffmann, M. et al. (2019) 'Analysis of Resistance of Ebola Virus GlycoproteinDriven Entry Against MDL28170, An Inhibitor of Cysteine Cathepsins'. 
Hoffmann, M., Schroeder, S., et al. (2020) 'Nafamostat mesylate blocks activation of SARS-CoV-2: New treatment option for COVID-19', Antimicrobial Agents and Chemotherapy, 2(April), pp. 1-7. doi: 10.1128/aac.00754-20.

Hoffmann, M., Kleine-Weber, H., et al. (2020) 'SARS-CoV-2 Cell Entry Depends on ACE2 and TMPRSS2 and Is Blocked by a Clinically Proven Protease Inhibitor', Cell, pp. 1-10. doi: 10.1016/j.cell.2020.02.052.

Hoffmann, M., Kleine-Weber, H. and Pöhlmann, S. (2020) 'A multibasic cleavage site in the spike protein of SARS-CoV-2 is essential for infection of human lung cells', Cell Press, pp. 1-6. doi: 10.1016/j.molcel.2020.04.022.

Hooper, J. D. et al. (2001) 'Type II transmembrane serine proteases. Insights into an emerging class of cell surface proteolytic enzymes', Journal of Biological Chemistry, 276(2), pp. 857-860. doi: 10.1074/jbc.R000020200.

Hoppe, M. M. et al. (2018) 'Biomarkers for homologous recombination deficiency in cancer', Journal of the National Cancer Institute, 110(7), pp. 704-713. doi: 10.1093/jnci/djy085.

Hopsu-Havu, V. K. and Glenner, G. G. (1966) 'A new dipeptide naphthylamidase hydrolyzing glycyl-prolyl-ß-naphthylamide', Histochemie, 7(3), pp. 197-201. doi: 10.1007/BF00577838.

Hopsu-Havu, V. K., Jansén, C. T. and Järvinen, M. (1970) 'A human serum aminopeptidase capable of splitting juxtaterminal bonds involving proline. Basic characteristics, normal values and clinical variations', Clinica Chimica Acta, 28(1), pp. 25-36. doi: 10.1016/0009-8981(70)90156-7.

Jaimes, J. A. et al. (2020) 'Phylogenetic Analysis and Structural Modeling of SARSCoV-2 Spike Protein Reveals an Evolutionary Distinct and Proteolytically Sensitive Activation Loop', Journal of Molecular Biology. Elsevier Ltd, 2(xxxx). doi: 10.1016/j.jmb.2020.04.009. 
Jeon, M. H. and Kim, T. H. (2016) 'Institutional preparedness to prevent future middle east respiratory syndrome coronavirus-like outbreaks in Republic of Korea', Infection and Chemotherapy, 48(2), pp. 75-80. doi: 10.3947/ic.2016.48.2.75.

Kameoka, J. et al. (1993) 'Direct association of adenosine deaminase with a T cell activation antigen, CD26', Science, 261(5120), pp. 466-469. doi:

10.1126/science.8101391.

Kawase, M. et al. (2012) 'Simultaneous Treatment of Human Bronchial Epithelial Cells with Serine and Cysteine Protease Inhibitors Prevents Severe Acute Respiratory Syndrome Coronavirus Entry', Journal of Virology, 86(12), pp. 65376545. doi: 10.1128/jvi.00094-12.

Kettmann, U., Humbel, B. and Holzhausen, H. J. (1992) 'Ultrastructural localization of dipeptidylpeptidase IV in the glomerulum of the rat kidney', Acta Histochemica, 92(2), pp. 225-227. doi: 10.1016/S0065-1281(11)80085-1.

Khan, A. et al. (2015) 'Emerging problems in infectious diseases lessons to learn from mers-cov outbreak in South Korea', Journal of Infection in Developing Countries, 9(6), pp. 543-546. doi: 10.3855/jidc.7278.

Ki, M. (2015) '2015 MERS outbreak in Korea: hospital-to-hospital transmission', Epidemiology and Health, 37(Figure 1), p. e2015033. doi: 10.4178/epih/e2015033. Killerby, M. E. et al. (2020) 'Middle east respiratory syndrome coronavirus transmission', Emerging Infectious Diseases, 26(2), pp. 191-198. doi: 10.3201/eid2602.190697.

Kim, Y. et al. (2016) 'Spread of mutant middle east respiratory syndrome coronavirus with reduced affinity to human CD26 during the south Korean outbreak', mBio, 7(2), pp. 1-8. doi: 10.1128/mBio.00019-16.

Kiyong'a, A. N. et al. (2020) 'Middle East respiratory syndrome coronavirus (MERSCoV) seropositive camel handlers in Kenya', Viruses, 12(4), pp. 8-13. doi: 
10.3390/v12040396.

Kleine-Weber, H. et al. (2018) 'Functional analysis of potential cleavage sites in the MERS-coronavirus spike protein', Scientific Reports, 8(1), pp. 1-11. doi:

10.1038/s41598-018-34859-w.

Kleine-Weber, H. et al. (2019) 'Mutations in the Spike Protein of Middle East

Respiratory Syndrome Coronavirus Transmitted in Korea Increase Antibody

Mediated Neutralization', Journal of Virology, 93(2), pp. 1-14.

Kleine-Weber, H. et al. (2020) 'Polymorphisms in dipeptidyl peptidase 4 reduce host cell entry of Middle East respiratory syndrome coronavirus', Emerging Microbes and Infections, 9(1), pp. 155-168. doi: 10.1080/22221751.2020.1713705.

Kleine-Weber, H., Pöhlmann, S. and Hoffmann, M. (2019) ‘Spike proteins of novel MERS-coronavirus isolates from North- and West-African dromedary camels mediate robust viral entry into human target cells', Virology, 535(July), pp. 261-265. doi: 10.1016/j.virol.2019.07.016.

Klemann, C. et al. (2016) 'Cut to the chase: a review of CD26/dipeptidyl peptidase4's (DPP4) entanglement in the immune system', Clinical and Experimental Immunology, 185(1), pp. 1-21. doi: 10.1111/cei.12781.

Kuo, L. and Masters, P. S. (2003) 'The Small Envelope Protein E Is Not Essential for Murine Coronavirus Replication', Journal of Virology, 77(8), pp. 4597-4608. doi: 10.1128/jvi.77.8.4597-4608.2003.

Lambeir, A. M. et al. (2003) ‘Dipeptidyl-peptidase IV from bench to bedside: An update on structural properties, functions, and clinical aspects of the enzyme DPP IV', Critical Reviews in Clinical Laboratory Sciences, 40(3), pp. 209-294. doi: $10.1080 / 713609354$.

Lamers, D. et al. (2011) 'Dipeptidyl peptidase 4 is a novel adipokine potentially linking obesity to the metabolic syndrome', Diabetes, 60(7), pp. 1917-1925. doi: 
$10.2337 / \mathrm{db} 10-1707$

Lau, S. K. P. et al. (2013) 'Genetic Characterization of Betacoronavirus Lineage C Viruses in Bats Reveals Marked Sequence Divergence in the Spike Protein of Pipistrellus Bat Coronavirus HKU5 in Japanese Pipistrelle: Implications for the Origin of the Novel Middle East Respiratory Sy', Journal of Virology, 87(15), pp. 8638-8650. doi: 10.1128/jvi.01055-13.

Lau, S. K. P. et al. (2017) 'Molecular evolution of MERS coronavirus: Dromedaries as a recent intermediate host or long-time animal reservoir?', International Journal of Molecular Sciences, 18(10). doi: 10.3390/ijms18102138.

Lee, S. S. and Wong, N. S. (2015) 'Probable transmission chains of Middle East respiratory syndrome coronavirus and the multiple generations of secondary infection in South Korea', International Journal of Infectious Diseases. International Society for Infectious Diseases, 38, pp. 65-67. doi: 10.1016/j.ijid.2015.07.014.

Li, F. (2015) 'Receptor Recognition Mechanisms of Coronaviruses: a Decade of Structural Studies', Journal of Virology, 89(4), pp. 1954-1964. doi: 10.1128/jvi.0261514.

Li, W. et al. (2004) 'Angiotensin-converting enzyme 2: A functional receptor for SARS coronavirus', Cellular and Molecular Life Sciences, 61(21), pp. 2738-2743. doi: $10.1007 / \mathrm{s} 00018-004-4242-5$.

Li, W. et al. (2017) 'Identification of sialic acid-binding function for the Middle East respiratory syndrome coronavirus spike glycoprotein', Proceedings of the National Academy of Sciences of the United States of America, 114(40), pp. E8508-E8517. doi: 10.1073/pnas.1712592114

Lin, B. et al. (1999) 'Prostate-localized and Androgen-regulated Expression of the Membrane-bound Serine Protease TMPRSS2', pp. 4180-4184.

Liu, C. et al. (2018) 'ACE2 polymorphisms associated with cardiovascular risk in 
Uygurs with type 2 diabetes mellitus 11 Medical and Health Sciences 1103 Clinical Sciences', Cardiovascular Diabetology. BioMed Central, 17(1), pp. 1-11. doi: 10.1186/s12933-018-0771-3.

Lu, G. et al. (2013) 'Molecular basis of binding between novel human coronavirus MERS-CoV and its receptor CD26', Nature. Nature Publishing Group, 500(7461), pp. 227-231. doi: 10.1038/nature12328.

Lu, L. et al. (2014) 'Structure-based discovery of Middle East respiratory syndrome coronavirus fusion inhibitor', Nature Communications, 5. doi: 10.1038/ncomms4067. Luczo, J. M. et al. (2009) 'Molecular pathogenesis of H5 highly pathogenic avaian influenza: the role of the haemagglutinin cleavage site motif', Reviews in medical virology, 19(1), pp. 57-64. doi: 10.1002/rmv.

Mackay, I. M. and Arden, K. E. (2015) 'MERS coronavirus: Diagnostics, epidemiology and transmission', Virology Journal. Virology Journal, 12(1), pp. 1-21. doi: 10.1186/s12985-015-0439-5.

Malik, A. and Alsenaidy, M. A. (2017) 'MERS-CoV papain-like protease (PLpro): expression, purification, and spectroscopic/thermodynamic characterization', 3 Biotech. Springer Berlin Heidelberg, 7(2), pp. 1-9. doi: 10.1007/s13205-017-0744-3. Mclntosh, K. et al. (1967) 'Recovery in tracheal organ cultures of novel viruses from patients with respiratory disease.', Proceedings of the National Academy of Sciences of the United States of America, 57(4), pp. 933-940. doi: 10.1073/pnas.57.4.933. De Meester, I. et al. (1994) 'Binding of adenosine deaminase to the lymphocyte surface via CD26', European Journal of Immunology, 24(3), pp. 566-570. doi: 10.1002/eji.1830240311.

De Meester, I. et al. (1999) 'CD26, let it cut or cut it down', Immunology Today, 20(8), pp. 367-375. doi: 10.1016/S0167-5699(99)01486-3.

Memish, Z. A. et al. (2013) 'Family cluster of middle east respiratory syndrome 
coronavirus infections', New England Journal of Medicine, 368(26), pp. 2487-2494. doi: 10.1056/NEJMoa1303729.

Memish, Z. A., Cotten, M., Watson, S. J., et al. (2014) 'Community Case Clusters of Middle East Respiratory Syndrome Coronavirus in Hafr Al-Batin, Kingdom of Saudi Arabia: A Descriptive Genomic study', International Journal of Infectious Diseases. International Society for Infectious Diseases, 23, pp. 63-68. doi: 10.1016/j.ijid.2014.03.1372.

Memish, Z. A., Cotten, M., Meyer, B., et al. (2014) 'Human Infection with MERS coronavirus after exposure to infected camels, Saudi Arabia, 2013', Emerging Infectious Diseases, 20(6), pp. 1012-1015. doi: 10.3201/eid2006.140402. Memish, Z. A., Al-Tawfiq, J. A., et al. (2014) 'Middle East respiratory syndrome coronavirus disease in children', Pediatric Infectious Disease Journal, 33(9), pp. 904906. doi: 10.1097/INF.0000000000000325.

Menachery, V. D. et al. (2019) 'Trypsin Treatment Unlocks Barrier for Zoonotic Bat Coronavirus Infection', Journal of Virology, 94(5), pp. 1-15. doi: 10.1128/jvi.0177419.

Meyer, B. et al. (2014) 'Antibodies against MERS coronavirus in dromedaries, United Arab Emirates, 2003 and 2013', Emerging Infectious Diseases, 20(4), pp. 552-559. doi: 10.3201/eid2004.131746.

Meyerholz, D. K., Lambertz, A. M. and McCray, P. B. (2016) ‘Dipeptidyl Peptidase 4 Distribution in the Human Respiratory Tract Implications for the Middle East Respiratory Syndrome', American Journal of Pathology. American Society for Investigative Pathology, 186(1), pp. 78-86. doi: 10.1016/j.ajpath.2015.09.014. Millet, J. K. and Whittaker, G. R. (2014) 'Host cell entry of Middle East respiratory syndrome coronavirus after two-step, furin-mediated activation of the spike protein', Proceedings of the National Academy of Sciences of the United States of America, 
111(42), pp. 15214-15219. doi: 10.1073/pnas.1407087111.

Mizumoto, K. et al. (2015) 'Estimating the risk of Middle East respiratory syndrome (MERS) death during the course of the outbreak in the Republic of Korea, 2015', International Journal of Infectious Diseases. International Society for Infectious Diseases, 39, pp. 7-9. doi: 10.1016/j.ijid.2015.08.005.

Mohd, H. A., Al-Tawfiq, J. A. and Memish, Z. A. (2016) 'Middle East Respiratory Syndrome Coronavirus (MERS-CoV) origin and animal reservoir Susanna Lau', Virology Journal. Virology Journal, 13(1), pp. 1-7. doi: 10.1186/s12985-016-0544-0. Müller, M. A. et al. (2014) 'Mers coronavirus neutralizing antibodies in camels, eastern Africa, 1983-1997', Emerging Infectious Diseases, 20(12), pp. 2093-2095. doi: 10.3201/eid2012.141026.

Müller, M. A. et al. (2015) ‘Presence of Middle East respiratory syndrome coronavirus antibodies in Saudi Arabia: A nationwide, cross-sectional, serological study', The Lancet Infectious Diseases, 15(5), pp. 559-564. doi: 10.1016/S1473-3099(15)700903.

Munster, V. J., de Wit, E. and Feldmann, H. (2013) 'Pneumonia from Human Coronavirus in a Macaque Model', New England Journal of Medicine, 368(16), p. 1559. doi: 10.1056/NEJMc1302436.

Nakagawa, K., Lokugamage, K. G. and Makino, S. (2016) Viral and Cellular mRNA Translation in Coronavirus-Infected Cells. 1st edn, Advances in Virus Research. 1st edn. Elsevier Inc. doi: 10.1016/bs.aivir.2016.08.001.

Nakayama, K. (1997) 'Furin: A mammalian subtilisin/Kex2p-like endoprotease involved in processing of a wide variety of precursor proteins', Biochemical Journal, 327(3), pp. 625-635. doi: 10.1042/bj3270625.

Niemeyer, D. et al. (2013) 'Middle East Respiratory Syndrome Coronavirus Accessory Protein 4a Is a Type I Interferon Antagonist', Journal of Virology, 87(22), 
pp. 12489-12495. doi: 10.1128/jvi.01845-13.

Oboha, I. K. et al. (2017) '2014 MERS-CoV Outbreak in Jeddah - A Link to Health

Care Facilities', Physiology \& behavior, 176(3), pp. 139-148. doi:

10.1016/j.physbeh.2017.03.040.

Omrani, A. S. et al. (2013) 'A family cluster of middle east respiratory syndrome coronavirus infections related to a likely unrecognized asymptomatic or mild case', International Journal of Infectious Diseases. International Society for Infectious Diseases, 17(9), pp. e668-e672. doi: 10.1016/j.ijid.2013.07.001.

Park, J. E. et al. (2016) 'Proteolytic processing of middle east respiratory syndrome coronavirus spikes expands virus tropism', Proceedings of the National Academy of Sciences of the United States of America, 113(43), pp. 12262-12267. doi: 10.1073/pnas.1608147113.

Peck, K. M. et al. (2017) 'Permissivity of Dipeptidyl Peptidase 4 Orthologs to Middle East Respiratory Syndrome Coronavirus Is Governed by Glycosylation and Other Complex Determinants', Journal of Virology, 91(19). doi: 10.1128/jvi.00534-17. Pederson, R. A. et al. (1998) 'Improved glucose tolerance in zucker fatty rats by oral administration of the dipeptidyl peptidase IV inhibitor isoleucine thiazolidide', Diabetes, 47(8), pp. 1253-1258. doi: 10.2337/diab.47.8.1253.

Peiris, J. S. M. et al. (2003) 'Coronavirus as a possible cause of severe acute respiratory syndrome', Lancet, 361(9366), pp. 1319-1325. doi: 10.1016/S01406736(03)13077-2.

Pinheiro, D. S. et al. (2019) 'The combination of ACE I/D and ACE2 G8790A polymorphisms revels susceptibility to hypertension: A genetic association study in Brazilian patients', PLoS ONE, 14(8), pp. 1-15. doi: 10.1371/journal.pone.0221248. Qian, Z., Dominguez, S. R. and Holmes, K. V. (2013) 'Role of the Spike Glycoprotein of Human Middle East Respiratory Syndrome Coronavirus (MERS-CoV) in Virus 
Entry and Syncytia Formation', PLoS ONE, 8(10), pp. 1-12. doi:

10.1371/journal.pone.0076469.

Rabeeah, A. A. Al et al. (2014) 'Hospital Outbreak of Middle East Respiratory

Syndrome Coronavirus', New England Journal of Medicine, 369(5), pp. 407-416. doi:

10.1056/NEJMoa1306742.Hospital.

Raj, V. S. et al. (2013) 'Dipeptidyl peptidase 4 is a functional receptor for the emerging human coronavirus-EMC', Nature, 495(7440), pp. 251-254. doi: 10.1038/nature12005.

Raj, V. S. et al. (2014) 'Adenosine Deaminase Acts as a Natural Antagonist for Dipeptidyl Peptidase 4-Mediated Entry of the Middle East Respiratory Syndrome Coronavirus', Journal of Virology, 88(3), pp. 1834-1838. doi: 10.1128/jvi.02935-13. Raschke, S. et al. (2013) 'Identification and Validation of Novel ContractionRegulated Myokines Released from Primary Human Skeletal Muscle Cells', PLoS ONE, 8(4). doi: 10.1371/journal.pone.0062008.

Reinke, L. M. et al. (2017) 'Different residues in the SARS-CoV spike protein determine cleavage and activation by the host cell protease TMPRSS2', PLoS ONE, 12(6), pp. 1-15. doi: 10.1371/journal.pone.0179177.

Reusken, C. B. E. M. et al. (2013) 'Middle East respiratory syndrome coronavirus neutralising serum antibodies in dromedary camels: A comparative serological study', The Lancet Infectious Diseases, 13(10), pp. 859-866. doi: 10.1016/S14733099(13)70164-6.

Reusken, C. B. E. M. et al. (2014) 'Geographic distribution of MERS coronavirus among dromedary camels, Africa', Emerging Infectious Diseases, 20(8), pp. 1370_ 1374. doi: 10.3201/eid2008.140590.

Reusken, C. B. E. M. et al. (2016) 'Cross host transmission in the emergence of MERS coronavirus', Current Opinion in Virology. Elsevier B.V., 16, pp. 55-62. doi: 
10.1016/j.coviro.2016.01.004.

Röhrborn, D., Eckel, J. and Sell, H. (2014) ‘Shedding of dipeptidyl peptidase 4 is mediated by metalloproteases and up-regulated by hypoxia in human adipocytes and smooth muscle cells', FEBS Letters, 588(21), pp. 3870-3877. doi:

10.1016/j.febslet.2014.08.029.

Sauter, N. K. et al. (1992) 'Binding of Influenza Virus Hemagglutinin to Analogs of Its Cell-Surface Receptor, Sialic Acid: Analysis by Proton Nuclear Magnetic Resonance Spectroscopy and X-ray Crystallography', Biochemistry, 31(40), pp. 9609-9621. doi: 10.1021/bi00155a013.

Sawicki, S. G., Sawicki, D. L. and Siddell, S. G. (2007) 'A Contemporary View of Coronavirus Transcription', Journal of Virology, 81(1), pp. 20-29. doi: 10.1128/jvi.01358-06.

Sayed, A. S. M., Malek, S. S. and Abushahba, M. F. N. (2020) 'Seroprevalence of Middle East Respiratory Syndrome Corona Virus in dromedaries and their traders in upper Egypt', Journal of Infection in Developing Countries, 14(2), pp. 191-198. doi: 10.3855/jidc.10862.

Schelle, B. et al. (2005) 'Selective Replication of Coronavirus Genomes That Express Nucleocapsid Protein', Journal of Virology, 79(11), pp. 6620-6630. doi:

10.1128/jvi.79.11.6620-6630.2005.

Scobey, T. et al. (2013) 'Reverse genetics with a full-length infectious cDNA of the Middle East respiratory syndrome coronavirus', Proceedings of the National Academy of Sciences of the United States of America, 110(40), pp. 16157-16162. doi: 10.1073/pnas.1311542110.

Seidah, N. G. and Chretien, M. (1999) 'Proprotein and prohormone convertases: A family of subtilases generating diverse bioactive polypeptides', Brain Research, 848(1-2), pp. 45-62. doi: 10.1016/S0006-8993(99)01909-5. 
Sethna, P. B., Hofmann, M. A. and Brian, D. A. (1991) 'Minus-strand copies of replicating coronavirus mRNAs contain antileaders', Journal of Virology, 65(1), pp. 320-325.

Seys, L. J. M. et al. (2018) 'DPP4, the Middle East Respiratory Syndrome Coronavirus Receptor, is Upregulated in Lungs of Smokers and Chronic Obstructive Pulmonary Disease Patients', Clinical Infectious Diseases, 66(1), pp. 45-53. doi: 10.1093/cid/cix741.

Shereen, M. A. et al. (2020) 'COVID-19 infection: Origin, transmission, and characteristics of human coronaviruses', Journal of Advanced Research. THE AUTHORS, 24, pp. 91-98. doi: 10.1016/j.jare.2020.03.005.

Shirato, K. et al. (2016) 'Clinical Isolates of Human Coronavirus 229E Bypass the Endosome for Cell Entry', Journal of Virology, 91(1), pp. 1-12. doi: 10.1128/jvi.01387-16.

Shirato, K. et al. (2019) 'Middle east respiratory syndrome coronavirus in dromedaries in Ethiopia is antigenically different from the Middle East isolate EMC', Frontiers in Microbiology, 10(JUN). doi: 10.3389/fmicb.2019.01326.

Shirato, K., Kawase, M. and Matsuyama, S. (2013) 'Middle East Respiratory Syndrome Coronavirus Infection Mediated by the Transmembrane Serine Protease TMPRSS2', Journal of Virology, 87(23), pp. 12552-12561. doi: 10.1128/jvi.01890-13. Shirato, K., Kawase, M. and Matsuyama, S. (2018a) 'Wild-type human coronaviruses prefer cell-surface TMPRSS2 to endosomal cathepsins for cell entry', Virology. Elsevier Inc., 517(September 2017), pp. 9-15. doi: 10.1016/j.virol.2017.11.012. Shirato, K., Kawase, M. and Matsuyama, S. (2018b) 'Wild-type human coronaviruses prefer cell-surface TMPRSS2 to endosomal cathepsins for cell entry', Virology. Elsevier Inc., 517(November 2017), pp. 9-15. doi: 10.1016/j.virol.2017.11.012. Sikkema, R. S. et al. (2019) 'Global status of middle east respiratory syndrome 
coronavirus in dromedary camels: A systematic review', Epidemiology and Infection, 147(May). doi: 10.1017/S095026881800345X.

Simmons, G. et al. (2005) 'Inhibitors of cathepsin L prevent severe acute respiratory syndrome coronavirus entry', Proceedings of the National Academy of Sciences of the United States of America, 102(33), pp. 11876-11881. doi:

10.1073/pnas.0505577102.

Steiner, D. F. (1998) 'The proprotein convertases', Current Opinion in Chemical Biology, 2(1), pp. 31-39. doi: 10.1016/S1367-5931(98)80033-1.

Szabo, R. and Bugge, T. H. (2008) 'Type II transmembrane serine proteases in development and disease', International Journal of Biochemistry and Cell Biology, 40(6-7), pp. 1297-1316. doi: 10.1016/j.biocel.2007.11.013.

Taguchi, F. et al. (1995) 'Localization of neutralizing epitopes and receptor-binding site in murine coronavirus spike protein', Advances in Experimental Medicine and Biology, 380(9), pp. 359-365. doi: 10.1007/978-1-4615-1899-0_58.

Tanaka, T. et al. (1992) 'Cloning and functional expression of the T cell activation antigen CD26', Journal of Immunology, 149(2), pp. 481-486.

Tang, X. C. et al. (2014) 'Identification of human neutralizing antibodies against MERS-CoV and their role in virus adaptive evolution', Proceedings of the National Academy of Sciences of the United States of America, 111(19). doi: 10.1073/pnas.1402074111.

Tani, H., Morikawa, S. and Matsuura, Y. (2012) 'Development and applications of VSV vectors based on cell tropism', Frontiers in Microbiology, 2(JAN), pp. 1-7. doi: 10.3389/fmicb.2011.00272.

Tikellis, C. and Thomas, M. C. (2012) 'Angiotensin-converting enzyme 2 (ACE2) is a key modulator of the renin angiotensin system in health and disease', International Journal of Peptides, 2012. doi: 10.1155/2012/256294. 
Tipnis, S. R. et al. (2000) 'A human homolog of angiotensin-converting enzyme:

Cloning and functional expression as a captopril-insensitive carboxypeptidase', Journal of Biological Chemistry, 275(43), pp. 33238-33243. doi:

10.1074/jbc.M002615200.

Tsiodras, S. et al. (2014) 'A case of imported Middle East Respiratory Syndrome coronavirus infection and public health response, Greece, April 2014',

Eurosurveillance, 19(16), pp. 1-6. Available at:

http://search.ebscohost.com.ezproxy.liv.ac.uk/login.aspx?direct=true \&db=edselc\&AN =edselc.2-52.0-84899656036\&site=eds-live\&scope=site.

Turk, V. et al. (2012) 'Cysteine cathepsins: From structure, function and regulation to new frontiers', Biochimica et Biophysica Acta - Proteins and Proteomics, 1824(1), pp. 68-88. doi: 10.1016/j.bbapap.2011.10.002.

Vaarala, M. H. et al. (2001) 'Expression of transmembrane serine protease TMPRSS2 in mouse and human tissues', Journal of Pathology, 193(1), pp. 134-140. doi: 10.1002/1096-9896(2000)9999:9999<::AID-PATH743>3.0.CO;2-T.

Varki, A. (2009) 'Sialic acids in human health and disease', 14(8), pp. 351-360. doi: 10.1016/j.molmed.2008.06.002.Sialic.

Viswanathan, K. et al. (2010) 'Glycans as receptors for influenza pathogenesis', Glycoconjugate Journal, 27(6), pp. 561-570. doi: 10.1007/s10719-010-9303-4.

Vliegen, G. et al. (2017) 'The expression of proline-specific enzymes in the human lung', Annals of Translational Medicine, 5(6), pp. 1-13. doi:

10.21037/atm.2017.03.36.

Walls, A. C. et al. (2020) 'Structure, Function, and Antigenicity of the SARS-CoV-2 Spike Glycoprotein', Cell. Elsevier, 181(2), pp. 281-292.e6. doi:

10.1016/j.cell.2020.02.058.

Walter, R. and Post-proline, Y. (1978) 'Post-proline Cleaving Aminopeptidase than 
the corresponding', The Journal of Biological Chemistry, 253(10), pp. 3708-3716.

Wang, C. et al. (2020) 'A novel coronavirus outbreak of global health concern', The Lancet, 395(10223), pp. 470-473. doi: 10.1016/S0140-6736(20)30185-9.

Wang, L. et al. (2015) 'Evaluation of candidate vaccine approaches for MERS-CoV', Nature Communications. Nature Publishing Group, 6, pp. 1-11. doi:

10.1038/ncomms8712.

Wang, L. et al. (2018) 'Importance of Neutralizing Monoclonal Antibodies Targeting Multiple Antigenic Sites on the Middle East Respiratory Syndrome Coronavirus Spike Glycoprotein To Avoid Neutralization Escape', Journal of Virology, 92(10), pp. 1-21. doi: 10.1128/jvi.02002-17.

Wang, N. et al. (2013) 'Structure of MERS-CoV spike receptor-binding domain complexed with human receptor DPP4', Cell Research. Nature Publishing Group, 23(8), pp. 986-993. doi: 10.1038/cr.2013.92.

Wang, Q. et al. (2007) 'Structural basis for receptor specificity of influenza B virus hemagglutinin', Proceedings of the National Academy of Sciences of the United States of America, 104(43), pp. 16874-16879. doi: 10.1073/pnas.0708363104. Wang, Z. et al. (2014) 'Soluble DPP4 originates in part from bone marrow cells and not from the kidney', Peptides. Elsevier Inc., 57, pp. 109-117. doi:

10.1016/j.peptides.2014.05.006.

Weihofen, W. A. et al. (2004) 'Crystal structure of CD26/dipeptidyl-peptidase IV in complex with adenosine deaminase reveals a highly amphiphilic interface', Journal of Biological Chemistry, 279(41), pp. 43330-43335. doi: 10.1074/jbc.M405001200. WHO (2004) 'Emergencies preparedness, response China's latest SARS outbreak has been contained, but biosafety concerns remain -', pp. 16-18. WHO (2019) 'Mers Situation Update', Who, (January), p. 22765492. Available at: http://applications.emro.who.int/docs/EMRPUB-CSR-241-2019-EN.pdf. 
WHO (2020) 'Coronavirus disease', World Health Organization, 2019(March), p. 2633. doi: 10.1001/jama.2020.2633.

Wilson, L. et al. (2004) 'SARS coronavirus E protein forms cation-selective ion channels', Virology, 330(1), pp. 322-331. doi: 10.1016/j.virol.2004.09.033.

Wilson, S. et al. (2005) 'The membrane-anchored serine protease, TMPRSS2, activates PAR-2 in prostate cancer cells', Biochemical Journal, 388(3), pp. 967-972. doi: 10.1042/BJ20041066.

De Wit, E. et al. (2013) 'Middle East respiratory syndrome coronavirus (MERSCoV) causes transient lower respiratory tract infection in rhesus macaques', Proceedings of the National Academy of Sciences of the United States of America, 110(41), pp. 16598-16603. doi: 10.1073/pnas.1310744110.

De Wit, E. et al. (2016) 'SARS and MERS: Recent insights into emerging coronaviruses', Nature Reviews Microbiology. Nature Publishing Group, 14(8), pp. 523-534. doi: 10.1038/nrmicro.2016.81.

Woo, P. C. Y. et al. (2005) 'Characterization and Complete Genome Sequence of a Novel Coronavirus, Coronavirus HKU1, from Patients with Pneumonia', Journal of Virology, 79(2), pp. 884-895. doi: 10.1128/jvi.79.2.884-895.2005.

Woo, P. C. Y. et al. (2012) 'Genetic relatedness of the novel human group C betacoronavirus to Tylonycteris bat coronavirus HKU4 and Pipistrellus bat coronavirus HKU5', Emerging Microbes and Infections, 1(000), p. 0. doi: 10.1038/emi.2012.45.

Xu, J. et al. (2019) 'Antibodies and vaccines against Middle East respiratory syndrome coronavirus', Emerging Microbes and Infections, 8(1), pp. 841-856. doi: 10.1080/22221751.2019.1624482.

Yamamoto, M. et al. (2016) 'Identification of Nafasmostat as a Potent Inhibitor of Middle East Respiratory Syndrome Coronavirus S Protein-Mediated Membrane 
Fusion Using the Split-Protein-Based Cell-Cell Fusion Assay', 60(11), pp. 65326539. doi: 10.1128/AAC.01043-16.Address.

Yamaya, M. et al. (2015) 'The serine protease inhibitor camostat inhibits influenza virus replication and cytokine production in primary cultures of human tracheal epithelial cells', Pulmonary Pharmacology and Therapeutics. Elsevier Ltd, 33, pp. 66-74. doi: 10.1016/j.pupt.2015.07.001.

Yang, Y. et al. (2013) 'The structural and accessory proteins M, ORF 4a, ORF 4b, and ORF 5 of Middle East respiratory syndrome coronavirus (MERS-CoV) are potent interferon antagonists', Protein and Cell, 4(12), pp. 951-961. doi: 10.1007/s13238013-3096-8.

Yang, Y. et al. (2014) 'Receptor usage and cell entry of bat coronavirus HKU4 provide insight into bat-to-human transmission of MERS coronavirus', Proceedings of the National Academy of Sciences of the United States of America, 111(34), pp. 12516-12521. doi: 10.1073/pnas.1405889111.

Yang, Y. et al. (2015) 'Two Mutations Were Critical for Bat-to-Human Transmission of Middle East Respiratory Syndrome Coronavirus', Journal of Virology, 89(17), pp. 9119-9123. doi: 10.1128/jvi.01279-15.

Yao, Y. et al. (2014) 'An animal model of mers produced by infection of rhesus macaques with MERS coronavirus', Journal of Infectious Diseases, 209(2), pp. 236242. doi: $10.1093 /$ infdis/jit590.

Yasuda, N. et al. (2002) 'Improvement of high fat-diet-induced insulin resistance in dipeptidyl peptidase IV-deficient Fischer rats', Life Sciences, 71(2), pp. 227-238. doi: 10.1016/S0024-3205(02)01637-5.

Yuan, Y. et al. (2017) 'Cryo-EM structures of MERS-CoV and SARS-CoV spike glycoproteins reveal the dynamic receptor binding domains', Nature Communications. Nature Publishing Group, 8(China CDC), pp. 1-9. doi: 
10.1038/ncomms15092.

Zaki, A. M. et al. (2012) 'Isolation of a novel coronavirus from a man with pneumonia in Saudi Arabia', New England Journal of Medicine, 367(19), pp. 1814-1820. doi: 10.1056/NEJMoa1211721.

Zeng, Q. et al. (2008) 'Structure of coronavirus hemagglutinin-esterase offers insight into corona and influenza virus evolution', Proceedings of the National Academy of Sciences of the United States of America, 105(26), pp. 9065-9069. doi: 10.1073/pnas.0800502105.

Zhou, J. et al. (2015) 'Middle East respiratory syndrome coronavirus infection: Virushost cell interactions and implications on pathogenesis', Virology Journal. Virology Journal, 12(1), pp. 1-7. doi: 10.1186/s12985-015-0446-6.

Zhou, J. et al. (2017) 'Human intestinal tract serves as an alternative infection route for Middle East respiratory syndrome coronavirus', Science Advances, 3(11). doi: 10.1126/sciadv.aao4966.

Zhou, Y. et al. (2020) 'Since January 2020 Elsevier has created a COVID-19 resource centre with free information in English and Mandarin on the novel coronavirus COVID- 19. The COVID-19 resource centre is hosted on Elsevier Connect, the company's public news and information ', (January).

Zhu, N. et al. (2020) 'A novel coronavirus from patients with pneumonia in China, 2019', New England Journal of Medicine, 382(8), pp. 727-733. doi:

10.1056/NEJMoa2001017.

Ziebuhr, J., Snijder, E. J. and Gorbalenya, A. E. (2000) 'Virus-encoded proteinases and proteolytic processing in the Nidovirales', Journal of General Virology, 81(4), pp. 853-879. doi: 10.1099/0022-1317-81-4-853.

Zmora, P. et al. (2015) 'TMPRSS2 isoform 1 activates respiratory viruses and is expressed in viral target cells', PLoS ONE, 10(9), pp. 1-14. doi: 
10.1371/journal.pone.0138380.

Zumla, A. et al. (2015) 'Middle East Respiratory Syndrome', Lancet, 386(9997), pp. 995-1007. doi: 10.1016/S0140-6736(15)60454-8. 


\section{Appendix}

\subsection{List of Figures}

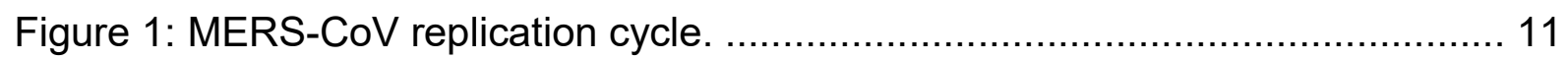

Figure 2: Schematic MERS-CoV particle....................................................... 16

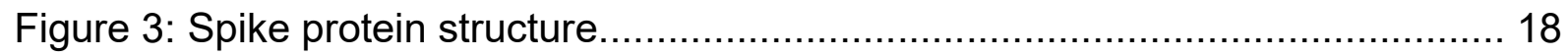

Figure 4: Spike protein crystal structure. …….................................................. 19

Figure 5: Polymorphic amino acid residues in DPP4 at the binding interface with MERS-S.

\subsection{List of Tables}

Table 1: Function of coronavirus non-structural proteins (nsp). 10

\subsection{List of Abbreviations}

\begin{tabular}{|c|c|}
\hline+ SS & positive single stranded \\
\hline 6HB & Six helix bundle \\
\hline aa & Amino acid \\
\hline ACE2 & Angiotensin Converting Enzyme 2 \\
\hline ADA & Asparagine \\
\hline Asp 708 & bat coronavirus \\
\hline BatCoV & Bovine coronavirus \\
\hline BCoV & Coronavirus disease 2019 \\
\hline COVID-19 & Cytoplasmic tail \\
\hline CT & Cathepsin B \\
\hline CTSB & Cathepsin L \\
\hline CTSL & Differentially expressed in squamous cell \\
\hline carcinoma \\
\hline DESC & Double membrane vesciles \\
\hline & \\
\hline & \\
\hline
\end{tabular}




\begin{tabular}{|c|c|}
\hline DPP4 & Dipeptidyl-peptidase 4 \\
\hline ds & double stranded \\
\hline $\mathrm{E}$ & Envelope \\
\hline ECP & endosomal cathepsin proteases \\
\hline EMC & Erasmus Medical Center \\
\hline ER & Endoplasmatic reticulum \\
\hline ERGIC & $\begin{array}{l}\text { Endoplasmatic reticulum-Golgi } \\
\text { intermediate complex }\end{array}$ \\
\hline ExoN & exoribonuclease \\
\hline FCoV & Feline coronavirus \\
\hline FDA & Food and Drug Administration \\
\hline FIPV & Feline Infectious Peritonitis Virus \\
\hline FP & Fusion peptide \\
\hline GBP & Guanylate-Binding Protein \\
\hline GIP & gastric inhibitory polypeptide \\
\hline GLP-1 & glucagon-like peptide 1 \\
\hline GTPase & Guanosine triphosphatase \\
\hline $\mathrm{HA}$ & Hemagglutinin \\
\hline HAT & Human airway trypsin like protease \\
\hline $\mathrm{HCoV}$ & Human coronavirus \\
\hline $\mathrm{HE}$ & Hemagglutinin-esterase \\
\hline $\mathrm{His}_{740}$ & Histidine \\
\hline HIV-1 & Human immunodeficiency virus 1 \\
\hline HR1 & Heptad repeat 1 \\
\hline HR2 & Heptad repeat 2 \\
\hline IAV & Influenza A virus \\
\hline IBV & Infectious bronchitis virus \\
\hline
\end{tabular}


Appendix

\begin{tabular}{|c|c|}
\hline IFN & Interferon \\
\hline $\mathrm{K}$ & Lysine \\
\hline $\mathrm{kb}$ & kilobase \\
\hline $\mathrm{KO}$ & Knock-out \\
\hline KSA & Kingdom of Saudi Arabia \\
\hline $\mathrm{M}$ & Membrane protein \\
\hline MERS & Middle east respiratory syndrome \\
\hline MERS-CoV & $\begin{array}{c}\text { Middle east respiratory syndrome } \\
\text { coronavirus }\end{array}$ \\
\hline MERS-S & Middle east respiratory syndrome spike \\
\hline Mpro & Main protease \\
\hline mRNA & Messenger RNA \\
\hline MVA & Modified vaccinia ankara \\
\hline $\mathrm{N}$ & nucleocapsid \\
\hline NendoU & $\begin{array}{c}\text { Replicative nidoviral uridylate-specific } \\
\text { endoribonuclease }\end{array}$ \\
\hline Neu5Ac & A-5-N-acetyl-neuraminic-acid \\
\hline $\mathrm{NH}_{4} \mathrm{Cl}$ & Ammoniumcholride \\
\hline NHP & Non-human primate \\
\hline $\mathrm{nm}$ & Nanometer \\
\hline nsp & Non structural protein \\
\hline NTD & $\mathrm{N}$-terminal domain \\
\hline ORF & Open reading frame \\
\hline PEDV & Porcine Epidemic Diarrhea Virus \\
\hline $\mathrm{pH}$ & Power of hydrogen \\
\hline PLpro & Papain-like protease \\
\hline pp1a & polyprotein 1a \\
\hline
\end{tabular}




\begin{tabular}{|c|c|}
\hline pp1b & polyprotein $1 \mathrm{~b}$ \\
\hline PPC & Proprotein convertases \\
\hline $\mathrm{R}$ & arginine \\
\hline RAS & renin-angiotensin system \\
\hline RBD & Receptor binding domain \\
\hline RBM & Receptor binding motif \\
\hline RdRp & RNA-dependent RNA polymerase \\
\hline RIG I & retinoic acid-inducible gene I \\
\hline RNA & Ribonucleic acid \\
\hline $\mathrm{S}$ & Spike \\
\hline S1 & Subunit 1 \\
\hline S2 & Subunit 2 \\
\hline SARS & Severe acute respiratory syndrome \\
\hline SARS-2-S & $\begin{array}{c}\text { Severe acute respiratory syndrome } 2 \\
\text { spike }\end{array}$ \\
\hline SARS-CoV & $\begin{array}{l}\text { Severe acute respiratory syndrome } \\
\text { coronavirus }\end{array}$ \\
\hline SARS-CoV-2 & $\begin{array}{c}\text { Severe acute respiratory syndrome } \\
\text { coronavirus } 2\end{array}$ \\
\hline SARS-S & Severe acute respiratory syndrome spike \\
\hline Ser $_{680}$ & Serine \\
\hline SNP & Single nucleotide polymorphism \\
\hline SP & Signal peptide \\
\hline T-cell & Thymus cell \\
\hline TD & Transmembrane domain \\
\hline TGEV & Transmissible Gastroenteritis Virus \\
\hline TMPRSS2 & $\begin{array}{c}\text { Transmembrane protease serine subtype } \\
2\end{array}$ \\
\hline
\end{tabular}


Appendix

Type II transmembrane serine protease 


\subsection{Acknowledgement}

First of all I would like to thank Prof. Dr. Stefan Pöhlmann for giving me the opportunity to work on this project. I am thankful for the valuable suggestions and your help during the whole course of my thesis.

I would like to thank Prof. Dr. Uwe Groß, for being part of my thesis committee and for being the second reviewer of this thesis

I would like to thank Markus Hoffmann for his constant support, his supervision and his helpful ideas and advices. You were a big help and it was fun working with you.

I would like to thank the members of the thesis committee Prof. Dr. Uwe Groß, Dr. Marcel Müller and Prof. Dr. Claus-Peter Czerny for their support and their ideas.

I would like to thank all members of the examination board.

I would like to thank all my collaborators, especially Simon Schroeder, Dr. Marcel Müller and Prof. Dr. Christian Drosten for their important work that they contributed to my publications.

I would like to thank all members of the infection biology unit. Special thanks goes to the technicians for the entertaining coffee breaks and the support in the lab and to Kathrin for her help with the paper work and organization.

At last but not least I would like to thank my parents and my little sister for their constant support, help and love that you gave me all my life and André for the proof reading of this thesis, the constant support and love and all the time you listened to me, helped me and for all moments we spend together. 


\subsection{List of publications}

1) Hoffmann M, Kleine-Weber H, Pöhlmann S., 2020, A Multibasic Cleavage Site in the Spike Protein of SARS-CoV-2 Is Essential for Infection of Human Lung Cells., Mol Cell. 2020 Apr 28. pii: S1097-2765(20)30264-1. PMID: 32362314

2) Hoffmann M, Schroeder S, Kleine-Weber H, Müller MA, Drosten C, Pöhlmann S., 2020, Nafamostat mesylate blocks activation of SARS-CoV-2: New treatment option for COVID-19., Antimicrob Agents Chemother. 2020 Apr 20. pii: AAC.00754-20. PMID: 32312781

3) Hoffmann M, Kleine-Weber H, Schroeder S, Krüger N, Herrler T, Erichsen S, Schiergens TS, Herrler G, Wu NH, Nitsche A, Müller MA, Drosten C, Pöhlmann S., 2020, SARS-CoV-2 Cell Entry Depends on ACE2 and TMPRSS2 and Is Blocked by a Clinically Proven Protease Inhibitor., Cell. 2020 Mar 4. pii: S0092-8674(20)30229-4. PMID: 32142651

4) Kleine-Weber $H$, Schroeder $S$, Krüger $N$, Prokscha $A$, Naim $H Y$, Müller MA, Drosten C, Pöhlmann S, Hoffmann M., Polymorphisms in dipeptidyl peptidase 4 reduce host cellentry of Middle East respiratory syndrome coronavirus. Emerg Microbes Infect. 2020 Jan 21;9(1):155-168. PMID: 31964246

5) Kleine-Weber H., Hoffmann, M., Pöhlmann, S.,Spike proteins of novel MERScoronavirus isolates from North- and West-African dromedary camels mediate robust viral entry into human target cells. Virology. 2019 Sep;535:261-265. PMID: 31357164 
6) Kleine-Weber H, Elzayat MT, Wang L, Graham BS, Müller MA, Drosten C, Pöhlmann S, Hoffmann M., 2019. Mutations in the Spike Protein of Middle East Respiratory Syndrome Coronavirus Transmitted in Korea Increase Resistance to Antibody-Mediated Neutralization . J Virol. 2019 Jan 4;93(2). pii: e01381-18. PMID: 30404801

7) Kleine-Weber, H., Elzayat, M.T., Hoffmann, M., Pöhlmann, S., Functional analysis of potential cleavage sites in the MERS-coronavirus spike protein. Sci Rep. 2018 Nov 9;8(1):16597. PMID: 30413791 


\subsection{Conference participations}

\section{Oral presentation}

1) Naturally occurring polymorphisms in dipeptidyl-peptidase 4 can affect MERSS driven host cell entry, Workshop: Cell biology of zoonotic viral infections: from reservoir to humans, 2019 Oct, 23

2) Analysis of polymorphisms in the spike protein of MERS-CoV, International Symposium on zoonosis Research, 2019, Oct 18

3) A MERS-coronavirus variant that emerged during the Korean outbreak was partially resistant against antibody-mediated neutralization, Society of Virology, 2019, Mar 21

4) Impact of naturally-occurring polymorphisms in dipeptidyl peptidase 4 on host cell entry of MERS-coronavirus, Society of Virology, 2019, Mar 20

5) Analysis of proteolytic activation of the spike protein of MERS coronavirus, International Symposium on zoonosis Research, 2018, Oct 12 


\section{Poster presentation}

1) Polymorphisms in the spike protein of the MERS-coronavirus responsible for the Korean outbreak confer against antibody-mediated neutralization, Keystone Symposia Positive-Stranded RNA Viruses, 2019 Jun

2) Functional characterization of polymorphisms in the receptor binding domain of the Middle East respiratory syndrome coronavirus spike glycoprotein, Society of Virology, 2018 Mar

3) Protease choice for priming of the Middle East respiratory syndrome coronavirus spike glycoproteins is cell line dependent, Society of Virology, 2018 Mar 